\title{
Integrated Design and Manufacturing for the High Speed Civil Transport
}

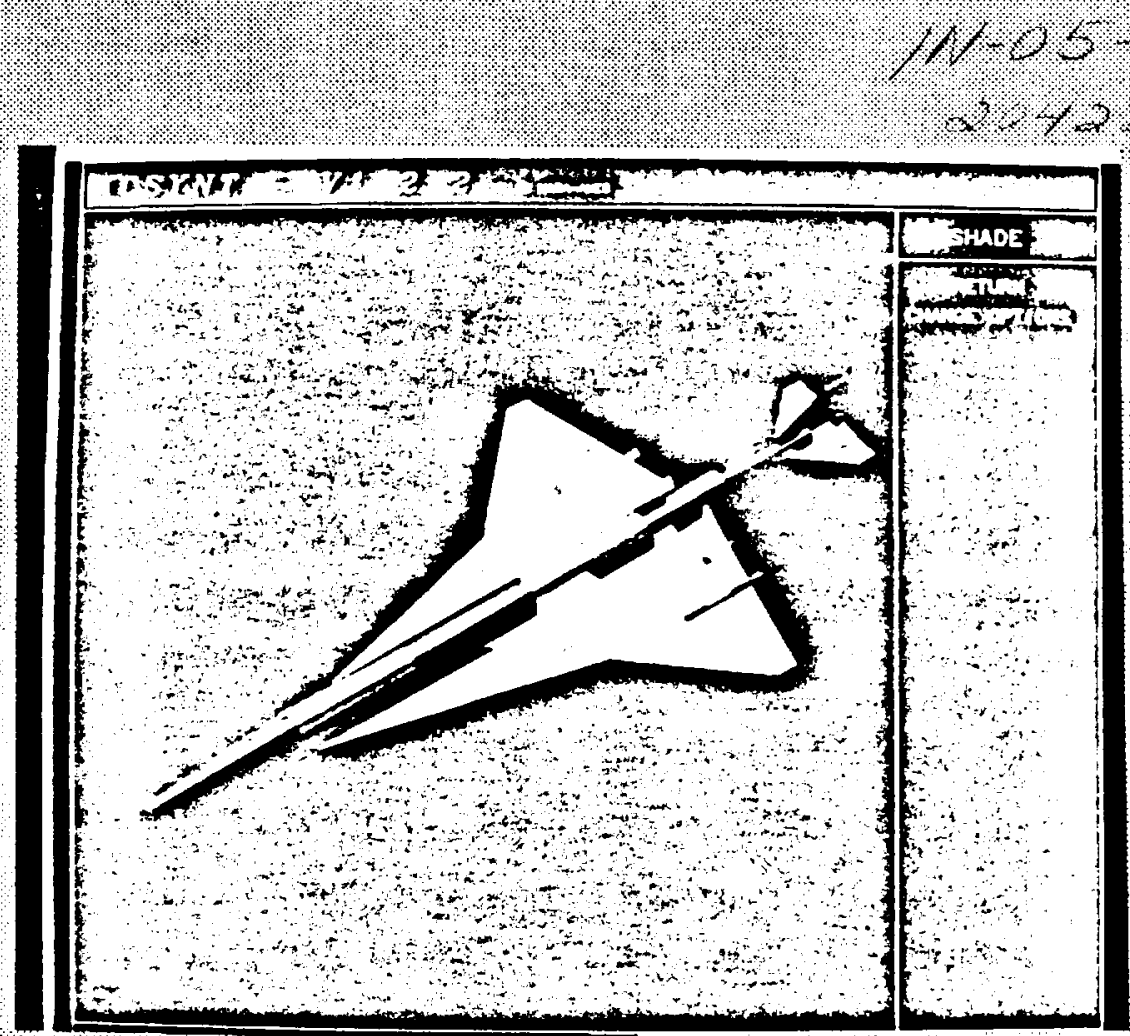

Final Report

NASA USRA Adranced Design Program Aeronautics

June 1993

(NASA-CR-195511) INTEGRATED DESIGN

ANO MANUFACTURING FOR THE HIGH

SPEED CIVIL TRANSPORT Final Report

(ceorgia Inst. of Tech.) $201 \mathrm{p}$

N94-24968

Unclas

$63 / 05 \quad 0204225$

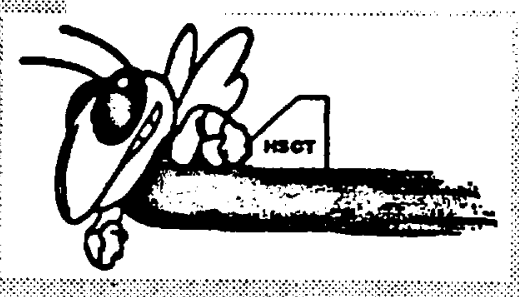

School of Aerospace Engineering

Georgia Institute of Technology Atlanta, GA. 30332 


\begin{abstract}
In June 1992, Georgia Tech's School of Aerospace Engineering was awarded a NASA University Space Research Association (USRA) Advanced Design Program (ADP) to address "Integrated Design and Manufacturing for the High Speed Civil Transport (HSCT)" in its graduate Aerospace Systems Design courses.

This report summarizes the results of the five courses incorporated into the Georgia Tech's USRA ADP program. It covers AE8113: Introduction to Concurrent Engineering, AE4360: Introduction to CAE/CAD, $\triangle E 4353$ : Design for Life Cycle Cost, AE6351: Aerospace Systems Design I, and AE6352: Aerospace Systems Design II.

AE8113: Introduction to Concurrent Engineering was an introductory course addressing the basic principles of Concurrent Engineering (CE) or Integrated Product Development (IPD). The design of a total system was not the objective of this course. The goal was to understand and define the "up-front" customer requirements, their decomposition, and determine the value objectives for a complex product, such as the High Speed Civil Transport (HSCT). A generic CE Methodology developed at Georgia Tech was used for this purpose.

AE4353: Design for Life Cycle Cost addressed the basic economic issues for an HSCT using a robust design technique, Taguchi's Parameter Design Optimization Method (PDOM). An HSCT economic sensitivity assessment was conducted using a Taguchi PDOM approach to address the robustness of the basic HSCT design.

AE4360: Introduction to CAE/CAD permitted students to develop and utilize CAE/CAD/CAM knowledge and skills using CATIA and CADAM as the basic geometric tools.

AE6351: Aerospace Systems Design I focused on the conceptual design refinement of a baseline HSCT configuration as defined by Boeing, Douglas, and NASA in their system studies. It required the use of NASA's synthesis codes FLOPS and ACSYNT. A criterion called the Productivity Index (P.I.) was used to evaluate disciplinary sensitivities and provide refinements of the baseline HSCT configuration.

AE6352: Aerospace Systems Design II was a continuation of Aerospace Systems Design I in which wing concepts were researched and analyzed in more detail. FLOPS and ACSYNT were again used at the system level while other off-the-shelf computer codes were used for more detailed wing disciplinary analysis and optimization.

The culmination of all efforts and submission of this report conclude the first year's efforts of Georgia Tech's NASA USRA ADP. It will hopefully provide the foundation for next years' efforts concerning continuous improvement of Integrated Design and Manufacturing for the HSCT.
\end{abstract}





\section{Table of Contents}

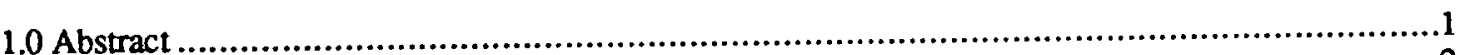

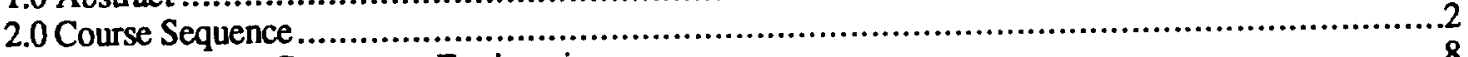

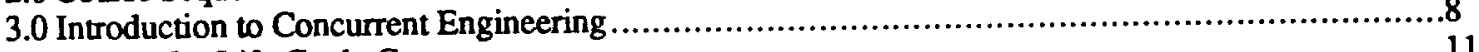

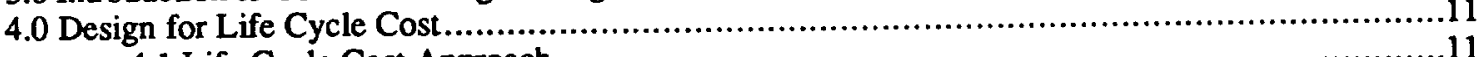

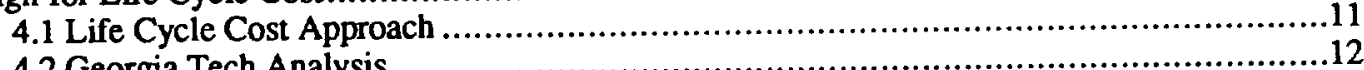

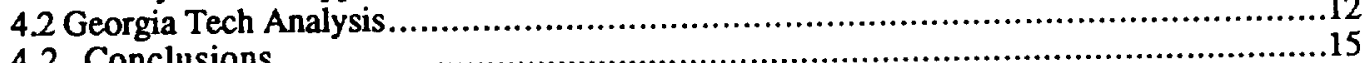

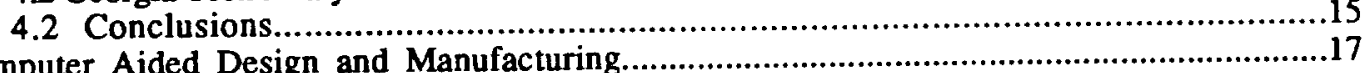

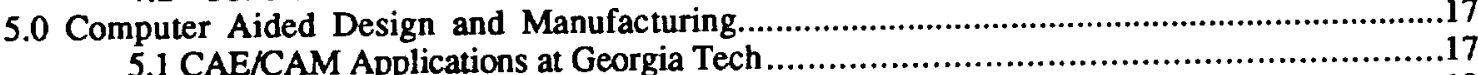

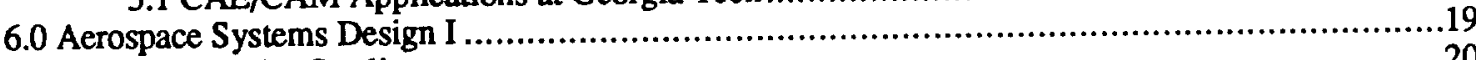

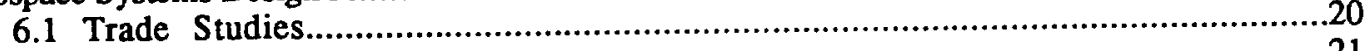

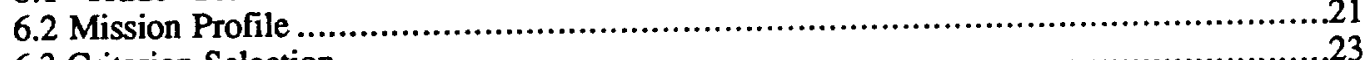

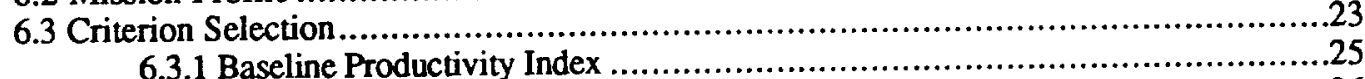

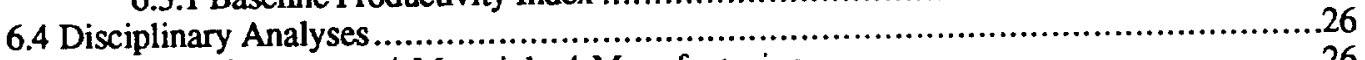

6.4.1 Structures / Materials / Manufacturing.....................................................26

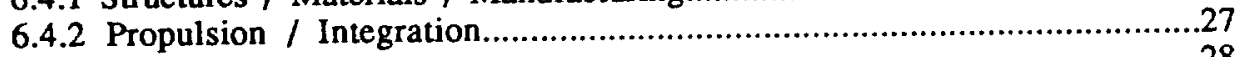

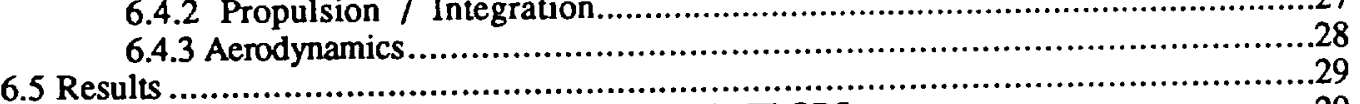

6.5.1 Structures and Propulsion Changes in FLOPS ....................................29

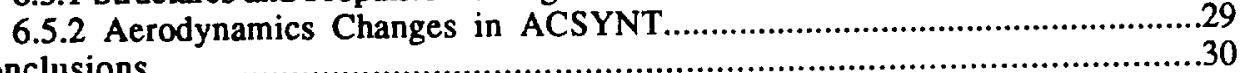

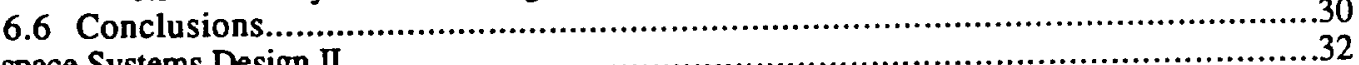

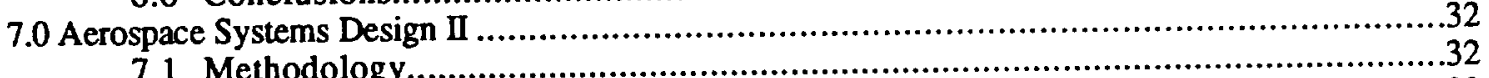

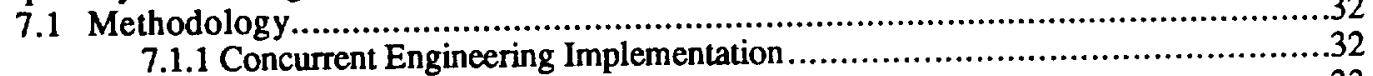

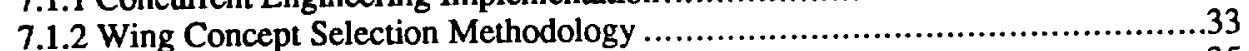

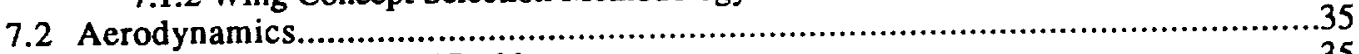

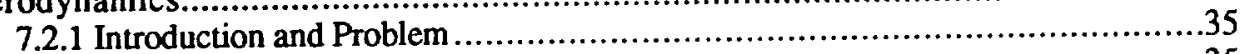

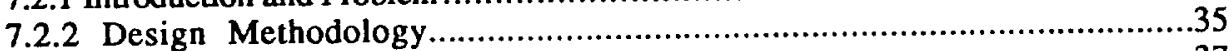

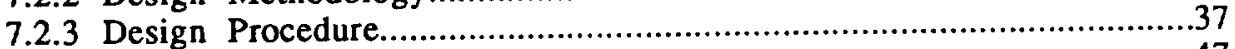

7.2.4 Concluding Remarks.................................................................47

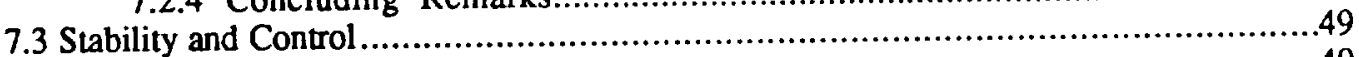

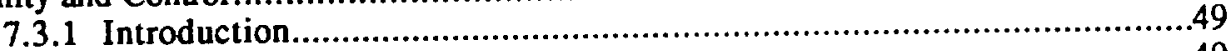

7.3.2 Georgia Tech's Methodology .......................................................49

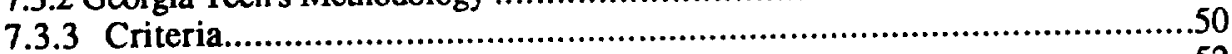

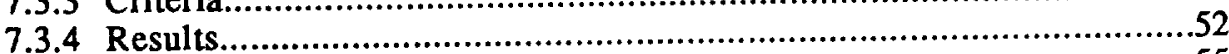

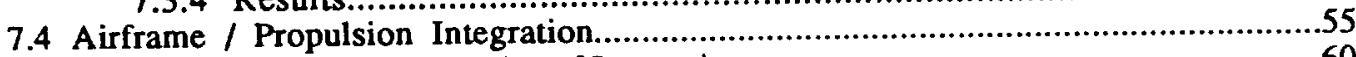

7.4.1 Concurrent Engineering of Integration..............................................60

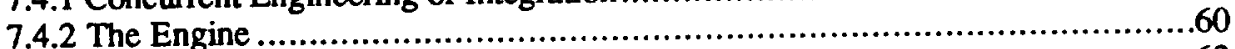

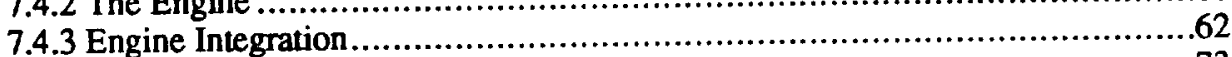

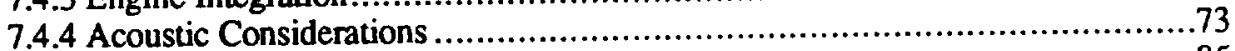

7.4.5 First Iteration Engine Configuration ...............................................85

7.4.6 Preliminary Engine Materials .....................................................86

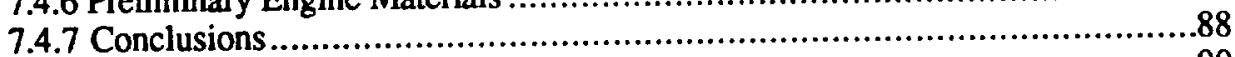

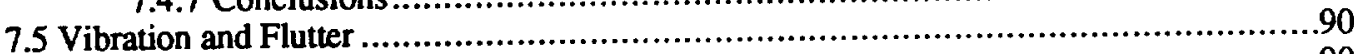

7.5.1 Technology Studies ..................................................................90

7.5.2 Georgia Tech Analyses..............................................................93

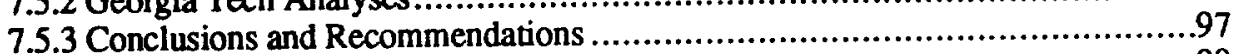

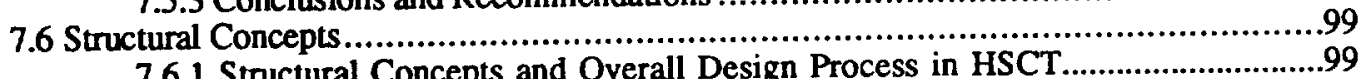

7.6.1 Structural Concepts and Overall Design Process in HSCT.........................99

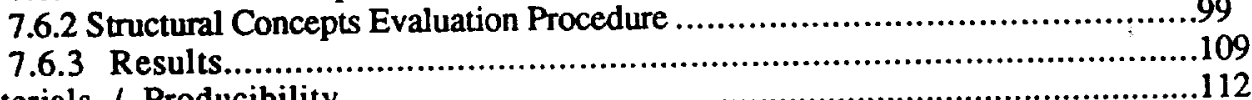

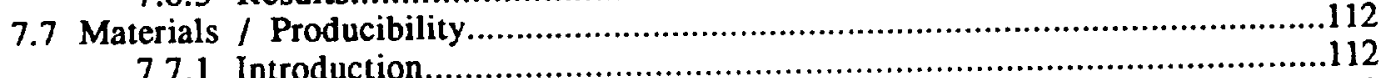

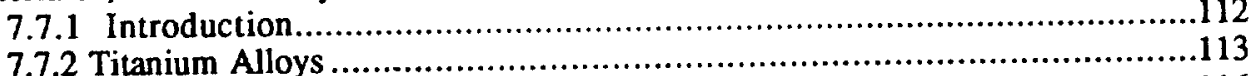

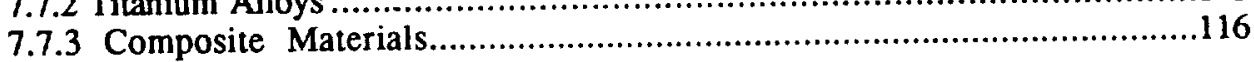





\section{Table of Contents}

7.7.4 Current Concepts and Considerations ..........................................118

7.7 .5 Composite Usage ...............................................................122

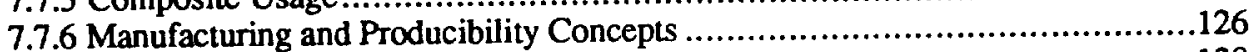

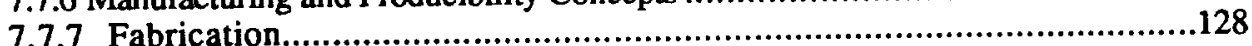

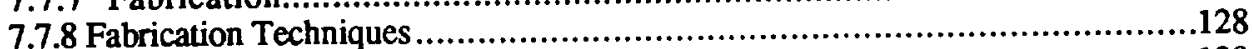

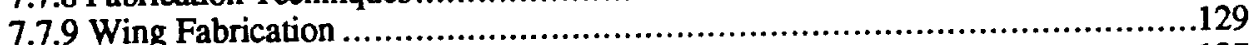

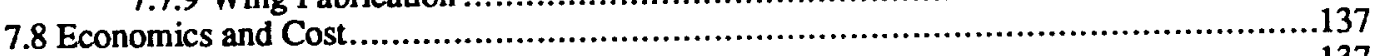

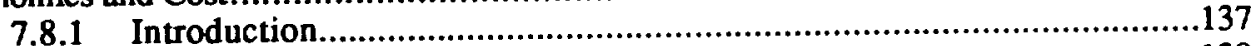

7.8 .2 Manufacturing Cost ..............................................................139

7.8.3 1981 Rand Model for Airframe Structural Modifications .........................141

7.8.4 Price H........................................................................147

7.8.5 Designer's Production Cost Trade-Off Tool.............................................151

7.8.6 ACSYNT

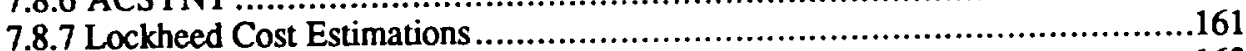

7.8 .8 Comparison of Models ..............................................................163

7.8.9 Utilization of Composite Materials.................................................164

7.8.10 Recommendations for further study ..........................................167

7.8 .11 Conclusions .................................................................... 168

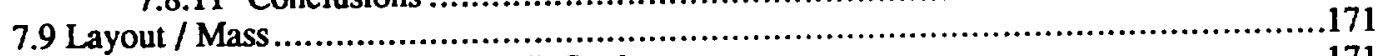

7.9.1 Summary of Lockheed's Study .................................................171

7.9.2 Georgia Tech's Methodology ................................................171

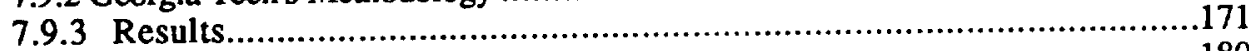

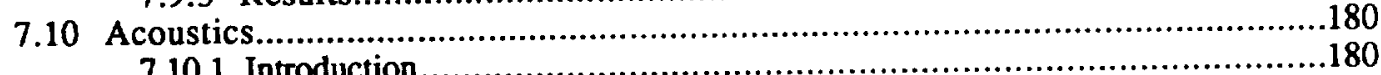

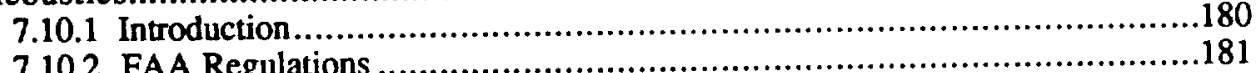

7.10 .2 FAA Regulations $\ldots \ldots \ldots \ldots \ldots \ldots \ldots \ldots \ldots \ldots \ldots \ldots \ldots \ldots \ldots \ldots \ldots \ldots \ldots \ldots \ldots \ldots \ldots \ldots \ldots \ldots \ldots \ldots \ldots \ldots \ldots \ldots \ldots \ldots \ldots \ldots \ldots \ldots \ldots \ldots \ldots \ldots \ldots \ldots \ldots \ldots \ldots$
7.10 .3

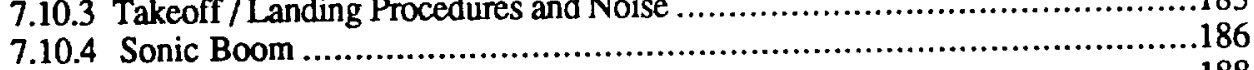

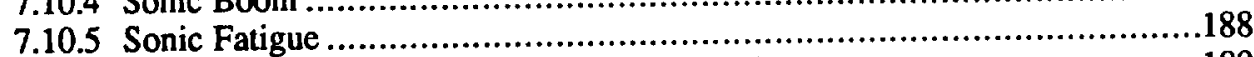

7.10 .6 Acoustics Conclusions and Recommendations................................189

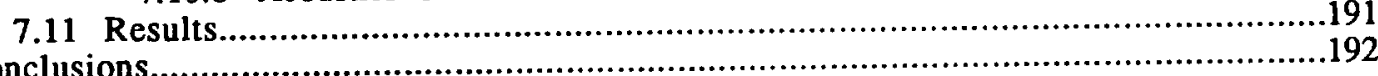





\section{List of Figures}

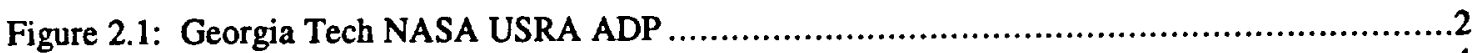

Figure 2.2: Traditionally Sequential Design Process...................................................................4

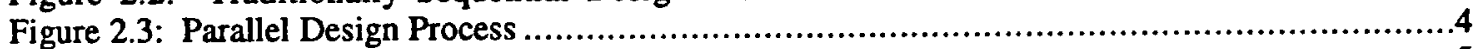

Figure 2.4: Georgia Tech's Concurrent Engineering Methodology..............................................5

Figure 2.5: Various Trades for Integrated Design and Manufacturing ..........................................

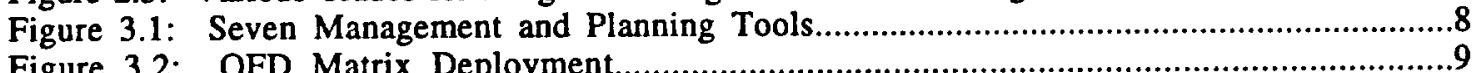

Figure 3.2: QFD Matrix Deployment

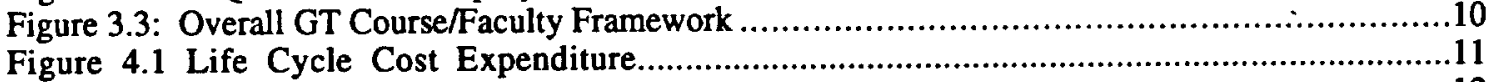

Figure 4.2 HSCT Economic Sensitivity Assessment. .........................................................

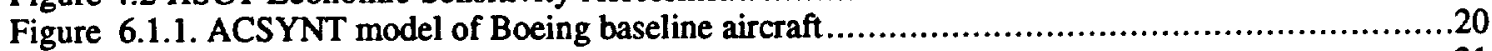

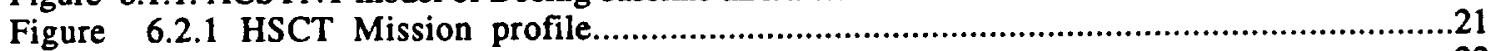

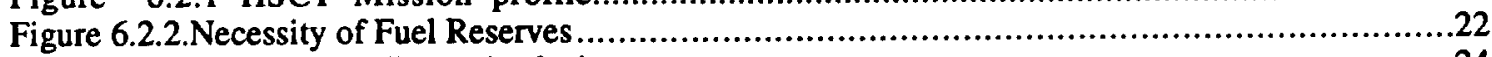

Figure 6.3.1. Multi-Disciplinary Analysis ..............................................................24

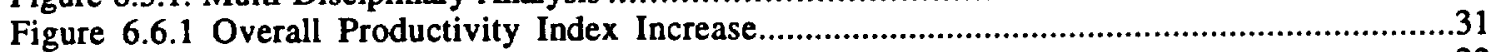

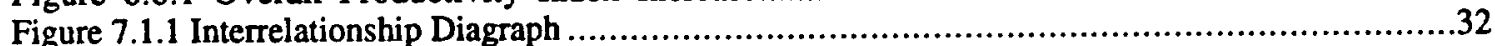

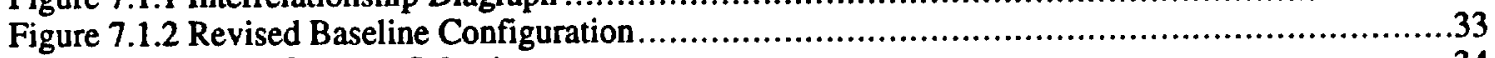

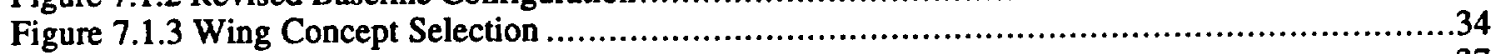

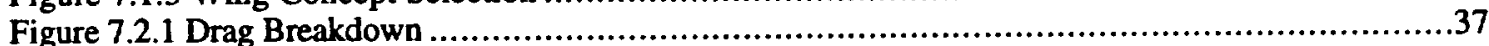

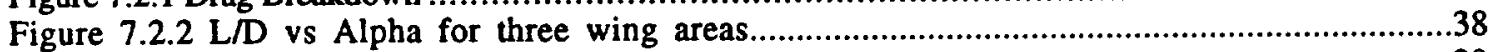

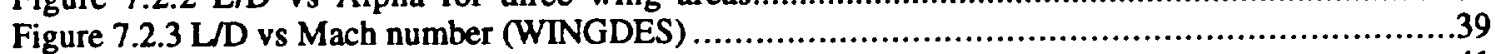

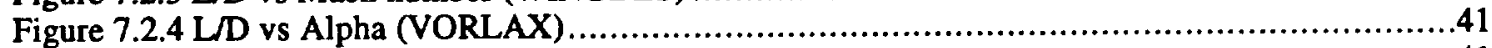

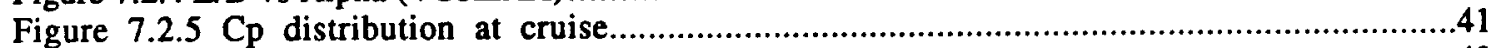

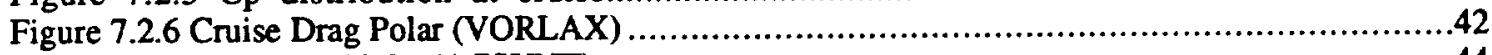

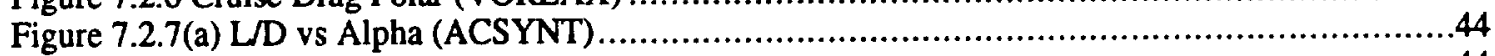

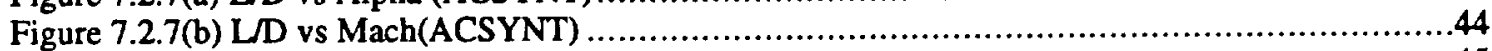

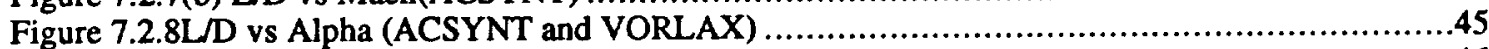

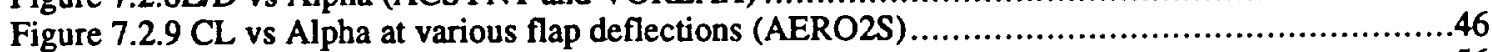

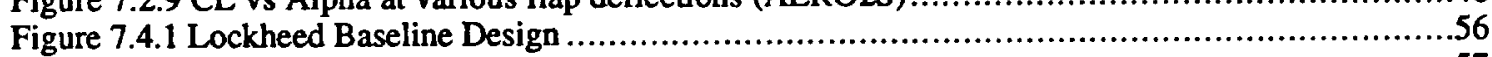

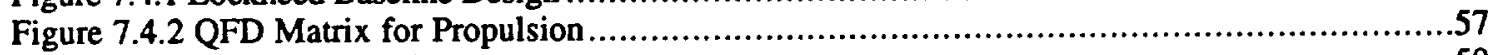

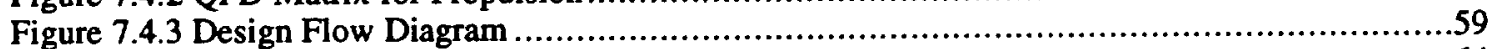

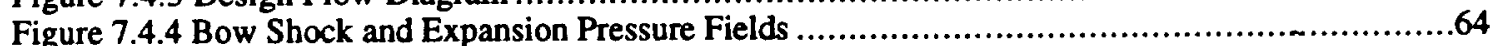

Figure 7.4.5 Longitudinal Displacement (Nacelle Diameters) .............................................65

Figure 7.4.6 Spanwise Displacement (Nacelle Diameters) ..................................................66

Figure 7.4.7 General Configuration Effects on Flutter Speed .............................................68

Figure 7.4.8 General Axisymmetric Nacelle Geometry ...................................................71

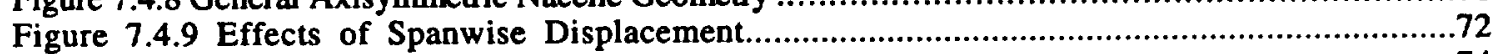

Figure 7.4.10 Longitudinal Stagger of Inboard Engine.............................................................74

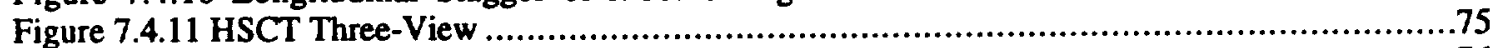

Figure 7.4.12 Illustration of FAR Noise Measurement Locations.............................................76

Figure 7.4.13 Inlet Diffusion Efficiency with Respect to Mach Number ....................................78

Figure 7.4.14 Mixed Compression Inlet Operation .............................................................79

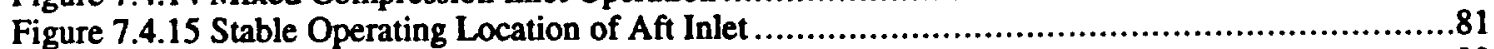

Figure 7.4.16 Illustration of Multiple Nozzle Concept .....................................................82

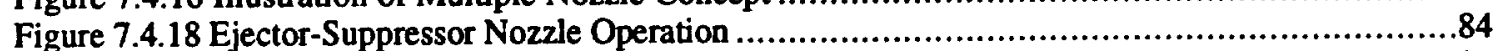

Figure 7.4.19 Composite Acoustical Noise Attenuator .........................................................87

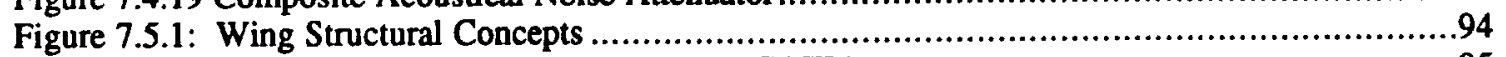

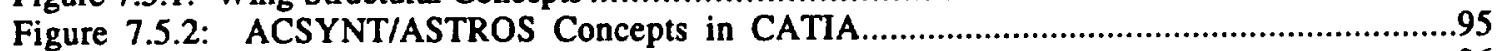

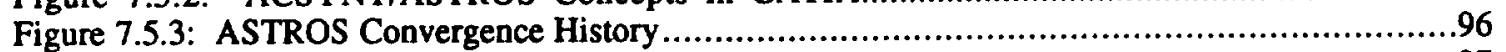

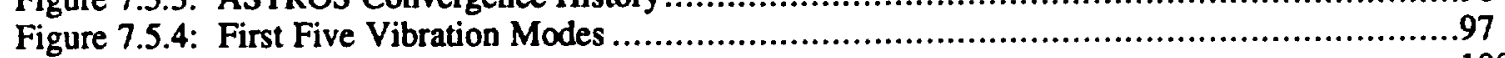

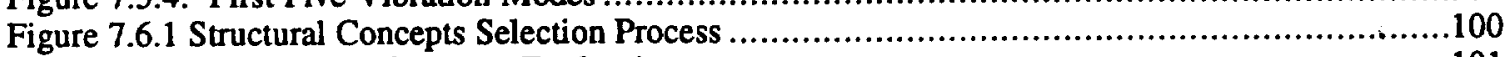

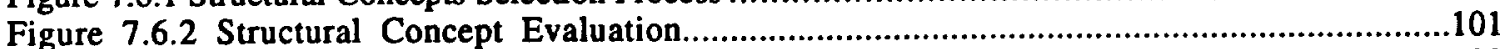

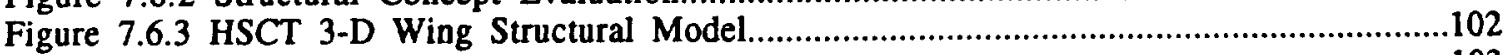

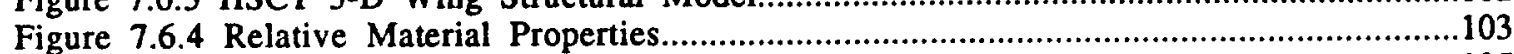

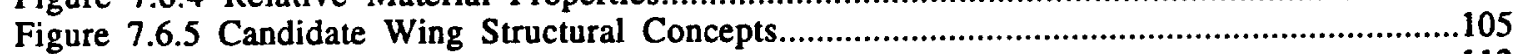

Figure 7.7.1 Material Temperature Capability.........................................................................112 



\section{List of Figures}

Figure 7.7.2 Tensile Strength of Titanium Reinforced with Boron-Aluminum

Figure 7.7.3 Tensile Strength of B/PI Reinforced Titanium..........................................119

Figure 7.7.4 Compressive Strength of Titanium Reinforced With Boron Aluminum .....................119

Figure 7.7.5 Strength, Stiffness and Density of Titanium Reinforced with Boron-Aluminum...............120

Figure 7.7.6 Mechanics of Materials .

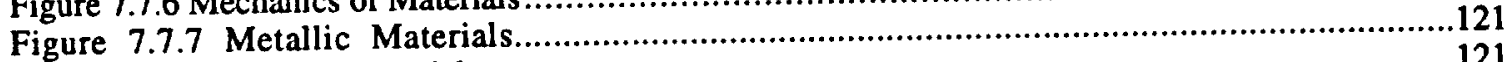

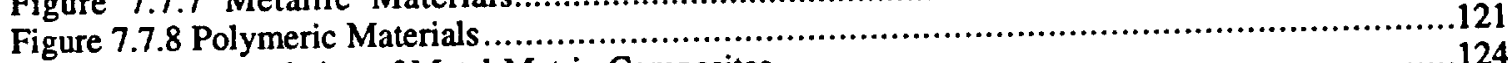

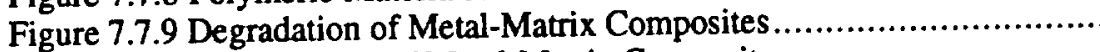

Figure 7.7.10 Degradation of Metal-Matrix Composites ....................................................124

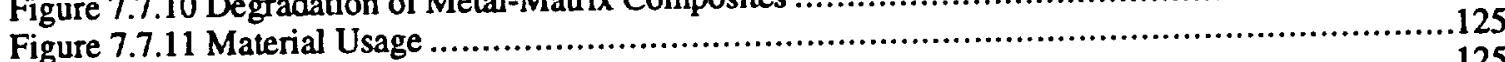

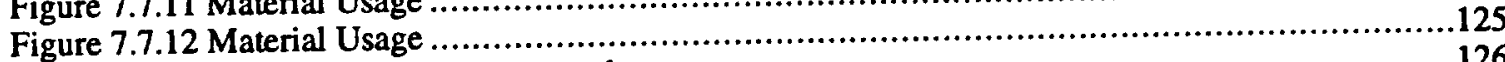

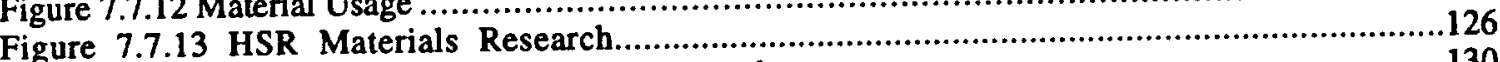

Figure 7.7.14. Integrated Manufacturing Approach....................................................................130

Figure 7.7.15 Structural / Manufacturing Concepts....................................................................131

Figure 7.7.16 Flow Chart of Producing Boron/Aluminum Composites ......................................134

Figure 7.7.17 Titanium Wing Skin Production Process.....................................................134

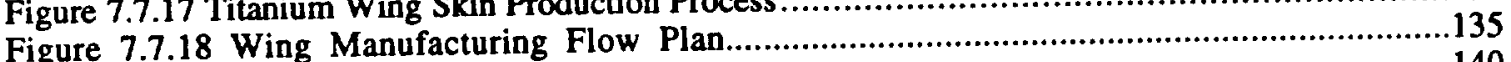

Figure 7.8.1 Roskam Mfg and Acquisition Cost Eqns......................................................140

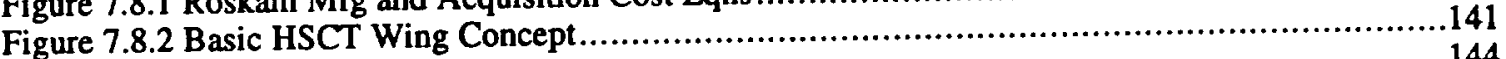

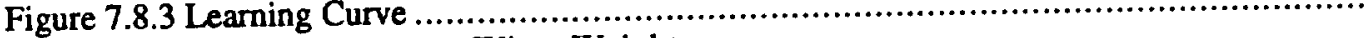

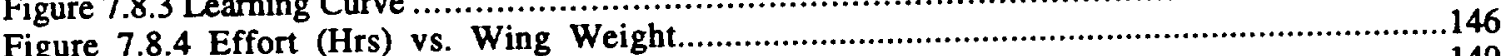

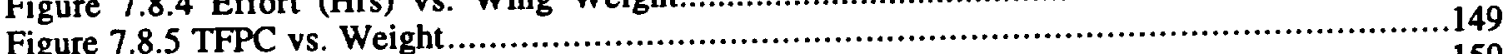

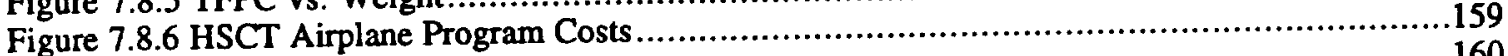

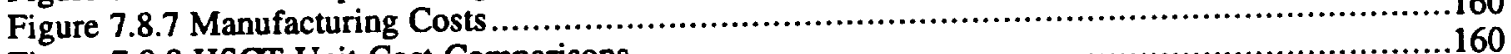

Figure 7.8.8 HSCT Unit Cost Comparisons ... Program Mgmt.

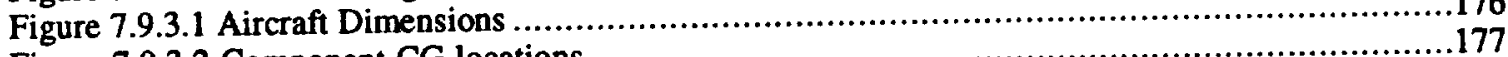

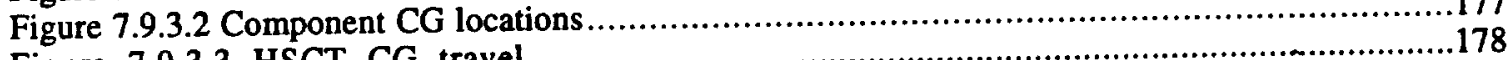

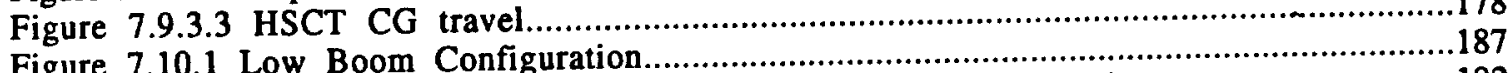

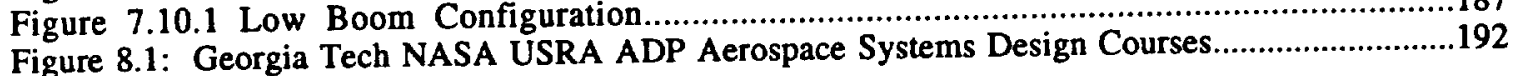




\section{List of Tables}

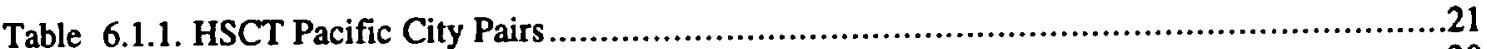

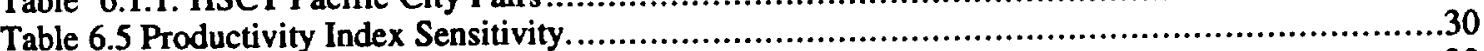

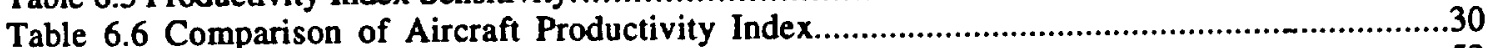

Table 7.3.1 Aircraft Stability Derivatives...........................................................................53

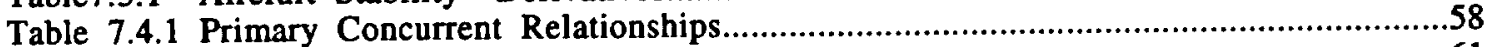

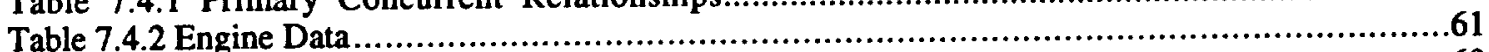

Table 7.4.3 Engine Installation FAR Requirements .........................................................69

Table 7.6.1 Material Candidates ..............................................................................103

Table 7.7.1. Property Comparisons with Competitive Materials ...............................................115

Table 7.7.2 Preliminary Design Composite Properties ........................................................117

Table 7.7.3. Suggested welding procedure schedule for GTAW of titanium (a) ...................................132

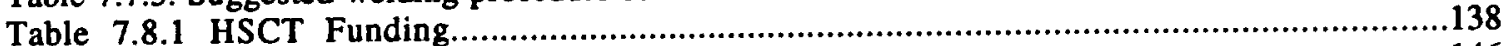

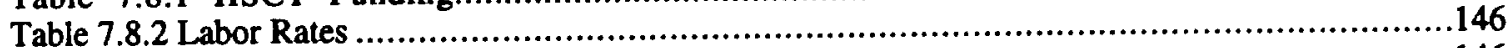

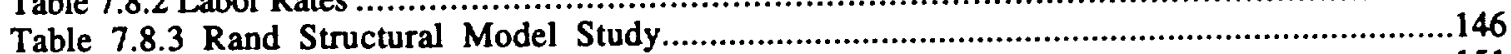

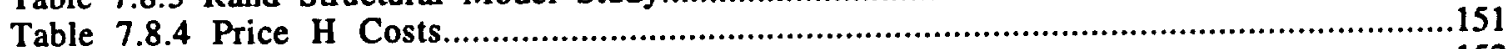

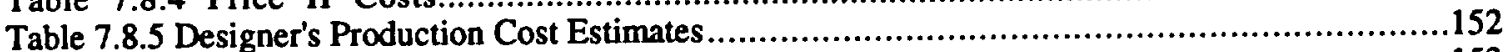

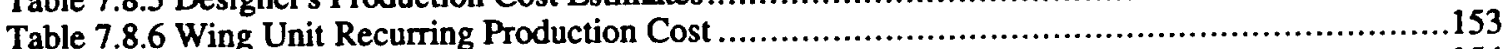

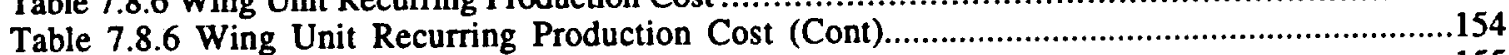

Table 7.8.6 Wing Unit Recurring Production Cost (Cont).............................................................155

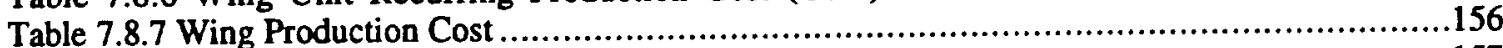

Table 7.8.7 Wing Production Cost (Cont) …...........................................................................157

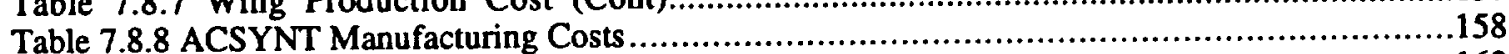

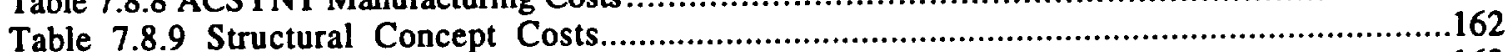

Table 7.8.10 Structural Concept Costs per pound..................................................................163

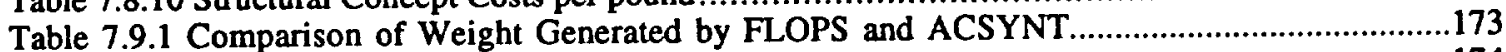

Table 7.9.2 Horizontal CG Locations (Referenced from A/C Nose) ...........................................174

Table 7.9.3 Summary of Points Used for CG Chart..........................................................175

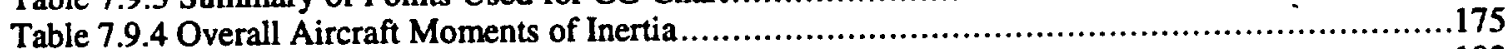

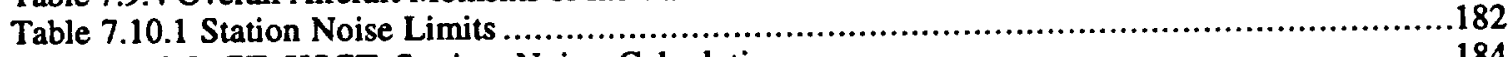

Table 7.10.2 GT HSCT Station Noise Calculations....................................................................184 


\section{FOREWORD}

This report documents work completed for the NASA University Space Research Association Advanced Design Program in Aeronautics at the Georgia Institute of Technology. Professor Daniel Schrage, Professor James Craig, and Dr. Dimitrios Mavris were the coordinators of this project. Mark Hale and Peter Rohl provided helpful suggestions during the course of the study. Reginald Abel and William Marx were the team leaders/program managers.

The design team consisted of -

Aerodynamics

Stability \& Control

Airframe/Propulsion Integration

Vibration \& Flutter

Structural Concepts

Materials/Producibility

Economics \& Cost

$\mathrm{CAD} / \mathrm{CAM}$

Layout \& Mass

Acoustics
Reginald Abel, Chandra Purnawan

Tom Taylor

Brian Byrd

William Marx

Chang-Sul Song

William Austin, Wiedong Chen

Dave McCreary, Reginald Abel, Wiedong Chen

Reginald Abel, William Austin

Tom Taylor, William Austin

Dave McCreary

COPYRIGHT @ 1993 GEORGIA INSTITUTE OF TECHNOLOGY, SCHOOL OF AEROSPACE ENGINEERING

PERMISSION TO REPRODUCE THIS DOCUMENT OR ANY

PART OF ITS CONTENTS MUST BE ACQUIRED FROM:

PROFESSOR DANIEL P. SCHRAGE

SCHOOL OF AEROSPACE ENGINEERING

GEORGIA INSTITUTE OF TECHNOLOGY

ATLANTA, GEORGIA 30332-0150 



\subsection{Abstract}

In June 1992, Georgia Tech's School of Aerospace Engineering was awarded a NASA University Space Research Association (USRA) Advanced Design Program (ADP) to address "Integrated Design and Manufacturing for the High Speed Civil Transport (HSCT)" in its graduate Aerospace Systems Design courses.

This report summarizes the results of the five courses incorporated into the Georgia Tech's USRA ADP program. It covers AE8113: Introduction to Concurrent Engineering, AE4360: Introduction to CAE/CAD, AE4353: Design for Life Cycle Cost, AE6351: Aerospace Systems Design I, and AE6352: Aerospace Systems Design II.

AE8113: Introduction to Concurrent Engineering was an introductory course addressing the basic principles of Concurrent Engineering (CE) or Integrated Product Development (IPD). The design of a total system was not the objective of this course. The goal was to understand and define the "up-front" customer requirements, their decomposition, and determine the value objectives for a complex product, such as the High Speed Civil Transport (HSCT). A generic CE Methodology developed at Georgia Tech was used for this purpose.

AE4353: Design for Life Cycle Cost addressed the basic economic issues for an HSCT using a robust design technique, Taguchi's Parameter Design Optimization Method (PDOM). An HSCT economic sensitivity assessment was conducted using a Taguchi PDOM approach to address the robustness of the basic HSCT design.

AE4360: Introduction to CAE/CAD permitted students to develop and utilize CAE/CAD/CAM knowledge and skills using CATIA and CADAM as the basic geometric tools.

AE6351: Aerospace Systems Design I focused on the conceptual design refinement of a baseline HSCT configuration as defined by Boeing, Douglas, and NASA in their system studies. It required the use of NASA's synthesis codes FLOPS and ACSYNT. A criterion called the Productivity Index (P.I.) was used to evaluate disciplinary sensitivities and provide refinements of the baseline HSCT configuration.

AE6352: Aerospace Systems Design II was a continuation of Aerospace Systems Design I in which wing concepts were researched and analyzed in more detail. FLOPS and ACSYNT were again used at the system level while other off-the-shelf computer codes were used for more detailed wing disciplinary analysis and optimization.

The culmination of all efforts and submission of this report conclude the first year's efforts of Georgia Tech's NASA USRA ADP. It will hopefully provide the foundation for next years' efforts concerning continuous improvement of Integrated Design and Manufacturing for the HSCT. 


\subsection{Course Sequence}

Figure 2.1 illustrates the sequence of Aerospace Systems Design courses offered as Georgia Tech's NASA USRA ADP.

\section{Integrated Design and Manufacturing for the High Speed Civil Transport}

Concurrent Engineering (CE) / Integrated Product Development (IPD) Approach

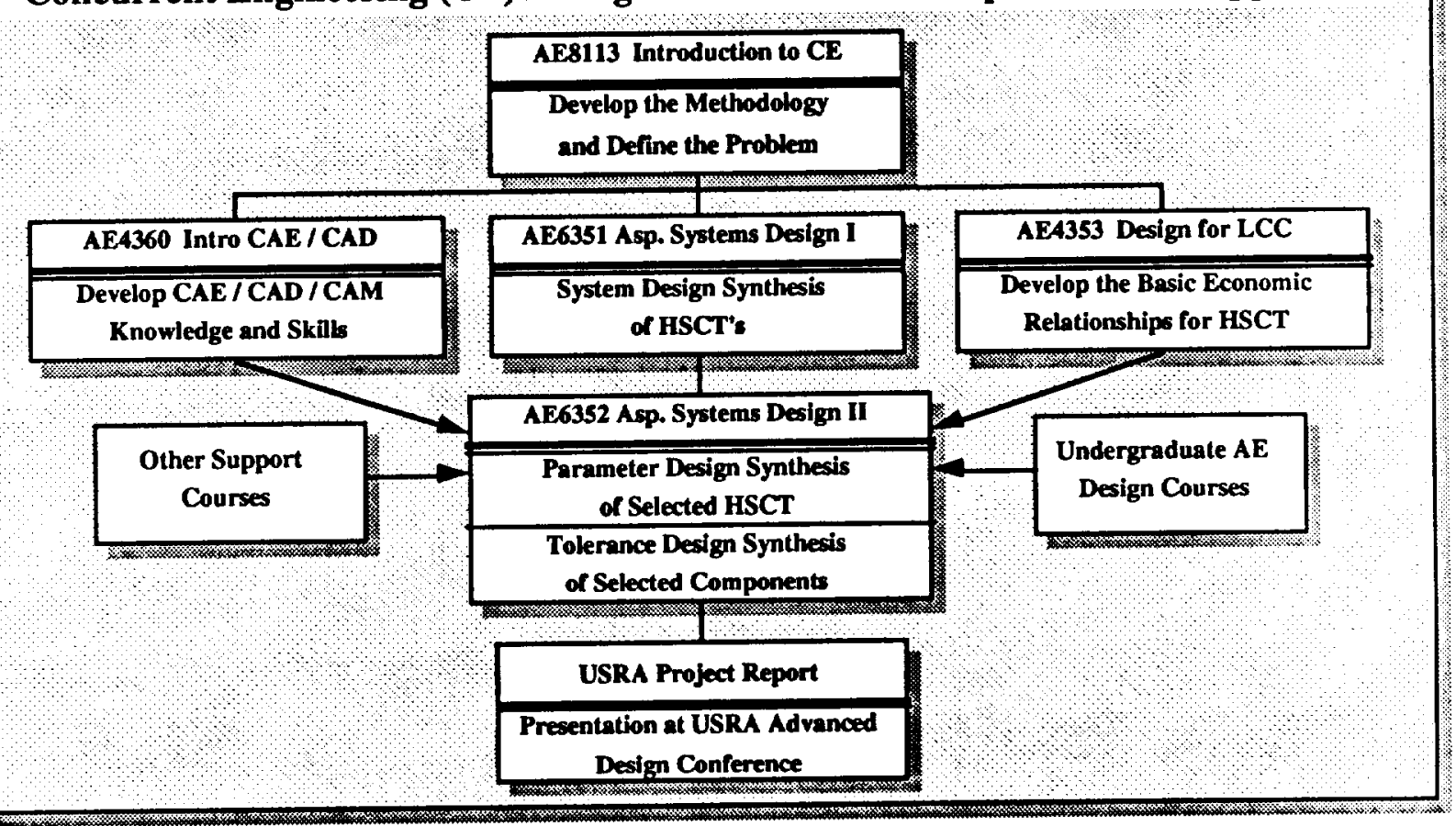

Figure 2.1: Georgia Tech NASA USRA ADP

Each course, with the exception of the CAE/CAD course, required students to work as multi-disciplinary teams. During the Fall and Winter Quarters, two separate 4- and 5-member teams worked on the required projects and submitted separate reports. For the Spring Quarter, the two teams were combined to one nine-member team in order to achieve more depth in the research and analyses. A Request for Proposal (RFP) was given as a handout at the beginning of each quarter stating the required tasks and deliverables. An oral presentation and submission of the final written report concluded each course. This report includes summaries of the first four courses as well as a detailed description of the research done for Aerospace Systems Design II. 
Over the years, aircraft research has evolved into distinct disciplines: aerodynamics, structures, propulsion, performance, controls, and others. With the distinction came isolation, as each discipline concentrated on activities related to its own concerns. This isolation has created at least two problems in the incorporation of advanced analysis techniques into the design process. First, disciplines have come to view production of their analysis results as a final product. Second, a discipline may require data from another discipline as input to an analysis, but may develop or acquire capabilities to generate these data locally. While this approach maintains independence from a multidisciplinary design group, it may not benefit from the total expertise of this group or their most recent improvements in each disciplinary area.

As industries and governments around the world refocus to achieve major quality improvements to become more competitive in the world marketplace, the term Concurrent Engineering (CE), or Integrated Product Development (IPD), is being used to express the desired environment. A major realization of this refocusing is that opportunities to improve quality are greatest early in the design process. CE has been defined as a systematic approach to the integrated, concurrent design of products and their related processes, including manufacture and support. CE has been called the implementation arm of the Total Quality Management (TQM) strategy. It has also been called a modern treatment of systems engineering which combines quality engineering methods in a computer integrated environment. Integrated Product Development (IPD) and the use of an Integrated Product Team (IPT) is the form of CE being applied on most of the aerospace community. For the purposes of this report, $\mathrm{CE}$ and IPD will be used synonomously. A next generation of CE or IPD is evolving and is specifically addressing affordability and the business processes to achieve it. One major goal of the research associated with this effort is to provide a framework for the aerospace community to move into IPD.

Integrated Design and Manufacturing of the HSCT requires the use of concurrent design or IPD to transform a traditionally sequential design process (Figure 2.2 ) to a more parallel process (Figure 2.3). 


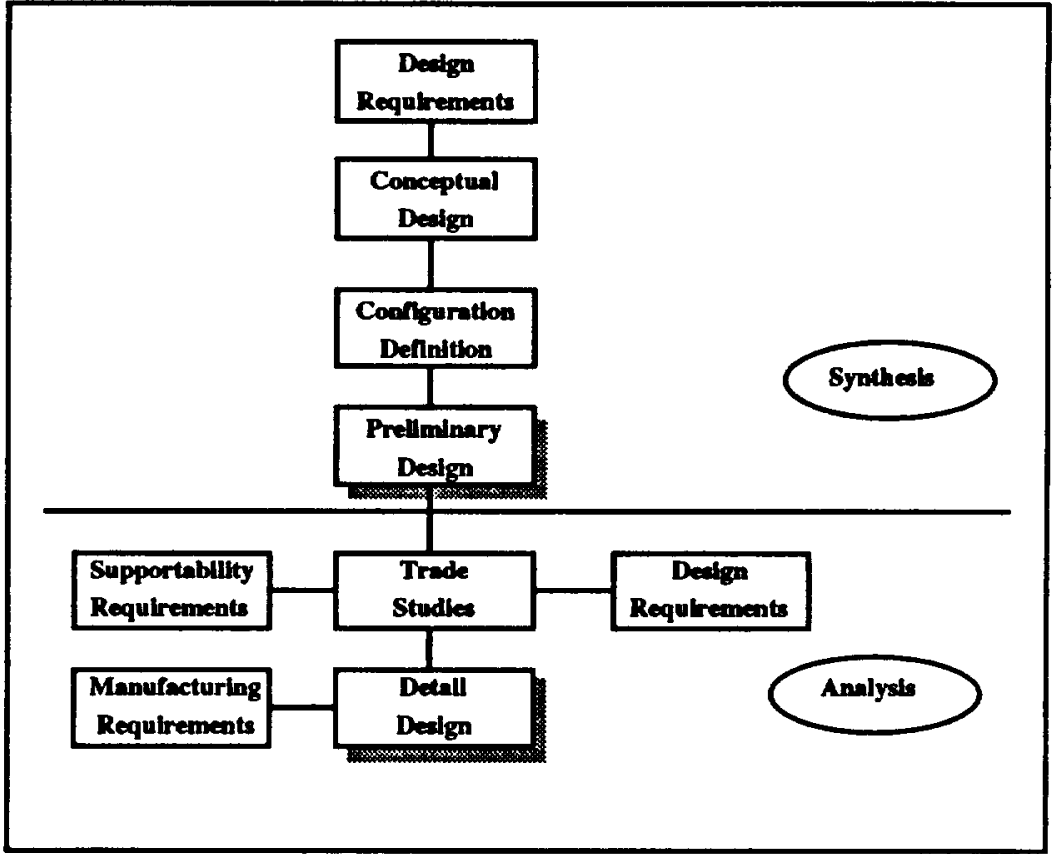

Figure 2.2: Traditionally Sequential Design Process

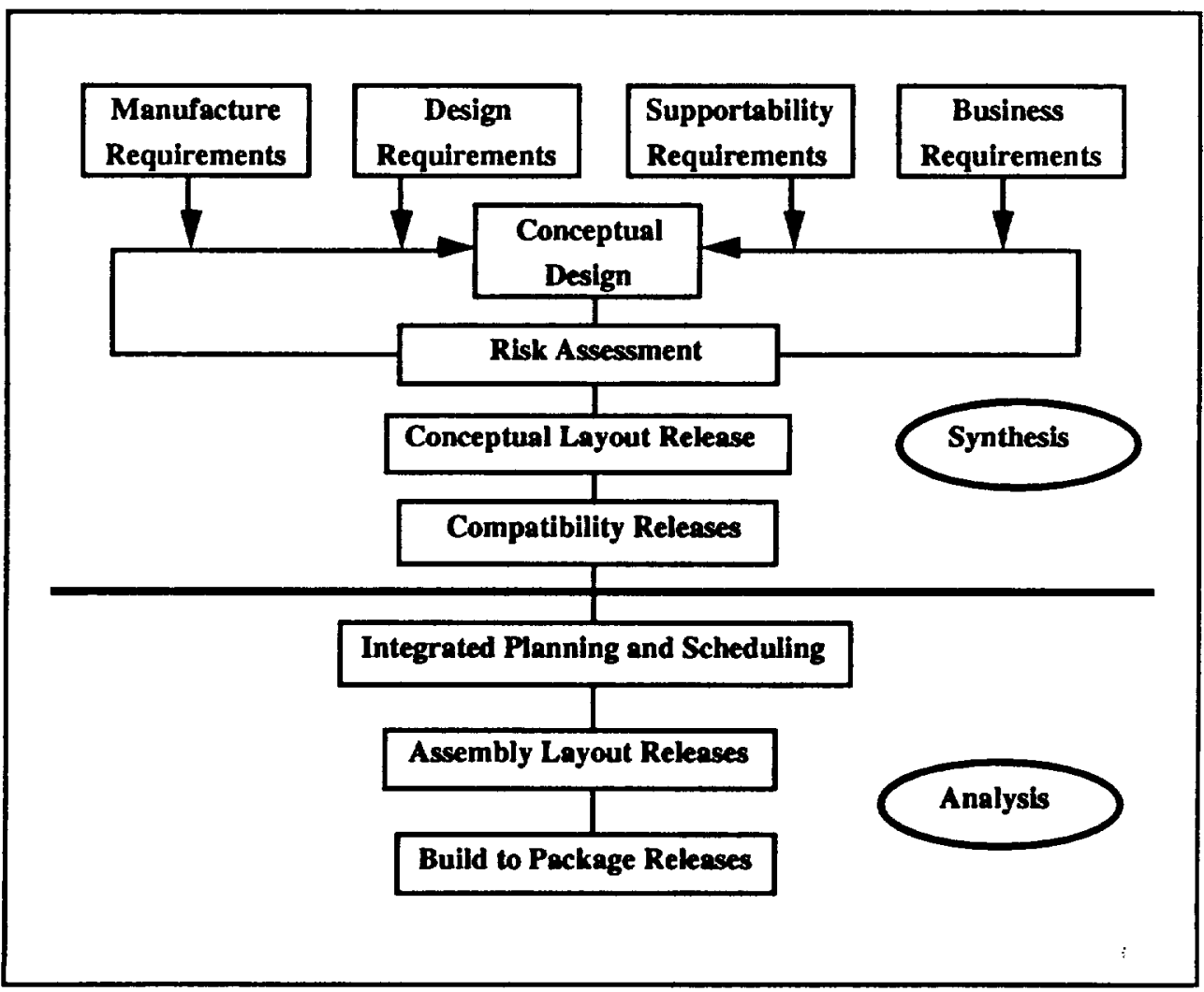

Figure 2.3: Parallel Design Process 
The generic methodology used by Georgia Tech in its NASA USRA ADP as well as other pilot projects is illustrated in Figure 2.4. The basis of Georgia Tech's methodology is built on the belief that CE includes the interaction of four key elements: Systems Engineering Methods, Quality Engineering Methods, a Top Down Design Decision Support Process, and a Computer Integrated Environment. Beneath the umbrella at the top of Figure 3 are the interactions of the four key elements. The Computer Integrated Environment is also located at the top of the umbrella to emphasize its importance in providing a mechanism for integration of the other three elements. Since CE is the concurrent design of products and processes, both product and process design must be integrated. This is accomplished through the incorporation of both Systems Engineering Methods (product design driven) and Quality Engineering Methods (process design driven). Systems Engineering focuses on system decomposition from system to component to part, while Quality Engineering focuses on system recomposition from part to component to system. This approach will allow trades between product and process at the appropriate levels and the rapid, parallel iterations so essential for improvements and integrated design and manufacturing (Figure 2.5).

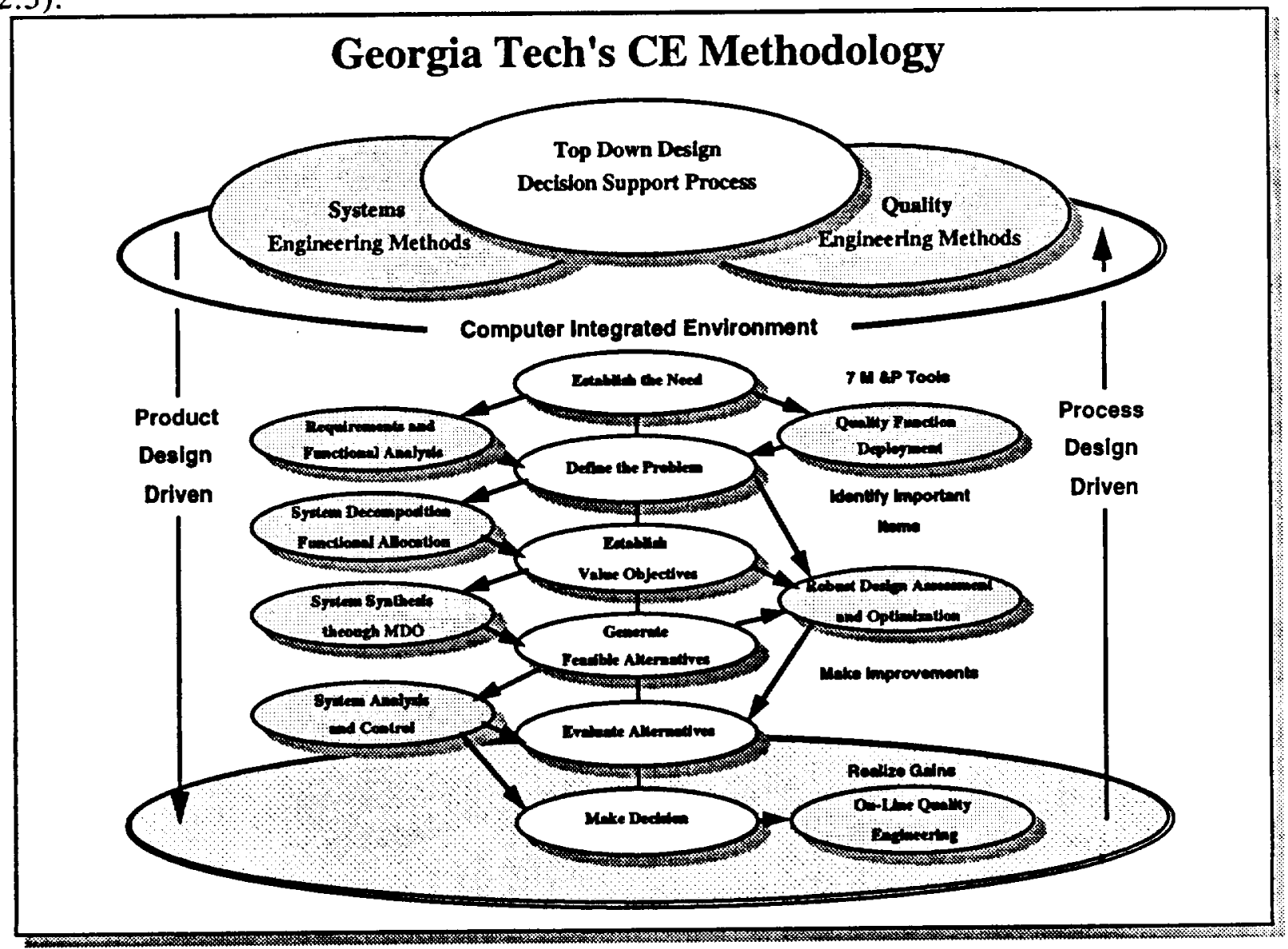

Figure 2.4: Georgia Tech's Concurrent Engineering Methodology 
The heart of the CE methodology is a Top Down Design Decision Support Process. Though decision support is not explicitly addressed in other evolving CE methodologies, it is an essential element, particularly for management, that is used to focus efforts on the design goals. It supplies a logical, rational means for including factors that must be considered when making a decision. The structure is not designed to restrict thinking, but to organize it and ensure its completeness. Since design can be viewed as an iterative decision making process, it can be described as a sequence of steps. The first course in the design sequence, Introduction to Concurrent Engineering, consisted of presenting the overall methodology and addressing the first three elements of the Top Down Design Decision Support Process:

- Establishing the Need,

- Defining the Problem, and

- Establishing Value Objectives.

The follow-on capstone design courses (AE6351 and AE6352) were aimed at completing the second half of the Top Down Decision Support Process, especially with system synthesis through Multidisciplinary Design Optimization (MDO), both at the system level and component level (wing). Trades at the component level using information from part level trades are considered essential if an integrated design and manufacturing approach is to take place. There are two principal reasons for this required approach. First, a complex system like an airplane is not manufactured at the system, or even component level. A prime-sub-supplier relationship is always involved, with the prime aircraft manufacturer being the final assembler. Second, the complexities and interactions involved in understanding the total decomposition and recomposition of design and manufacturing of a total aircraft system is overwhelming for both industry and government, let alone academia. Therefore, choosing one primary component, such as a wing, is the only viable approach for a pilot project.

The goals of this course were to:

- Generate Feasible Alternatives [to the existing Boeing/Douglas baseline configuration],

- to Evaluate these Altematives [using the Productivity Index as the criterion], and

- to Make a Decision [by modifying the initial baseline configuration based upon evaluation of the suggested alternatives].

- Accomplish a first level analysis at the system level with FLOPS and ACSYNT.

- Use results from the component level trades to close the loop back to the system level (Figure 2.5) 


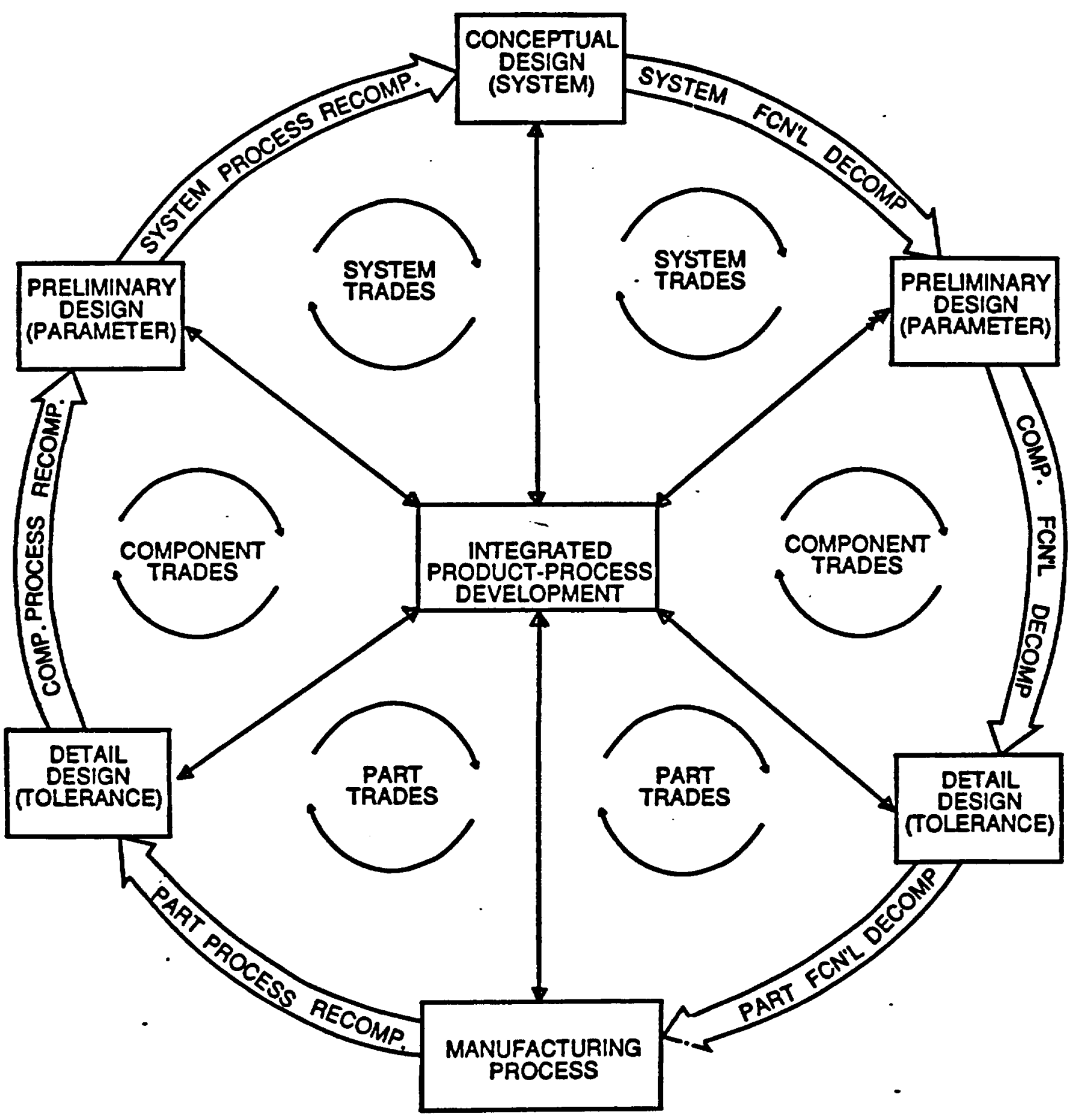

Eigure 2.5: Various Trades for Integrated Design and Manufacturing 


\subsection{Introduction to Concurrent Engineering}

Concurrent Engineering (CE) has been defined as "a systematic approach to the integrated, concurrent design of products and their related processes including manufacture and support." This approach is intended to cause the developer, from the outset, to consider all elements of the product life cycle from concept through disposal, including quality, cost, schedule, and user requirements. The design of a total system was not the objective of this course. The goal was to understand the overall generic CE methodology (see Figure 2.4) and define the "up-front" requirements, their decomposition, and the value objectives for a complex product such as the HSCT. This first education/research project consisted of three tasks, with deliverables for each.

The first task consisted of defining the HSCT problem by developing an initial Quality Function Deployment (QFD) Matrix that related the HSCT customer requirements to key product and process characteristics. Some of the Seven Management and Planning Tools (Figure 3.1) and Systems Engineering Tools (Requirements and Functional Analysis) were used to identify and decompose the customer requirements into key product and process characteristics.

The second task was the Establishment of Value Objectives for the HSCT. Value Objectives consist of setting feasibility constraints and establishing a Criterion Function describing a weighted relationship of pertinent criteria. The task consisted of deploying the key product and process characteristics of the first QFD Matrix to a second QFD Matrix (see Figure 3.2).

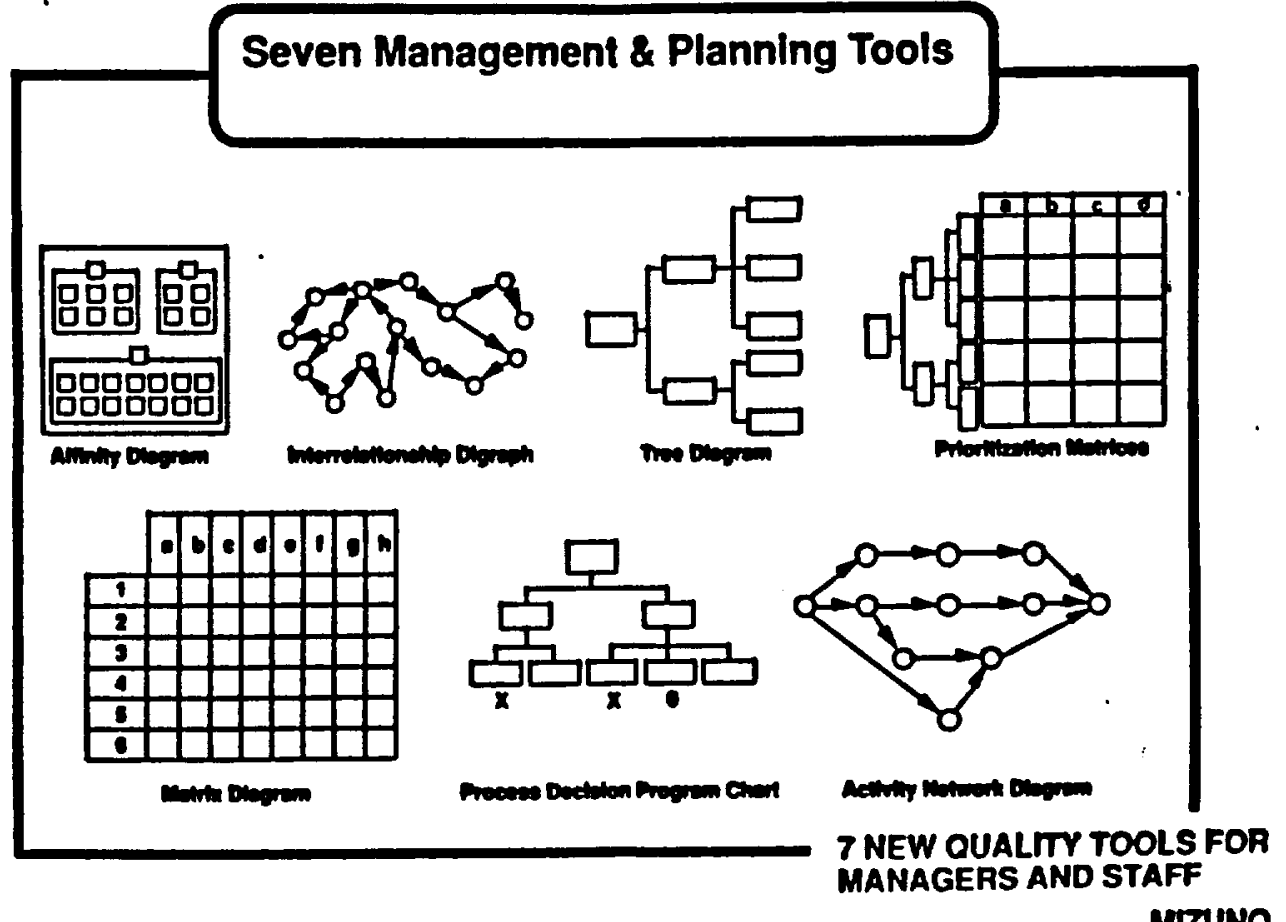

Figure 3.1: Seven Management and Planning Tools 


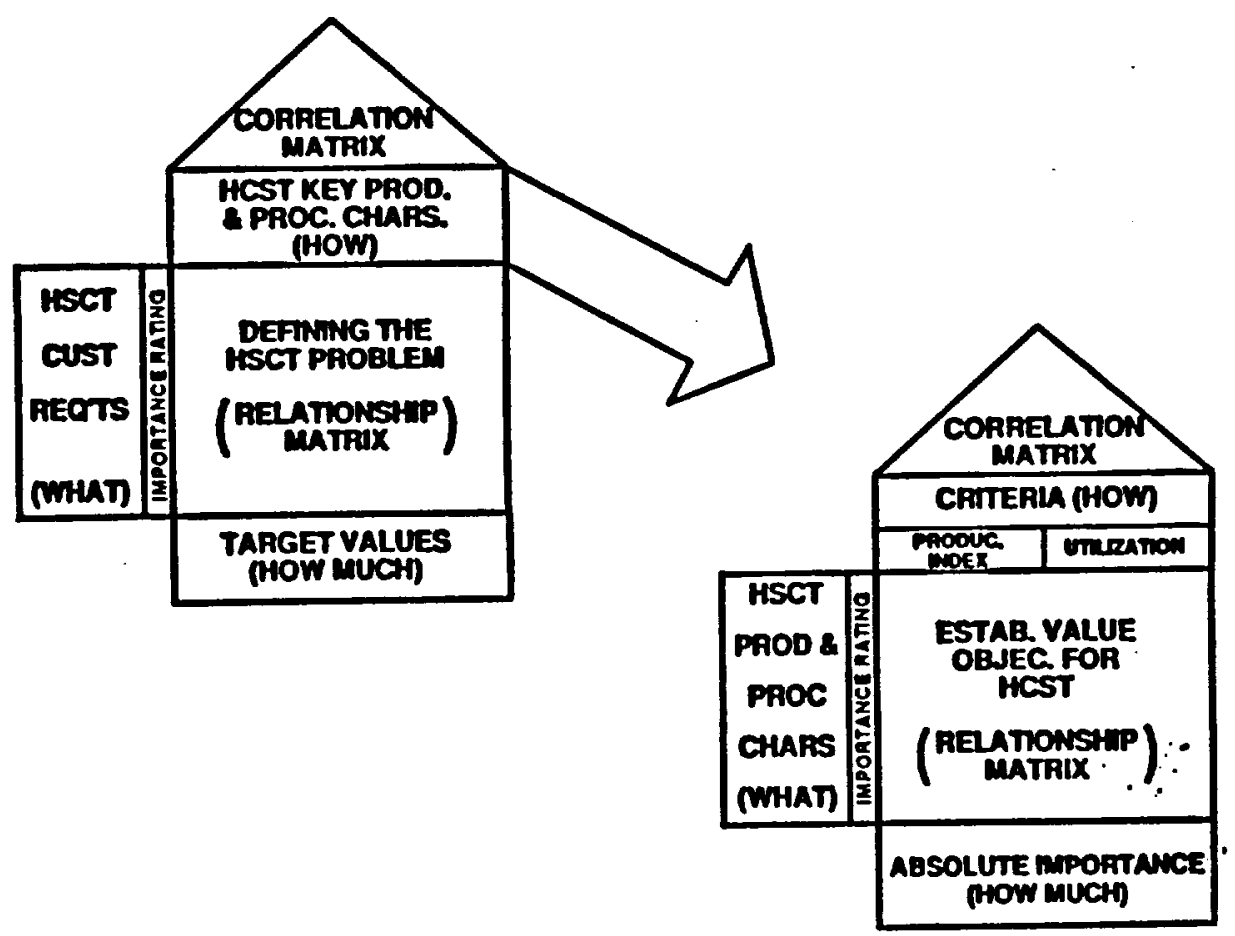

Eigure 3.2: OFD Matrix Deployment

This second QFD Matrix showed the relationships between the key product and process characteristics of the first QFD Matrix and the criteria that could be used to generate a criterion function and feasibility constraints. Some of the Seven Management and Planning Tools and Functional Analyses were used for brainstorming and to decompose the characteristics and criteria to secondary and tertiary levels.

The third task was the oral presentation on December 2,1992, of the results to an External Advisory Board (EAB) consisting of selected members of industry and academia (Figure 3.3). Also illustrated in Figure 3.3 is the overall framework of courses, faculty expertise, constraints, and technology areas required to successfully address integrated design and manufacturing for the HSCT. Submission of the final report was also a part of this task. Finally, an Activity Network Diagram was used to develop a schedule of events for the remaining NASA USRA ADP design courses.

As a result of this course, the team members had defined the customer requirements and key product and process characteristics as well as determined their interrelationships with the use of QFD Matrices. Value Objectives were established for the HSCT, again using QFD. Upon reviewing both matrices, it was evident that those key product and process characteristics that had the strongest correlation with the customer requirements (in the first QFD Matrix) also had the strongest correlation with the criteria used to determine the value objectives (in the second QFD Matrix). The teams had the capability to generate a criterion function which could be used to 
evaluate design alternatives generated in the first Aerospace Systems Design course, AE6351. However, since the purpose of this first sequence of courses was to develop and exercise the CE design methodology (Figure 2.4), the Boeing/Douglas baseline configuration was selected as a baseline concept; the criterion function was not limited to the Productivity Index to evaluate alternative designs from the baseline. Maximization of the Productivity Index (P.I.) became the overall system objective function. As illustrated in the second QFD Matrix (Figure 3.2), both a Productivity Index (P.I.) and a Utilization Index were identified as criteria that could be used to evaluate alternatives. Also, Life Cycle Costs (LCC) were included and were addressed in the Design for LCC course, AE4353.

\section{USRA Advanced Design Program GEORGIA TECH HIGH SPEED CIVIL TRANSPORT (HSCT)}

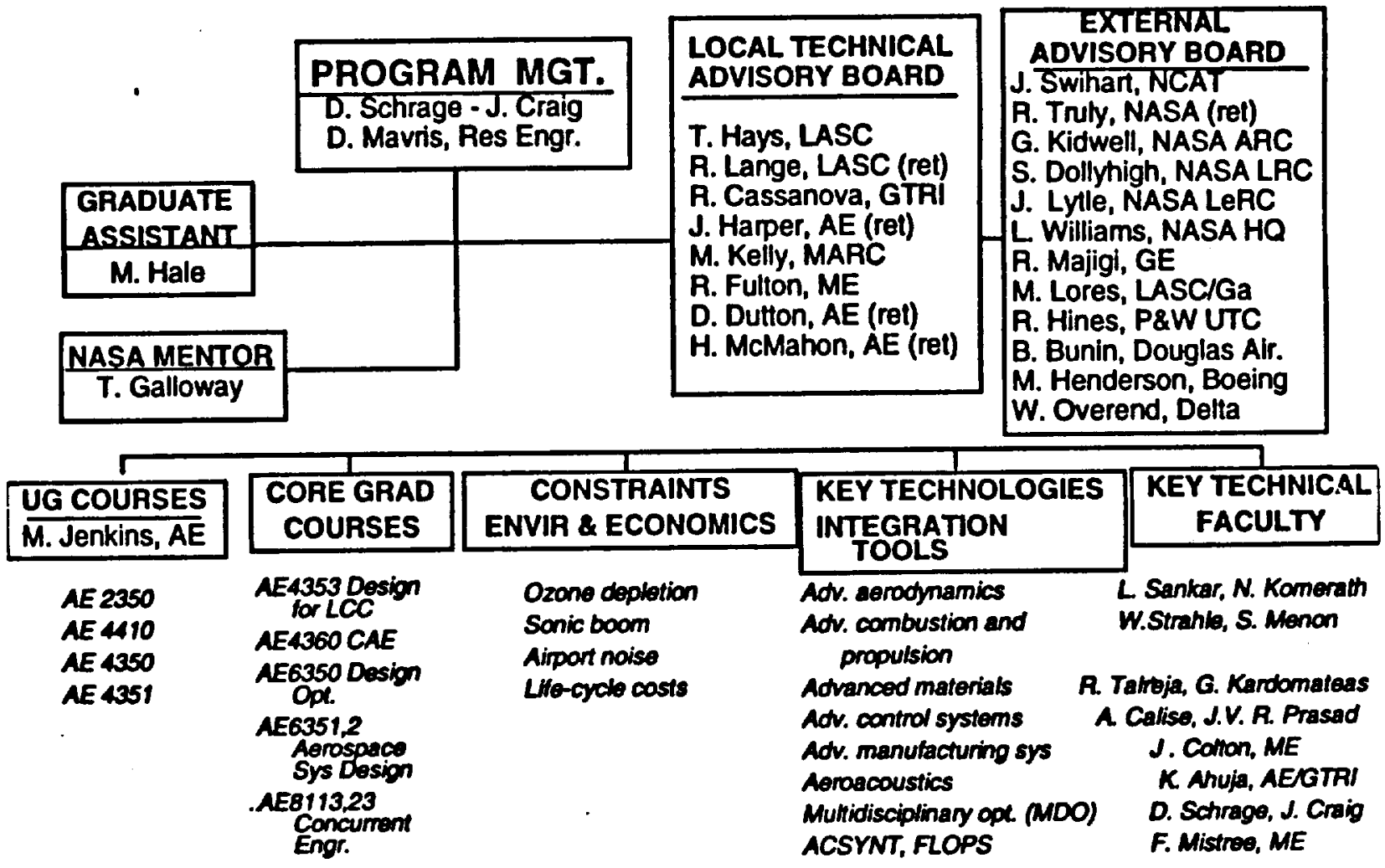

Figure 3.3: Overall GT Course/Faculty Framework 


\subsection{Design for Life Cycle Cost}

During the mid - 1960s, the United States actively pursued the supersonic transport (SST) concept. In 1971, however, the U.S. Government canceled the prototype program because of increasing concerns over its economic and environmental viability. For an airplane to be economically viable, it must offer a value to the airline that is equal to or more than the price charged by the manufacturer to cover manufacturing costs. Economic viability occurs when a market size justifies the investment and risk that both the manufacturer and an airline undertake when deciding to develop or purchase an airplane[1].

\subsection{Life Cycle Cost Approach}

As the budgets of aircraft manufacturers and airlines become tighter, the total cost of a product becomes extremely important. This total cost or Life Cycle Cost (LCC) is defined as the total cost of a system over its full life. This includes the cost of development, acquisition, operation, support and disposal. The life cycle cost of the system has to be addressed during the design process. As shown in figure 4.1, the decisions made during the early phases of a project commit the vast majority of life-cycle funds.

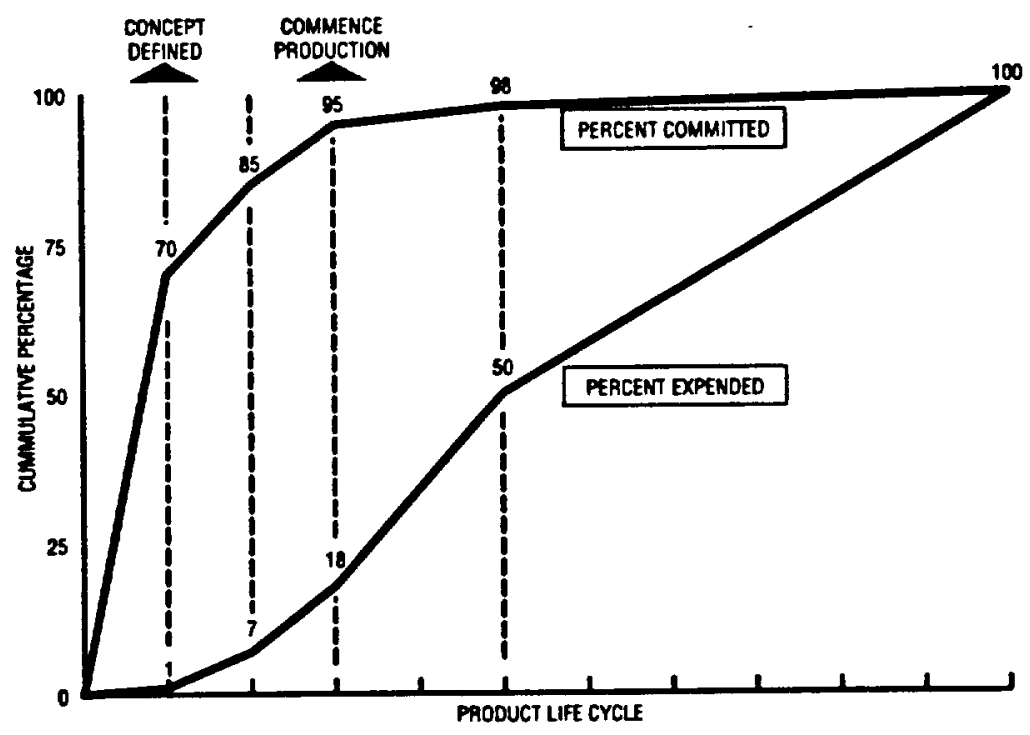

Source: Aerospace America, April 1993, p21

\section{Eigure 4.1 Life Cycle Cost Expenditure}

The ability to design around potential problems through essential cost effective trades from the beginning can reduce or eliminate the need for major "show-stopping" changes in the future. 
This benefit is realized in reduced development cost, reduced delays, redesigns, and inherent product development cycle times, as well as more marketable products.

\subsection{Georgia Tech Analysis}

The major focus of the Design for Life Cycle Cost Course AE4353 was to conduct a sensitivty assessment of the HSCT, focusing on the Airline and Manufacturer Return on Investments (ROI). ROI was chosen as a first attempt to include business practices into the $\mathrm{CE}$ design methodology (figure 2.4), and move to an extended CE methodology, IPPD. There are several methods to achieve this goal. One Quality Engineering method which is now used extensively in both the United States and Asia is Taguchi's Parameter Design Optimization Method (PDOM).

One of the most important things in LCC analysis or Economic Sensitivity Assessment (ESA), the term being used for the HSCT, is to understand the significant cost drivers early in the design process. These cost factors can be divided into two categories - control factors and noise factors. Control factors are those factors which a design engineer can control during the design process. Noise factors on the other hand are those critical factors, such as the external environment, over which the designer has no control, but which will have a major influence on his design decisions and on the viability of his product. In the airline industry, for example, the cost of fuel is a critical noise factor. To conduct the HSCT economic sensitivity assessment, the Taguchi PDOM was used in conjunction with Systems Synthesis through Multidisciplinary Optimization(MDO) and Quality Function Deployment (QFD). The outline of this process is illustrated in figure 4.2 .

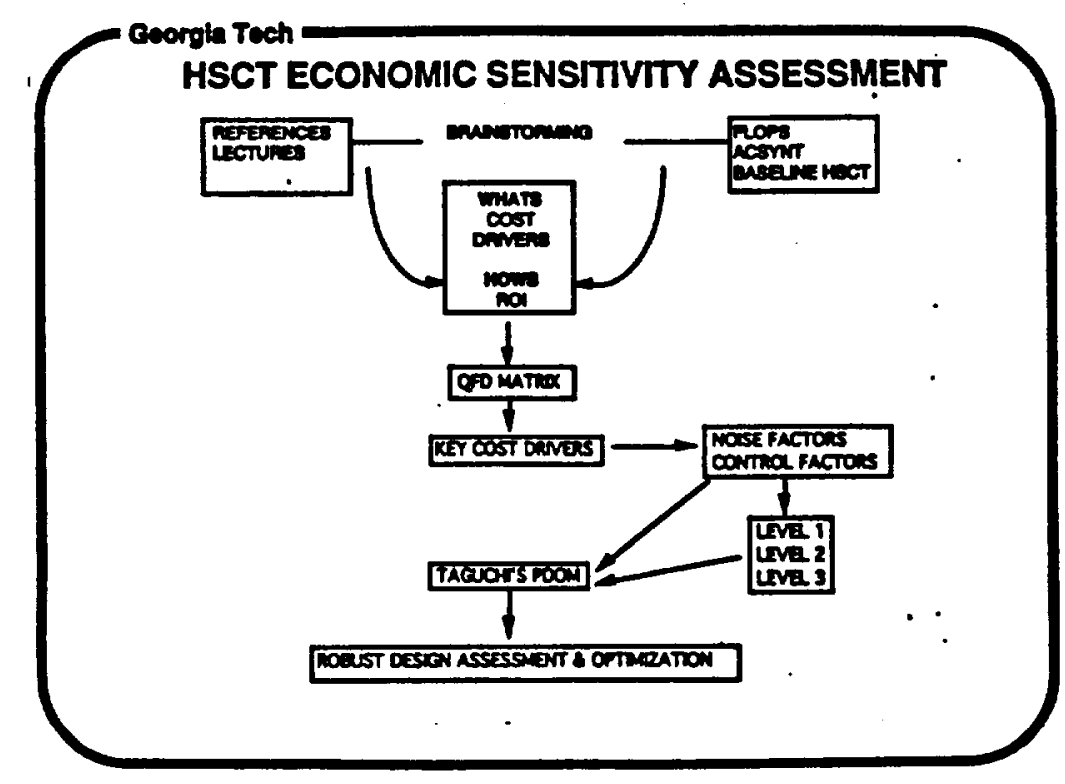

Eigure 4.2 HSCT Economic Sensitivity Assessment. 
The process began with Quality Function Deployment. This was used to determine the Key Cost Drivers for the HSCT manufacturer and airline industry. These cost drivers were separated into control and noise factors which were subsequently used to conduct the Taguchi PDOM.

The cost drivers for the airline were determined to be:

$\begin{array}{ll}- & \text { Acquisition Cost } \\ \text { - } & \text { Depreciation } \\ \text { - } & \text { Fuel Cost } \\ \text { - } & \text { Load Factor } \\ \text { - } & \text { Facility/Building Cost } \\ \text { - } & \text { Maintenance Cost } \\ & \text { Flight Equipment Maintenance - Inventory }\end{array}$

For the manufacturer, we determined that the important cost drivers were:

- $\quad$ New Manufacturing Techniques

- $\quad$ Engine Development

- Material Development - Engineering Costs

- $\quad$ Profit Margin

- Raw Materials

The second preliminary step was to determine the return on investment(ROI) criteria for both groups. This ROI criteria relates to business practices and was simply a listing of the important issues that determine the level of profit for the groups.

For the airline:

For the manufacturer:
1) Ticket Price

2) Labor and overhead rates

3) Aircraft Performance Characteristics

4) Turnaround times

1) Production Cost

2) Research and Development Cost

3) Aircraft Selling price

4) Airline Payment schedule

5) Warranty Obligation

This information was then placed in the QFD House of Quality to determine the key cost drivers. The key cost drivers were determined following the weighting scheme implemented in the QFD matrix. The key cost drivers were found to be: 


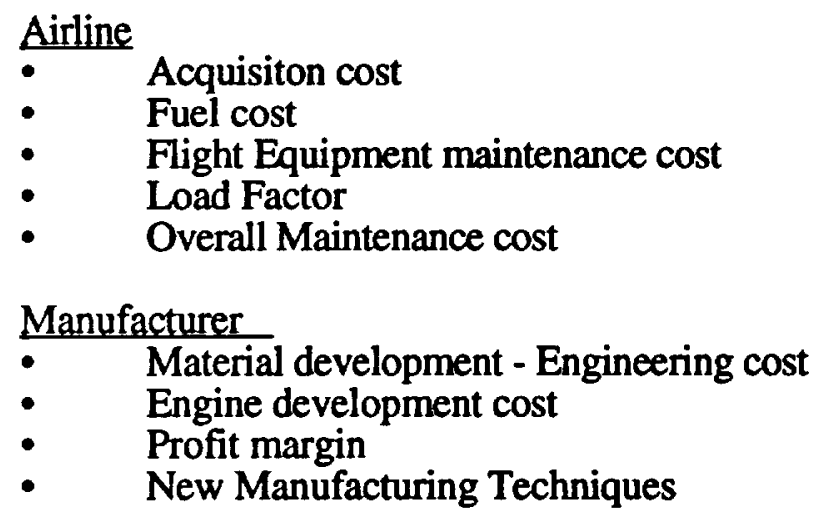

These cost drivers were divided into control factors and noise factors. These were then used as inputs to the ACSYNT ${ }^{\circledR}$ aircraft synthesis program. The economics module of ACSYNT was used as the simulation model for exercising Taguchi's PDOM. The Boeing/NASA HSCT baseline configuration was used as a fixed input to this economics module for the cost sensitivity analysis.

\section{ACSYNT analysis}

The ACSYNT input variables used in this study represented the best effort made to match the cost drivers output by the QFD matrix. For the manufacturer, the control factors specified to ACSYNT were: Engineering Labor Rates (material development), Manufacturer Fee (profit margin) and the Construction Factor (new manufacturing techniques). The noise factors were the Production Quantity and the Average Price Index. For the airline, the control factors were the Maintenance Labor Rates (maintenance cost), the Maintenance of Flight Equipment, and Flight Operations Costs. The noise factors were the Cost of Fuel, and the Load Factor. These factors were then varied in accordance with the orthogonal arrays of the Taguchi PDOM.

Using these Taguchi orthogonal arrays, the optimum control factors which maximized the ROI for the manufacturer and the airline were determined. These optimum factors were:

\section{1-1-1 Airline}

Lower Maintenance Labor Rates

Lower Maintenance Flight Equipment

Lower Flight Operation Cost 


\title{
2-3-3 Manufacturer
}

\author{
Lower Engineering Labor Rates \\ Highest Fuselage Construction Factor \\ Highest Manufacturer Fee
}

\subsection{Conclusions}

This Economic Sensitivity Assessment has analysed the High Speed Civil Transport (HSCT) for manufacturing and operational improvements which could maximize the Return On Investment for both the Aircraft Manufacturer and the Aircraft Operator (airlines)

Important Cost Drivers were determined for the two groups. These cost drivers were examined according to their effects on the ROI of both groups, that is, whether they were control factors or noise factors. These factors were assigned levels and were subsequently put into Taguchi Orthogonal Arrays.

The results of the Taguchi PDOM are separated into two groups.

1) For ACSYNT, the optimum airline ROI occurs when:

- There is the lowest maintenance labor rate

- There is the lowest flight equipment cost

- There is the lowest flight equipment maintenance.

The optimum manufacturer ROI occurs when:

- There is the lowest engineering labor rate

- The construction factor is the highest

- The manufacturer fee is the highest.

These optimum input results were combined and executed to determine if indeed this "optimum" combination would result in higher Return on Investments when compared to the baseline aircraft.

The results indicated that the airline is directly affected by the manufacturer and not vice versa. For the ACSYNT analysis, the airline ROI went down and the manufacturer's return increased. This is due to the input and analysis structure of ACSYNT. In ACSYNT the results of the manufacturer is directly coupled to the airline. There is however no coupling loop from the airline back to the manufacturer. Thus, the optimum of the airline has no effect on the manufacturer. To investigate the coupling that exists between these two parties, an off line analysis has to be conducted.

Although the identification of the optimum control factors in itself is not earth-shattering, the fact that an open loop system exists in the ACSYNT economic analysis between the 
manufacturer and it primary customer, the airline, demonstrates that CE and IPPD in particular is not implemented in this commonly used synthesis and analysis tool.

\section{References}

1. Kulfan, Robert M. "High Speed Civil Transport Opportunities, Challenges and Technological Needs", Keynote Speech on 34th National Conference on Aeronautics, November 26, 1992 


\subsection{Computer Aided Design and Manufacturing}

CAD/CAM/CAE technology has undergone enormous changes in the past 25 years. CAD systems, which began as two dimensional automated drafting systems, were used for computer aided drafting, not computer aided design. As hardware became more powerful and numerical algorithms were improved, three dimensional wire frame systems evolved. In the past, although design work could be accomplished on these systems, the challenge existed in integrating them into the analysis and manufacturing processes. Today, CAD/ CAM tools can not only perform analysis while the design is being developed; they can also allow the design data to be passed directly to the user for access to numerical controlled manufacturing machines[1].

As an intergral part of the Concurrent Engineering approach, CAD/CAE provides the computer integrated atmosphere which encompasses this methodology. This evolving capability makes the feasibility of conducting MDO a reality. Creating a digital product model enables electronic data sharing by all parties involved in product definition. This common database eliminates duplication efforts, and provides everyone with access to current data. With the improvements in 3-D modeling, design information can be relayed with great detail. Simulating product performance helps the designer to understand, before the product is fabricated, how it will perform. Simulations can be used early in the design process and the results incorporated during the development cycle. Digital mockups can be used to simulate the hardware assembly, thereby reducing the need for expensive physical mockups[2].

The capabilities of CAD/CAE are tremendous. Using today's common database approach, the designer can create a 3-D model that can be used for numerous activities. Analysts can construct finite element models from the design geometry data set. This data set can also be used to construct configuration models which are used to determine part interferences and fit. Tooling and access platforms can also be developed from this database, allowing the early identification of problems usually not found until fabrication[2]. Additionally, traditional drawings can be created by taking 2-D views of the 3-D models and letting the computer automatically add the necessary dimensions.

\subsection{CAE/CAM Applications at Georgia Tech}

The fundamentals of Computer Aided Design were taught in the AE4360 class as part of the Concurrent Engineering/ Integrated Product Design course sequence outlined earlier. The purpose of this class was twofold. First, it presented the primary concepts behind the 
computational representation of objects. Second, it introduced two primary design and analysis tools.

These were:

\section{1) Professional CADAM ${ }^{\mathrm{MM}}$ \\ 2) CATIA $^{\text {TM }}$}

Professional CADAM is an interactive computer aided design system that is currently supported by the IBM Corporation. It is used primarily for 2-D geometric representation, and can be used for several analyses. CADAM was used to create the three view orthographic drawings of the aircraft used in this study. It was also used to illustrate the CG location of major aircraft components.

CATIA is a Computer-graphics Aided Three-dimensional Interactive Application system. CATIA, developed by Dassault, has become an industry standard throughout most of the aerospace community. It is used to create three dimensional geometric models using wireframe, surface and solid modeling constructions. Additional application modules incorporated with CATIA provide capabilities for kinematics, robotics, Finite Element Modeling mesh generation, $\mathrm{NC}$ mill and lathe programming, structural member design and image generation. CATIA was used to ensure that the primary structure designed to support the wing would fit within the volume generated from the aerodynamic study.

\section{References}

1. "Keeping ahead of the CAD/CAM curve,"Aerospace America, June, 1993 pp 20

2. "CE: Engineering a change in the Design Process," Aerospace America, April, 1993,pp 21 


\subsection{Aerospace Systems Design I}

This first design course addresses "System Synthesis through Multi-disciplinary Design Optimization (MDO)." Two closely related projects were associated with this course. The first was the conceptual design refinement of a baseline HSCT configuration defined by Boeing and Douglas in their systems studies. This project was essentially individual in nature and was intended to familiarize the team members with conceptual design systems synthesis trade-offs for the HSCT. The second project was team oriented and was intended to introduce students to some analytical methods and tools used in preliminary design. NASA's synthesis codes FLOPS and ACSYNT were the primary tools used for these studies. One of the two teams used ACSYNT and the other used FLOPS. The same initial configuration and mission profile were modeled in both.

This project was modeled after the producibility technology studies that the LockheedCalifornia Company conducted in the mid-1970s. The purpose of the studies, funded by NASA's Langley Research Center (LaRC), was to assess materials and producibility methods for the design of the primary structure of a supersonic cruise aircraft. Emphasis was placed on an integrated design and manufacturing approach to develop low-cost producible structural configurations by identifying potential materials and fabrication technologies that would be available in the 1980s and 1990s for advanced technologies. While the studies are somewhat out of date, they served as a good foundation for Georgia Tech's first efforts, and introduced students to the nethods and tools used in industry.

The criterion used to evaluate the initial baseline configuration was the Productivity Index (P.I.). This criterion shows the relationships between optimum aircraft performance and various economic and technical design constraints. The development of an economically viable supersonic cruise aircraft is primarily dependent upon the successful integration of interactive advanced technologies involving:

- aerodynamics/performance.

- propulsion/integration. and

- structures / materials / manufacturing.

Parametric variations were performed on key design parameters in these three areas. These variations were related to the Productivity Index (P.I.) and ideas for modification of the initial baseline configuration were generated individually by team members in each of the three respective areas. Upon culmination of all ideas and efforts, a final revised baseline configuration was selected to be used for the next quarter's capstone preliminary design course, Aerospace Systems Design II, AE 6352. 


\subsection{Trade Studies}

The baseline airplane used for this study was the Boeing Commercial Airplane Group Model 1080. This baseline is based on Market Driven Design Requirements, Environmental Requirements, and Technical \& Economic Viability. Boeing determined that a cruise speed of Mach 2.4 would provide a good balance in trip time benefit and technology risk. Aircraft size and complexity increase significantly with increasing Mach number. The upper airplane weight limit for airport runways is projected to be approximately $900,000 \mathrm{lbs}$. This weight limit therefore constrained the aircraft maximum Mach to values between 2.0 and 2.5. The initial baseline design range of $5000 \mathrm{nmi}$ was chosen by Boeing to serve more than $80 \%$ of the revenue passenger miles in the HSCT nonstop market. A design range of $6500 \mathrm{nmi}$ would capture approximately $85 \%$ of the nonstop HSCT revenue passenger miles, however, an initial aircraft with a $6500 \mathrm{nmi}$ range would be heavy and expensive. Figure 6.1 .1 shows the baseline model that was created in ACSYNT.

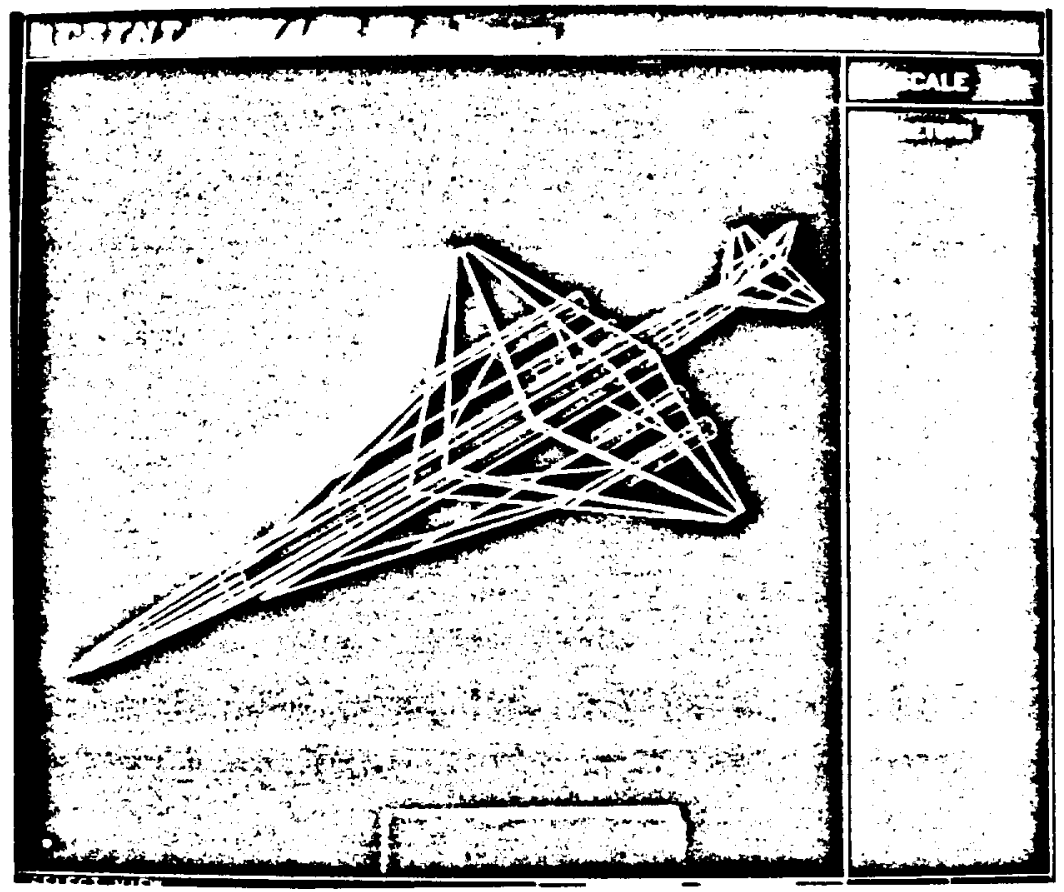

Figure 6.1.1. ACSYNT model of Boeing baseline aircraft

The process of creating the baseline in ACSYNT was extremely tedious. In addition to obtaining detailed geometric information about the aircraft, a great deal of time and effort was spent determining the exact engine parameters for the baseline. After much effort, we were able to arrive at a baseline that matched the Boeing airplane in weight and known performance. Table 6.1.1 shows a list of important city pairs which could be served nonstop by the baseline aircraft. Currently, the nonstop travel time from Los Angeles to Sydney at subsonic speeds is 
approximately 14 hours. By comparison, Boeing calculated that the proposed baseline could make a 7.3 hour, one stop flight. This stop would be in Honolulu for one hour. The 10 hour Mach 0.84 flight to Tokyo would be replaced by a 4.3 hour HSCT flight.

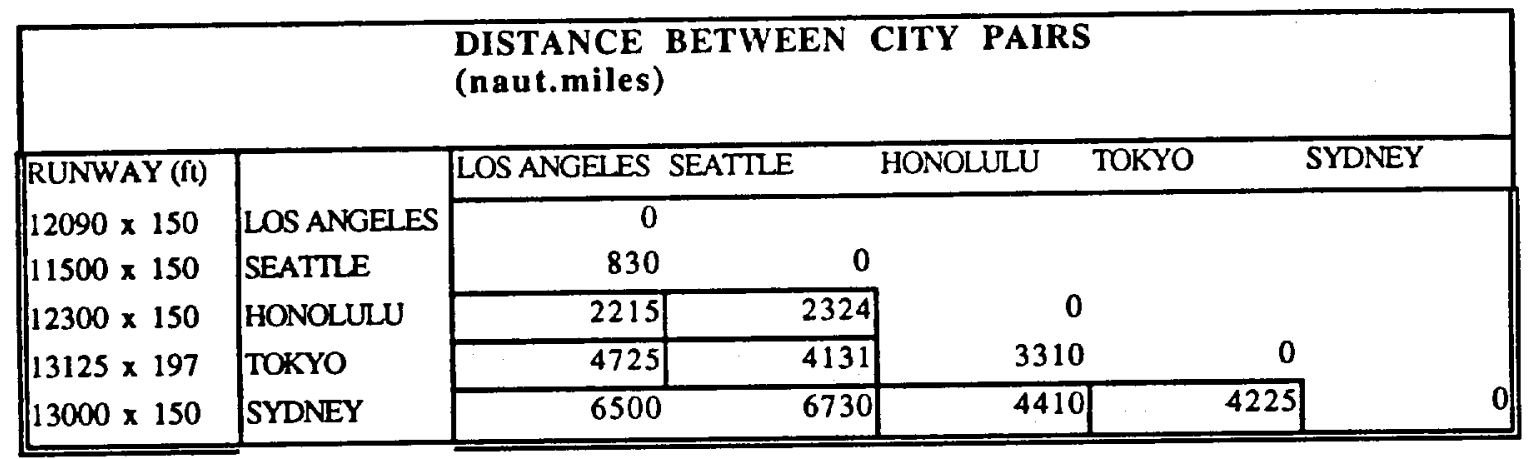

\section{Table 6.1.1. HSCT Pacific City Pairs}

\subsection{Mission Profile}

The mission profile for this baseline is greatly simplified for our first attempt at developing an overall methodology. This is because of the fact that our selected missions are all continuous and over open water. Figure 6.2.1 shows the generic mission profile that was used for our analysis.

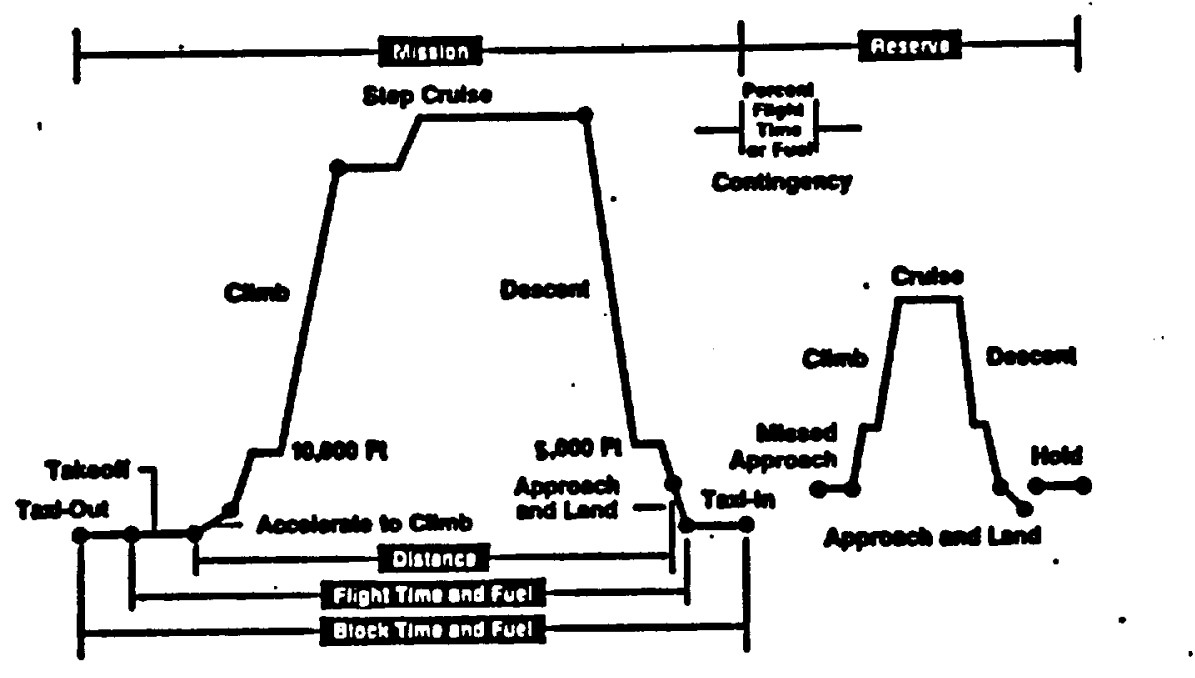

Source: AlAA perspectives in Aircraft Systems Design Short Course, February 20, 1993

Figure 6.2.1 HSCT Mission profile 
Following takeoff and climb to $10,000 \mathrm{ft}$, we specified continuous climb to an altitude of $56,000 \mathrm{ft}$, after which time a step cruise was implemented. This step cruise at Mach 2.4 ended at $66,000 \mathrm{ft}$, the altitude at which the majority of the cruise mission was spent. Following cruise, we specified descent to $5,000 \mathrm{ft}$, after which there was approach and landing.

Step cruise was implemented because the optimum fuel efficiency altitude of an aircraft increases as fuel is burned off and the airplane weight decreases. Provisions were made for reserve fuel. The reserve fuel was $13 \%$ of the total fuel. As shown in figure 6.2.2, this reserve was carried according to Federal Air Regulations (FAR) and consisted of allowances for contingency fuel, missed approach fuel, and fuel for travel to alternate airports.

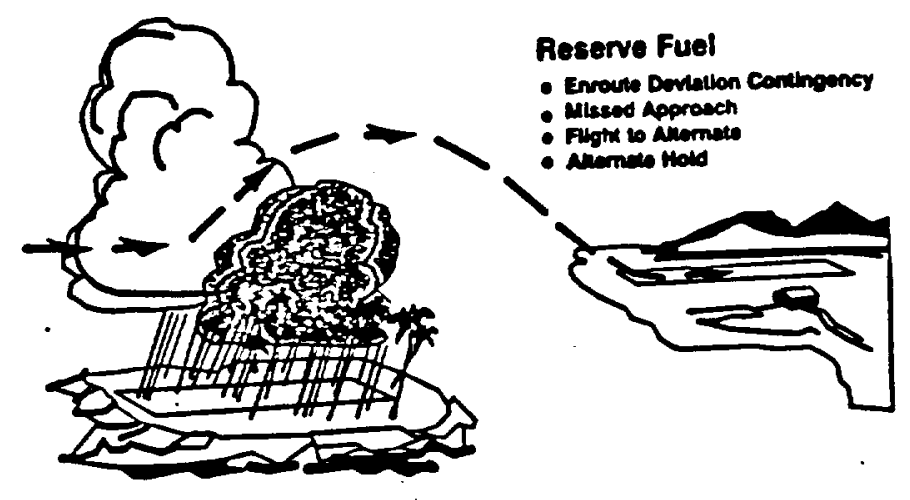

Source: McMasters J. AlAA perspectives in Aircraft Systems Design Short Course, February 20, 1993

Figure 6.2.2.Necessity of Fuel Reserves 


\subsection{Criterion Selection}

The paramount issue in the decision process is whether an ecologically suitable HSCT can be developed with acceptable risk that will provide safe and profitable operation. The pivotal concerns regarding any future HSCT are noise and pollutant emissions (both on the ground and at altitude), performance, cost, and development risk. Recently, an assessment was conducted of the mission performance benefits associated with the technology improvements and goals of NASA's HiSAIR Program. Advanced technologies in the areas of structures, propulsion, flight-deck systems, and aerodynamics were applied to a representative Mach 2.4 vehicle concept. The payoffs associated with each particular discipline were broken down to identify the result from the proposed major elements within each discipline. For each technology, a sizing thumbprint was generated, including selected constraints. The focus of these efforts was on minimizing the aircraft's TOGW by applying advanced technologies to key parameters within each discipline.

Our approach is very similar to that used by NASA for their study. While minimizing TOGW is often used as a criterion, or objective function, it is often not a complete measure and does not relate to ecomonic considerations. Instead of concentrating efforts on minimizing the TOGW, the objective of this analysis was to consider a criterion one step above the TOGW in the hierarchy of design variables: the Productivity Index (P.I.) was selected as the target variable of this study. The Productivity Index does indeed incorporate the aircraft's TOGW, as well as other important parameters in an explicit manner such as the payload, empty weight, fuel weight, and block speed. The Productivity Index is a commonly used criterion that relates pertinent product and process parameters to overall affordability. The Productivity Index relates design parameters to economic parameters and is defined as:

$$
P . I .=\frac{P . L . \times V_{B}}{W_{E}+W_{F}}
$$

where: $\quad$ P.L. $=$ Payload

$$
V_{B}=\text { Block Speed }
$$

$W_{E}=$ Weight Empty

$W_{F}=$ Fuel Weight.

Traditionally, productivity has been a measure of relating a commercial aircraft's capability to economic viability. Thus, our selection of the productivity index as an analytical measure to evaluate alternative configuration refinements directly corresponds to an aircraft meeting its technical design goals, as well as being an economical success.

Boeing constrained the baseline aircraft by means of the "Thumbprint" plot. The mission sized and configured aircraft is determined by specifying the performance requirements and imposing operational constraints. Operational constraints such as fuel efficiency and 
takeoff/landing field length have to be imposed on a configuration based on a specific range or payload requirement. The disciplines that contribute to the thumbprint constraints are shown in figure 6.3.1.

To conduct our study of the effect of multi-disciplinary changes on the baseline Productivity Index, we have varied numerous design variables. For aerodynamics, we have focused on variables that impact Block Speed and MTOW. For propulsion we have looked at the effect of MTOW, which is a function of the Fuel Weight. Similarly, for Structures, we have varied Empty Weight and Payload respectively. It was anticipated, that following our multi-disciplinary analysis, we would be able to present a revised baseline aircraft which maximizes the vehicle Productivity Index.

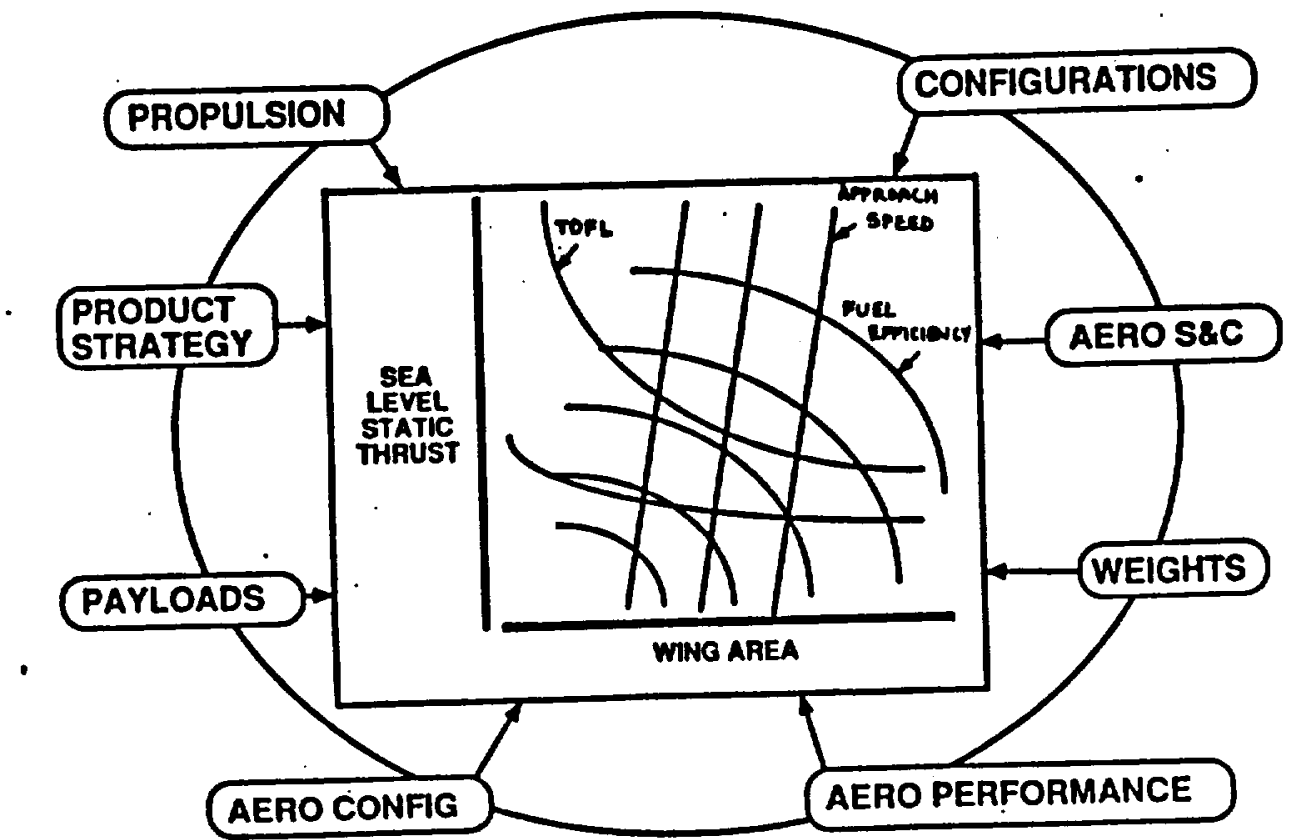

Source: McMasters J. AIAA perspectives in Aircraft Systems Design Short Course, February 20, 1993

Figure 6.3.1. Multi-Disciplinary Analysis 


\subsubsection{Baseline Productivity Index}

As discussed in the previous section, the Productivity Index constitutes four design variables: payload, block speed, empty weight, and fuel weight. The baseline P.I. for our concept(s) modeled in FLOPS and ACSYNT were calculated as follows:

Payload:

294 pax. $\quad x$

+9 stewardesses $\quad x$

+2 galley crew $\quad x$

+3 crew

$x \quad(225 \mathrm{lbs} /$ crew member $)$

TOTAL PAYLOAD

$(170 \mathrm{lbs} / \text { person }+30.2 \mathrm{lbs} \text { baggage/person })^{*}$

$\left(\begin{array}{ll}\text { ( } & )^{*} \\ ( & )^{*}\end{array}\right.$

TOTAL PAYLOAD $61,736 \mathrm{lbs}$

Block Speed:

Block Speed $=\quad$ (Block Range / Block Time)

$=\quad(5000 \mathrm{nmi} / 4.31 \mathrm{hrs})$

\begin{tabular}{cll}
\multicolumn{1}{c}{} & $(5000 \mathrm{nmi} / 4.31 \mathrm{hrs})$ \\
\hline BLOCK SPEED & $\mathbf{1 1 6 0} \mathrm{kts}$ & (output from FLOPS) \\
\hline
\end{tabular}

\section{EMPTY WEIGHT}

FUEL WEIGHT
295,744 lbs

305,612 lbs (output from FLOPS)

(output from FLOPS)

These values lead to an initial Productivity Index for the FLOPS baseline of:

$$
P . I_{(\text {(nitial/FLOPS })}=119.1 \mathrm{kts}
$$

The values for block speed, empty weight, and fuel weight output from ACSYNT lead to an initial Productivity Index of essentially the same value as that calculated with the parameters output from FLOPS.

* Default values for person and baggage weights from ACSYNT. 


\subsection{Disciplinary Analyses}

\subsubsection{Structures / Materials / Manufacturing}

During the mid 1970s, the Lockheed-California Company studied the application of composite materials to the HSCT airframe structure. They conducted trade-offs relating the amount of composites applied to resulting TOGW reduction and range increases. In September, 1976, the Lockheed-California Company submitted Technology Assessment Studies Applied to Supersonic Cruise Vehicles to NASA Langley Research Center. These studies included research of structures and materials, propulsion, acoustics, aerodynamics, performance, and economics for a supersonic transport. Their assessment of structures and materials technology applications was presented for two start-of-design points: near-term (then 1980) and far-term (then 1990).

For their near-term structural concept, the primary construction material (with the 1980 technology) was titanium alloy $6 \mathrm{Al}-4 \mathrm{~V}$. Composite materials accounted for $7 \%$ of the airframe mass. The aircraft had a TOGW of $750,000 \mathrm{lbs,}$ a wing-loading of $68.7 \mathrm{lb} / \mathrm{ft}^{2}$, cruise Mach of 2.55 , and $\mathrm{T} / \mathrm{W}$ of 0.36 . The empty weight of the aircraft was $362,800 \mathrm{lbs}$. Aircraft performance analyses conducted on this aircraft revealed that the aircraft could not achieve its maximum potential performance levels due to approach speed and flyover noise constraints. A penalty of 360 nautical miles relative to the maximum potential range, 4200 nautical miles, was incurred due to the imposition of landing approach speed and flyover noise constraints.

Their far-term structural design employed "assumed" 1990's technologies that could be used with a high-confidence level for both primary and secondary structural applications. The predicted 1990 design employed both advanced metallic and composite materials. This aircraft had the same TOGW of $750,000 \mathrm{lbs}$, the same T/W of 0.36 , and the same wing loading of $68.7 \mathrm{lb} / \mathrm{ft}^{2}$.

Examination of their near-term and far-term structures technology trends and potential benefits indicated that major structural mass reduction could be achieved with the increased use of advanced composite materials. They estimated that approximately $30 \%$ of the airframe mass consisted of secondary structure which could incorporate composites with minimum development effort and risk. Approximately $65 \%$ of the airframe mass is primary structure which could incorporate composite materials, but would require extensive development effort and involve higher risks; materials and manufacturing costs increase and the available data base decreases with temperature. In addition to the titanium alloy used in their near-term concept, the far-term concept made use of high temperature polyimides and metal matrix composites.

The aircraft was then modified to reflect the overall technology assessment studies results. This resulted in a configuration with 290 passengers, a wing-loading of $88 \mathrm{lb} / \mathrm{ft}^{2}$, a lift-off T/W of 0.30 , cruise Mach of $2.55,5 \%$ fuel reserves, and advanced systems. At the initial TOGW of $750,000 \mathrm{lbs}$, the aircraft had a predicted range of 4466 nautical miles. Further design changes 
were made by applying composite materials to the secondary structure of the wing and fuselage. This resulted in a mass savings of $11,500 \mathrm{lbs}$ and a range increase of 243 nautical miles. The composite material application for this configuration was approximately $30 \%$ of the airframe mass. The unrestricted application of advanced composite material (64\%) encompassed the previously identified $30 \%$ secondary structure plus the wing aft box, the wing-tip, and fuselage shell structure. This resulted in an additional range increase of 207 nautical miles. The mass savings for this concept was not stated.

The previous two examples of structural/material trade-offs are results of technology assessments for the 1970s. Many of the major aircraft manufacturers today are conducting similar research related to structures/materials/manufacturing to add to the existing technology base for the HSCT. For example, Douglas has addressed three primary issues in their preliminary structural design for the HSCT. First, the candidate airframe materials have been selected for their potential of known long-term thermal stability and adequate mechanical properties at sustained elevated temperatures, minimum material density, and the ability to be fabricated and assembled at reasonable cost. At Mach 2.4, these materials are titanium, discrete-reinforced elevatedtemperature aluminum, and high-temperature polymeric composites (HPCs). However, the longterm stability, strength, durability, and damage tolerance properties and producibility characteristics of many of these materials are not yet established. Years of work remain before a final material can be selected with confidence. Second, they are employing structural concepts which either minimize the effects of thermal gradients in the structure or are robust enough to withstand them without serious weight penalty. This issue becomes very critical as design speeds increase above Mach 1.8. Third, since the HSCT cruises at an altitude of nearly 70,000 feet at Mach 2.4, Douglas is exploring unique pressurized fuselage concepts which will ensure survivable cabin decompression scenarios, again with minimal weight penalty.

\subsubsection{Propulsion / Integration}

The major challenges confronting the propulsion community for civil supersonic transport applications have been identified as high propulsion system efficiency at both supersonic and subsonic cruise conditions, low-cost fuel with adequate thermal stability at high temperatures, low noise cycles and exhaust systems, low emission combustion systems, and low drag installations. There are also several challenging environmental issues. While the sonic boom problem is essentially airframe driven, the excessive airport noise levels are due to the very high takeoff exhaust velocities associated with supersonic engines. Engine exhaust emissions is another environmental concern requiring research.

Prior progress has been made in reducing supersonic transport engine thrust specific fuel consumption (TSFC). An afterburning turbojet was developed in the early 1970's for one of the 
first proposed U.S. supersonic transports. This engine performed relatively well at supersonic cruise conditions, but its subsonic efficiency was very inferior to comparable high bypass ratio subsonic engines. Consequently the United States embarked on a 10-year NASA sponsored variable cycle engine (VCE) research program that achieved considerable progress during the 1970 's and early 1980's. Compared to the afterburning turbojet, the hypothetical VCE engines defined in 1981 (which assumed technology levels beyond 1981) consumed 10 percent less fuel at supersonic and transonic conditions, and 25 percent less at subsonic speeds--reflecting the cycle changing feature of the VCE's. A simultaneous 25 percent reduction in engine weight occurred mainly as a result of improved materials. Even though this was a drastic improvement, the subsonic efficiency of the 1981 VCE's is still only about one-half of today's high bypass ratio turbofans. Today, several alternative engine cycle concepts are under study, including more advanced VCE's and turbine bypass engines.

As far as the fuel issue is concerned, conventional low-cost Jet A fuel cannot withstand the high temperatures associated with flight speeds much above Mach 2. If subjected to temperatures above approximately 250 degrees Celsius, they thermally decompose and form coke deposits that clog fuel supply components and fuel injectors. Consequently, there is a challenge to extend the thermal stability of conventional jet fuel to higher temperatures without incurring a significant fuel price increase. Engine developers are facing the typical dilemma associated with engine design: performance driven designs will increase $\mathrm{NO}_{\mathrm{x}}$ emissions while emissions driven designs will reduce performance.

\subsubsection{Aerodynamics}

The cruise aerodynamic efficiency will have a significant effect on the economic viability of the High Speed Civil Transport. A one percent reduction in cruise drag will save approximately 4,900 pounds of fuel and reduce the mission sized takeoff weight by some 7,700 pounds[4]. The wing planform configurations used for the baseline HSCT are designed to achieve attached flow over the wing at cruise conditions. This slender, thin wing tends to develop leading edge vortices at subsonic off design conditions. These vortices have to be controlled to improve the low speed performance which dictates a high lift to drag ratio at takeoff and landing. High L/D at low speed would lower community noise levels by making a steeper climbout after takeoff possible.

From several industry analyses, the lift to drag ratio of the baseline aircraft at altitude has been shown to be between 8.0 and 11.0. With Hybrid Laminar Flow Control (HLFC) technology being developed by NASA, it is reasonable to assume that approximately 90 percent of the wing could be laminarized. This could result in an approximate drag reduction of 11 percent[1]. This drag reduction would significantly impact the range characteristics of the aircraft. 


\subsection{Results}

As indicated in Section 6.0, two teams performed sensitivity analyses with respect to the Productivity Index in our three critical design areas: structures, propulsion, and aerodynamics. Both teams made recommendations for all three sections. At the end of the quarter, it was mutually agreed upon by the two teams to model the changes with respect to structures and propulsion in FLOPS, and to model the recommendations made with respect to aerodynamics in ACSYNT.

\subsubsection{Structures and Propulsion Changes in FLOPS}

Three parameters in FLOPS were changed in our initial baseline configuration based on our new sensitivity analysis with respect to the Productivity Index. An aggressive use of composites [mainly] in the wing, an increase in the engine overall pressure ratio, and a decrease in engine turbine inlet temperature all increased the Productivity Index.

The variable FCOMP was used to model the use of composites in the wing. After changes, $22,564 \mathrm{lbs}$ of composites were used in the revised baseline (20,637 lbs in the wing) as compared to none in the initial baseline. The percentage of the composites used can be broken down as follows: $(91.4 \%)$ wing, $(7.1 \%)$ landing gear, $(1.1 \%)$ controls, $(0.2 \%)$ horizontal tail, and the remaining $(0.2 \%)$ in the vertical tail.

This addition of more than 22,500 lbs of composites, coupled with an increase in engine overall pressure ratio (from an initial value of 18 to a final value of 22) and a decrease in turbine inlet temperature (from 3360 degrees Rankine to 3200 degrees Rankine) resulted in 21,629 lbs less fuel required to meet the $5000 \mathrm{nmi}$ range requirement.

These changes increased the baseline P.I. from $119.1 \mathrm{kts}$ to $127.5 \mathrm{kts}$.

\subsubsection{Aerodynamics Changes in ACSYNT}

\section{Methodology of Parametric Variations}

To determine the effect of HLFC technology on the productivity index of the baseline aircraft, the ACSYNT laminar to turbulent factor SFWF was used. This factor enables the tailoring of the aerodynamic performance of major aircraft components. In essence, an 11 percent reduction in the SFWF factor resulted in a corresponding reduction in turbulent drag. Based on NASA studies, it was determined that this 11 percent reduction would require full wing HLFC. If only leading edge HLFC was employed, this would result in a reduction of approximately 6 percent. In addition to determining the effect of HLFC on the Productivity Index, the wing area was varied to observe its effect as well. The baseline area of 7700 square feet was varied between 
6800 and $8500 \mathrm{ft}^{2}$, while keeping the aspect ratio and wing sweep constant. The lower limit of $6800 \mathrm{ft}^{2}$ was set because the ACSYNT sizing program was unable to reliably perform a mission for a configuration below this limit.

\section{Results}

For this particular study, the range and Mach number of the baseline was held constant. Based on the area and HLFC changes, it was found that the maximum P.I. occured when the wing area was 7700 square feet, and full wing HLFC was employed. The Productivity Index increase was from 117.4 knots to approximately 121.8 knots. Having determined the maximum P.I. based on these changes, the "revised" baseline was analysed to verify that it met the necessary constraints. The FAR 25 landing constraint for this vehicle is 11,000 feet. It was determined that all HLFC configurations with wing areas in excess of $7600 \mathrm{ft}^{2}$ conformed to this rule.

Additionally, the sensitivity of the P.I. to changes in wing area was determined by performing a curve fit to the data points and taking the first derivative of the function. These sensitivities are shown below.

\begin{tabular}{|l|l|l|l|}
\hline AREA (sq. feet) & No HLFC & Leading Edge HLFC & Full Wing HLFC \\
\hline 6800 & 0.03 & -0.0024 & -0.0022 \\
7700 & 0.000129 & -0.00506 & -0.00025 \\
8500 & -1.593 & -0.00725 & -0.0017 \\
\hline
\end{tabular}

Table 6.5 Productivity Index Sensitivity.

\begin{tabular}{|l|l|l|l|}
\hline AlRCRAFT & $\begin{array}{l}\text { Concorde (acsynt) } \\
(3424 \text { nmi misson) }\end{array}$ & $\begin{array}{l}\text { Boeing 747-200 } \\
\text { (5000 nmi mission) }\end{array}$ & $\begin{array}{l}\text { HSCT base (acsynt) } \\
\text { (5000 nmi mission) }\end{array}$ \\
\hline Gross Weight (lbs) & 399,051 & 773,800 & 727,291 \\
Block Speed (knots) & 1124.46 & 463.86 & 1169.43 \\
Payload (lbs) & 25,000 & 90,710 & 61,735 \\
Empty Weight (lbs) & 169,060 & 365,800 & 294,524 \\
Block Fuel (lbs) & 167,258 & 269,600 & 320,638 \\
PRODUCTIVITY & $\mathbf{8 3 . 5 8}$ & $\mathbf{6 6 . 2 2}$ & $\mathbf{1 1 7 . 3 5}$ \\
INDEX (Knots) & & & \\
\hline
\end{tabular}

Table 6.6 Comparison of Aircraft Productivity Index

\subsection{Conclusions}

From the disciplinary sensitivity analyses conducted in AE6351, it was determined that improvements could be obtained in the baseline HSCT configuration using the Productivity Index 
(P.I.) as the Criterion Function (Figure 6.6.1). However, these improvements can not be achieved if the resulting manufacturing considerations are not taken into account, Therefore, a major focus for AE6352 would be to address integrated design and manufacturing issues at the wing level to close the loop in Figure 2.5.

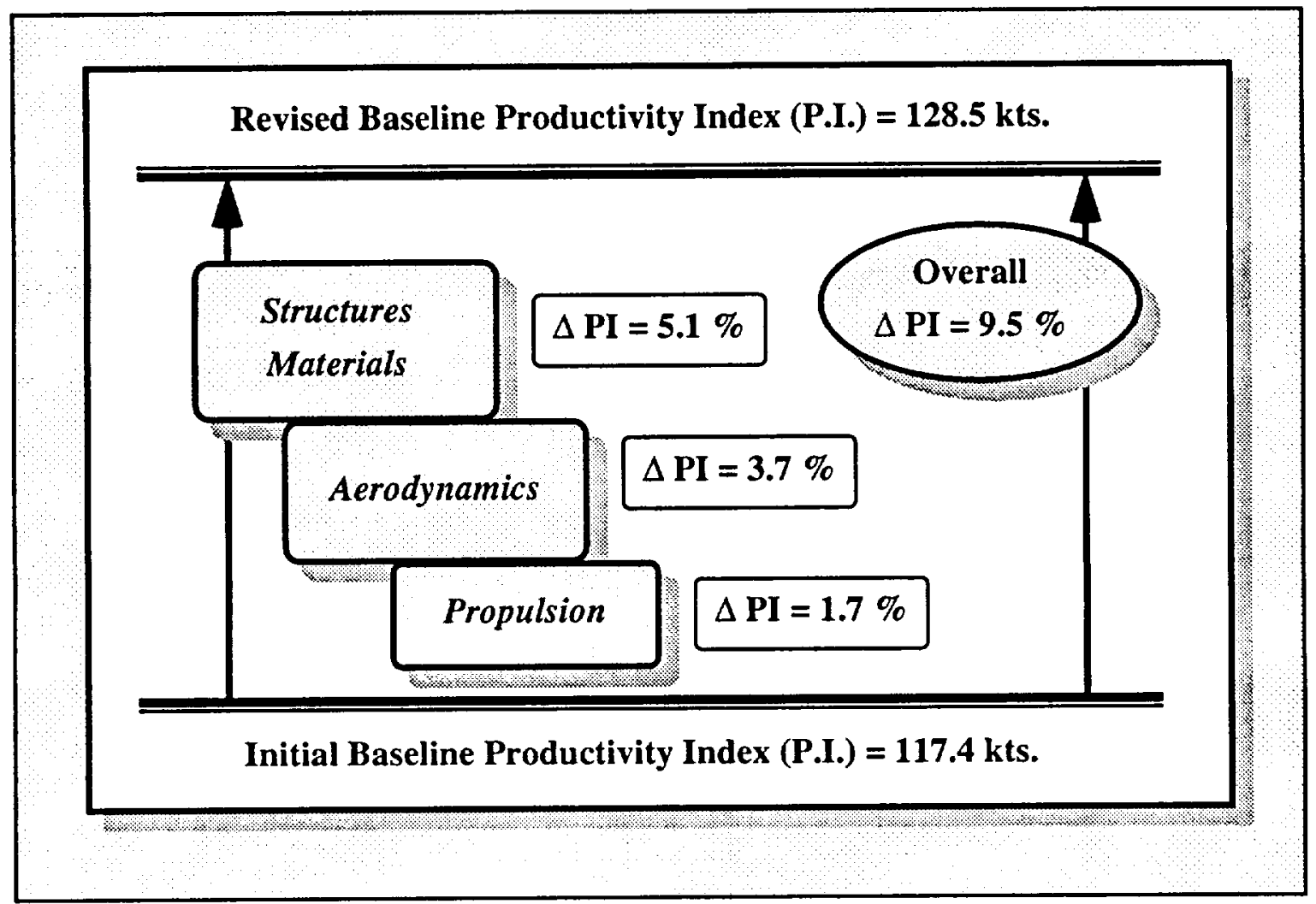

Figure 6.6.1 Overall Productivity Index Increase 


\subsection{Aerospace Systems Design II}

\subsection{Methodology}

\subsubsection{Concurrent Engineering Implementation}

The methodology used for the final quarter's work builds heavily upon what was learned the previous quarters. At the beginning of the quarter, some of the Seven Management and Planning Tools learned in Introduction to Concurrent Engineering were used to enable the team members to understand the design processes related to wing concept selection before analyses were attempted.

Tree Diagrams, Affinity Diagrams, Interrelationship Diagraphs, and a QFD Matrix were generated at the beginning of the quarter. As an example, Figure 7.1.1 shows the Interrelationship Diagraph with this quarter's nine areas of interest. The arrows indicate which disciplines interact and/or exchange information with the others.

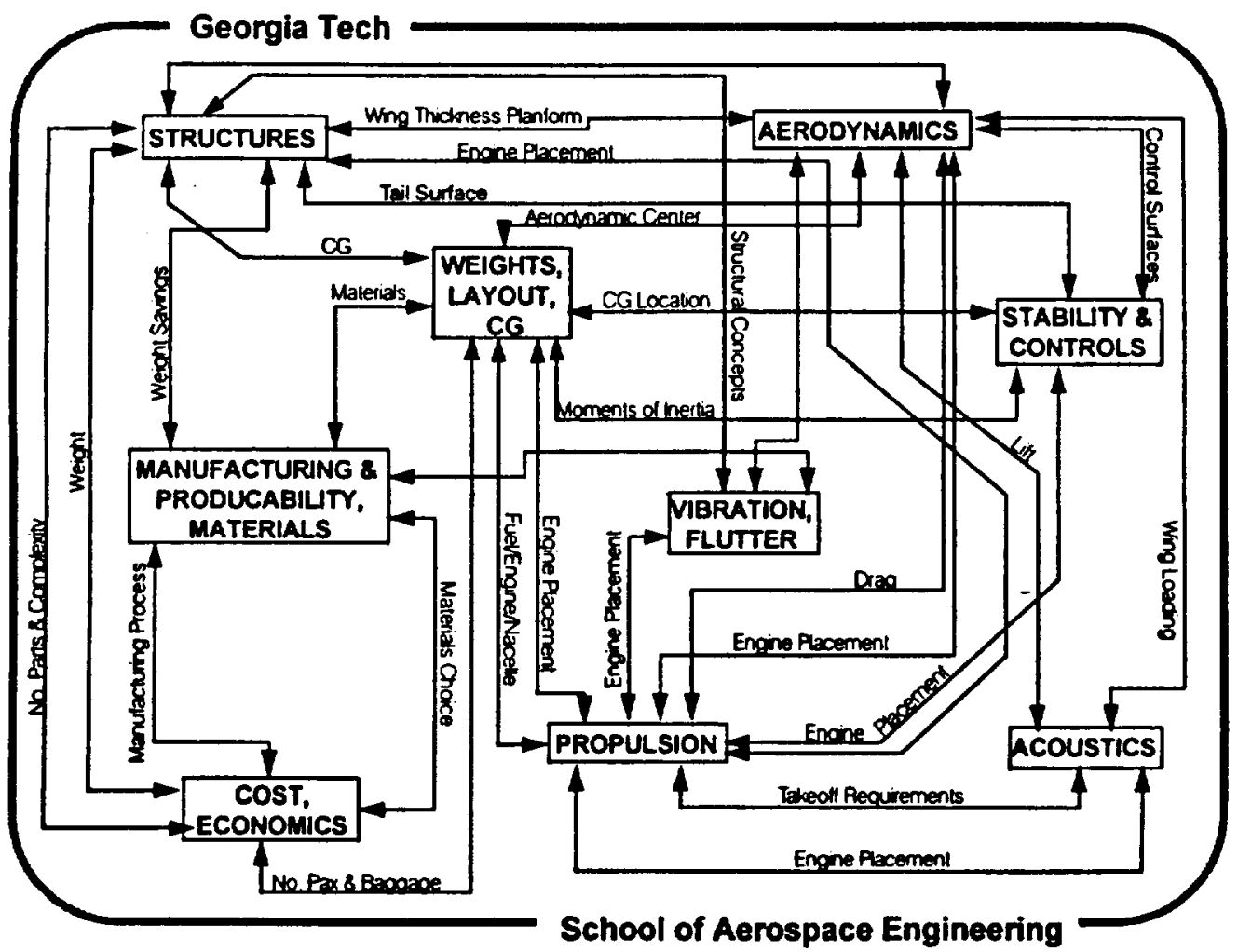

Figure 7.1.1 Interrelationship Diagraph

The above mentioned Concurrent Engineering Tools were used to determine the relationships between several key design areas and the cost analysis parameters used to make a wing concept selection. 


\subsubsection{Wing Concept Selection Methodology}

Figure 7.1.3 shows the relationships between last quarter's baseline (Figure 7.1.2) modified for maximization of the Productivity Index and the research and analysis of wing concepts for this quarter.
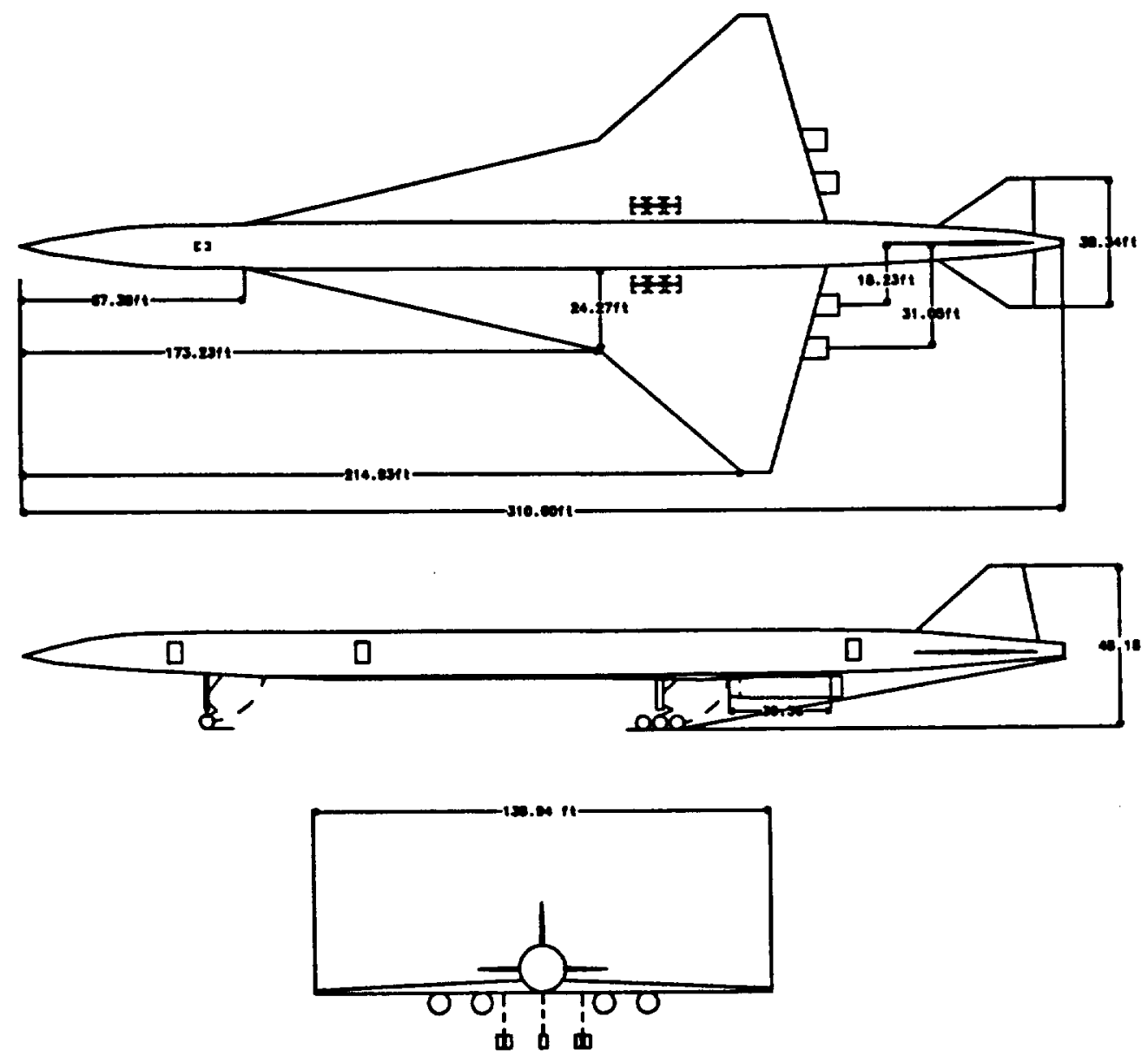

Figure 7.1.2 Revised Baseline Configuration 


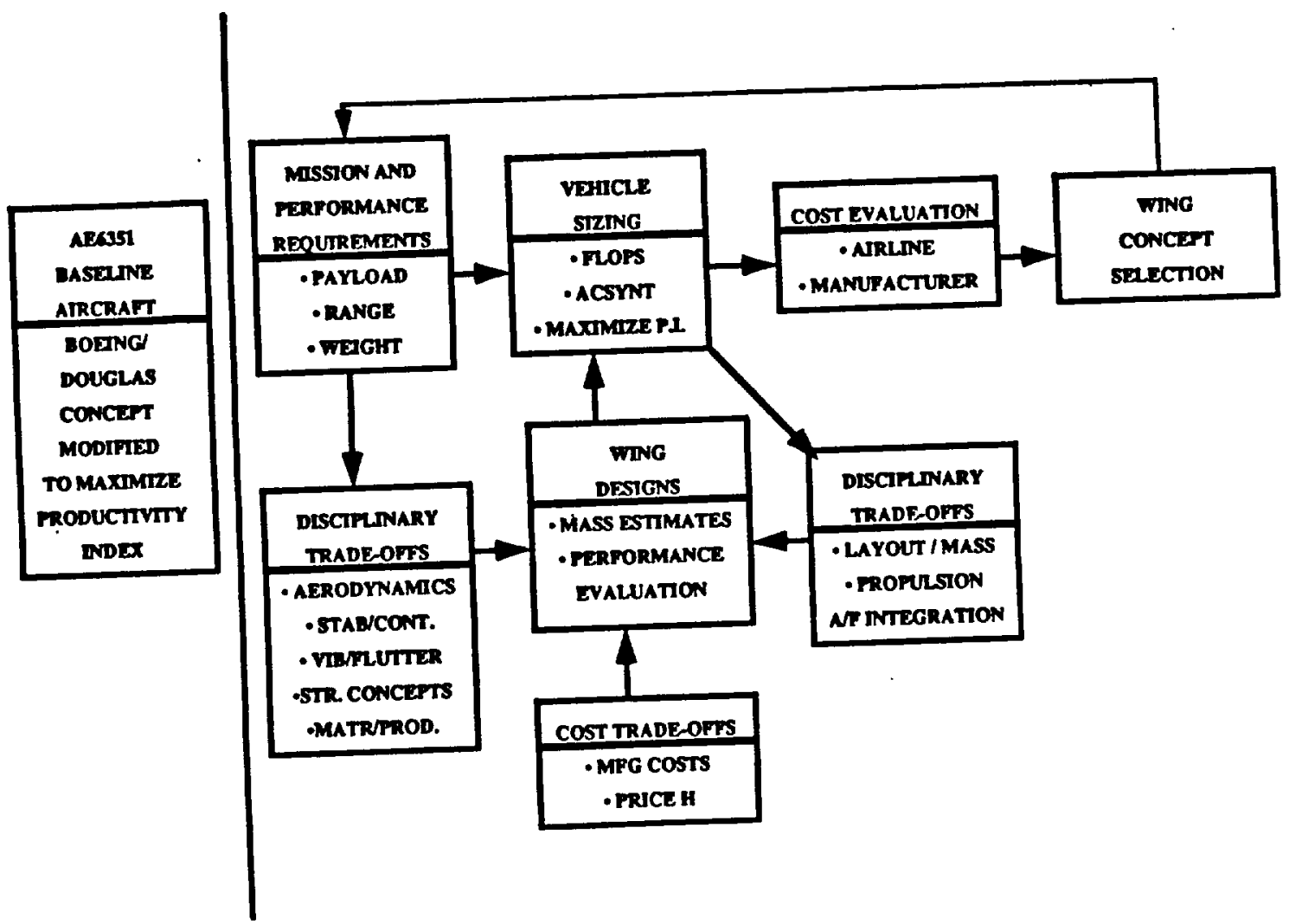

Eigure 7.1.3 Wing Concept Selection

The mission and performance requirements influence the system at two levels. First the mission and performance requirements are used by the synthesis codes FLOPS and ACSYNT for vehicle sizing. Second, some of these same mission performance requirements, in addition to others particular to certain disciplines, are used in the disciplinary trade-offs conducted at the wing level. Other disciplines, such as Layout / Mass Analysis and Airframe / Propulsion Integration, may only begin after some of the initial vehicle sizing has begun.

A designer's production cost trade-off tool (see Section 7.8) was used at the wing level to determine relative manufacturing costs associated with different wing concepts generated by the multidisciplinary trade-off studies. Once the parameters describing a new wing concept are determined, they can be inserted back into FLOPS and ACSYNT for overall vehicle performance estimation as well as airline and manufacturer cost estimation. Finally, the wing concept selection can be made based upon recommendation by the disciplines at the wing level and based upon vehicle performance and cost at the system level. 


\subsection{Aerodynamics}

\subsubsection{Introduction and Problem}

The preliminary design of the High Speed Civil Transport wing represents a challenge from the aerodynamic point of view. As part of a multi-disciplinary team, design trade-offs have to be made in an iterative manner, in conjunction with other design groups. Emphasis has to be placed on the interrelationships which occur between these groups. The aerodynamic design of the HSCT wing has to address several key issues. The aerodynamic results must:

1) Provide the necessary structural volume.

2) Ensure ease of fabrication.

3) Meet the necessary performance requirements.

As a baseline case study, the Lockheed Arrow wing supersonic concept was used[7]. Although this concept was formulated in the 1970s, it provides an excellent framework for the multi-displinary design analyses. The primary sources for aerodynamic data for this Lockheed study were wind tunnel tests. This wind tunnel data was corrected to account for wind tunnel wall effects and scaling effects, and was subsequently used to determine numerous performance characteristics of the full sized aircraft. For the aerodynamic studies conducted in this report, data was obtained primarily through the use of Computational Fluid Dynamics (CFD). Over the past 15 years, improvements in numerical algorithms and computer hardware have made it possible to expand the applications of CFD in the design environment by providing a technique for doing parametric variations in trade studies. Selected wind tunnel tests should be conducted however to validate critical design conditions.

\subsubsection{Design Methodology}

\section{Initial Trade Studies}

Two simplified trade studies were conducted early in the wing development study. These trade studies focused on:

\footnotetext{
- Wing Area Variation

- Wing Thickness Variation
} 
The wing thickness to chord ratio $(t / c)$ was varied to determine the minimum thickness distribution that would satisfy the structural depth criteria. This $t / c$ ratio has a tremendous impact on the profile drag of the entire configuration, thus the thickness distribution had to meet this stringent aerodynamic and performance criteria as well. The wing area study was conducted with lift to drag ratio being the primary criteria. From the Brueget Range equation, the $L D$ ratio is extremely important.

$$
\text { Range }=\frac{\mathrm{a}_{0} \sqrt{\theta_{\text {mo }}}}{\mathrm{TSFC}}\left(M \frac{\mathrm{L}}{\mathrm{D}}\right) \ln \frac{\mathrm{W}_{1}}{\mathrm{~W}_{2}}
$$

As shown in equation 7.2.1, the range is directly influenced by the L/D ratio, which from aerodynamic analysis, can be readily manipulated. The L/D during the cruise regime of flight is therefore of great importance. Thus, for a given cruise Mach number, the wing area was varied and the configuration that produced the highest lift to drag ratio was selected.

The wing planform was not changed from the Boeing baseline case. This planform was derived from compromises for high and low speed performance, landing gear depth requirements, and other issues. The subsonic leading edge was maintained to approximately $55 \%$ semi-span. This yielded improved subsonic L/Ds due to leading edge suction and permitted the larger side of body chord lengths that were needed to keep the $t / c$ low in the vicinity of the landing gear[1]. This high inboard sweep, however, results in high structural aspect ratio and low wing span. To improve the $L / D$ even further, the outboard wing was unswept to a supersonic leading edge sweep angle of approximately 47 degrees. By unsweeping the outboard stations, more wing span was achieved for a much less change in structural aspect ratio. Thus there was an improvement in the L/Ds because of the greater wing span, without accruing the weight penalties associated with higher structural aspect ratios[1]. The existing planform was also relatively simple from a manufacturing point of view.

\section{Additional Considerations}

In addition to determining the maximum L/D ratios for cruise conditions, analysis was conducted to determine the maximum lift coefficient that could be obtained for low speeds at legitimate angles of attack. The high lift system of the aircraft has to be designed to increase wing lift for takeoff and landing. This increased lift reduces the runway length required for takeoff. These high lift devices must also be designed to minimize drag during the climbout and approach phases to reduce the airport sideline and approach noise levels. This is a challenging task, since traditionally, high drag was considered helpful for deceleration purposes at landing conditions. 


\subsubsection{Design Procedure}

Several design tools were used to conduct this preliminary aerodynamic design and assessment. These CFD design and analysis codes were used at different stages to complement each other. Four primary codes were used. These were:

1) WINGDES

2) VORLAX

3) AERO2S

4) ACSYNT aerodynamics module.

\section{High Speed Analysis}

WINGDES ${ }^{\circledR}$ is a NASA Langley wing design code that can be used for supersonic speeds. It was the only code available for the supersonic analysis of the wing without the fuselage. The numerical method is based on linearized theory potential flow solutions for a zero thickness lifting surface represented by an array of horseshoe vortices[2]. WINGDES evaluates the drag on the wing by an integration of pressures acting on the lifting surface. Figure 7.2.1 depicts a typical supersonic lift - drag polar curve and shows the main contributions to the drag[2].

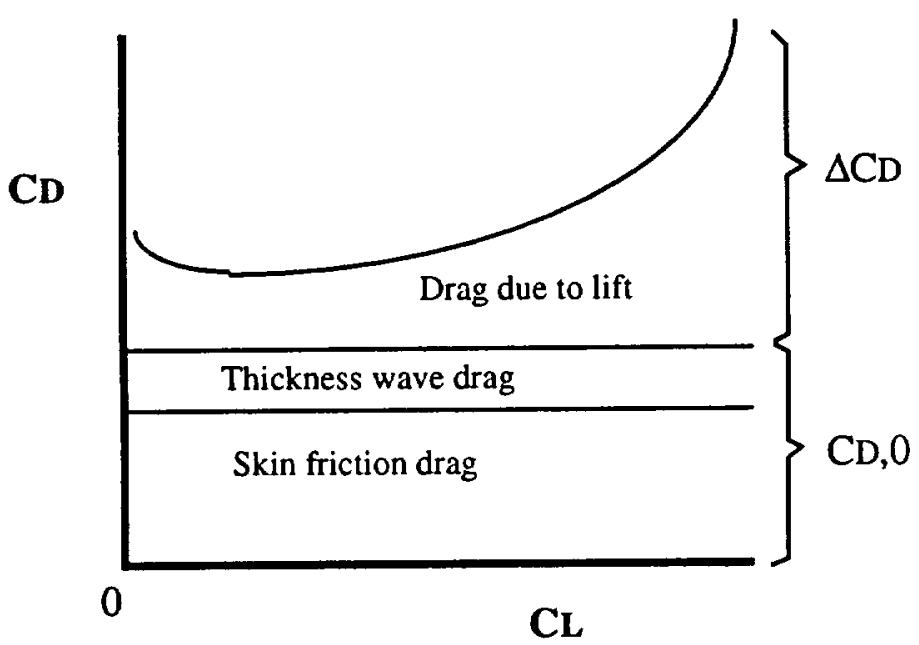

Figure 7.2.1 Drag Breakdown

As shown, the drag due to lift is about half the total. WINGDES allows for the separation of the drag due to lift into two fundamental components[2]:

1) Vortex drag associated with the spanwise distribution of the lifting force 
2) Wave drag due to lift, associated with the longitudinal distribution of lift and the resultant disturbance waves(supersonic flight only)

WINGDES is unable to account for the thickness wave drag and the skin friction drag. Consequently, this code was only used to conduct initial trade off studies.

For the wing area variation, WINGDES was run at three different wing surface areas. These were 7200, 7700 and 8200 square feet respectively. The results were interesting. Considering the drag limitations of the program, it would be assumed that the wing with the largest area would have the highest lift to drag ratio.

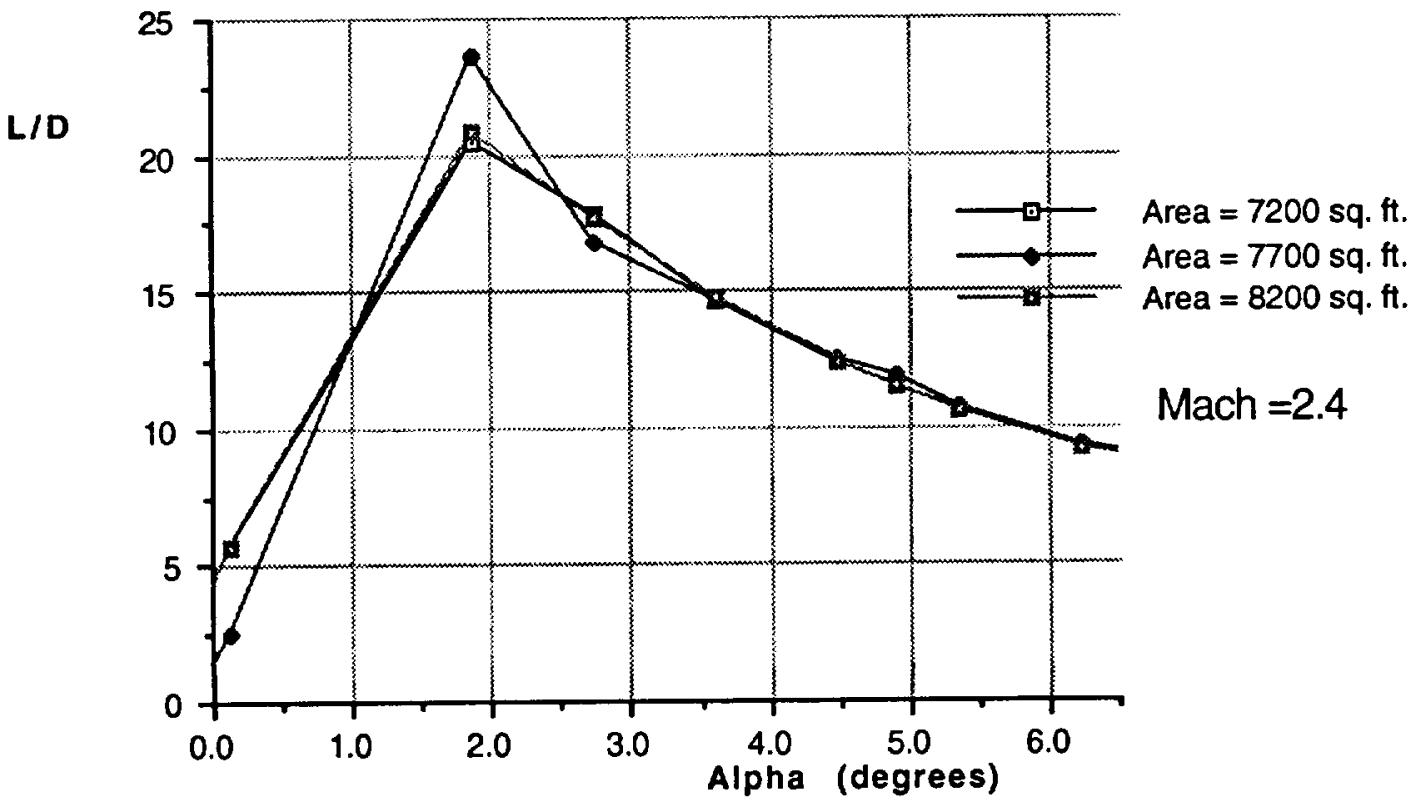

Figure 7.2.2 L/D vs Alpha for three wing areas

However, as shown in figure 7.2.2, it was determined that the baseline wing area of 7700 square feet provided the maximum lift to drag ratio at the angles of attack associated with high speed cruise. These angles of attack were between 1 and 3 degrees. Note that these L/D ratios are high, since they do not account for profile drag contributions. Figure 7.2.3 shows L/D as a function of Mach numbers. This shows that $L / D$ decreases as the Mach number is increased.

Having determined the optimum wing area using a stand alone wing program, the remainder of the high speed analysis was conducted using the entire configuration. 


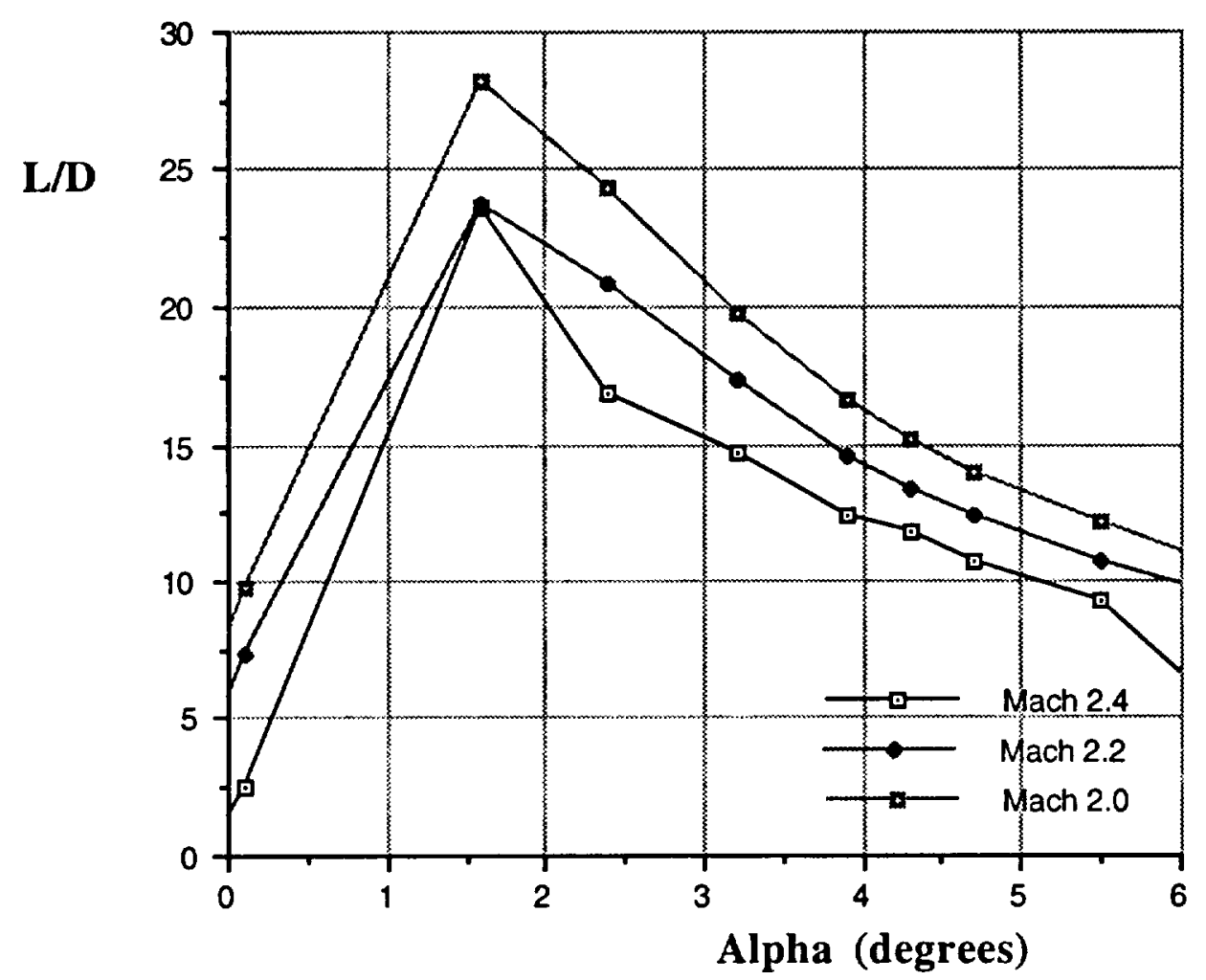

Figure 7.2.3 L/D vs Mach number (WINGDES)

The effects of this wing area on the overall configuration was investigated using VORLAX ${ }^{\circledR}$. VORLAX is computer program written by the Lockheed California Company which uses a vortex lattice method to calculate the aerodynamic load distributions at subsonic and supersonic Mach numbers for arbitrary nonplanar configurations[3].

VORLAX inputs include:

1) wing surface area

2) Mach number

3) Wing Aspect ratio

As mentioned earlier, the planform and aspect ratio was not changed from the baseline. Additionally, the wing area result from WINGDES was used to continue the analysis. 
Correlation with experimental data and with results from other theories show good agreement with overall force and moments due to lift. It also provides good results in the distribution of the load coefficients. Like WINGDES, VORLAX does not account for the effects of skin friction drag. The results from VORLAX however were very useful in determining the pressure distributions at arbitrary locations on the wing and body. These pressure distributions were used in the structural analysis of the wing, since loading distributions were obtained at spanwise and chordwise locations. The moment results were also used for the stability and control analyses.

The VORLAX analysis was conducted primarily at the high speed conditions. It was used to determine the angles of attack at which the maximum lift to drag ratio was developed for a series of cruise Mach numbers. These Mach numbers were:

$$
\begin{array}{ll}
- & \text { Mach } 1.6 \\
- & \text { Mach } 2.0 \\
- & \text { Mach } 2.2 \\
- & \text { Mach } 2.4 \\
- & \text { Mach } 2.5
\end{array}
$$

Since the angles of attack for this analysis were for the overall configuration, the issue of cabin floor angles became important. High floor angles at cruise would present a problem relating to airline and public acceptance of the vehicle[4]. These angles would add substantial difficulty and inconvenience to cabin operations. Low cabin floor angles can be achieved by reducing the fuselage floor incidence angle relative to the wing reference plane. For this configuration study, the wing reference plane and the fuselage were made to coincide. Although this is not widely done in practice, it provided a starting point for the analysis. 


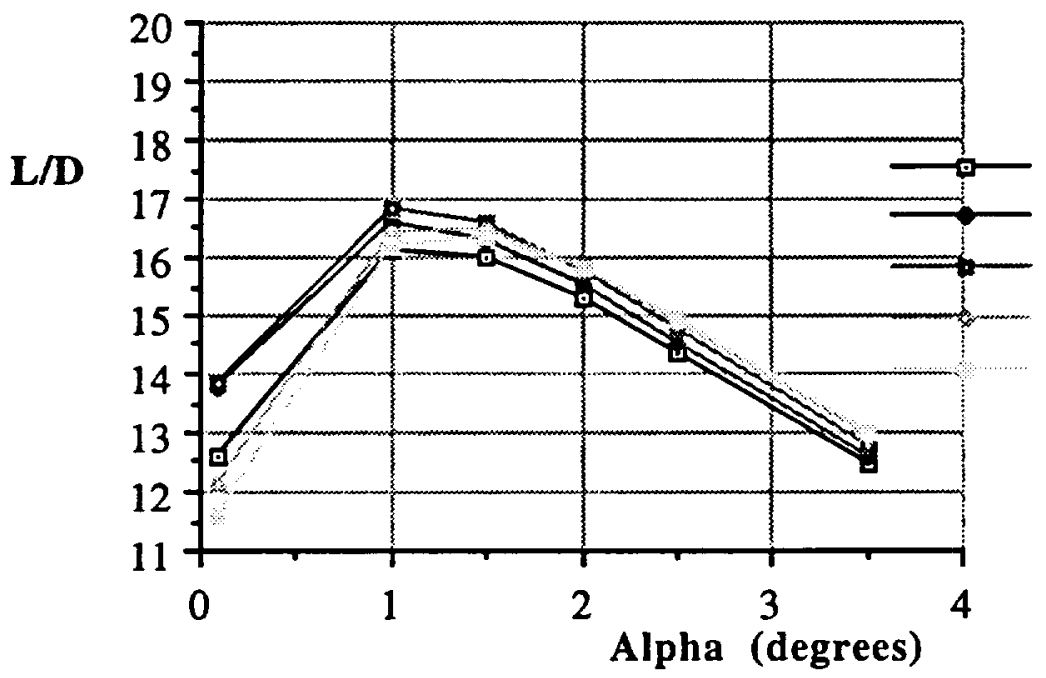

Mach 1.6 cruise

Mach 2.0 cruise

Mach 2.2 cruise

Mach 2.4 cruise

Mach 2.5 cruise

Figure 7.2.4 L/D vs Alpha (VORLAX)

As shown in figure 7.2.4, the maximum trimmed $L / D$ occurs at angles of attack between 1 and 2 degrees. These angles are acceptable from the cabin attitude standpoint. Once again, these L/D values do not account for the effects of profile drag. This analysis however has provided the pressure distributions associated with the above cruise conditions. Figure 7.2.5 shows the pressure coefficient at the Mach 2.4, alpha 2.0 condition.

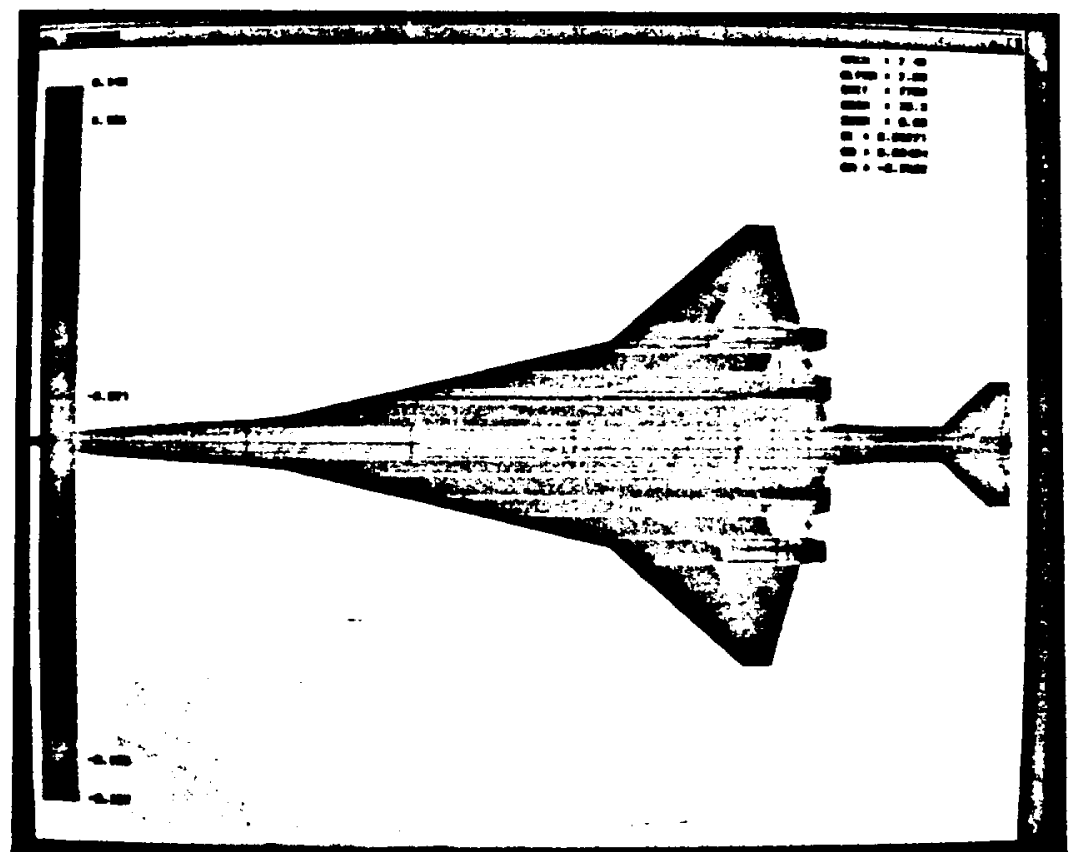

Eigure $7.2 .5 \mathrm{Cp}$ distribution at cruise. 
Figure 7.2.6 shows the cruise drag polar at a 2 degree angle of attack.

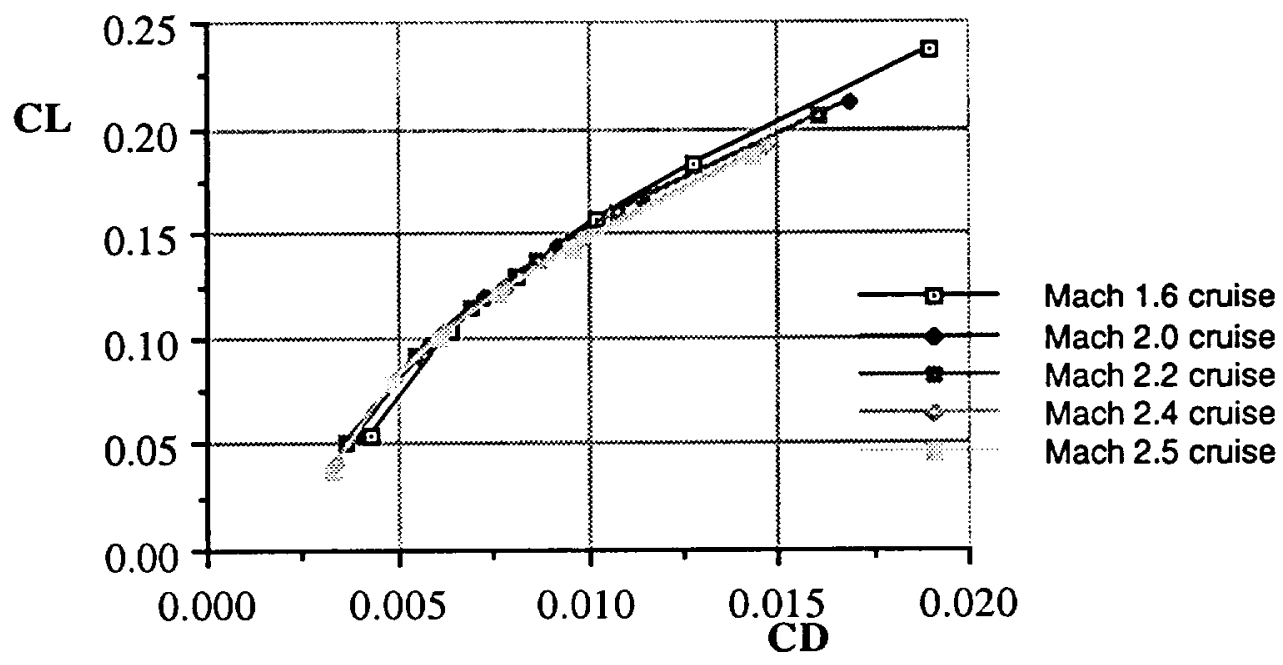

Figure 7.2.6 Cruise Drag Polar (VORLAX)

The analyses conducted so far have neglected skin friction. As shown in figure 7.2.1, this drag contribution is quite pronounced. For a wing operating at high speed, the profile drag is very dependent on the wing wetted area and thickness. To account for this drag contribution, the ACSYNT aerodynamics module was used. ACSYNT ${ }^{\circledR}$ was developed by the NASA Ames Research Center over a twenty year period for conceptual design studies of advanced aircraft. The aerodynamics module of ACSYNT uses empirically and theoretically derived methods to calculate the aerodynamic coefficients of the configuration. ACSYNT incorporates VORLAX to find the pressure distribution on the aircraft. The zero lift drag is estimated from parametric prediction equations[5].

ACSYNT computes the total zero-lift drag as:

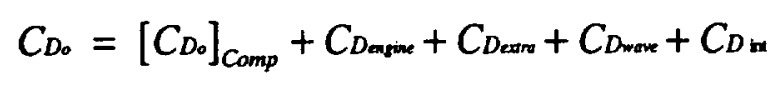

where

$\left[C_{D_{0}}\right]_{\text {Comp }}=$ Sum of skin-friction and pressure drag components

$C_{D_{\text {aggen }}}=$ External cowling and boattail drag

$C_{\text {Daro }}=$ External Stores drag

$C_{\text {Dowe }}=$ Wave drag 


$$
C_{D \text { ix }}=\text { Interference drag. }
$$

The parasite drag of the configuration is computed in the following way:

$$
\left[C_{D o}\right]_{n}=F F_{n} C f_{n} \frac{S_{\text {weln }}}{S_{\text {ref }}}
$$

where

$C_{D_{0}} \quad=$ Zero-lift drag of the nth component

$F F_{n}=$ Form factor to account for viscous separation

$C f_{n}=$ Compressible skin-friction coefficient of the nth component

$S_{\text {wen }}=$ Wetted area of the $n$th component, $\mathrm{ft}^{2}$

$\mathrm{S}_{\mathrm{ref}} \quad=$ Reference area ( wing planform area $), \mathrm{ft}^{2}$

The skin-friction coefficient in equation 7.2.3 for each component is dependent on the Reynolds number. The skin friction coefficent is computed by methods described by Bertram in reference[5]. ACSYNT also calculates the form factors to be applied to each component to account for the pressure drag due to viscous separation. A factor which accounts for wing sweep and Mach number is calculated from equation 7.2 .4

$$
\text { FSM }=\frac{1.75 \cos \Lambda_{\%}}{\sqrt{1.75 \cos ^{2} \Lambda_{\% /}}}
$$

For the wing, the form factor $\mathrm{FF}_{\mathfrak{n}}$ used by ACSYNT in the profile drag calculation is:

$$
1+K_{v} F_{S M}\left[\frac{1}{c}\right]_{a v e}+60\left[\frac{1}{c}\right]_{a v e}^{4}
$$

where

$$
\begin{aligned}
& {\left[\frac{t}{c}\right]_{a v e}=\text { Average thickness ratio }} \\
& K_{v}=0.6, \text { if a } 6 \text { series airfoil is used, } 1 \text { otherwise. }
\end{aligned}
$$

After numerous iterations on the profile drag characteristics of the wing, the $t / c$ was set at 0.032 at the root and 0.024 at the wing tip. This thickness ratio provided the necessary structural depth needed for the primary structure of the wing. This requirement was specified by the 
structural and flutter analysis. This distribution also provided the volume required to stow the landing gear.

As shown in figure 7.2.7, the maximum L/D ratio for the configuration has been reduced. These trimmed values, however, are still in the 1 to 3 degree angle of attack range.

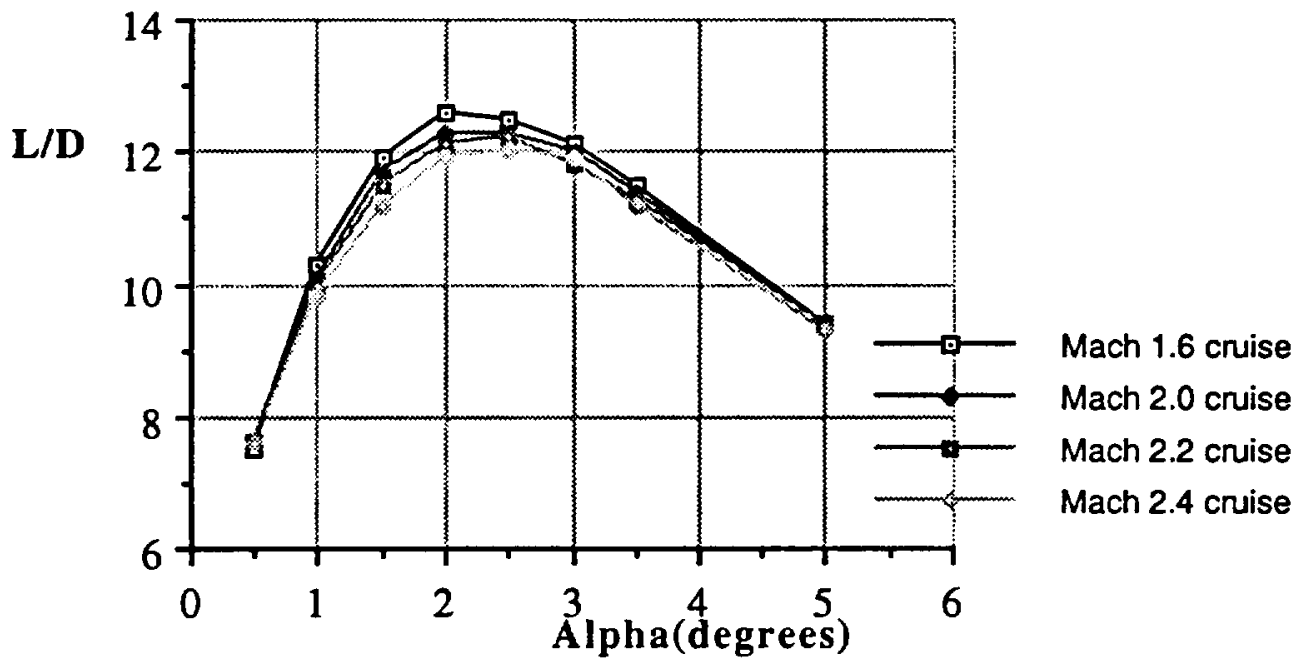

Figure 7.2.7(a) UD vs Alpha (ACSYNT)

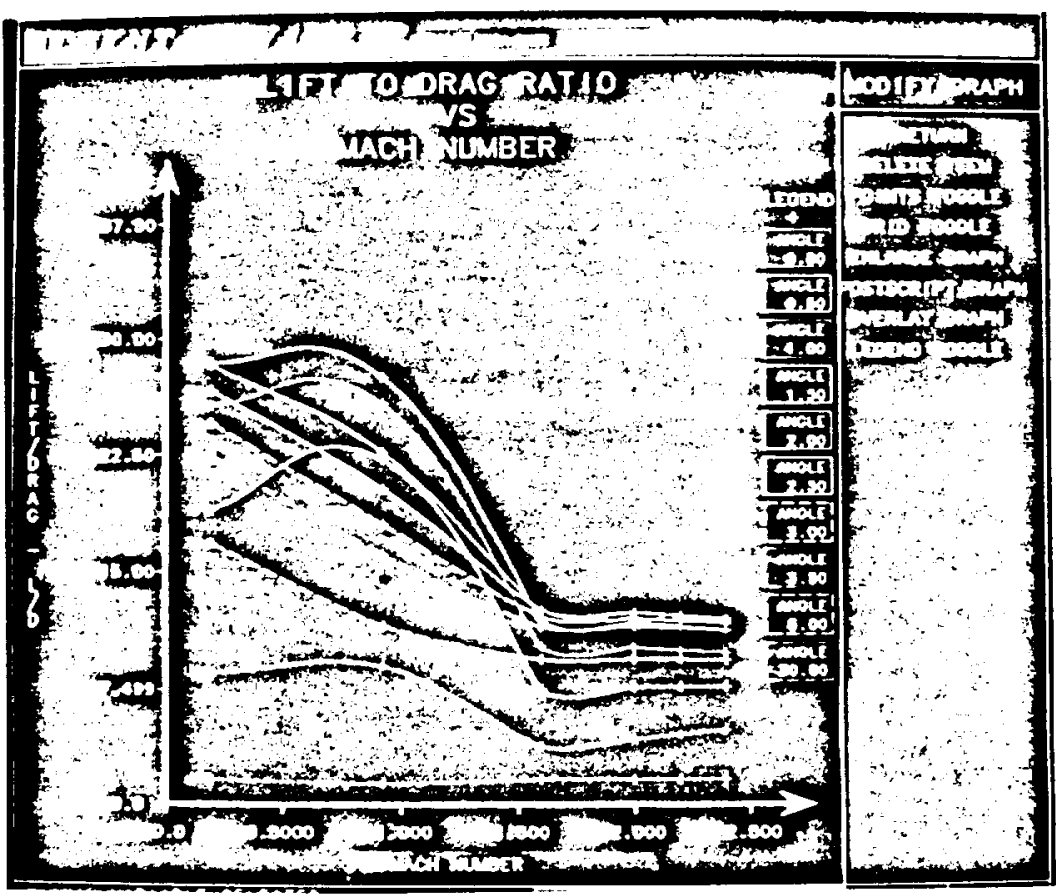

Figure 7.2.7(b) L/D vs Mach(ACSYNT) 
As seen in figure 7.2.7(a), the lift to drag ratio decreases as Mach number is increased. The maximum L/D occurs at a cruise Mach number of 1.6 and angle of attack of 2 degrees. This $L D$ is approximately 12.5 . Looking at the ratios at higher cruise Mach numbers we can see that there is not a significant difference as the cruise speed is increased from Mach 1.6 to 2.4. For Mach 2.4 cruise, the L/D is approximately 12 . This occurs at an angle of 2.5 degrees. Since this decrease in lift to drag ratio is only on the order of 4 percent, the increased block time and productivity associated with a higher cruise Mach number outweighs the minor range/weight penalty associated with this L/D ratio decrease. Figure 7.2.7(b) shows the polar generated by ACSYNT's graphical interface. Figure 7.2.8 compares the ACSYNT results with VORLAX.

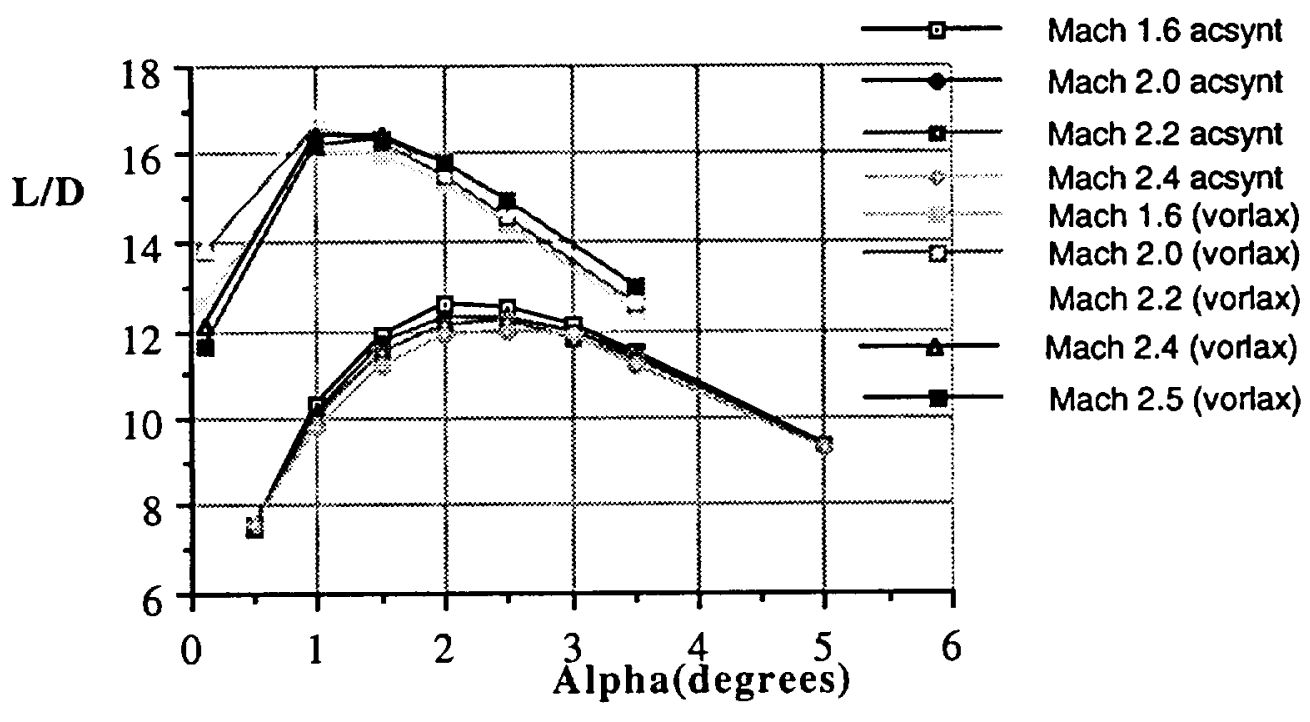

Figure 7.2.8L/D vs Alpha (ACSYNT and VORLAX)

\section{Low Speed Analysis}

Additional analysis of the low speed characteristics of the wing was conducted using the AERO2S analysis code. AERO2S is a NASA program which can be used for the subsonic aerodynamic analysis of wings with leading and trailing edge flaps. This code uses a linearizedtheory, attached flow method for the estimation of the longitudinal aerodynamic performance of wing-horizontal tail configurations that employ simple flap systems[6]. These calculations provides a generally good prediction of the aerodynamic performance provided the speed is below the drag rise Mach number. This code does not take into account the viscous effects in the flow. Instead it uses an attached flow method which is based on the premise that high levels of aerodynamic efficiency require a flow that is as nearly attached as circumstances permit[6]. Thus, under this premise, the analysis was conducted with an angle of attack limit of 17 degrees. This limit was 
placed to account for the wing stall which occurs as viscous separation dominates the flow field at high angles.

AERO2S was run at several combinations of leading and trailing edge flap deflections. As shown in figure 7.2.9, the maximum lift coefficient of 0.7 was achieved with a leading edge deflection of 25 degrees and flap deflection of 40 degrees. The lift to drag ratio at smaller deflections was between 6 and 7. This shows that in addition to achieving the high lift coefficients needed for reduced reduced runway lengths, the wing configuration could still enable the steeper climbouts that are necessary to reduce the noise footprint of the vehicle. Recent journal articles suggest that the maximum lift coefficient can be increased further by larger leading edge deflections.

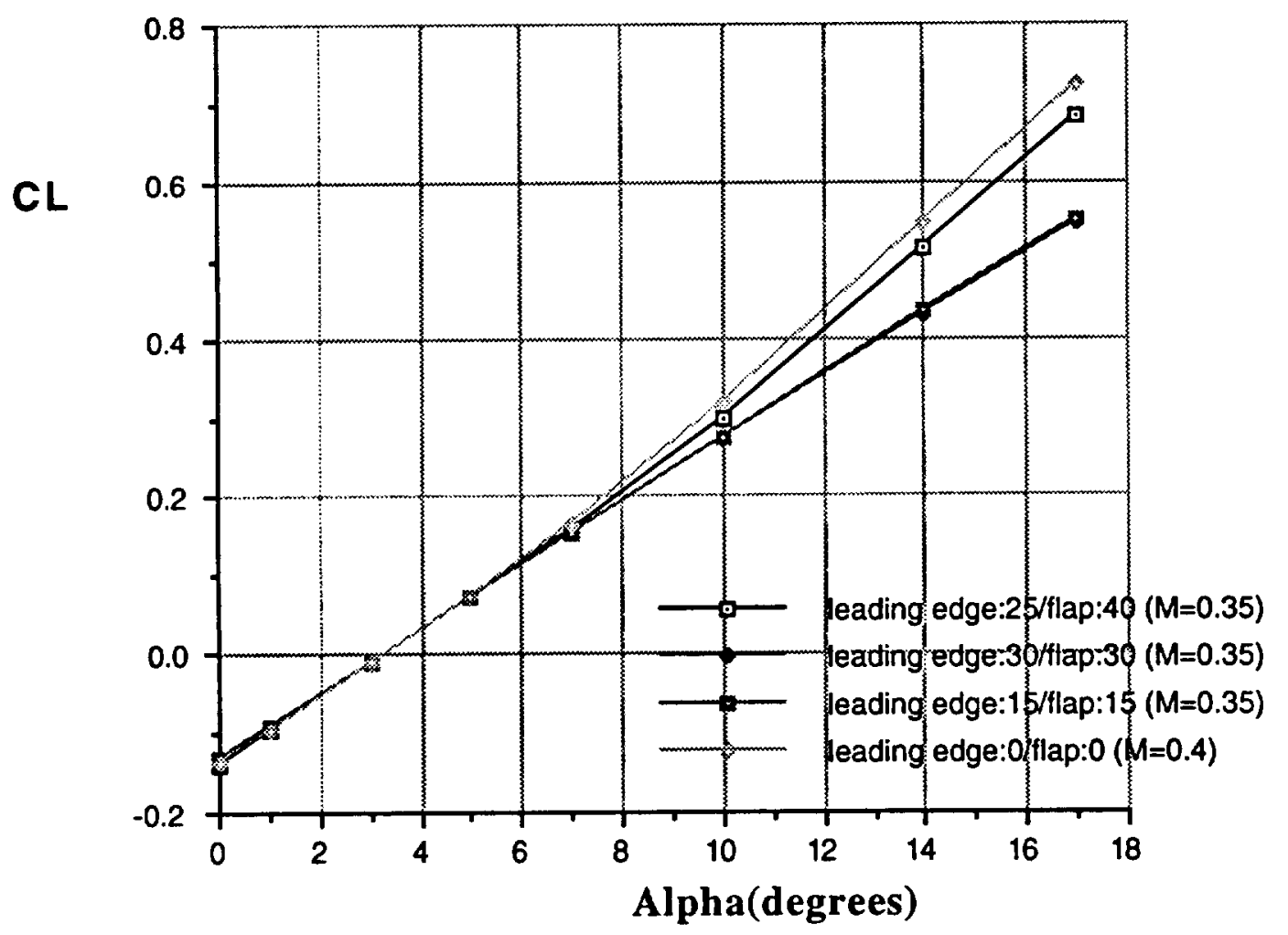

Figure 7.2.9 CL vs Alpha at various flap deflections (AERO2S) 


\subsubsection{Concluding Remarks}

The preliminary design of the HSCT wing requires numerous tradeoffs to be made. The wing has to meet necessary performance requirements, while providing the compromises specified by the other design groups. Several analyses were conducted. Initially, the baseline configuration was studied to determine the optimum area for cruise purposes. The maximum L/D at various cruise conditons were then determined using several design codes. These codes determined the wing pressure loading characteristics and the cabin floor angles. Finally, the low speed characteristics were investigated.

The results from these analyses suggest the following:

1) A wing area of 7700 square feet is optimum for high speed cruise.

2) A t/c ratio of 0.032 (root) and 0.024(tip) provides the necessary structural and volume requirements, while still meeting the aerodynamic performance criteria.

3) The maximum $L / D$ at cruise occurs at acceptable cabin floor angles.

4) The CLmax achieved with leading and trailing edge devices provides the performance needed for landing and takeoff.

\section{References.}

1. High Speed Civil Transport Study, NASA Contractor Report 4233. Prepared for NASA Langley Research Center, Contract NAS1-18377, 1989

2. Carlson, Harry W., Mann. Micheal J., Survey and Analysis of research on supersonic drag-due to lift minimization with recommendations for wing design. NASA Technical Paper 3202 ,September 1992.

3. Miranda, Luis R., et al, A generalized vortex lattice method for subsonic and supersonic flow considerations, NASA Contractor report 2865 Vorlax Report. Contract NAS1-12972, December 1977

4. Radkey, R.L., Welge, H.R., Roensch, RL., Aerodynamic design of a Mach 2.2 supersonic cruise aircraft. AIAA paper 76-955, 1976.

5. Gwartney, J., Hunter, George, Sorenson, John.,Comparison of Design and analysis methods employed by ACSYNT and TASP. Prepared for NASA Ames Research Center. Order No. A08144D(CPC) June 1992

6. Carlson, Harry W, Darden, Christine M, Mann, Micheal J., Validation of a computer code for analysis of subsonic aerodynamic performance of wings with flaps in combination with 
a canard or horizontal tail and an application to optimization. NASA Technical Paper 2961, 1990

7. Messina, A.F., et al., NASA CR-132575: Substantiating Data Report: Arrow Wing Supersonic Cruise Aircraft Structural Design Concepts Evaluation. Vol 1 Section 3, 1977 


\subsection{Stability and Control}

\subsubsection{Introduction}

Stability and control for a transport aircraft is very important. The aircraft must be comfortable for passengers and should be pleasant for the aircrews to operate as well as controllable and safe to fly. Until recently at the conceptual design level usually all that is normally done is a static analysis. With the appearance of better and faster computer tools a more in depth analysis can be preformed earlier in the design process to help insure that ballast is not carried by production aircraft. Stability and control is a discipline which is tightly linked to propulsion, aerodynamics, performance, overall configuration and mass analysis. The placement and specifications of the propulsion system often sizes control surfaces during one engine inoperative. The results of aerodynamic and performance are integral to stability and control. The center of gravity location must be agreed upon between stability \& control, weights and structural design groups. The overall configuration (tailless, conventional, canard, sweep, etc) determines how and what level of automatic control will be applied to the aircraft.

\section{Summary of the Lockheed Report}

Page 3-44 in the Lockheed report[11] states that the baseline aircraft will be equipped with a three axis stability augmentation system(SAS) which is required to function at all times. No responses without SAS were considered.. For the analysis a Continuous Systems Modeling Program interactive computer graphics technique was used.

\subsubsection{Georgia Tech's Methodology}

Once again Georgia Tech sought to combine information from the Lockheed and other studies with information from other disciplines represented in the design team and appropriate computer codes. Initially APAS II was expected to provide most of the stability derivatives necessary for analysis. Unfortunately problems in learning the code and acquiring documentation and suitable models prevented its use during AE6352. For this reason it was required that the team fall back on the pen and paper approximations found in Roskam's VI[ref 9] and VII[ref 10 ] as well as Nicolai[ 4], Etkin[1] and Hage[6]. 


\subsubsection{Criteria}

This section details the criteria required by applicable Federal Aviation Regulations (FAR) dealing with stability and control. For this class of aircraft these regulations are FAR 25 . For the most part these criteria are considered to be met (with respect to flying qualities) if the aircraft meets the requirements outlined by Nelson which close this section.

Longitudinal controllability and trim is outlined in FAR 25.143, FAR 25.145 and FAR 25.161. A quick summary of these requirements mean that when the aircraft is trimmed at a given flight condition it can be safely and easily maneuvered to another speed or flight condition and that it can be controlled while a configuration change is being made. Configuration changes include: change in the center of gravity location, change in thrust setting (voluntary or otherwise), failure of control or trim surfaces or changes in flap position.

The flight conditions under consideration are: takeoff, climb, level flight, descent and landing. Configuration changes include the sudden failure of the critical engine, the failure of the second critical engine after the aircraft has been trimmed from the critical engine inoperative. Force limits for the pilot are specified for both temporary and prolonged application.

FAR 25.145 deals with the requirement that the aircraft be capable of pitching nose down at any speed below $1.2 \mathrm{~V}$ stall so that the aircraft is accelerated to $1.2 \mathrm{~V}$ stall. Configurations include gear extended, flaps extended and retracted, power off and at max continuous power. Further requirements are outlined so that control forces will not suddenly exceed those exertable by one hand $(50 \mathrm{lbs})$.

FAR 25.161 states that trim must be maintained during climb at maximum continuous power at $1.4 \mathrm{~V}$ stall with gear retracted and flaps both retracted and in takeoff position. Trim must also be maintained during power off glide at $1.4 \mathrm{~V}$ stall and flaps both retracted and extended and most unfavorable CG positions at both max landing weight and for which landing is approved. Trim must be maintained during engine out requirments at various configurations.

Directional and Lateral controllability and trim is covered by FAR 25.143, FAR 25.147 and FAR 25.161. In summary, the aircraft when trimmed is required to be able to make turns at specified bank angle into and away from inoperative engines and make sudden changes in heading while keeping the wings approximately level again configurations are specified.

Heading changes at $1.4 \mathrm{~V}$ stall up to 15 degrees with critical engine(s) out, unfavorable CG location, gear up, flaps in approach position and max landing weight. 20 degree banked turns are required both toward and away from inoperable engine(s) at $1.4 \mathrm{~V}$ stall with remaining engines at max contiuous power, unfavorable CG location, gear up and down, flaps in most favorable climb position.

Minimum control speed is specified in FAR 25.149. The aircraft while undergoing failure of the critical engine is required to be controlled such that straight line flight is possible with zero 
sideslip or bank angle of not more than 5 degrees away from the inoperative engine with less than $150 \mathrm{lbs}$ force on the rudder pedal and at a speed less than 1.2 times $\mathrm{V}$ stall. Configurations are again specified. The aircraft is out of ground effect.

Takeoff groundrun controllability is detailed in FAR 25.107, 25.143, 25.149, 25.231, $25.233,25.237$. In summary the aircraft is required to be controllable during takeoff and ground operations including rotation and straight line takeoff in crosswinds in a variety of configurations. These requirements insure that the aircraft has positive steering, no possibility of wing-over and capability to stay on the runway.

Landing groundrun controllability is covered in FAR 25.231, 25.233, 25.237. These requirements are much the same as for takeoff with the additional considerations of thrust reversers, brakes, spoilers, touch down in a crabbed position during crosswind, and control deflection for most favorable nose wheel steering.

Roll performance is covered under FAR 25.147. The aircraft when trimmed at a given flight speed and configuration is required to be capable of specified roll maneuver (See lateral controlabillity above).

Static longitudinal stability is covered by FAR 25.171, 25.173, 25.175, 25.253 and 25.255. The aircraft when trimmed at specified speeds requires a pull on the controls to obtain and maintain lower speeds and a push is required to obtain and maintain higher speeds. When the pull or push is released the aircraft must return to a specified percentage of the trim speed. The stick force gradient is specified to be at least a minimum value.

Static directional and lateral stability is covered in FAR 25.171 and 25.177. The aircraft is required to return from sideslip condition to a zero sideslip condition. The rudder pedal force required to initiate sideslip will not all the pedal-force-gradient to reverse its sign. The aircraft when put in a positive sideslip must tend to raise the left wing. In terms of stability derivatives these requirements mean $C_{n B}>0$ and $C_{1 B}<0$.

Dynamic longitudinal stability is covered in FAR 25.181. The requirement is for heavy damping in the short period mode with controls fixed or free. Since this is vague as to specific criteria military specifications are usually used to check the handling qualities. (See information from Nelson below for requirements)

Dynamic directional and lateral stability is also covered in FAR 25.181. The requirement is that Dutch roll oscillations between stalling and maximum allowable speed be positively damped with controls free and controllable. As with dynamic longitudinal stability due to the lack of detail military specifications are used to check the handling qualities. (This information closes the section).

Stall characteristics are covered in FAR 25.201, 25.203, 25.205, 25.207. When the aircraft is put into a stall from wing level flight, turning flight, accelerated turning flight, or engine 
out the aircraft is required to show no sudden uncontrollable pitch up, adequate roll control and limited wing drop, adequate directional control, adequate stall warning and resistance to spin departure.

Note that FAR regulations require the aircraft be controllable with respect to aeroelastic effects which are often difficult to calculate. In preliminary design traditional practice is to use a ratio factor to convert coefficients or derivatives from ridged to elastic. Methods to compute these ratios (for transport aircraft only) can be found in Airplane Flight Dynamics and Automatic Flight Control Systems by J. Roskam and requires information on structural stiffness and elastic axes locations. Often these values are guestimated based on data from similar aircraft in service.

According to Nelson[3] this is a Class III aircraft: large, heavy, low-to-medium maneuverability airplanes, such as heavy transport/cargo/tanker. Level 1 flying qualities are defined as clearly adequate for the mission flight phase. Flight phase categories are defined as follows. Category A are Nonterminal flight phases that require rapid maneuvering, precision tracking, or precise flight-path control. Included in the category are air-to air combat, ground attack, weapon delivery/launch, aerial recovery, reconnaissance, in-flight refueling (receiver), terrain-following, antisubmarine search and close-formation flying. Category B are Nonterminal flight phases that are normally accomplished using gradual maneuvers and without precision tracking, although accurate flight-path control may be required. Included in the category are climb, cruise, loiter, in-flight refueling (tanker), descent, emergency descent, emergency deceleration, and aerial delivery. Category $\mathrm{C}$ are Terminal flight phases are not normally accomplished using gradual maneuvers and usually require accurate flight-path control. Included in this category are takeoff, catapult takeoff, approach, wave-off/go-around and landing. For Class III aircraft Level I longitudinal flying qualities require that in the Phugoid mode be $>.004$ and in the short period mode that in Categories A \& C, $0.35<x<1.30$, while Category B, $0.3<x<2.0$. The lateral requirements for Level I are as follows. Minimum time to double amplitude in the spiral mode of 20 seconds for all Categories. Maximum roll time constants for the roll mode of 1.4 seconds. Dutch roll: Category

A Minimum $x^{*}=0.19$, Minimum xwn $=0.35 \mathrm{rad} / \mathrm{sec}$, Minimum $w n=0.4 \mathrm{rad} / \mathrm{sec} ;$ Category B \& C Minimum $x^{*}=0.08$, Minimum $x w n=0.15 \mathrm{rad} / \mathrm{sec}$, Minimum wn $=0.4$.

\subsubsection{Results}

Information was exchanged along lines explained in the introduction section within the team. CG Locations and moments of inertia came from the weights group. Aerodynamic data came from the Aero/Performance group via VORLAX code, and engine data was required from the propulsion group. Sizing for the most part was determined in the previous quarter to meet takeoff, landing and mission requirements. The stability derivatives in table 7.3 .1 were calculated by the 
formulas in the given references[1,10]. These derivatives were then fed into MATLAB codes which were to determined the dynamic stability data. Due to the limitations of our tools to predict the responses in the high speed regime analysis was done only at low speed for the rigid aircraft. Results of the MATLAB code were somewhat spotty and therefore suspect. At this time it is suspected that the aircraft will not meet necessary criteria without the inclusion of a SAS system as in the Lockheed study.

\section{Table7.3.1 Aircraft Stability Derivatives}

FLIGHT CONDITION M =.2 SEA LEVEL

LONGITUINAL
CL $=.275$
$C D=.025$
$C L a=2.793$
$C D a=.4655$
CMa $=-.6152$
CLaDOT $=.3364$
CMaDOT $=-3.811$
CLQ $=1.773$
CMQ $=-1.589$
CLM $=0$
CDM $=0$
CMM $=0$
CLde $=.29$
CMde $=-1.13$
LATERAL
CYa=-.4509
$C L b=-.0218$
$\mathrm{CNb}=.190$
CLP $=-.3354$
$\mathrm{CNP}=-.0307$
CLR $=.0616$
CNR $=-.1916$
CLda $=.052$
$\mathrm{CNda}=.006$
$\mathrm{CYdR}=.15$
CLdR $=.0003$
CNdR $=-.09$
$C Y R=0$
$\mathrm{CYP}=0$ 


\section{References}

1. Etkin, Bernard, Dynamics of Flight Stability and Control Second ed. 1982, John Wiley \& Sons, Inc.

2. LAN \& ROSKAM, Airplane Aerodynamics and Performance

3. NELSON, ROBERT C., Flight Stability and Automatic Control, 1989, McGraw- Hill, Inc.

4. NICOLAI, Fundamentals of Aircraft Design, 1984, METS, Inc.

5. ROSKAM, J., Airplane Design: Part I, Preliminary Sizing of Airplanes.

6. PERKINS \& HAGE, Airplane Performance Stability and Control, John Wiley \& Sons, Inc.

7. ROSKAM, J., Airplane Design: Part II, Preliminary Configuration Design and Integration of the Propulsion System.

8. ROSKAM, J., Airplane Design: Part V, Component Weight Estimation.

9. ROSKAM, J., Airplane Design: Part VI, Preliminary Calculation of Aerodynamic, Thrust and Power Characteristics.

10. ROSKAM, J., Airplane Design: Part VII, Determination of Stability, Control and Performance Characteristics: FAR and Military Requirements

11. Messina, A.F., et al., NASA CR-132575: Substantiating Data Report: Arrow Wing Supersonic Cruise Aircraft Structural Design Concepts Evaluation. Vol 1 Section 3, 1977

Also Thanks to:

Aaron L. Harcrow, Jr. of Lockheed's Advanced Design Division for instruction and introduction to APAS II.

Johnny B. Stamper also of Lockheed's Advanced Design Division for timely loan of reference material. 


\subsection{Airframe / Propulsion Integration}

The Lockheed corporation performed a study of engine integration concerns (SEE Ref. 1). The focus of their study was the affects of nacelle placement on drag, flutter, control, and unstart. The report concluded that spanwise nacelle placement was constrained by flap sizing and control concerns. Longitudinal movement of the engines were constrained by flutter for aft movement and thermal fatigue for forward movement. The study examined the affects of moving the engine exhaust forward to the trailing edge. After examination of the total affect on range, it was felt that the Range improvement did not warrant movement of the engines from their baseline configuration. This baseline configuration is illustrated in Figure 7.4.1. 
Figure 7.4.1 Lockheed Baseline Design 1
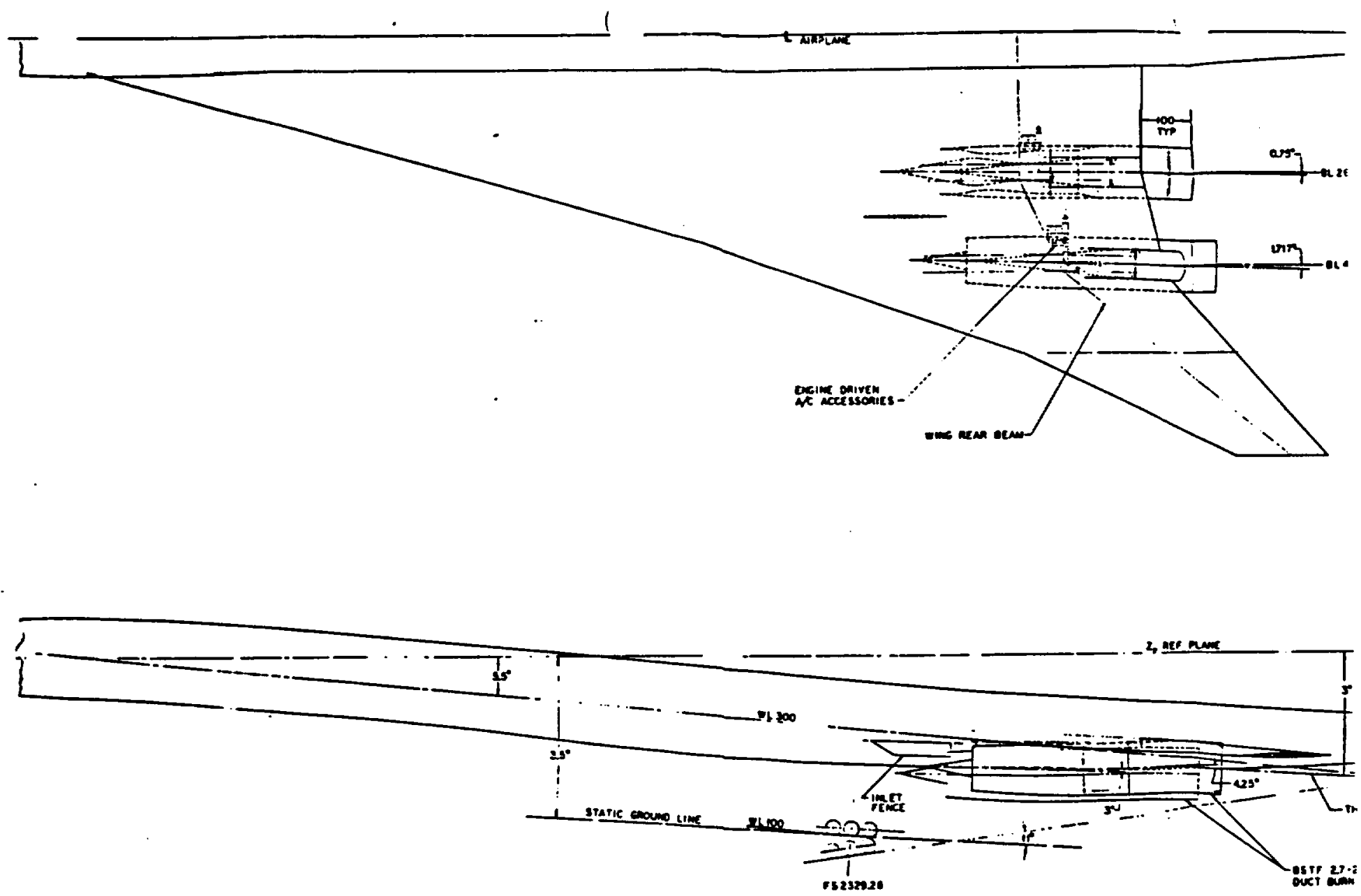
Figure 7.4.2 QFD Matrix for Propulsion

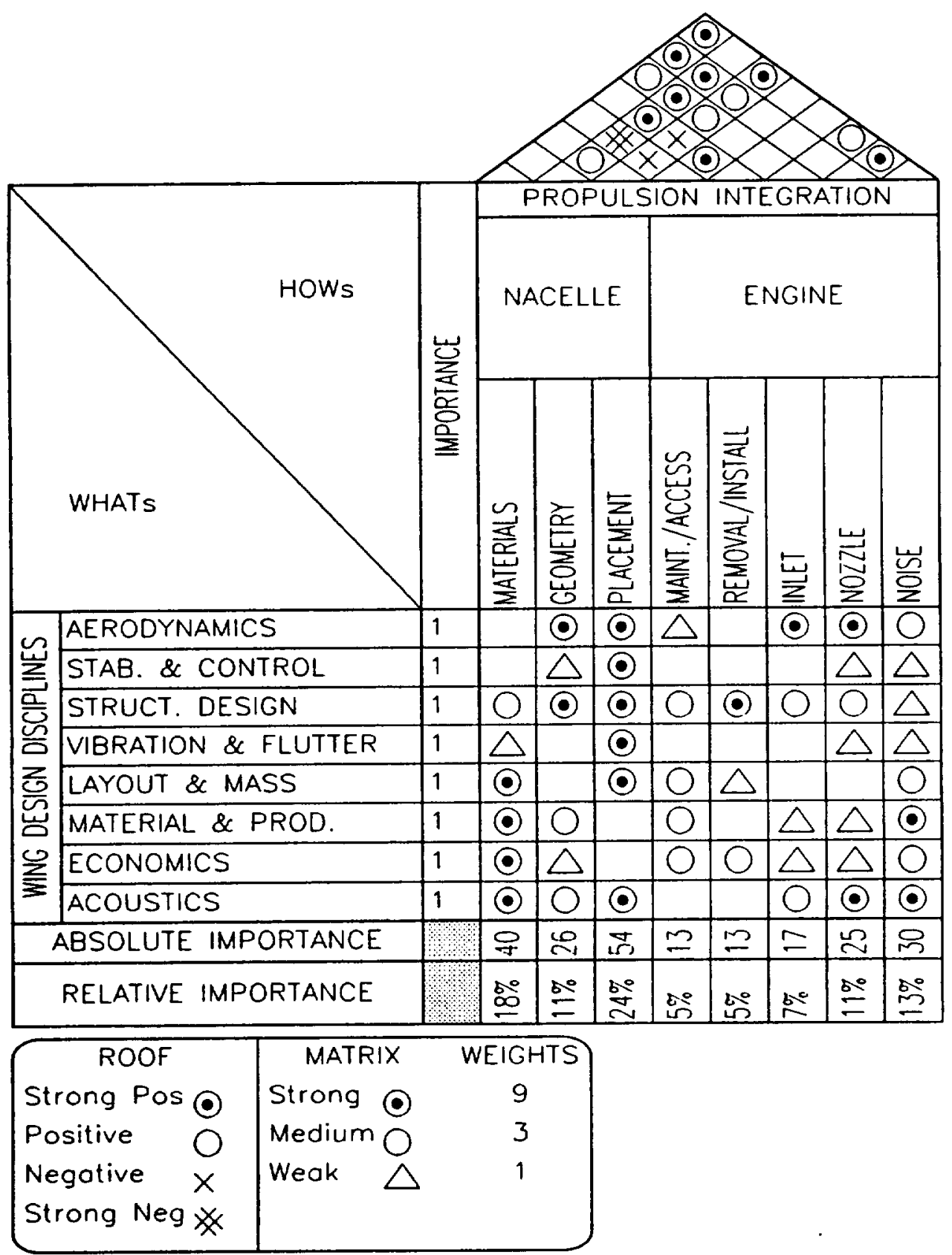


Table 7.4.1 Primary Concurrent Relationships

\section{Georgia Tech}

\section{PRIMARY CONCURRENT INTERRELATIONSHIPS}

DISCIPLINE

Aerodynamics

Stability and Control

Structures

Flutter

Layout and Mass

Acoustics

\section{CONSTRAINTS}

Drag

Flap Sizing

OEO Control Attach Constr.

Flutter Speed

Placement

Noise

School of Aerospace Engineering 
Eigure 7.4.3 Design Flow Diagram

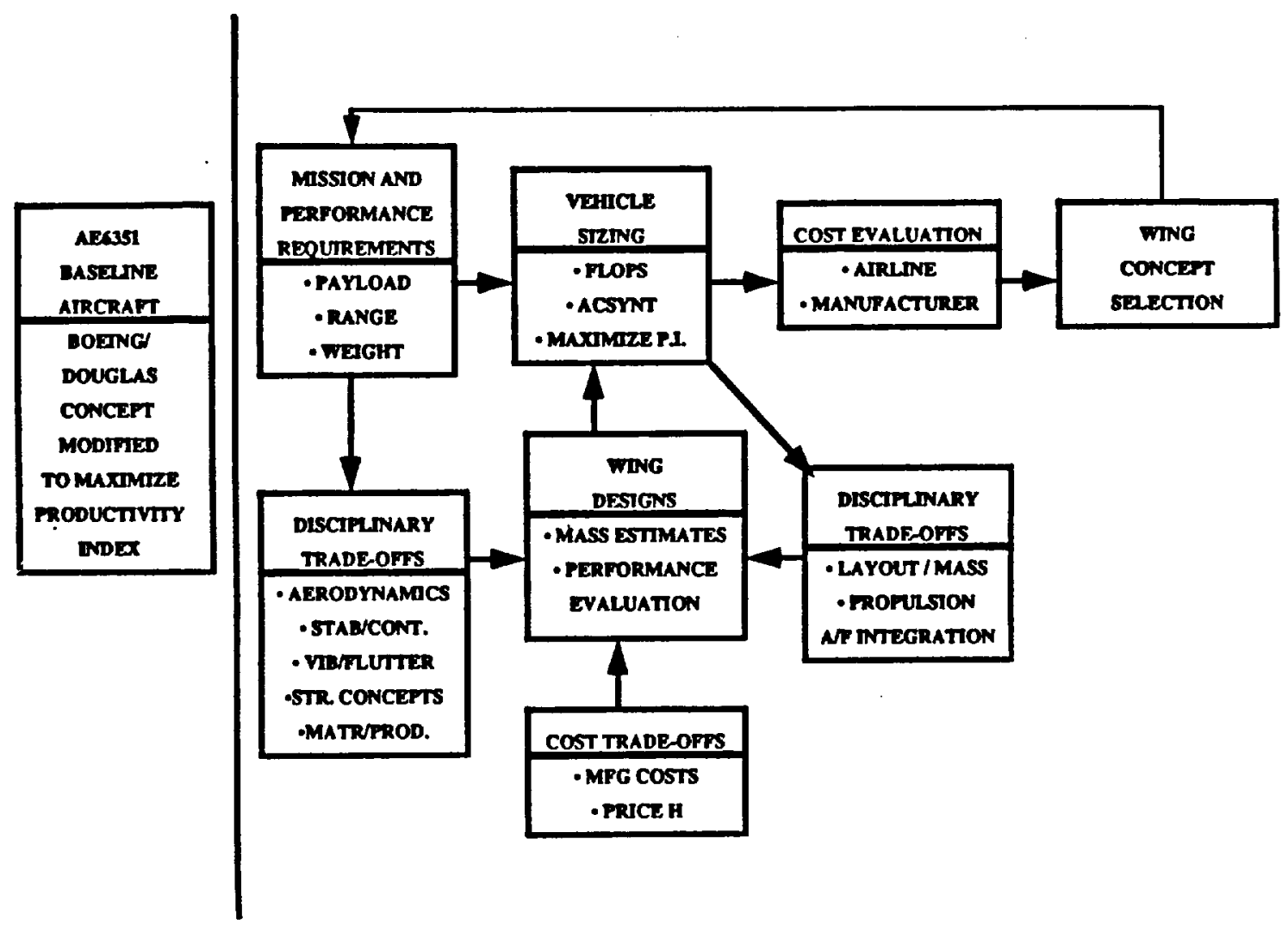




\subsubsection{Concurrent Engineering of Integration}

The goal of the engine/airframe integration team is to mate the propulsion system to the HSCT airframe in an 'optimum' manner. The introduction of Concurrent Engineering principles allowed the term optimal to be better quantified. In this way, research could be better focused and research time appropriately allocated.

The initial task of the study was to develop a Quality Functional Deployment (QFD) matrix for the propulsion integration (PI) group. This diagram is displayed in Figure 7.4.2. The fundamentals of propulsion integration were traded off against primary research topics in other aircraft disciplines. This exercise allowed the PI group an initial grasp on which areas of engine integration would be of primary concern. The use of successive, interrelated QFD matrixes allows the "voice of the customer" to be an influential factor in engineering research, analysis, and design.

The next task was the development of an interrelationship diagram between the engine integration team and the other disciplines involved. This diagram depicts where lines of communication would be most important and is shown in Figure 7.4.3. From this diagram, the group was able to develop a preliminary idea of what information would need to be exchanged during the study. A table of this information is given in Table 7.1. A very important tool is the design flow diagram shown in Figure 7.4.4. This diagram is a synthesis of the inputs of all the design groups, and allowed the PI group to see its functional role in the development of the HSCT wing. The figure illustrates that the PI group will receive data on the sizing of the vehicle. Through research, analysis, and considerations of mass and layout constraints, the PI group is tasked to forward proposed integration schemes. These proposals, along with that of other disciplines, is synthesized into a wing design concept. This wing concept is then used to resize the vehicle, which initiates another iteration cycle. The use of $\mathrm{CE}$ techniques insures that each iteration will bring further optimization, refinement, and definition to the HSCT design. Therefore, Concurrent Engineering was used to define the problem, develop a solution method, and to define a direction for optimization of a solution.

\subsubsection{The Engine}

The engine to be used for integration was optimized in a previous study (See Ref. 2). The engine was optimized using the Quick Naval Engine Performance (QNEP) program developed by NASA and the Navy. This program is integrated into the FLight Optimization Program (FLOPs) developed at NASA, which allows analysis of engine installed performance. The proposed engine is a non-afterburning turbobypass engine. This engine has the ability to emulate both the performance of a turbofan or a turbojet depending on the flight conditions. The engine was 
Table 7.4.2 Engine Data

\section{Non-Afterburning Turbobypass Engines}
DESIGN THRUST, IbS
53048
ENGINE WEIGHT, lbs
CRUISE MACH NUMBER
12000
CRUISE ALTITUDE, ft
MAX TURBINE INLET TEMP, $R$
OVERALL PRESSURE RATIO
2.4
BYPASS RATIO
55000
CRUISE SFC, lbm/hr lbf
3200
THRUST/ WEIGHT
20
0.135
1.275
0.295 
optimized on the basis of Specific Fuel Consumption (SFC) and adherence to pertinent FAR regulations (e.g. take-off field length).

For the present wing development study, engine cycle optimization and NOX emissions were not included. The engines were dealt with as if they were to be delivered from an outside engine manufacturer. In this scenario, the engine company is required to deliver, along with the engine, all data necessary for proper integration and installation. The data necessary for the present study was extracted from the QNEP engine deck generation module. APPENDIX A lists the component, flow, and performance data that would be delivered with the engine utilized in the study.

Four non-afterburning turbobypass engines were utilized in the integration study. The engines operated with an overall pressure ratio of 20, a maximum turbine inlet temperature of 3200 $\mathrm{R}$, and a cruise bypass ratio of 0.135 . Each engine weighed $12,000 \mathrm{lbs}$ and was capable of delivering 53,048 pounds of continuos static thrust. The cruise specific fuel consumption was $1.2754 \mathrm{lbm} / \mathrm{hr} / \mathrm{lbf}$ and the preliminary thrust to weight was 0.29 . The pertinent engine data is listed in Table 7.4.2.

\subsubsection{Engine Integration}

As shown in the Propulsion QFD matrix, the primary focus of the integration study was engine location. Engine location affects drag, flutter, structural weight, acoustics, and control and stability. An optimal engine location must take all of these considerations into account and trade off the effects to each group. The primary concern in the PI study was drag due to engine/nacelle installation. Changes in drag affect SFC, range, fuel weight, operating cost, and ultimately life cycle cost. Therefore, this was of utmost importance in integration of the propulsion system.

Nacelle drag can be broken into three contributing components: skin friction, wave drag, and drag due to lift. Skin friction is dependent primarily on the wetted area of the nacelle. Drag due to lift is that component of the lift vector which is directed against the flight direction due to angle of attack. Wave drag is the most complicated of the three. It is due to shock and shock field interactions between the fuselage, the wing, and the nacelles. Each of these aircraft components imparts and has imparted on it an interference drag due to the other components. The wave drag is thus very complex and is dependent on the effective volume of the components as well as their placement. It has been shown that through proper placement, a nacelle installed drag can be achieved that is lower than the isolated nacelle drag. This process is discussed in relation to the three drag components.

As mentioned earlier, friction drag is mainly a function of the nacelle aerodynamics and wetted area. Therefore, significant reductions in friction drag can only be affected by nacelle 
geometry changes. In the present study, this option was not focused on because the nacelles were sized to fit the preliminary engines. Any tailoring of the nacelles would have to wait until the design and geometry of the engine is more concrete.

Drag due to lift can be reduced through proper nacelle design and location. If nacelles are placed properly on a wing, pressure forces on the nacelles generate lift. This nacelle lift can augment the wing lift allowing the aircraft to fly at a lower angle of attack. This effectively reduces the drag component of the lift vector. This method was used in the HSCT nacelle placement, however it does have its penalties. The nacelle pressure field can distort the wing camber and also the fan cowl. These effects will have to be studied further.

Wave drag is quite complex and has to do with the interaction of shocks and the pressure fields they create. Basically, as flow passes through a shock, its pressure is raised. As flow passes through an expansion, its pressure drops. These characteristics are illustrated in Figure 7.4.5. The flow through the initial nacelle shock creates a cowl drag due to higher pressures on the cowl curvature. The flow through the aft expansion has its pressure dropped so that it effectively "sucks" on the nacelle. This is what is termed "boattail" drag. A variety of tactics are used to reduce wave drag. One is to orient the nacelles in a position relative to the wing so that the wing shocks creates a "sucking" force on the nacelle, and the nacelle shocks create a "pushing" force on the wing. Another tactic involves the relative positioning of the nacelles. Optimally, the nacelles would be situated so that the increased pressure field from one nacelle pushes on the boattail of the other. However, this positioning would lead to major structural concerns due to the large stagger. Alternately, the nacelles can be staggered to take advantage of the shock fields in a sub-optimal, yet effective manner.

In order to study the effects of interference and wave drag, the Revised Wave Drag Analysis Program (AWAVE) developed at NASA Langley was utilized. The wing, fuselage, and nacelle data for the HSCT were input into the program. Data was then collected on the drag effects of nacelle placement. Spanwise, longitudinal, and staggered nacelle placements were studied. Figure 7.4.6 illustrates the effect of longitudinal motion of the engines. As can be seen, aft positioning of the nacelles tends to reduce drag. Inlet stagger also has a distinct effect. The drag effects of spanwise nacelle movement is illustrated in Figure 7.4.7. Reductions in drag can be accomplished through proper coupling of inlet stagger and spanwise placement. These trends were used in the locating of the nacelles. 
Figure 7.4.4 Bow Shock and Expansion Pressure Fields 4
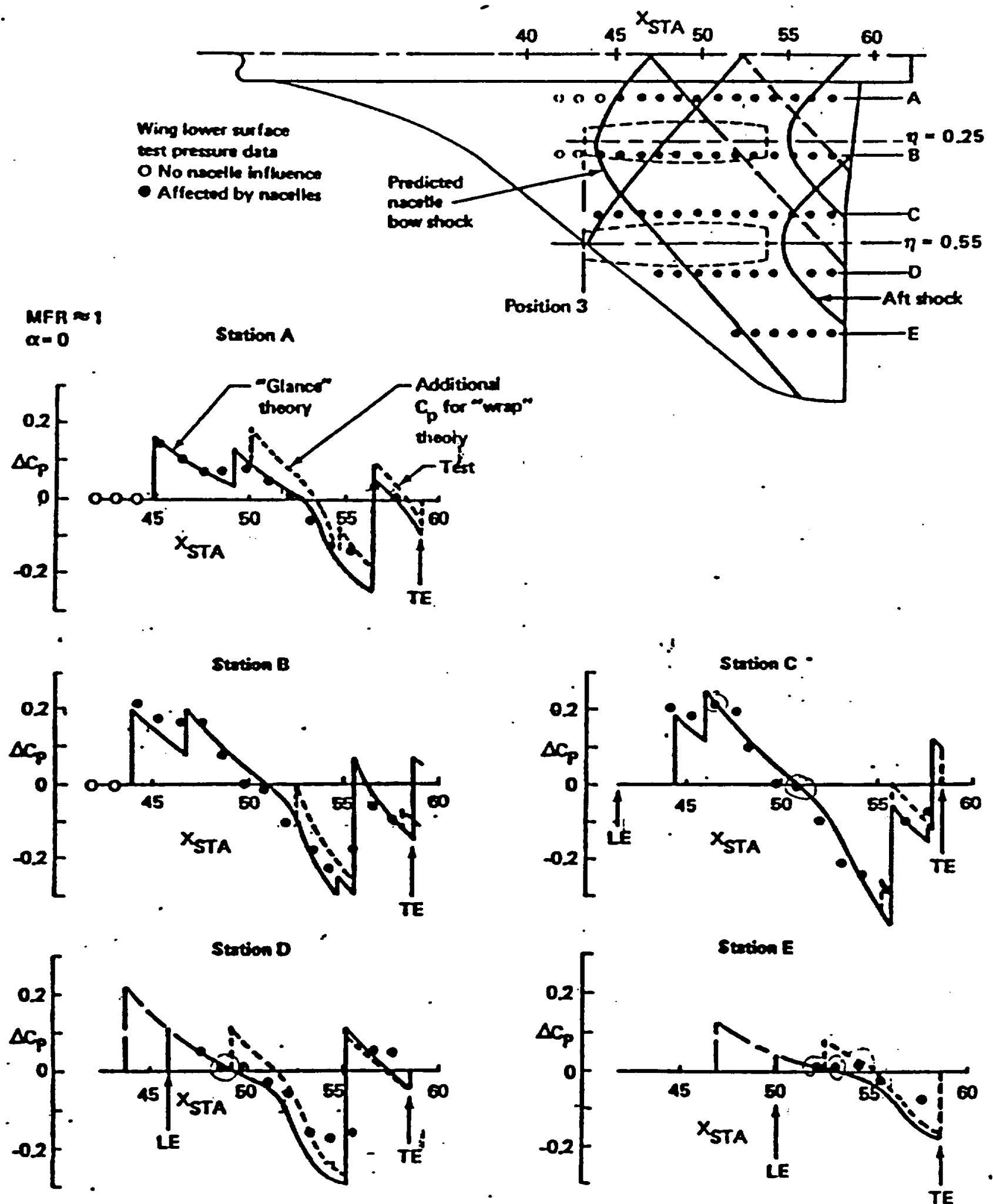
Figure 7.4.5 Longitudinal Displacement (Nacelle Diameters)

\section{LONGITUDINAL DISPLACEMENT, NO STAGGER}

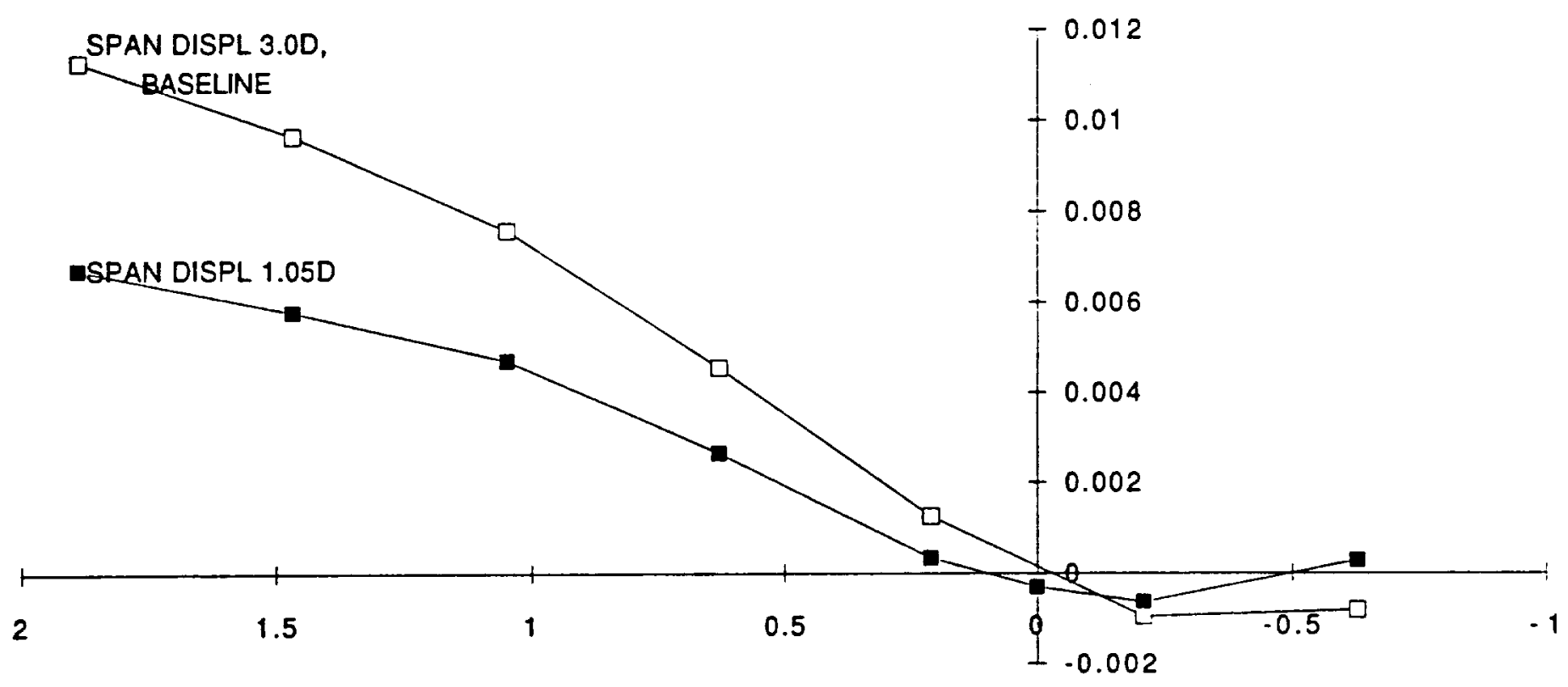

LOONGITUDINAL DISPLACEMENT, (NACELLE DIAMETERS) 


\section{EFFECTS OF SPANWISE DISPLACEMENT, INBOARD POSITION FIXED}

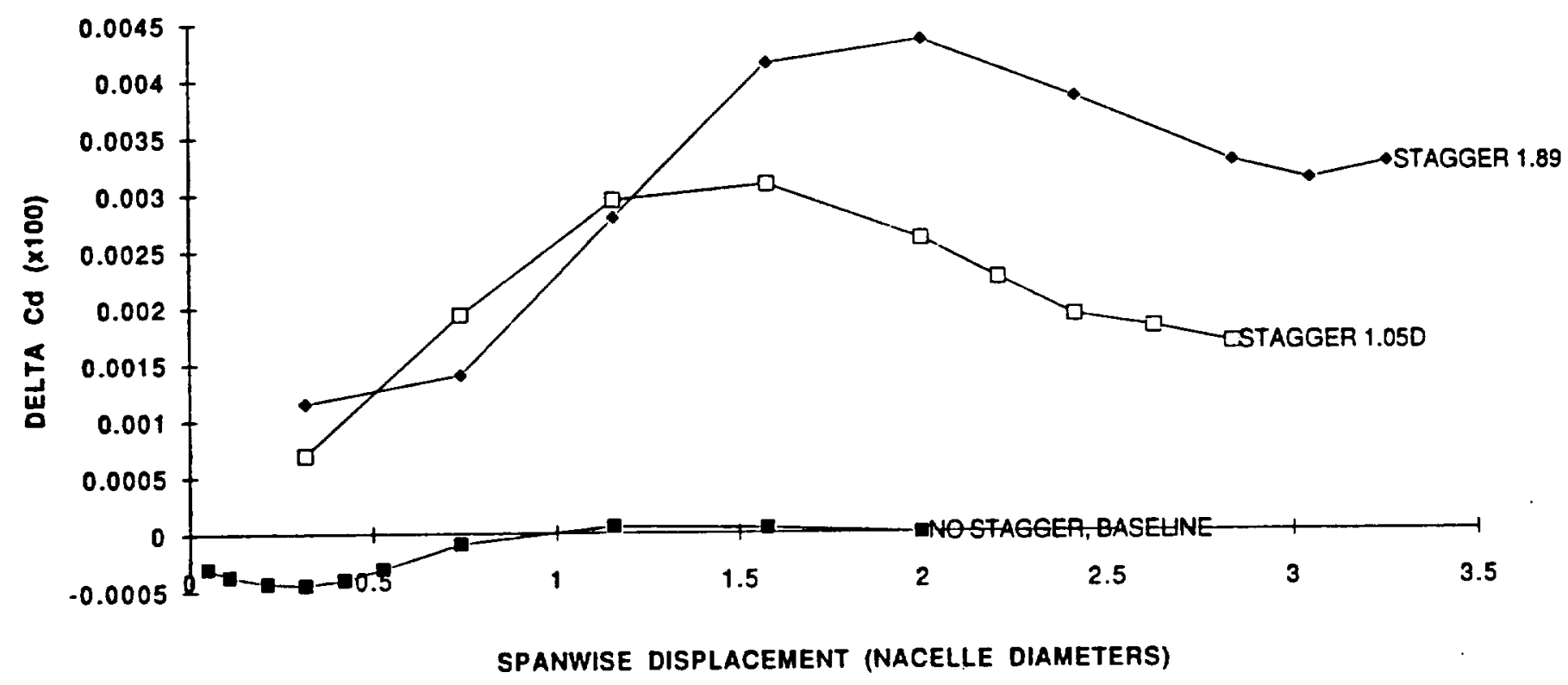


Engine location also directly affects other wing properties. Analysis has shown a direct impact on the wing flutter characteristics (See FLUTTER Chapter). Communication with the flutter group indicated that movement of the engines outboard causes a reduction in the flutter speed. Aft movement causes a reduction in the torsional flutter speed. To increase flutter speed, weight must be added to the wing structure. Figure 7.4.8 illustrates the general influence of several engine configurations on flutter speed.

The wing structure is directly affected by engine placement. Outboard movement of the engines can reduce required structural weight. This is due to the alleviation of the wing bending moment during flight. Aft movement of the engines leads to increased structural weight due to the increased twisting torques (See STRUCTURES Chapter).

Engine location is also a major concern to the controls group. The controls group indicated the desire to avoid placing wing flaps above the engines. This is due to concerns of thermal fatigue, jet interference, and mechanical interference. The configuration of the engines must therefore allow adequate flap sizing (SEE Aerodynamics). Also of concern is the One Engine Out (OEO) FAR requirement (See Table 7.3). Outboard engine movement increases the moment arm associated with engine failure. This leads to control concerns and weight penalties due to increased sizing of tail surfaces.

Two configurations have been developed for further consideration by the PI team. The highest risk of the two involves placing two engines in one nacelle. The other configuration is a relatively lower risk and involves optimization of the current spanwise engine placement.

\section{Twin-Podded Engines}

Examination of Figure 7.4.7 illustrates that reductions in drag occur for close nacelle placement. A high risk proposition is to either place the engines very close, or to pod two engine in the same nacelle much as the Concorde. The engines would be separated by a splitter gate and would incorporate individual two-dimensional inlets and nozzles. The nacelle would be located near midspan as a tradeoff between flutter, static, and control structural concerns. The advantages of such a design are reduction in drag due to less interference and potentially less wetted area. The closer configuration also reduces the moment arm due to OEO operation. This configuration could also ease maintenance due to concentration of engine accessories. Structurally, less access panels would be required.

There are also drawbacks to such a configuration. Due to the proximity of the engines, even with the gate, unstart of one engine unstarting the adjacent engine would be a concern. Also of concern are the blade throw angles due to a turbine or compressor structural failure. A prime concern would be a blade "spit" from one engine causing severe damage to the adjacent engine. Nacelle structural reinforcement would be necessary at a weight penalty. Figure 7.4.9 illustrates 
Figure 7.4.7 General Configuration Effects on Flutter Speed 1

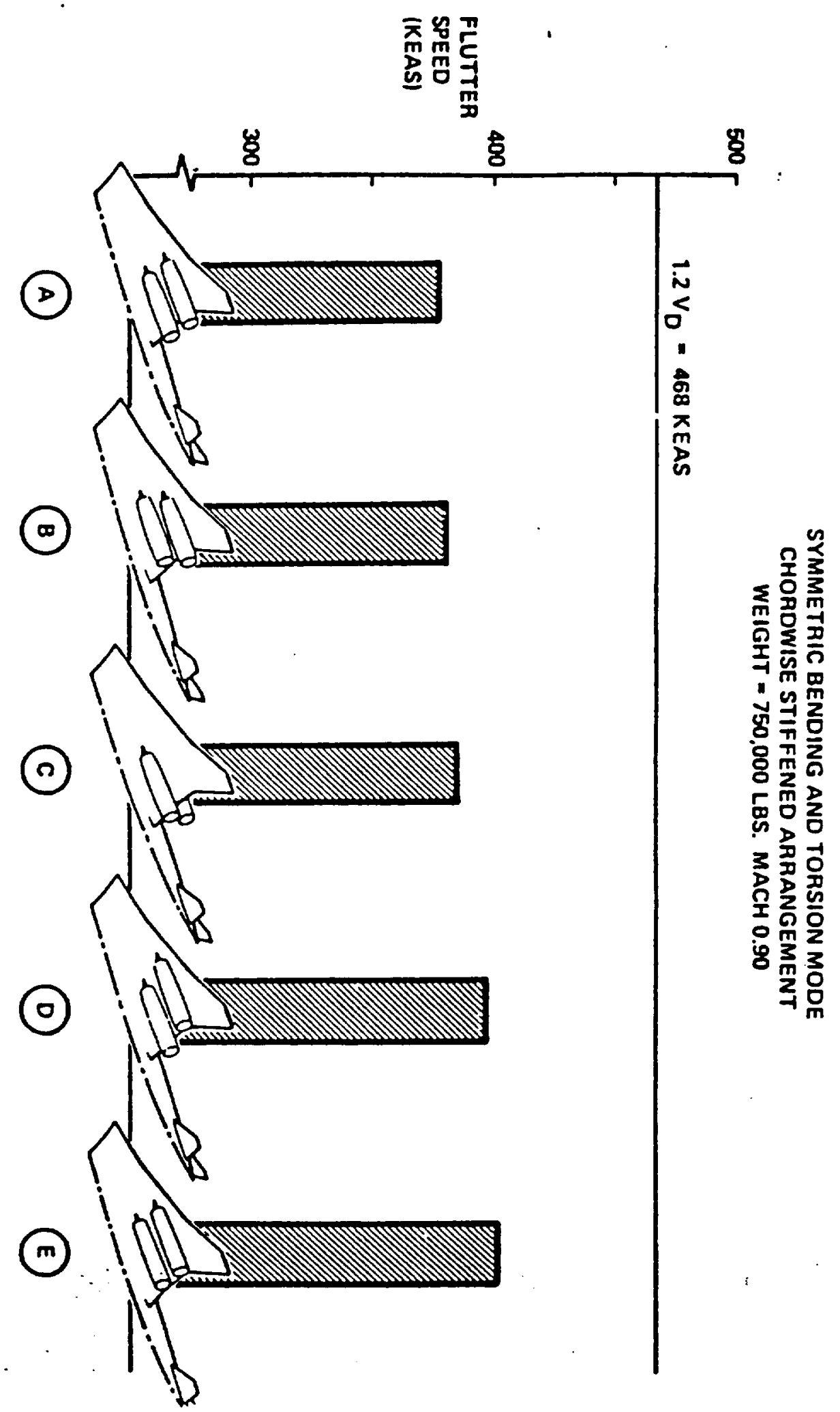


Table 7.4.3 Engine Installation FAR Requirements

\begin{tabular}{|c|c|c|}
\hline REQUIREMENT & $\begin{array}{l}\text { PERTINENT FAR } \\
\text { PARAGRAPHS }\end{array}$ & SUMMARY * \\
\hline One Engine Inoperable & $\begin{array}{l}25.121 \\
25.367 \\
25.1431\end{array}$ & $\begin{array}{l}0.5 \% \text { Climb gradient at lift off } \\
\text { Controllable } \\
\text { Structure must withstend } \\
\text { unsymmetric loods }\end{array}$ \\
\hline Nolse Requirements & 36 Sec. C36.5 & $\begin{array}{l}\text { Takeoff }<105 \text { EpndB } \\
\text { Sideline }<102.5 \text { EpndB } \\
\text { Approech }<105 \text { EpndB } \\
\text { Tradeoffs allowed if: } \\
\text { Sum of exceedences }<3 \text { EpndB } \\
\text { Each exceedance }<2 \text { EpndB } \\
\text { Offset by reduction elsewhere }\end{array}$ \\
\hline Thrust Reverser & 33.97 & $\begin{array}{l}\text { Accidental inflight operation will not } \\
\text { cause loss of control }\end{array}$ \\
\hline Fire Zones & $\begin{array}{l}25.1181,25.1207 \\
33.17\end{array}$ & $\begin{array}{l}\text { Powerplant fire protection } \\
\text { Fire prevention: drainage, ventilation, } \\
\text { firewalls }\end{array}$ \\
\hline Engine Proximity & 25.903 & $\begin{array}{l}\text { Engines must be isolated: failure of one } \\
\text { engine will not prevent continued safe } \\
\text { aircraft operation or require immediate } \\
\text { crew action }\end{array}$ \\
\hline $\begin{array}{l}\text { Structurel requirements for } \\
\text { engine torque end side lood }\end{array}$ & $\begin{array}{l}25.361 \\
25.363\end{array}$ & $\begin{array}{l}\text { Withstand sudden engine stop or max accel. } \\
\text { Lateral limit loed factor: } 1.33 \text { or } 1 / 3 \text { side } \\
\text { load factor }\end{array}$ \\
\hline Engine Accessories & $\begin{array}{l}25.951-25.1001 \\
25.1011-25.1027 \\
25.1141-25.1167 \\
33.25\end{array}$ & $\begin{array}{l}\text { Fuel system requirements } \\
\text { Oil system requirements } \\
\text { Powerplant controls and accessories } \\
\text { Accessory attachment }\end{array}$ \\
\hline Foreign object Ingestion & 33.77 & $\begin{array}{l}\text { Ingestion of tire tread, bird, or rotor blade } \\
\text { may not cause engine to: } \\
\text { 1) Catch fire } \\
\text { 2) Burst } \\
\text { 3) Generate major losses } \\
\text { 4) Lose shutdown capability }\end{array}$ \\
\hline
\end{tabular}

* See listed FAR sections for detailed informetion 
the typical 15 degree blade throw angles of concern. Another concern would be thrust-reverser operation. Side placement of reversers would be inhibited due to proximity interference. Top and bottom placement could involve blowing hot exhaust gases back onto the wing and trailing surfaces. This is also a primary concern. This configuration has been proposed as one that warrants further study.

\section{Conventional Engine Placement}

The baseline configuration represents a lower risk proposal, and therefore it was chosen to further pursue its optimization. The baseline nacelle geometry is presented in Figure 7.4.10. The engines were located at $27 \%$ and $46 \%$ half-span. The initial nacelle design was a cylindrical, axisymmetric design sized to the nozzle area requirements. The nacelles were faired as illustrated to reduce shock strength. The nacelles were 30.36 feet long with an outer diameter of 6.18 feet. The effective wetted area was 525.35 feet, resulting in a friction drag coefficient of 0.00018 per nacelle. Future studies and iterations will further define and optimize the exact nacelle geometries.

Several considerations affect spanwise nacelle motion. As mentioned earlier, spanwise movement creates a tradeoff between structural weight and flutter speed. The airplane must also meet the FAR requirements for takeoff pitch and roll (See Table 2). Studies were done to examine the effects on nacelle drag of span movement. The results are presented in Figure 7.4.11. Analysis of the data revealed that movement of the inboard engine outboard would increase drag. Spanwise movement of the outboard engine would not result in any significant drag reductions. Movement of the outboard engine would also cause control, flutter, and structural concerns. After consultation with the structures and controls disciplines, it was decided to leave the engines at the baseline span locations for the first iteration. This placement also allows for normal side thrustreversal operation.

The PI group chose to use nacelle longitudinal movement to further optimize the integration of engine and wing. Figure 7.4.12 depicts the results of a study to examine the drag affects of moving the engines longitudinally. Aft placement of the engines resulted in the least drag, but adds concerns due to wing structural augmentation to handle the increased twisting torque. As mentioned previously, nacelle stagger can also be used to reduce drag. The results of the analysis of the effect of stagger on drag are depicted for the baseline spanwise placement. The benefits of proper nacelle stagger can be seen. The longitudinal nacelle location proposed for the first iteration were $202.60 \mathrm{ft}$. from nose to inlet for the inboard engine, and $199.26 \mathrm{ft}$. for the outboard. This results in a total drag coefficient reduction of 0.0064 . First iteration nacelle location is shown in Figure 7.4.13.

The longitudinal positioning of the engines represents a compromise between drag reduction and wing structural augmentation. Both engines trail the wing by approximately four 


\section{Figure 7.4.8 General Axisymmetric Nacelle Geometry}
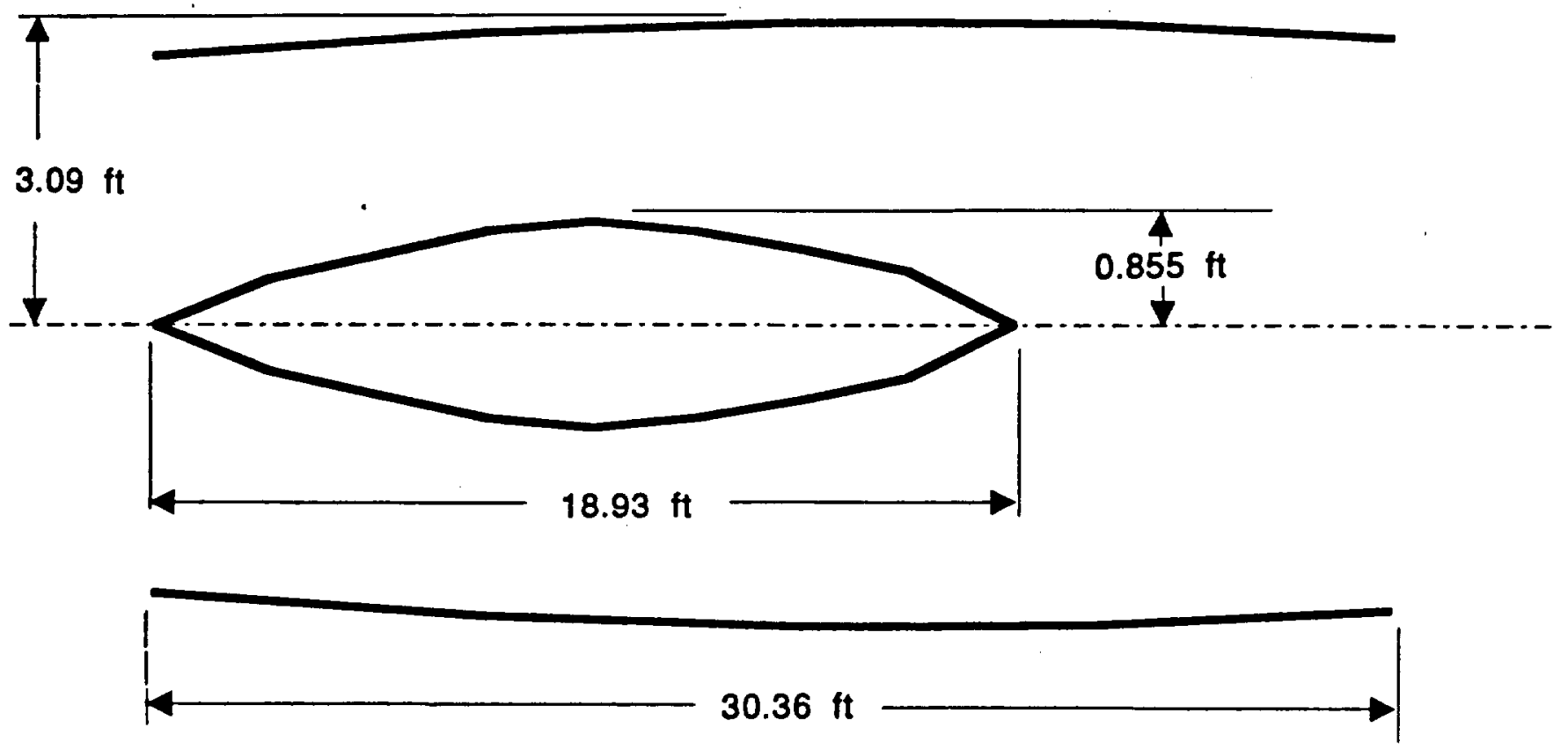
Eigure 7.4.9 Effects of Spanwise Displacement

\section{EFFECTS OF SPANWISE DISPLACEMENT, NO STAGGER}

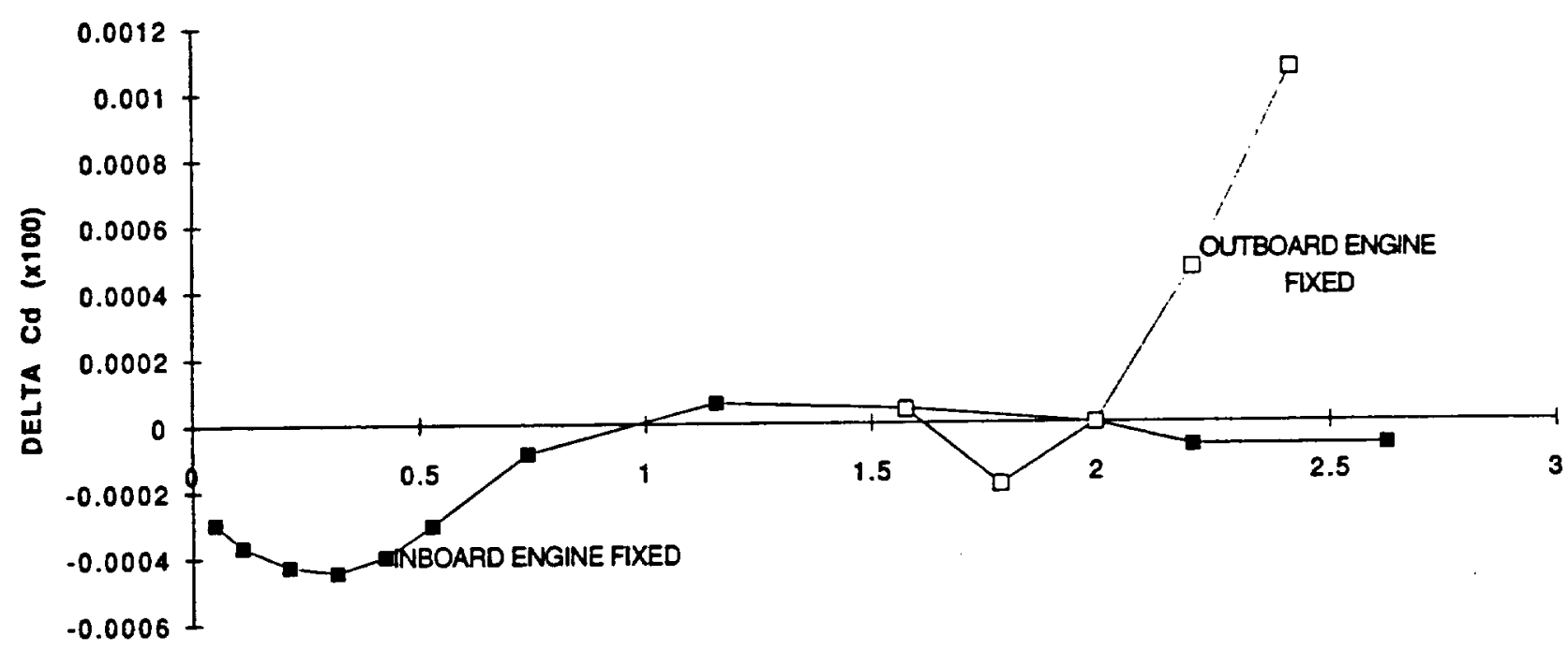

SPANWISE DISPLACEMENT (NACELLE DIAMETERS) 
feet. This aft placement of the engines accounts for concerns of wing trailing edge sonic and temperature degradation due to hot exhaust. As mentioned earlier however, aft placement of the engines can require increases in torsional control structure. Preliminary structural analysis indicates that the four feet of trail will not present a significant structural weight increase. These effects need further research during the next iteration.

\subsubsection{Acoustic Considerations}

As shown in the Propulsion QFD matrix, engine noise is a primary concern in the development of the HSCT. If the aircraft fails to meet FAR 36 requirements, the entire project may be in jeopardy. For this study, it was chosen not to focus on acoustic properties due to the lack of sufficient analysis tools. However, this section touches on some of the key concerns of engine noise.

FAR airport requirements require that aircraft noise be measured at three points: Approach, Takeoff, and Sideline as depicted in Figure 7.4.14 (Also See Table 7.2). Airport community noise is due primarily to engine noise. Engine noise is a result of two major mechanism. One is jet noise due to the mixing of the high velocity exhaust gases with ambient air. The other mechanism is the shrill whine associated with fan and compressor operation. Methods for suppressing these noises are also discussed in the Nozzle Operation and Inlet Operation sections of this report.

Current research in noise suppression involves relative positioning of the engines. It has been shown that in certain configurations, the noise from one engine can be used to "mask" noise from the other. For example, in an over-under engine configuration, takeoff and approach noise is reduced due to masking by the lower engine. Sideline noise may be reduced in a conventional under wing placement by proper alignment of the engines. For the proposed HSCT conventional nacelle placement, this may result in reversal of the engine stagger (placing the outboard engine behind the inboard). However, this could lead to lower flutter speeds and increased wing trailing edge sonic and thermal degradation. At this time, present knowledge of this technique's effectiveness does not warrant change. Much research is necessary in this area. The PI group proposes that the next phase of development include focused research in this area. 
Figure 7.4.10 Longitudinal Stagger of Inboard Engine

\section{LONGITUDINAL STAGGER OF INBOARD ENGINE, OUTBOARD FIXED}

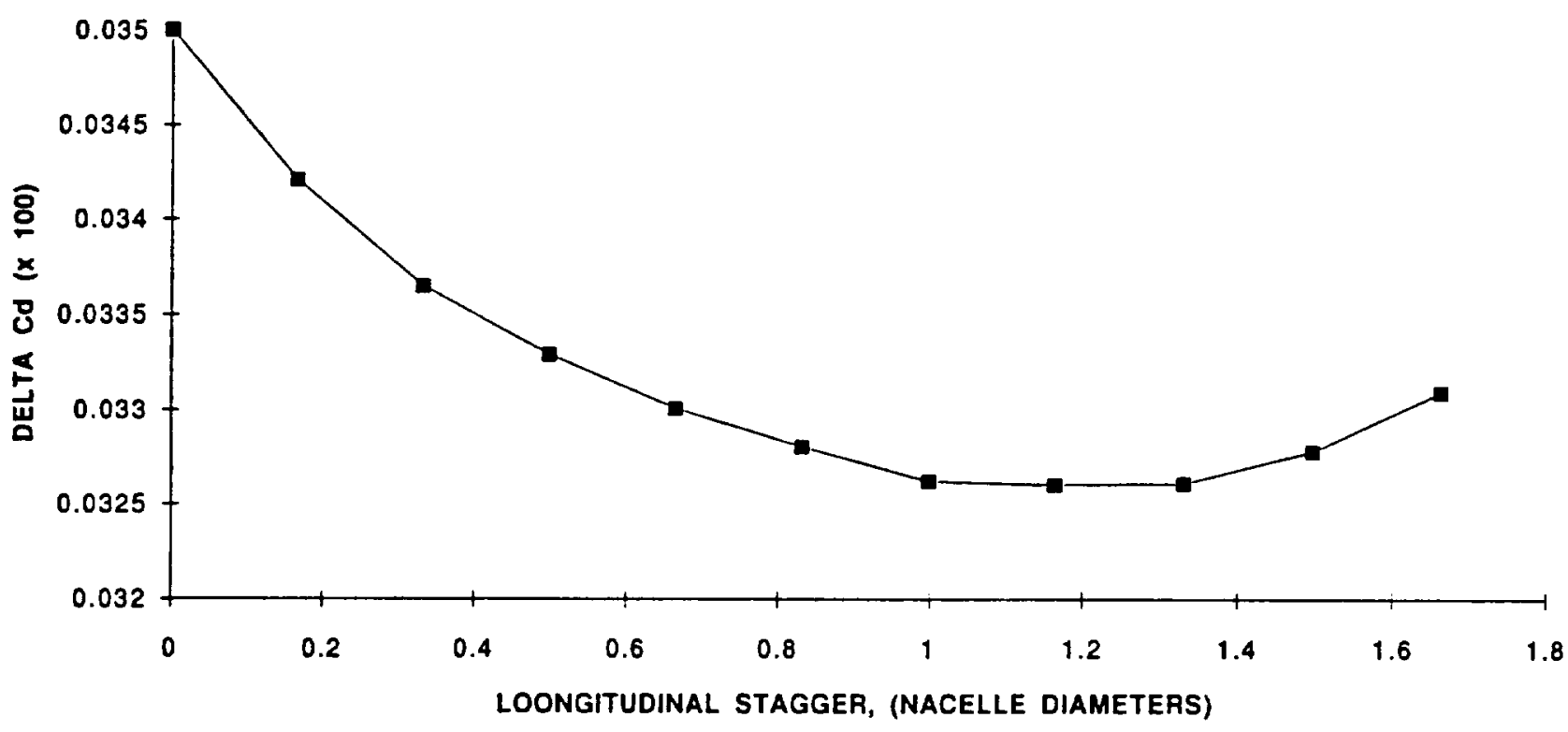




\section{Figure 7.4.11 HSCT Three-View}
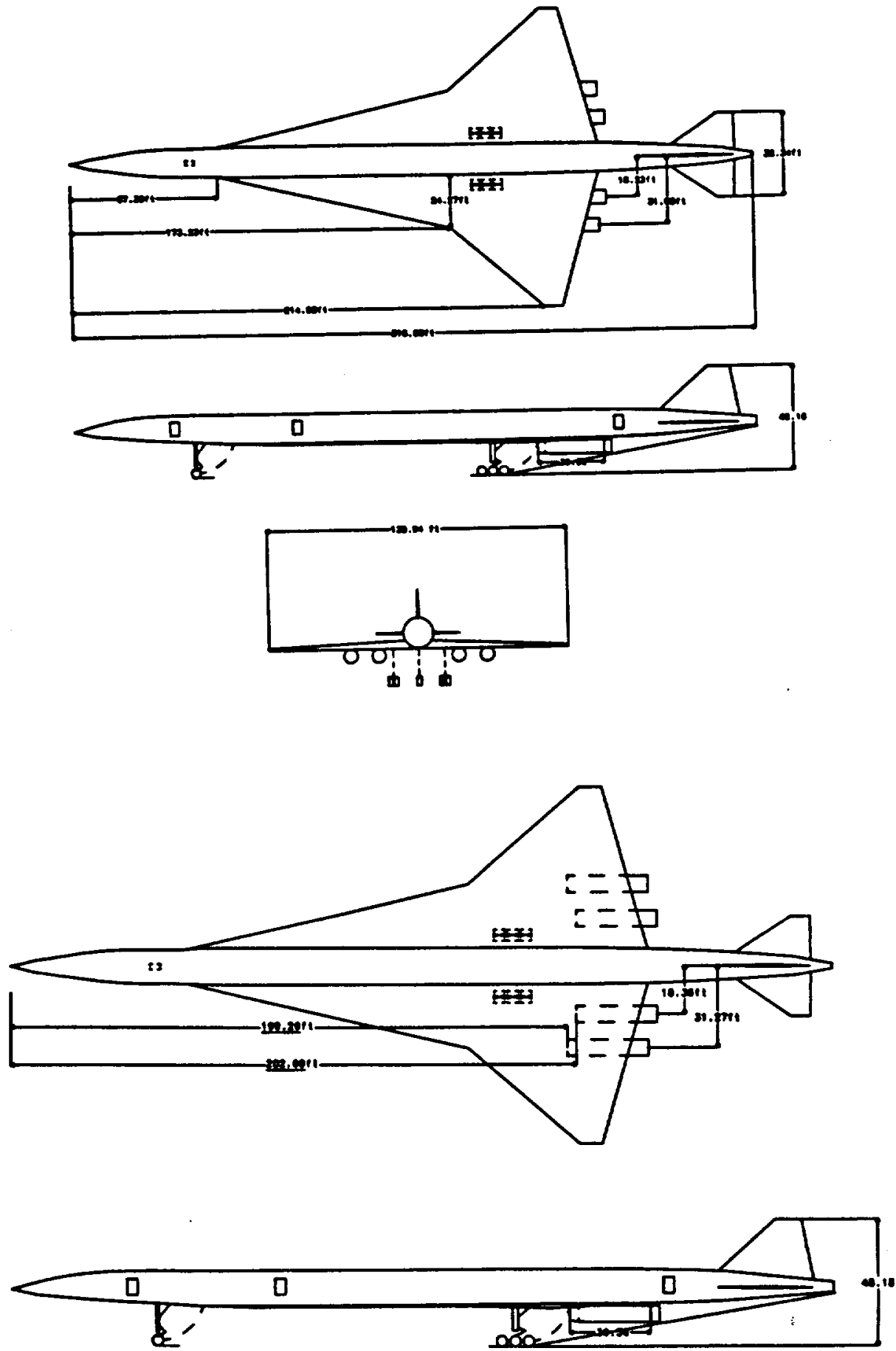
Figure 7.4.12 Illustration of FAR Noise Measurement Locations 8

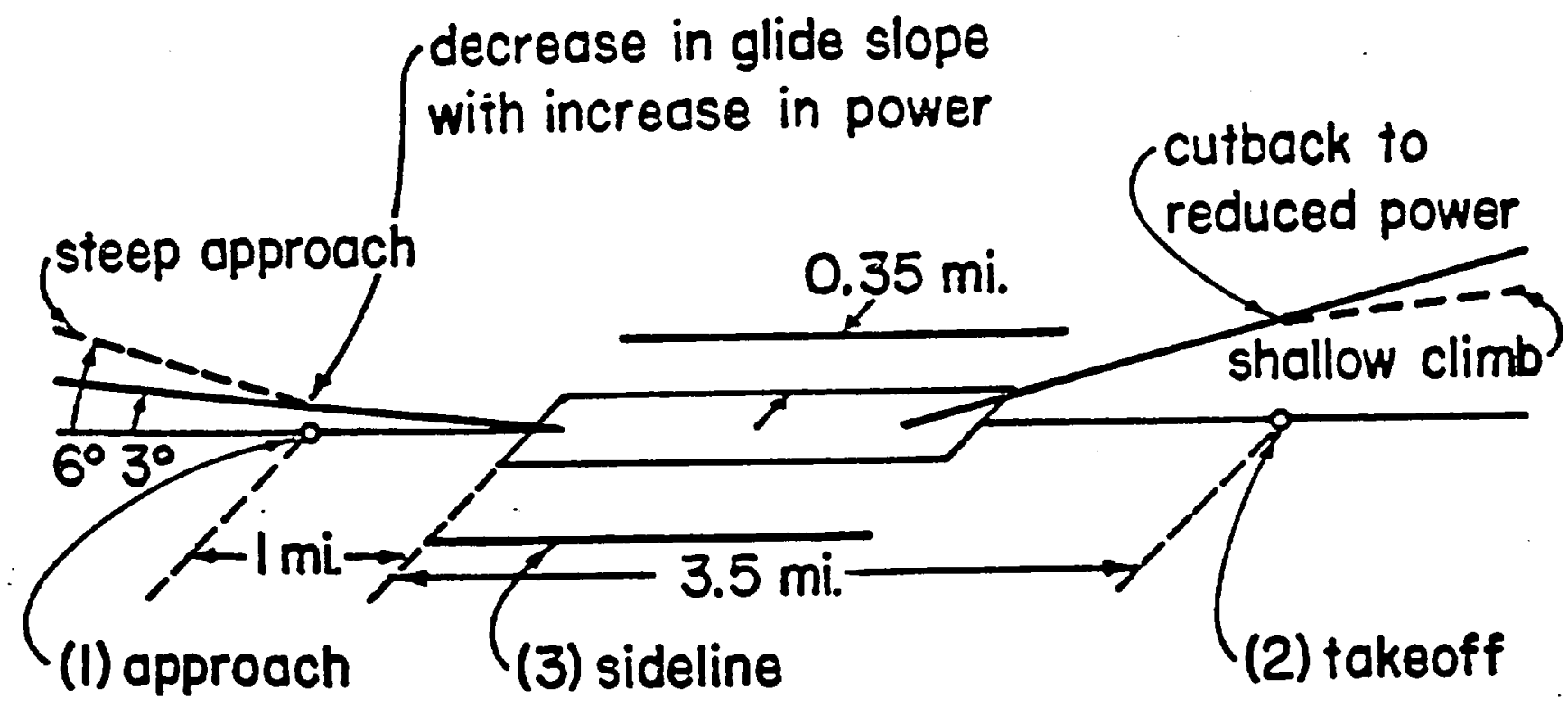




\section{Engine Inlet Design}

The purpose of engine inlets or diffusers is to reduce the velocity of intake air without significant losses in total pressure. The inlets for the HSCT must be designed to provide satisfactory diffusion through all flight regimes, and excellent performance at supersonic cruise. A variety of inlets were available for analysis. The three major categories of inlets are external compression, internal compression, and mixed compression. The primary difference between them is the location of the shocks utilized for diffusion, as implied by the names. Figure 7.4.15 presents the general operating performance of each type of inlet. From this it can be seen that mixed-compression inlets exhibit the best performance at the Mach 2.4 cruise of the HSCT.

For the HSCT, a convergent-divergent, variable geometry, axisymmetric, mixedcompression inlet was chosen. This inlet is depicted in Figure 7.4.16. An axisymmetric engine was chosen over a two-dimensional design for several reasons. For the proposed nacelle configuration, an axisymmetric inlet represents easier integration. Flow properties are also more uniform for the axisymmetric inlet. In addition, variation of nozzle geometry can be accomplished through internal spike translation instead of an internal lip. The variable geometry inlet allows for tailoring of the throat and inlet geometries to match the flight regime. Though variable geometry does not allow optimal performance through all regimes, it does provide performance improvement.

\section{Engine Inlet Operation}

The inboard and outboard inlets for the HSCT will be offset from the wing approximately 16 inches and 7 inches respectively to allow for diversion of the wing boundary layer. This reduces the amount of low energy air ingested by the engine. Porous boundary layer bleed and suction will be used to control separation and losses within the inlet. The inlet geometry will be varied by translation of an inlet spike (See Figure 7.4.16a). During takeoff, Figure 7.4.16c depicts operation of the inlet in a choked configuration. This reduces propagation of compressor noise out of the engine.

Mixed-compression inlets are subject to the phenomena of start and unstart. An engine is "started" at supersonic speeds by ingesting the inlet shock. Figure 7.4.16b illustrates how the engine will be started by opening spillage doors in the inlet. If the engine is not started, poor diffusion performance results. Unstart results when a perturbation such as a gust causes the throat shock to move forward out of the inlet. This results in increased inlet pressures, reduced mass flows, and significant thrust reduction. This effect can also be conveyed to the adjacent engine, leading to dual unstart and potentially hazardous control problems. The stagger of the HSCT engine inlets makes this an even greater concern. Figure 7.4.17 indicates that the configuration is close to the unstart unstable area. Therefore, an interference gate will be introduced between the 
Figure 7.4.13 Inlet Diffusion Efficiency with Respect to Mach Number 10

INLET/ENGINE INTEGRATION

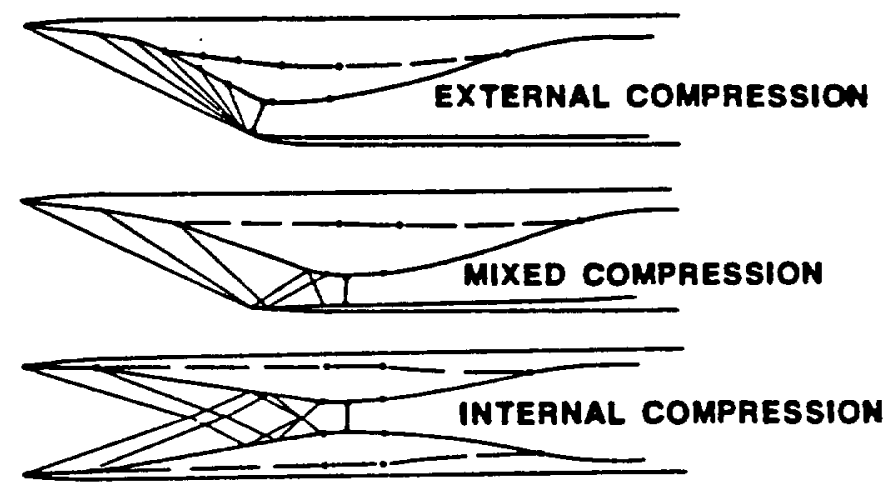

Fig.74.13 Comparison of supersonic inlet diffuser types.

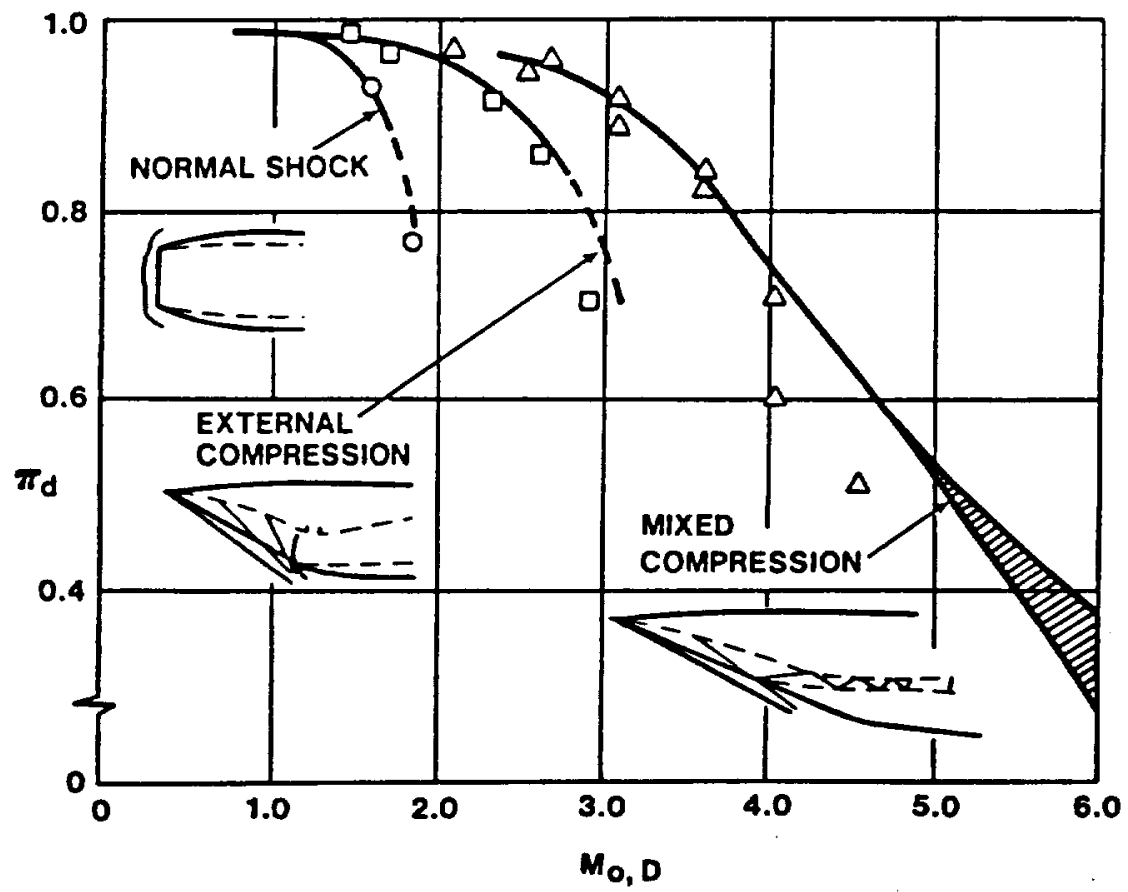


Figure 7.4.14 Mixed Compression Inlet Operation 8

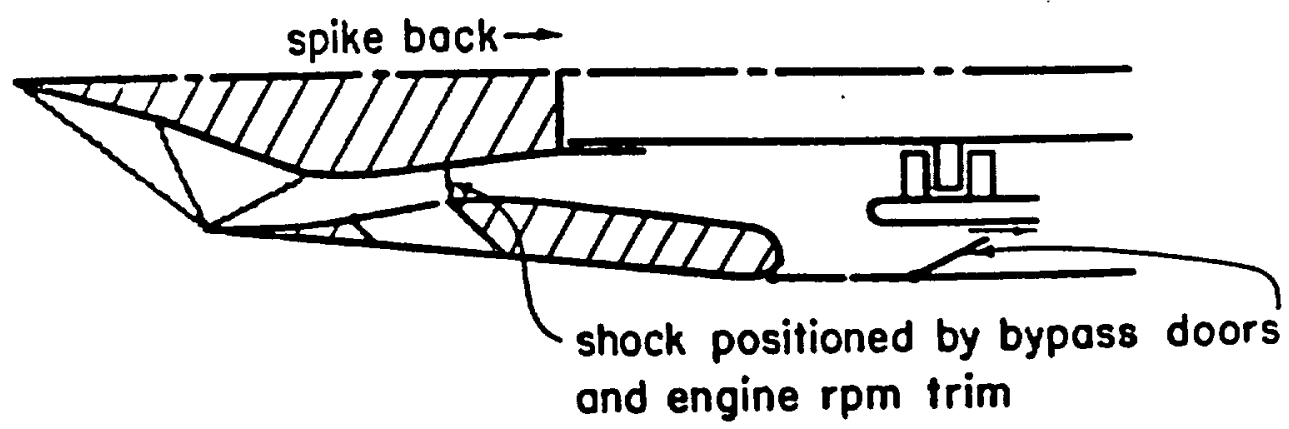

o) $M_{0}=2.7$ cruise

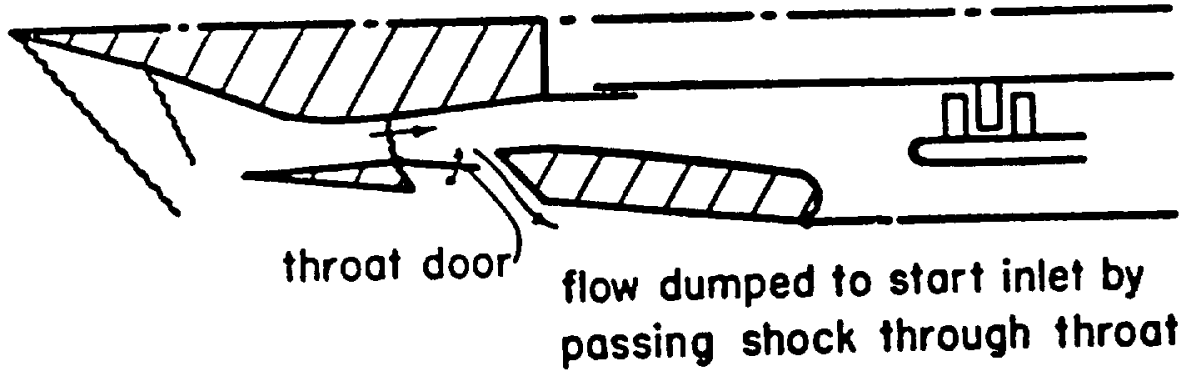

b) Inlet "stort"

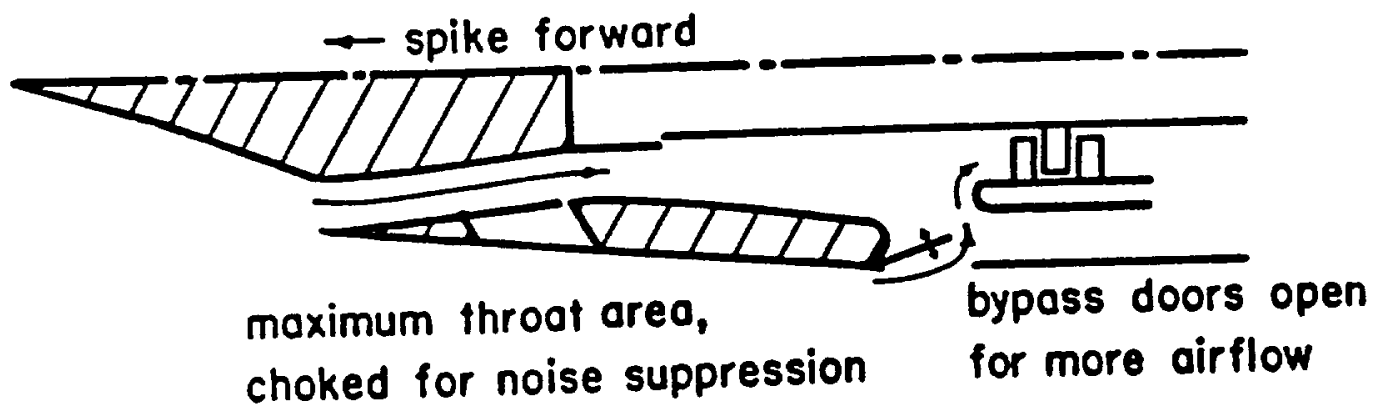

c) Takeoff 
inlets at a mild weight penalty. The proposed variable geometry inlet also provides increased unstart stability by positioning the shock just aft of the inlet throat during flight.

Another concern is Foreign Object Ingestion. Vortexes created by the inlet tend to cause debris such as dirt and pebbles to be ingested during takeoff. To help control this, a blower will be installed on each inlet to break up these vortexes.

A focus for future research will be aimed at the controls for the variable geometry spike. Two prime concerns need to be addressed. The first is the control system itself. It must be robust and accurate enough to deal almost instantaneously to engine flow perturbations. The other concern will be the increased weight of a variable geometry inlet. Present technology has developed viable inlets, however future materials and controls research can reduce both the size and the weight of the actuators, controls, and components. Research must also be aimed at proper integration of the inlet controls, including the placement of flow measuring devices.

\section{Engine Nozzle Design}

The purpose of the nozzle is to efficiently expand exhaust gases to aircraft velocity. The engine nozzle is the single most important component in optimal engine matching and performance. A variety of nozzle types are available for supersonic engines. These include axisymmetric, twodimensional, plug, and ejector nozzles, among others. The proposed nozzle for the HSCT is an axisymmetric, variable geometry, ejector-suppressor, multiple-nozzle concept. The reasons for proposing this configuration are analogous to those for choosing the inlet. In addition, the ejectorsuppressor nozzle represents the cutting edge of research in jet noise suppression.

The ejector-suppressor nozzle utilizes three mechanisms in the reduction of jet noise. The walls of such a nozzle are lined with material that is used to acoustically damp jet noise. The walls are configured with a liner of porous materials and cavities that act as a Helmholtz transmitter for noise. In addition, instead of one nozzle, the core flow is expanded by a number of smaller nozzles as depicted in Figure 7.4.18. Studies have shown that this configuration effectively reduces jet noise. The ejector-suppressor nozzle also utilizes bypass air to reduce noise. Because jet noise is a function of exhaust velocity, the ejector nozzle reintroduces flow bypassed around the combustor to reduce exhaust velocity. Because of the additional mass flow, this can be done without substantial thrust penalties. Preliminary indications are that this nozzle configuration will reduce noise by as much as 20 EPNdB before 1997 .

\section{Engine Nozzle and Thrust Reverser Operation}

Figure 7.4.19 illustrates the operation of the nozzle. At takeoff, the bypass doors are opened to allow for reduced exhaust velocity and noise. At other operating conditions, the bypass air can either be dumped or used to "fill" the nozzle and reduce flow separation along the walls. 
Eigure 7.4.15 Stable Operating Location of Aft Inlet 1

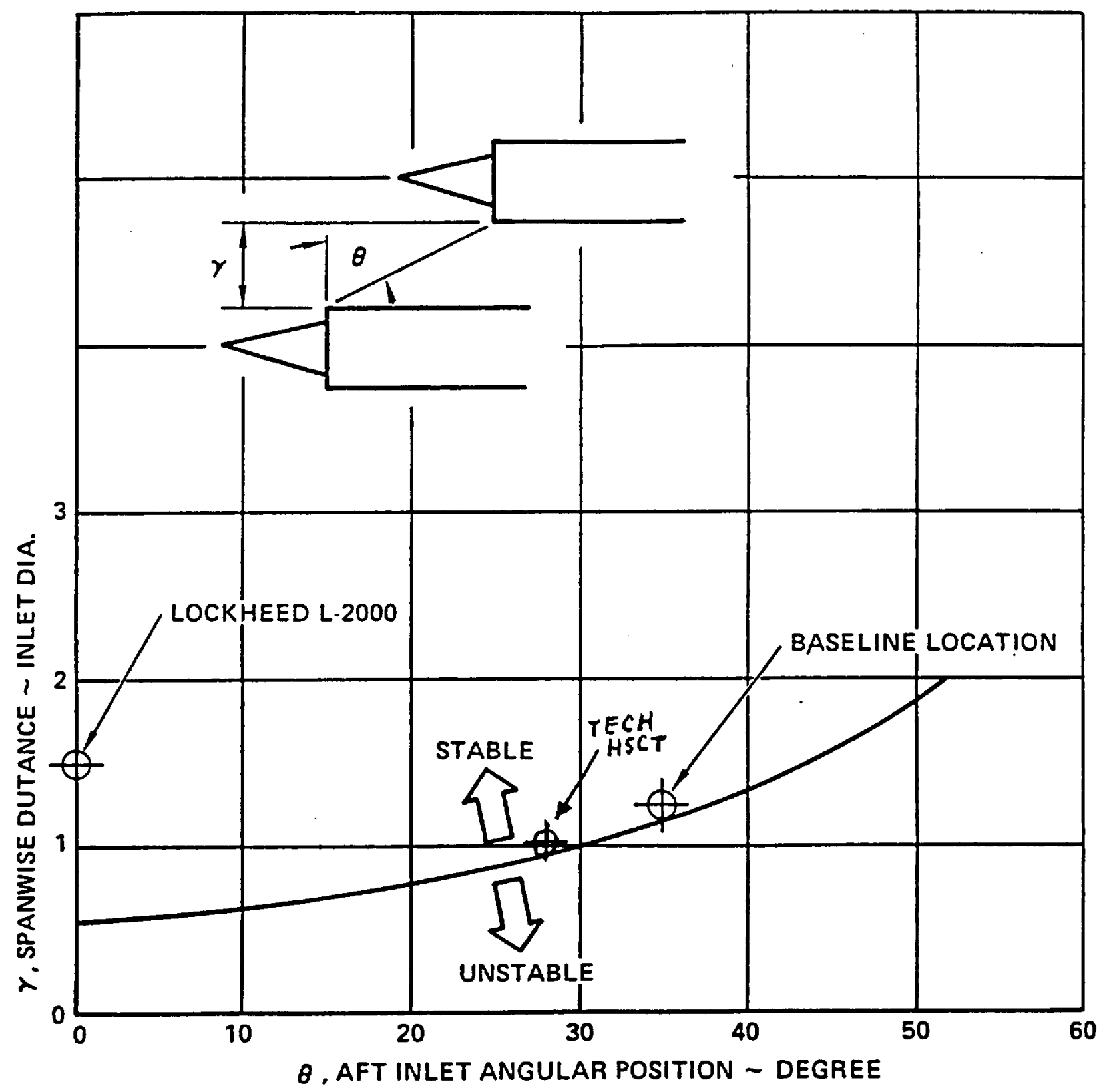


Eigure 7.4.16 Illustration of Multiple Nozzle Concept 2

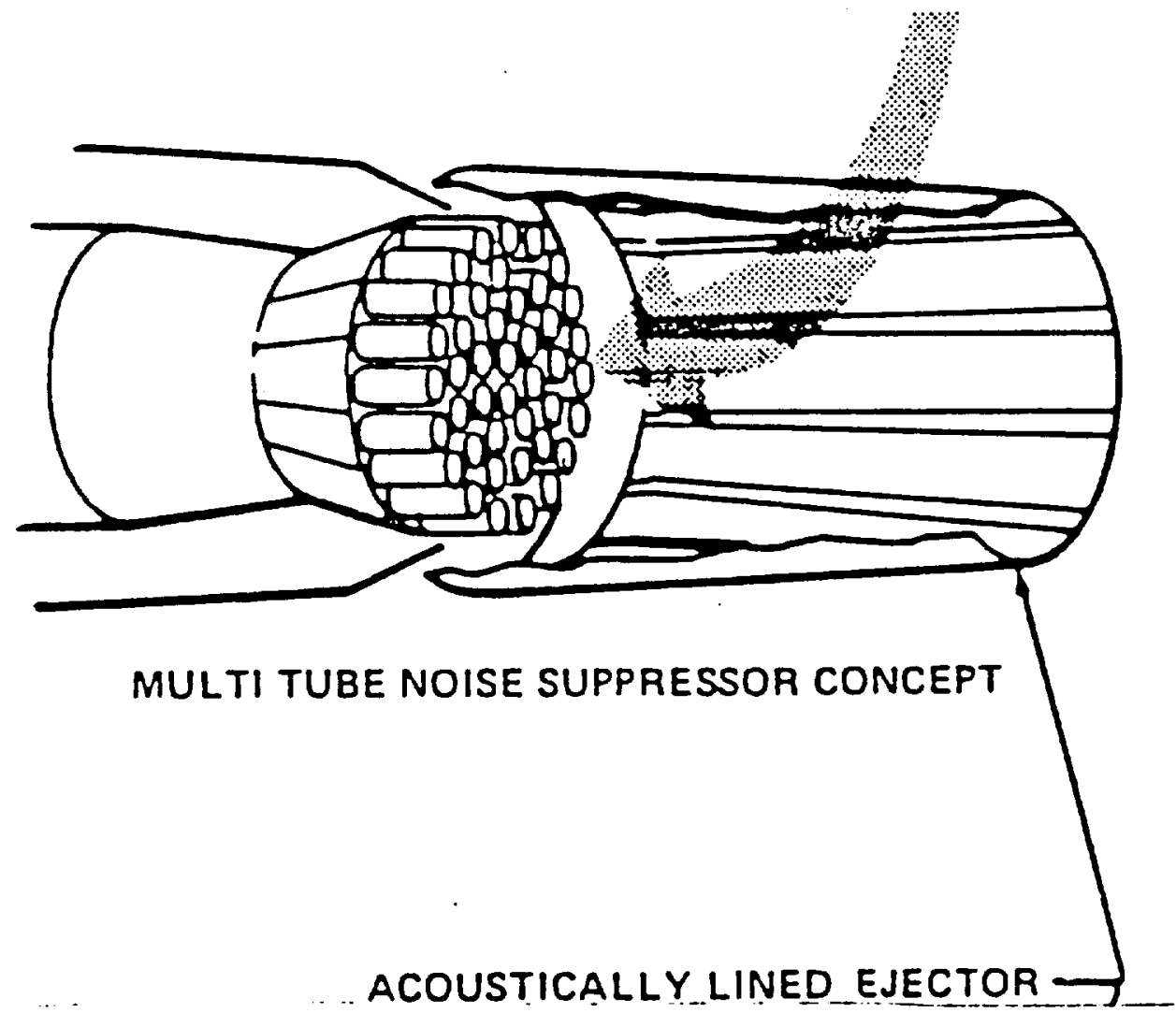


Figure 7.4.17 Ejector-Suppressor Nozzle Noise Suppression Trends 2

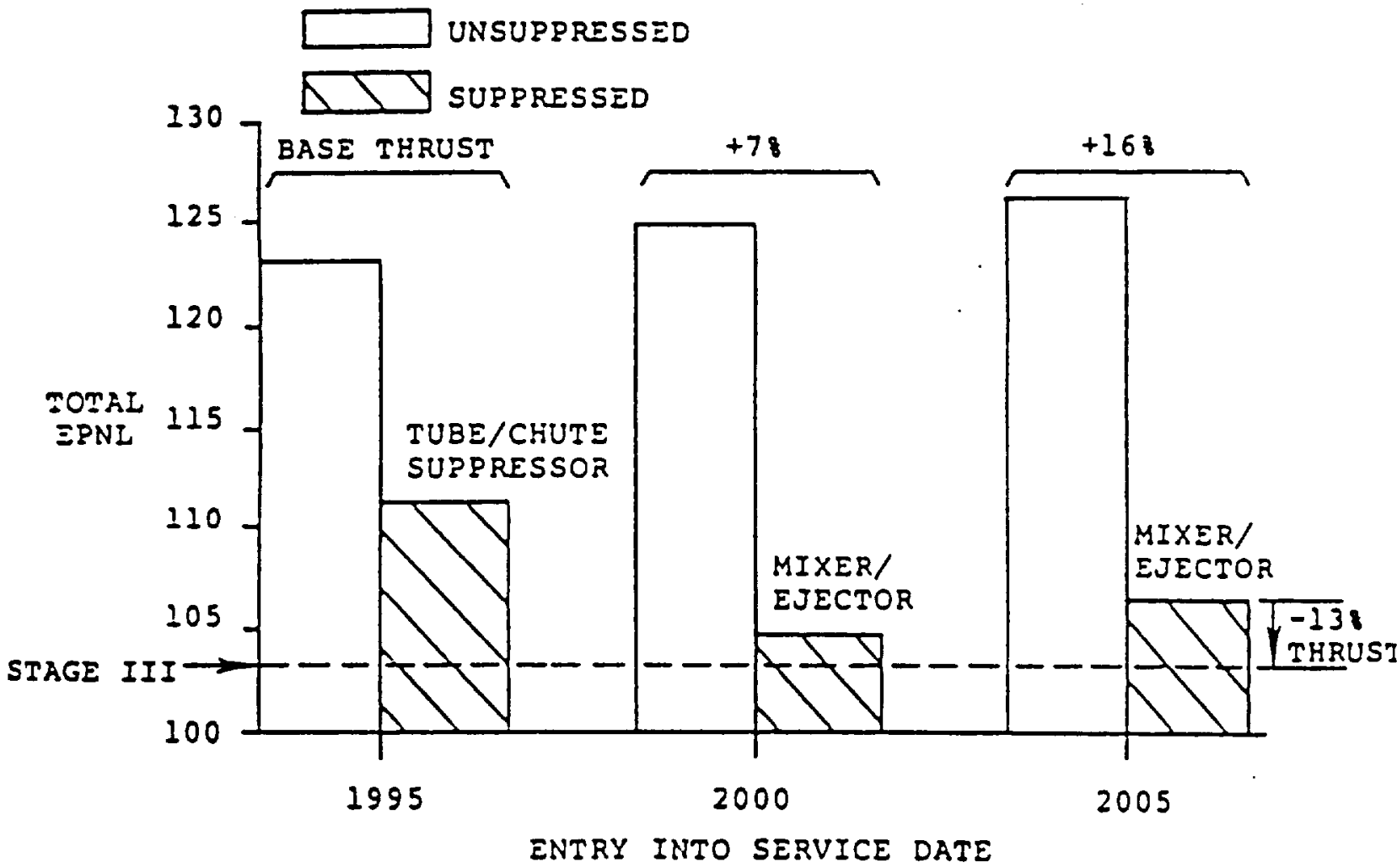


Figure 7.4.18 Ejector-Suppressor Nozzle Operation ${ }^{2}$

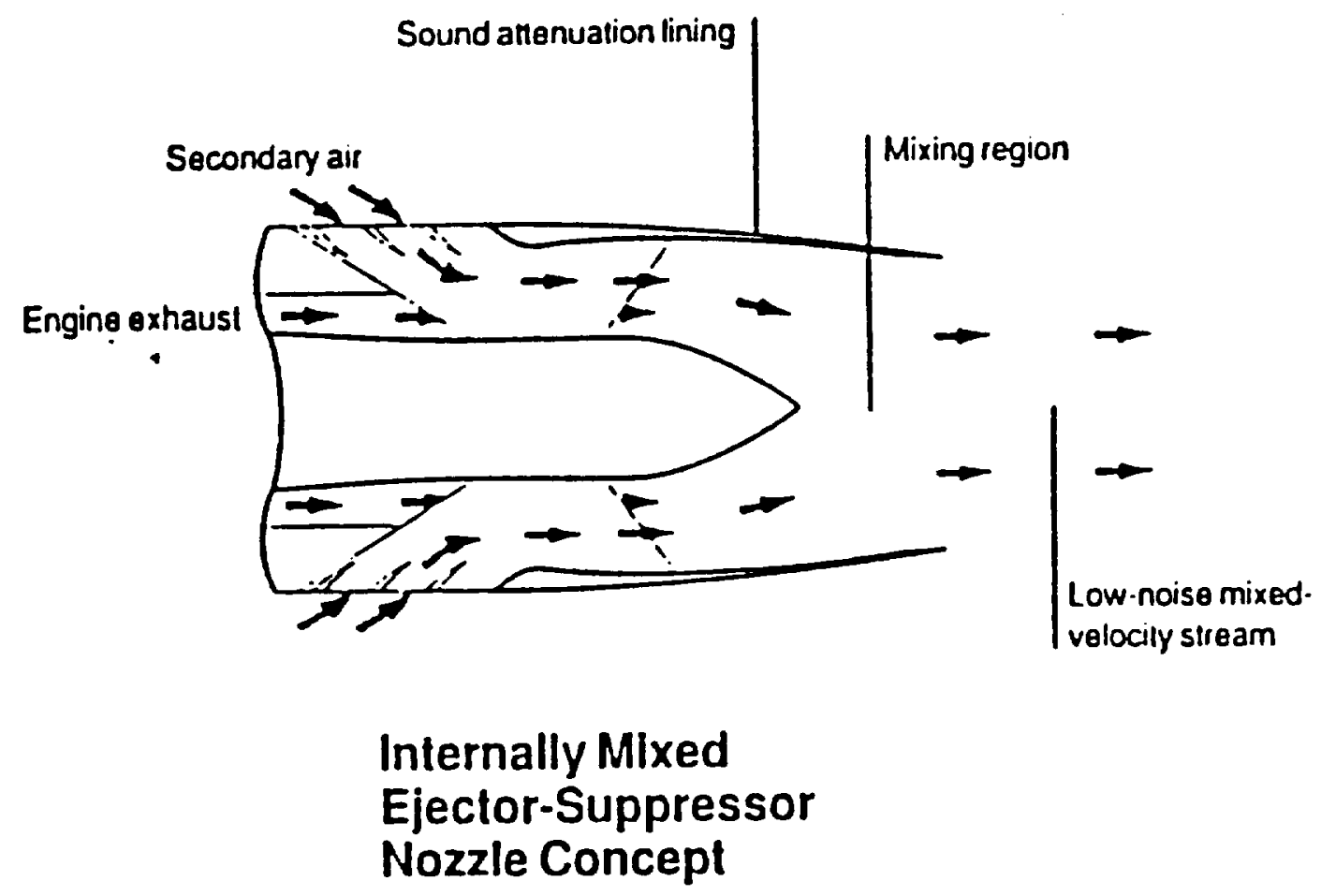


Variation of nozzle geometry is provided by a translating spike. The geometry variation is used to improve expansion performance through all flight regimes. Research similar to that recommended for the inlet must be done on the nozzle controls and materials. The ejector-suppressor nozzle is significantly longer than conventional nozzle configurations. Therefore reduction in nozzle material weight will be a prime focus. Temperature effects on nozzle materials will also be a major concern.

\section{Thrust Reversers}

Thrust reversers for the HSCT must meet FAR requirements (See Table 2). For the HSCT, conventional cascade thrust reversers will be utilized. The thrust reversers will be located on either side of the engines. During deceleration after landing, the cascades are introduced into the nozzle flow to reverse the flow direction. A major concern is the reingestion of hot, caustic exhaust gases which can be detrimental to engine components. This is impacted by wing geometry, air flow, thrust reverser design, etc. and therefore will not be studied until the aircraft design is more fully defined.

\subsubsection{First Iteration Engine Configuration}

The initial configuration has the engines located at $27 \%$ and $46 \%$ span. The nacelle inlet will be located 202.60 feet from the nose for the inboard engine and 199.26 feet for the outboard engine. The engines will be towed in approximately two degrees to better ingest underwing airflow. The nozzles will be tilted down four degrees to provide additional lift for the aircraft.

Initial research indicates that the engine and nacelle can both be mounted directly to the wing. Because of the aft positioning of the engines however, they may be semi-nacelle mounted. This involves a semi-load carrying nacelle and requires an increase in nacelle structural weight. FAR requirements concerning fire zones and blade throw (See Table 2) will require further nacelle structure augmentation around the engine power section. The exact mounting method of the engines will be a focus for further research.

Engine accessories will be mounted over the engine and in the wing. Under engine mounting requires increased nacelle area and volume in the air flow and thus increased drag. The exact location of engine accessories such as fuel and oil lines, pumps, etc. must meet FAR requirements (See Table 2). Fire zone, drainage, and bypass requirements must be met. Components will be accessed by a series of access doors in the wing and nacelle. Interchangeabilty of parts between engines will be emphasized. The choice and location of accessories and their access will be defined in future iterations as the aircraft structure and requirements are further developed. 


\subsubsection{Preliminary Engine Materials}

The initial choice of material for the nacelle in general is Titanium, as recommended by the materials group. Material selection for the detailed nacelle design will require further research. Nacelles are exposed to jet fuel, hydraulic oils, anti-icing, and other corrosive agents. Exposure to these substances degrades metal performance, therefore the PI group has done some preliminary investigation into the utilization of composites. A potential candidate for the nacelle structure is carbon fiber impregnated with a polyimide resin. For additional strength, sheets of this material would be bonded over an aluminum honeycomb core. For those areas that must be fireproofed, the core can be filled with a polyimide foam. Fireproof composite cover sheets are also being developed and qualified at this time. For panels and fairings, glass reinforced nylon and epoxy may be used.

Nacelles may also be used for noise attenuation. Preliminary testing shows that the use of composites attenuates over a broader frequency range than just metal. A proposed acoustical liner is presented in Figure 7.4.20. It consists of a porous woven wire mesh outer skin bonded to an aluminum perforated facing skin. This is bonded to honeycomb core and then closed with an aluminum alloy backing skin. A double layer of this assembly may prove to have better attenuation characteristics. More research in the nacelle noise attenuation area is necessary. 
Eigure 74.19 Composite Acoustical Noise Attenuator 7

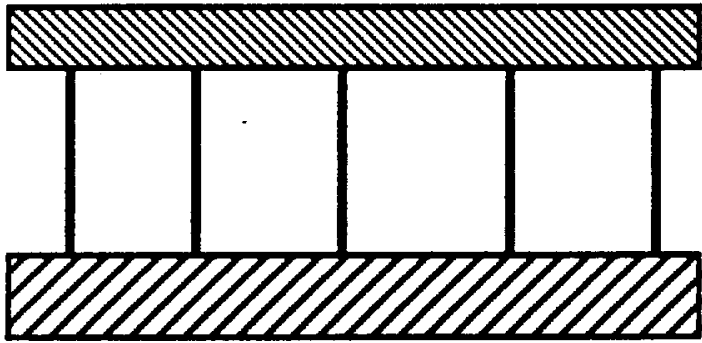

Single Laver Acoustic Liner

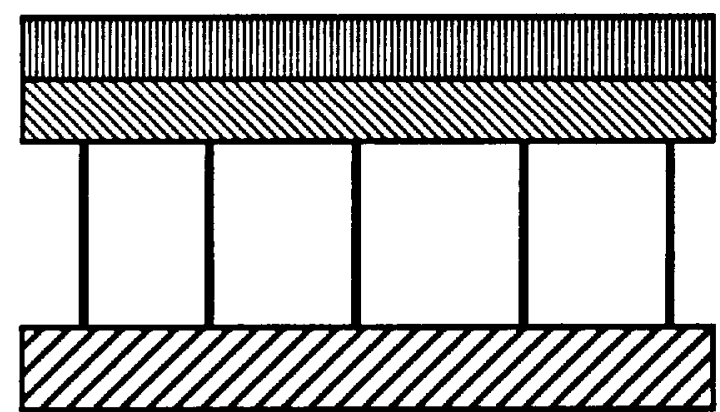

woven wire cloth perforated face sheet

honeycomb core

backing skin

\section{Single Layer Lower Acoustic Liner}

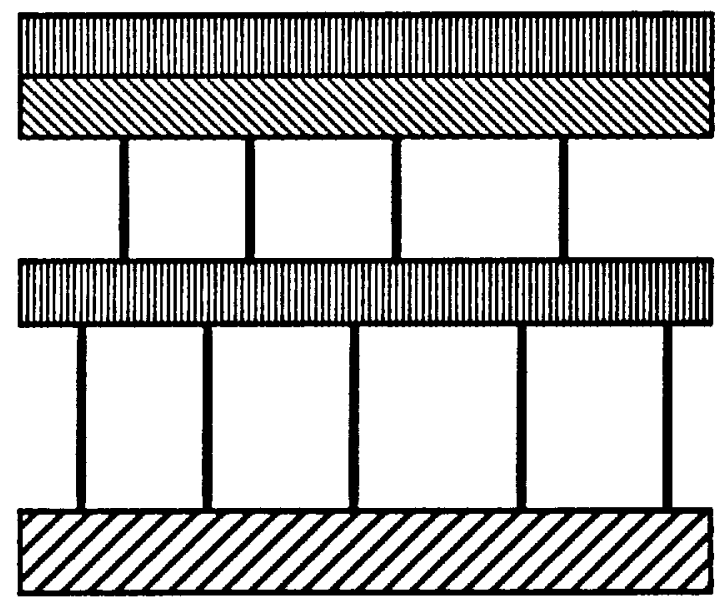

woven wire cloth

perforated face sheet

honeycomb core

woven wire cloth

honeycomb core

backing skin

\section{Double Laver Lower Acoustic Liner}




\subsubsection{Conclusions}

This study has utilized Concurrent Engineering as a method in the integration of the engines for the HSCT. Time constraints have allowed only one iteration of the proposed configuration. This is due to the fact that propulsion integration relies directly on several other disciplines that have on-going research. Therefore, PI iteration times are directly influenced by the exchange of data from other disciplines. This is the way of Concurrent Engineering and helps insure that research time is not wasted on options that are not feasible or efficient.

The process of $\mathrm{CE}$ in this study has led to results that compare well with research being done elsewhere. CE methods have also helped to point out concerns and research areas that other studies may have overlooked or felt were not important. This is due to the fact that our research path was focused before initiation of the study. This was done by utilizing the QFD matrix in conjunction with $\mathrm{CE}$. The technical analysis of engine location, inlets, nozzles, and noise were identified as most important in this phase of the design. The research was then tailored to weight these heaviest in the optimization process.

In each section, the PI group has tried to point out areas where further studies utilizing the CE method can prove to be rewarding. The primary focus of continued propulsion integration research should be on noise reduction techniques. Lack of advances in this area can severely hamper HSCT development. In addition to the on-going nozzle, inlet, and materials studies, research into engine noise "masking" seems promising. Another prime research candidate may be the twin podded engine concept. The benefits of such a configuration warrant its continued analysis. Finally, the PI team feels that continued iterations of the wing design, utilizing CE techniques, will lead to a robust, quality design that meets the needs of the customer.

\section{References}

1. Smyth, S. J., Propulsion Section of Arrow Wing Supersonic Structural Design Concepts Evaluation, NASA CR-132575, 1977.

2. Byrd, Brian K., "Optimization of the High Speed Civil Transport Propulsion System: A Study Utilizing the FLight OPtimization System," March 12, 1993.

3. Ganley, G. A., "Concorde Development. Powerplant Installation and Associated Systems," SAE Technical Paper Series 912180, 1991.

4. Kulfan, Robert M., "Application of Favorable Aerodynamic Interference to Supersonic Airplane Design," SAE Technical Paper Series 901988, 1990.

5. Luttgeharm, Clint, "Selecting Materials for Complex Aircraft Structures," vol. 11 Aerospace Engineering, April, 1991. 
7. McGaral, W. and K. Campbell, "Development of Composite Materials Applications to Production Nacelle Component Structures," SAE Technical Paper Series 902017, 1990.

8. Kerrebrock, Jack L., Aircraft Engines and Gas Turbines, The MIT Press, 1977.

9. McCloy, R.W., The Fundamentals of Supersonic Propulsion, The Boeing Company, 1967.

10. Oates, Gordon C., Aircraft Propulsion Systems Technology and Design, American Institute of Aeronautics and Astronautics, 1989. 


\subsection{Vibration and Flutter}

\subsubsection{Technology Studies}

Aeroelastic considerations play a very important role in achieving weight targets for the primary structure. A recent study by Boeing suggests that aeroelastic effects can determine the viability of the overall HSCT configuration. The impact of aeroelasticity on the United States earlier SST concept has been described by the Director of Engineering Technology for the SST program, "..For the first time, a fully integrated aeroelastic analysis of an SST configuration was executed in sufficient depth to obtain realistic structural sizing needed to support releases to manufacturing. ...Aeroelastic deflections under limit load were found to cause changes in pitching moment of the same order as the rigid data itself. Hence, it proved necessary to account for the complete impact of all significant inputs to the aeroelastic analysis, including hydraulic fluid elasticity, before proper fixed and movable surface sizing could be made. The ineptness in the existing computer systems became evident. There were lengthy turnaround delays for a single cycle of critical data intended to establish whether the configuration aeroelastically converged, due to design changes, within the established criteria. It became apparent after the allotted 9 months for configuration firm-up that even with the addition of a canard (with its attendant weight, complexity and added body stiffness) to achieve reasonable aeroelastic forgiveness, the weight of the final product yielded a non-economic commercial aircraft when compared to the original Boeing SST program goals. With DOT-SST project office concurrence, it was decided to reopen configuration selection process for 1 year under rigid government and Boeing review controls, and to accelerate the ability to cycle given designs and conduct trade studies on configuration alternatives. It was also decided to separate the prototype and production programs to allow the prototype design to proceed with added technical risk to support a better performance objective. This decision was based on a sober understanding of the aeroelastic influences on the ultimate design." [2]

Major configuration design decisions such as placement of the wing on the body, determination of the operational cg range, the location, size, and geometry of the tail surfaces, the type, size, location and power requirements for flight control surfaces, and the type and weight of various structural areas are paced by the engineering efforts involved in aeroelastic analysis. In the US. SST program, the entire aircraft design development process became paced by the aeroelastic design cycle. The entire aeroelastic design cycle was estimated to require from 12 to 24 months depending on the complexity of the airplane configuration, the assigned manpower, test facilities scheduling, and the degree of computerized analysis in each technical discipline.

The results from Boeing's earlier analyses of the SST (B2707-300) concept for vibration and flutter indicate that the spanwise and chordwise location of the engines was mainly dictated by wing-engine pod interference effects, and engine unstart considerations. A nacelle location 
conducive to low drag placed the engine nozzle behind the wing trailing edge. Therefore potentially beneficial dynamic coupling effects from forward engine placement on subsonic airplanes could not be realized. Initial analysis efforts were concerned mainly with the definition of primary structure in the main wing box. As additional detailed information on wing leading and trailing edge structure and engine support beams became available, it was found that these elements had an important effect on flutter characteristics. A half airplane finite-element model (FEM) with 3400 structural nodes, fairly large by the standards of 1970 , was created, and reduced to less than 200 nodes for vibration analysis. Approximately 20 degrees-of-freedom were used for modal flutter analysis. The reduction of the finite-element model for vibration analysis and the use of only $\mathbf{2 0}$ modal degrees-of-freedom for flutter analysis is indicative of the software and hardware limitations of the time.

The B2707-300 structural model was divided into 29 substructures for flutter sensitivity and optimization studies. A structural weight increment of approximately 12,000 lbs over strength requirements was needed to meet the stiffness requirements. It was found that by using a mass balance (wing tip boom) in conjunction with increased stiffness for the inboard and outboard engine beams, the weight increment for flutter clearance could be reduced to about $7000 \mathrm{lbs}$. The $7000 \mathrm{lb}$ weight increment was distributed as follows: $3000 \mathrm{lbs}$ for outboard wing stiffening, 1500 lbs for engine beam stiffening, and $2500 \mathrm{lbs}$ for mass balance weight and boom installation.

Even after the cancellation of the U.S. SST Program, efforts were continued to increase the technological data base already accumulated for a supersonic transport. Two blended body airplanes with titanium skins, a delta-wing and an arrow-wing, were structurally analyzed in some detail. The delta-wing configuration was sized based on nine maneuver and two gust conditions with and without internal pressures, one ultimate pressure condition, and four ground load conditions. Rigid loads for the delta-wing configuration were derived from the wind tunnel pressure data, and the incremental aeroelastic loads were calculated from linear potential flow theory. The arrow-wing configuration was sized based on five maneuver conditions, and the same internal pressure and ground load conditions.

Symmetric flutter analyses were conducted with 20 vibration modes for each configuration for a single combination of configuration and flight condition. The single flight condition selected was a Mach 0.9, forward cg condition. Flutter clearance was required to a design dive speed of $420 \mathrm{KEAS}$ with a flutter suppression control system providing clearance beyond the dive speed. A flutter weight increment of almost 39,000 lbs was required to clear the dive speed for the deltawing configuration. About half of the weight added is due to an increase in the spar cap area padup necessary for chordwise splice joints with increased skin gages. The flutter weight increment for the arrow-wing configuration was about 13,000 lbs. A stiffness design satisfactory for all weight conditions was not determined due to limited resources. An interesting aspect of stiffness 
design for the arrow-wing configuration is flutter sensitivity to stiffness increase at the wing tip. The increase in stiffness necessary to meet the flutter speed requirement is more than offset by the increased weight suggesting an opportunity for synthesis of aerodynamic and structural design, i.e., Concurrent Engineering and Multidisciplinary Design Optimization.

During the mid 1970s, the Lockheed-California Company conducted an Evaluation of Structural Design Concepts for an Arrow-Wing Supersonic Cruise Aircraft [5] and found that a significant mass penalty was paid in the wing tip to meet the flutter speed requirements. Several approaches were considered. The principal approach was to provide additional stiffening to the wing tip over and above that provided for strength design. This stiffening was provided primarily by increasing the thickness of the surface structure in the wing tip region, and resulted in a significant mass penalty. An alternate approach to improving the aeroelastic behavior of the wing tip, thereby reducing the mass penalty, was to increase the depth of the wing tip structural box-with due consideration to the associated aerodynamic performance degradation due to increased wave drag. However, results from analysis showed that if the baseline use of titanium for the wing tip structure was retained, an increase in wing tip thickness afforded no significant benefits since the wave drag penalties offset the savings resulting from the reduced surface panel thickness. Therefore, another approach to improving the aeroelastic behavior was to change the structural material. It was found that the most significant improvement in performance was achieved with the application of boron-aluminum composite material on the unmodified baseline wing tip. It is apparent that advanced materials should be considered as structures rather than as materials; hence the increasing use of the term engineered advanced materials. Because advanced materials can be tailored in so many ways to the various requirements of a particular engineering component, the key to optimizing cost and performance is a fully integrated design process capable of balancing all of the relevant design and manufacturing variables. To summarize, the Lockheed-California Company tried three approaches to remedy the structural problem of meeting flutter speed requirements: (1) providing additional stiffening, (2) changing the dimensions of the wing-tip structural box, and (3) changing the structural material.

Lockheed performed vibration analyses with NASTRAN using the Givens Method.[4] The flutter analyses were performed with the Lockheed company system named FAMAS using the "p-k method." The p-k method permits a flutter analysis to be performed which yields a solution of matched Mach number, altitude, and velocity. Starting from the strength-designed structure, the required flutter margin was achieved by use of a method of flutter optimization employing computer graphics. In optimizing for flutter, stiffness and corresponding mass increments were investigated as a means of satisfying the flutter constraint and the minimum mass combination identified. 
The first step of Lockheed's analysis was the development of a structural model. At first, a 2-D and then later, 3-D models were developed to simulate chordwise-stiffened, spanwisestiffened, and monocoque (biaxially stiffened) wings. The concepts had 188 symmetric degreesof-freedom since that was the maximum size that could be run in the Lockheed FAMAS computer system.

For their vibration analyses, the stiffness matrices of each structural arrangement were combined with the appropriate inertia matrices to compute the symmetric and anti-symmetric Eigenvectors and Eigenvalues of the free-free airplane. The inertia matrices were formed for two airplane conditions: Operating Weight Empty (OWE) and Full Fuel and Full Payload (FFFP). These weight conditions represent the extremes of minimum and maximum weight. No intermediate weight conditions were examined in these Lockheed studies.

The steady and unsteady Aerodynamic Influence Coefficients (AICs) were then computed for a large array of Mach numbers. The flutter analysis was then performed using the results from the vibration analysis and aerodynamic formulation. Finally, the flutter optimization was performed which consisted of solving for "an amount" of a particular design variable necessary to achieve the required flutter speed.

As a result of Lockheed's analyses, a hybrid concept was selected as the final structural design configuration based on their vibration and flutter analyses. Their 3-D model wing surface represented a hybrid structural arrangement with the inboard wing having chordwise-stiffened wing panels and the wing tip, outboard of BL 406, was monocoque (biaxially stiffened). Lockheed stated that the most critical symmetric flutter condition occurred at Mach 0.9 at FFFP for the $750,000 \mathrm{lb}$ baseline aircraft.

\subsubsection{Georgia Tech Analyses}

Lockheed's methodology was used as a guide in modeling the vibration and flutter analysis. Though their data is relevant to 1970s technology, the methodology is still valid for our analysis, with a few exceptions. In contrast to Lockheed's utilization of NASTRAN and FAMAS for their vibration and flutter analysis, ASTROS was our tool designated for both the vibration and flutter analysis. Our structural model was developed first using partial output from FLOPS. Six structural concepts were developed (Figure 7.5.1). 


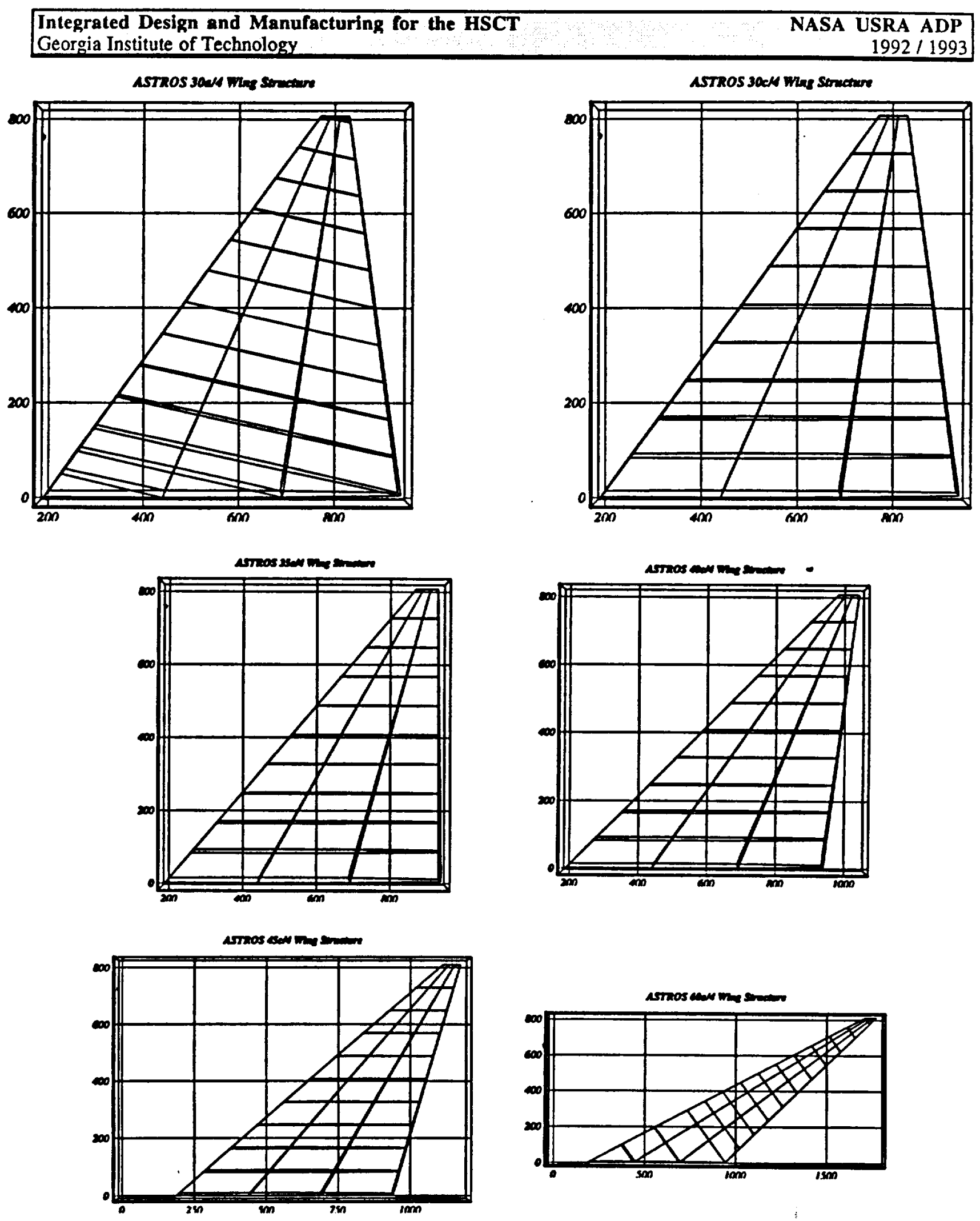

Eigure 7.5.1: Wing Structural Concepts 
The ACSYNT geometry file for our baseline aircraft and the six wing structural concepts were modeled in CATIA. Of these six structural concepts, two were judged to be feasible for our baseline aircraft's wing planform shape. Both have a 30 degree sweep of the wing quarter chord with 4 spars located at $15,35,55$, and 75 percent chord. One concept has the ribs parallel to the fuselage longitudinal axis; the other has the ribs angled with respect to the longitudinal axis. The concept with the ribs parallel was selected for this initial analysis since it has no triangular membrane elements. The 30 degree quarter chord swept concept is shown with our ACSYNT geometry in CATIA in Figure 7.5.2.

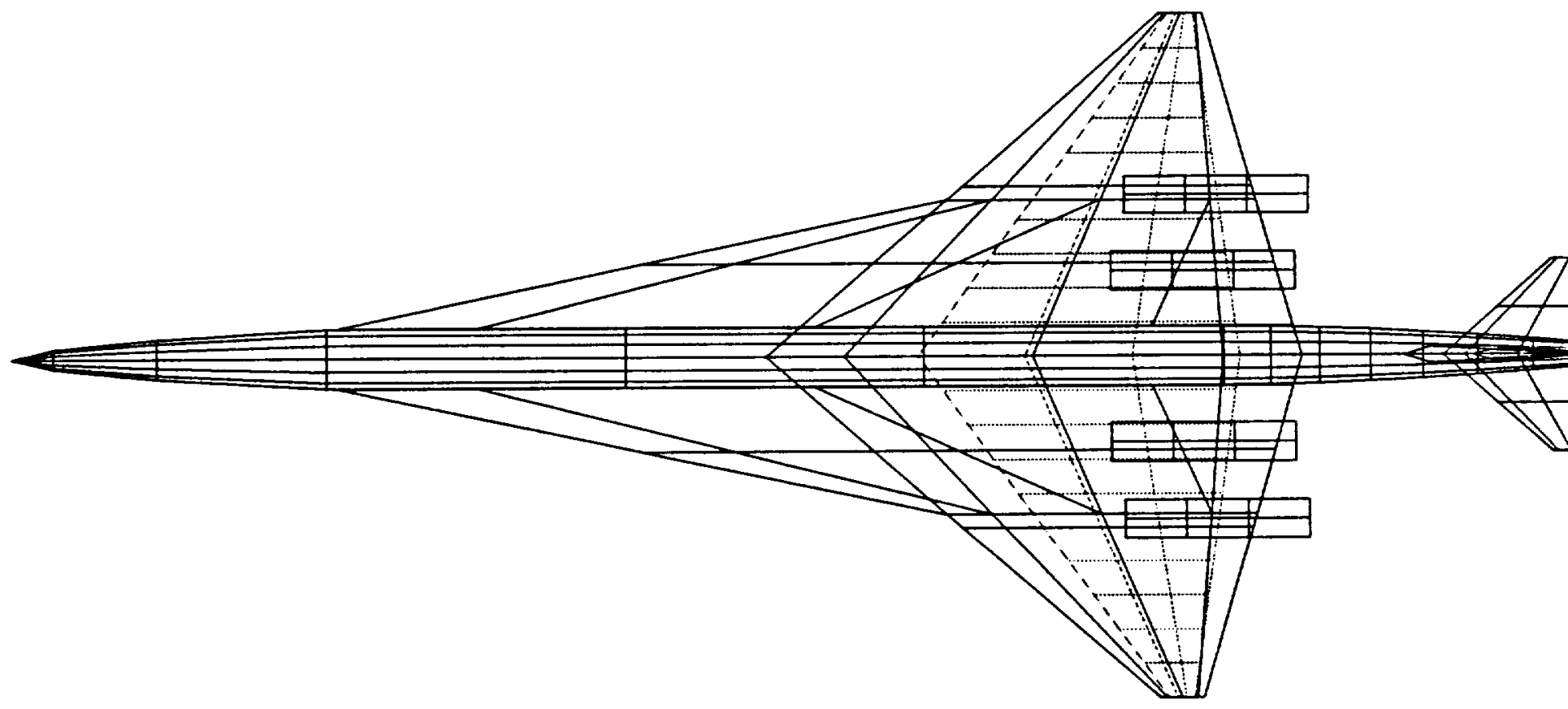

Figure 7.5.2: ACSYNT/ASTROS Concepts in CATIA 
A recent Lockheed / NASA Langley AIAA paper [3] defines two critical [static] load cases for an HSCT within the flight maneuver envelope which generate large wing root bending moments. Both cases are at a load factor of 2.5, which was subsequently used in ASTROS as our static load case. The entire ASTROS wing concept was modeled with a single material, Titanium alloy Ti-6Al-4V.

For the 30 degree swept model with 10 ribs parallel to the longitudinal axis, at a load factor of 2.5 , the basic wing structural weight converged to just under $30,000 \mathrm{lbs}$. Figure 7.5 .3 shows the ASTROS convergence history for half of the wing structure (4 spars, 10 ribs, 88 nodes).

ASTROS Convergence History

Wing Structural Weight

2.5 Load Factor Static Case

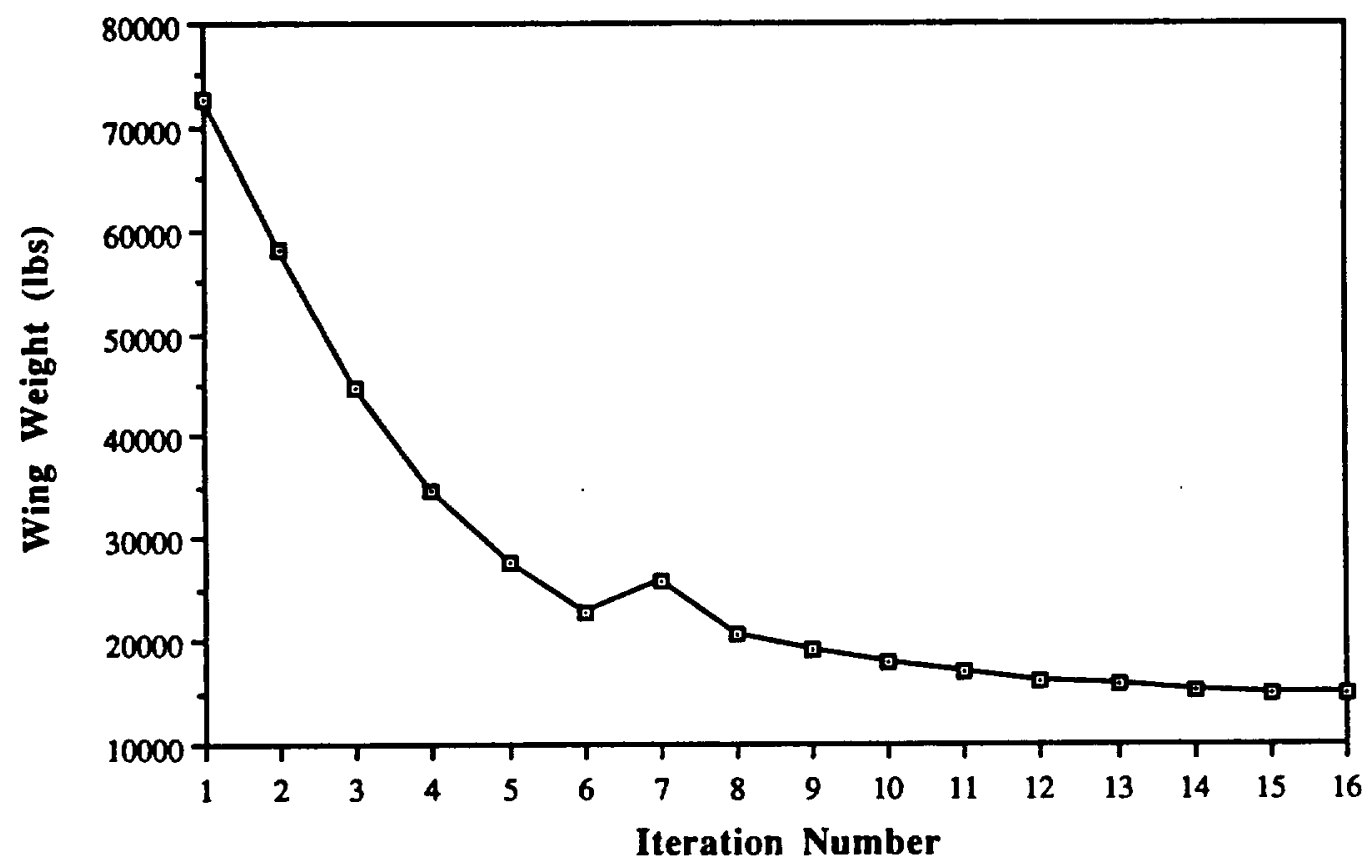

Figure 75.3: ASTROS Convergence History

Assuming a significant increase in wing weight will occur to meet the stiffness requirement, this strength-designed basic wing structural weight appears reasonable.

The first five vibration modes for our converged strength-designed concept were also determined using ASTROS (with a lower frequency constraint of $1.5 \mathrm{~Hz}$ ). The first five modes entailed three bending modes and two torsion modes and are shown in Figure 7.5.4. 

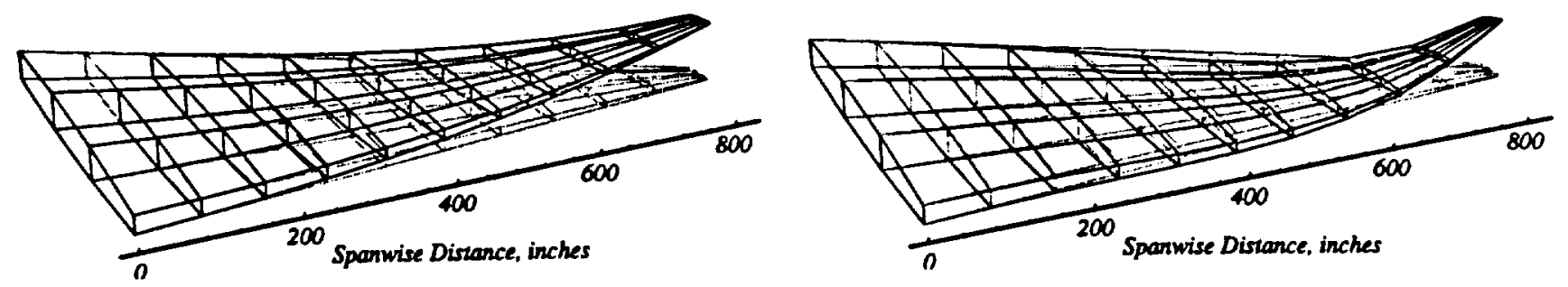

HSCT Wing 3rd Bending Mode

HSCT Wing 1st Torsion Mode

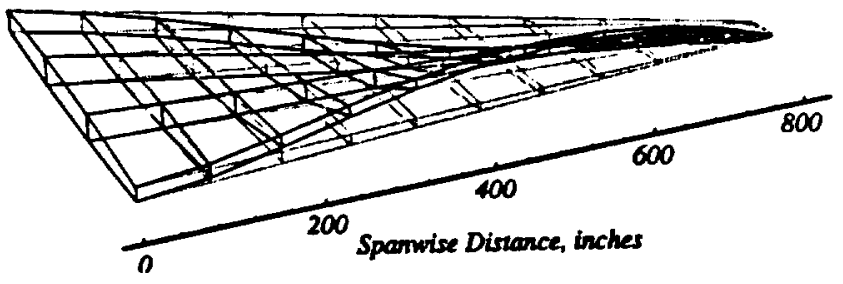

HSCT Wing 2nd Torsion Mode

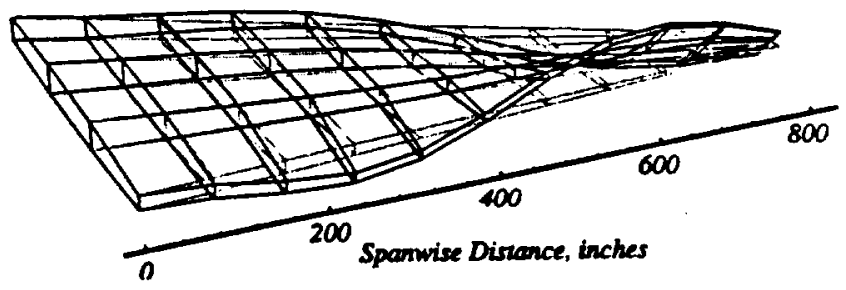

Eigure 7.5.4: First Five Vibration Modes

\subsubsection{Conclusions and Recommendations}

As mentioned earlier, both Lockheed and Boeing stated that the critical condition for flutter analysis was at Mach 0.9. Instead of calculating a flutter speed for our structural concept, and then performing an optimization to add stiffness and/or strength (mass) to the concept, ASTROS permits the flutter speed to be input as a constraint and designs the wing to meet that constraint (in 
addition to other load cases). Hence Mach 0.9 can be input as a flutter speed constraint at a chosen altitude in ASTROS.

The recent Boeing study states that the cycle time for a preliminary design aeroelastic cycle for an HSCT can range from 6 to 12 months with current state-of-the-art technology. The long flow time required for aeroelastic analysis is not consistent with the time available for configuration studies in a preliminary design cycle. Boeing is currently studying new methods to reduce cycle time in preliminary design of an HSCT; much of this reduction is driven by the excessive time required for an aeroelastic analysis cycle.

In agreement with the aforementioned statements, the flutter analysis for our structural concept was not completed. The relevant boundary conditions (both single- and multi-point constraints) and load cases (both static and dynamic) have been determined; however, convergence was not achieved for our flutter analysis.

For future analysis, recommendations (in addition to successfully determining a single converged flutter wing design) include:

- Analyzing the structure at some subcritical load cases, both static and dynamic;

- Analyzing different structural concepts, with ribs in different arrangement;

- Analyzing possible hybrid structural arrangements;

- Analyzing different materials in the structural concepts; and

- Inclusion of engine/nacelle weights and inertial reactions.

- Analyzing an adaptive, flexible wing based on the use of active controls.

\section{References}

[1] Advanced Materials by Design, Summary Report, Congress of the United States, Office of Technology Assessment, OTA-E-352, June, 1988.

[2] Bhatia, Kumar G., and Wertheimer, Jiri, Aeroelastic Challenges for a High Speed Civil Transport, AIAA-93-1478, 34th AIAA/ASME/ASCE/AHS/ASC Structures, Structural Dynamics, and Materials Conference, La Jolla, CA, April 1993.

[3] Dovi, A.R., et al, Multidisciplinary Design Integration System for a Supersonic Transport Aircraft, AIAA-92-4841, 4th AIAA/USAF/NASA/OAI Synopsium on Multidisciplinary Analysis and Optimization, Cleveland, OH, September, 1992.

[4] Messina, A.F., et al, "Vibration and Flutter", Section 10 of Arrow Wing Supersonic Structural Design Concepts Evaluation. NASA CR-132575, 1977.

[5] Sakata, I.F., and Davis, G.W., Evaluation of Structural Design Concepts for an Arrow-Wing Supersonic Cruise Aircraft, NASA CR-2667, May, 1977. 


\subsection{Structural Concepts}

\subsubsection{Structural Concepts and Overall Design Process in HSCT}

In order to develop an economically viable High-Speed Civil Transport, it is essential to design and manufacture a minimum weight aircraft structure that meets customer requirements. The structural design concepts of the wing structure were studied based upon:

1) Previous study developed from the Boeing baseline design

2) Lockheed's previous structural concept studies.

The overall methodology applied for this structural concept study is shown in figure 7.6.1. The methodology requires that the design team consider the effects of every activity of the design and manufacturing of the aircraft including the detailed manufacturing, material processing, tooling, and assembling technologies. This concurrent design method is trying to resolve the conflicts arising from multidisciplinary interactions and constraints from each discipline as early in the design stage as possible.

\subsubsection{Structural Concepts Evaluation Procedure}

The purpose of structural concept evaluation is to analyze various structural concepts applicable to the HSCT design configuration and help to find the optimum (weight and life-cycle cost) structural concept. The concept evaluation procedure is based on the method used by the Lockheed study [2]. 


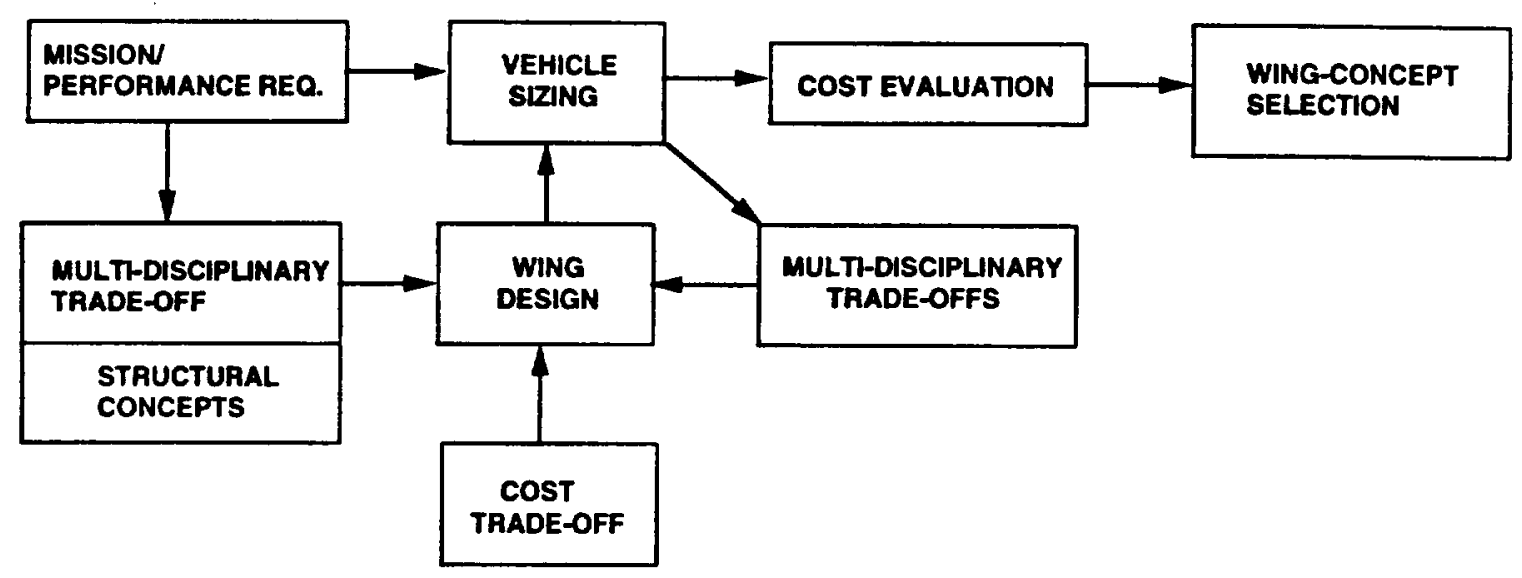

Eigure 7.6.1 Structural Concepts Selection Process

The overall structural concept evaluation procedure is shown in figure 7.6.2. In order to evaluate the structural concepts, the following elements must be considered:

- Baseline Structural Configuration

* Candidate Structural Concepts

* Mission Requirements / Environment

- Structural Design Requirements

- Methods of Evaluation

* Evaluation Guidelines

The preliminary Georgia Tech HSCT configuration was developed from Boeing's baseline configuration. It is shown in figure 7.6.3. Based on this configuration, the size of the wing for 
structural concept evaluation was defined as a finite element model. The candidate materials for structural concept evaluation for the wing structure were selected by the materials group with the following considerations:

* high structural efficiency

* reliability

* low cost

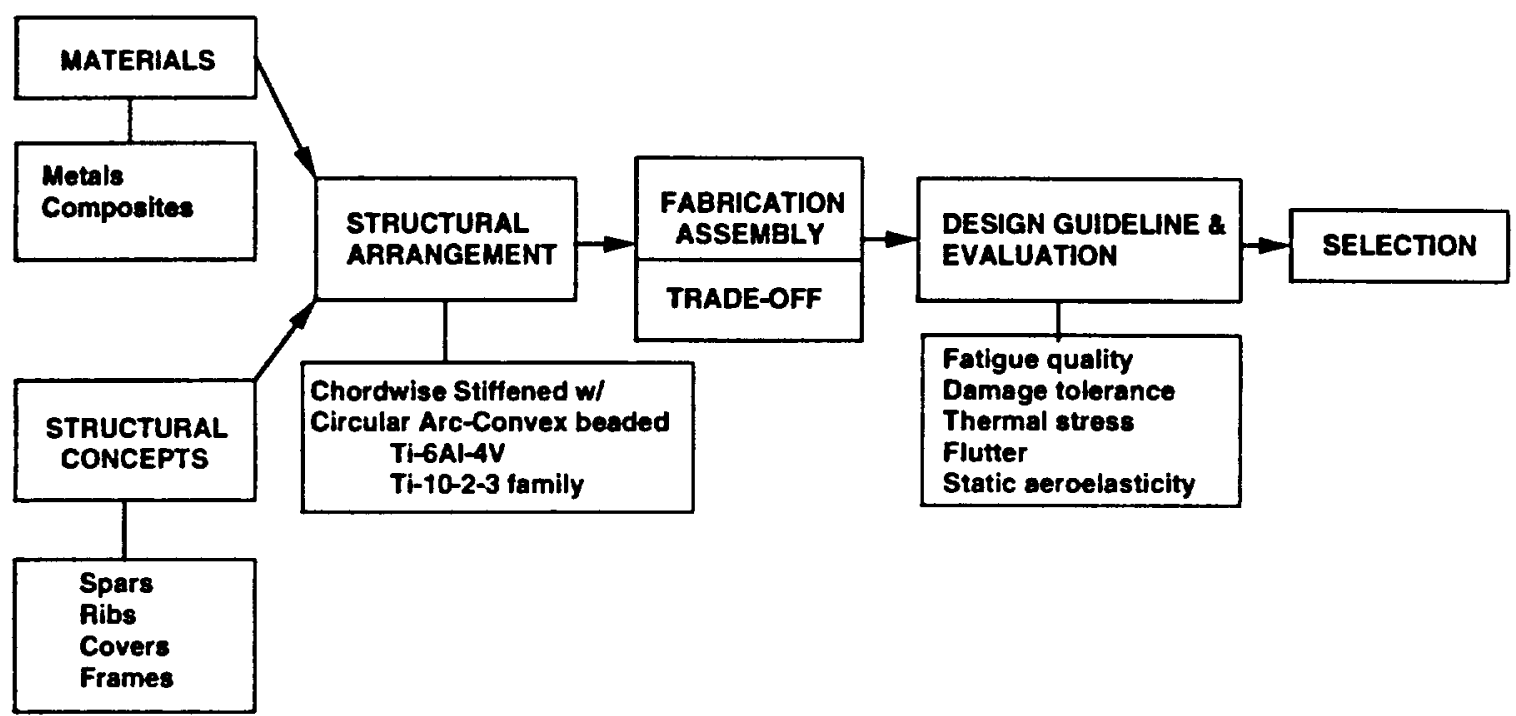

Eigure 7.6.2 Structural Concept Evaluation 
Eigure 7.6.3 HSCT 3-D Wing Structural Model

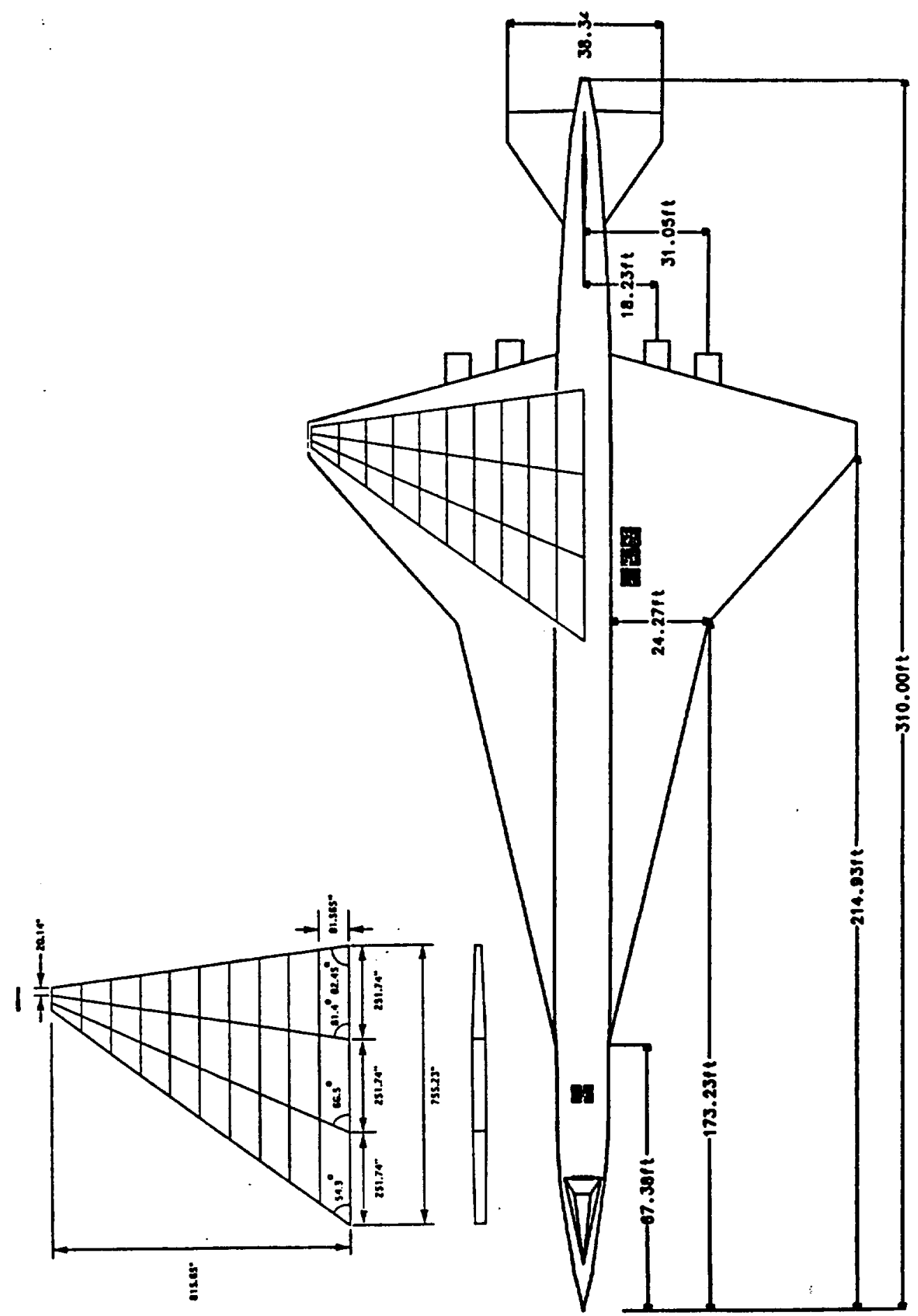


Table 7.6.1 lists the candidate materials.

\begin{tabular}{|c||c|c|c|c|}
\hline Property & Ti-6Al-4V & Ti-10-2-3(1) & Ti-10-2-3 (2) & Ti-10-2-3 (3) \\
\hline $\begin{array}{c}\text { Density } \\
\left(\mathrm{lb} / \text { }^{3}\right)\end{array}$ & 0.163 & 0.168 & 0.168 & 0.168 \\
\hline $\begin{array}{c}\text { Tensile } \\
\text { Strength(KSI) }\end{array}$ & 130 & 180 & 160 & 130 \\
\hline $\mathrm{KI}_{\mathrm{C}}$ (KSI in) & 45 & 40 & 75 & 100 \\
\hline Specific TS & 674 & 1071 & 950 & 797 \\
\hline Specific $\mathrm{KI}_{\mathcal{C}}$ & 10.9 & 9.5 & 17.7 & 23.7 \\
\hline $\begin{array}{c}\text { Poisson's } \\
\text { Ratio }\end{array}$ & 0.29 & 0.3 & 0.3 & 0.3 \\
\hline
\end{tabular}

Specific tensile strength $=$ Tensile Strength $/$ Density

Specific $\mathrm{KI}_{\mathbf{c}}=\mathrm{KI}_{\mathbf{c}} /$ Density

Table 7.6.1 Material Candidates

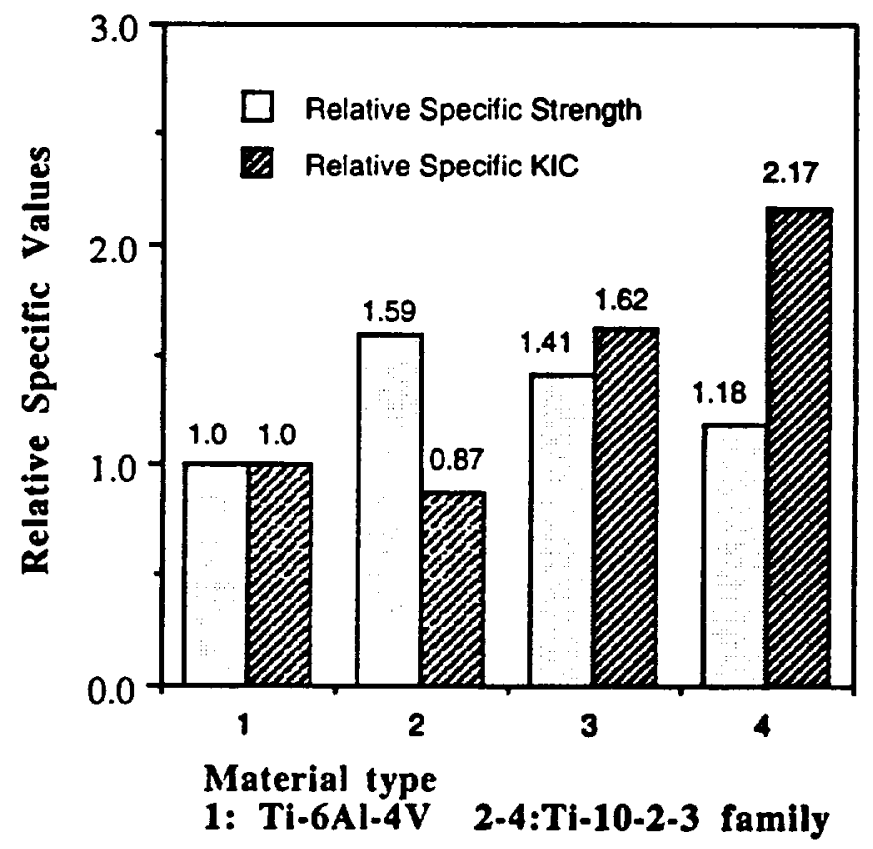

Eigure 7.6.4 Relative Material Properties

In the previous supersonic airplane study by Lockheed [2], an extensive and detailed analysis was carried out on several structural concepts including chordwise-stiffened, spanwise- 
stiffened, and monocoque. The list is shown with associated structural arrangements in figure 7.6.5 [2].

Manufacturability, producibility, and requirement for assembly with other substructures should be considered in structural concept evaluation. These considerations resulted in some specific rules for the shape of each concept. These requirements may change in the future due to the introductions of new materials, new manufacturing techniques, assembly requirements, and tooling techniques. 
Eigure 76.5 Candidate Wing Structural Concepts 2

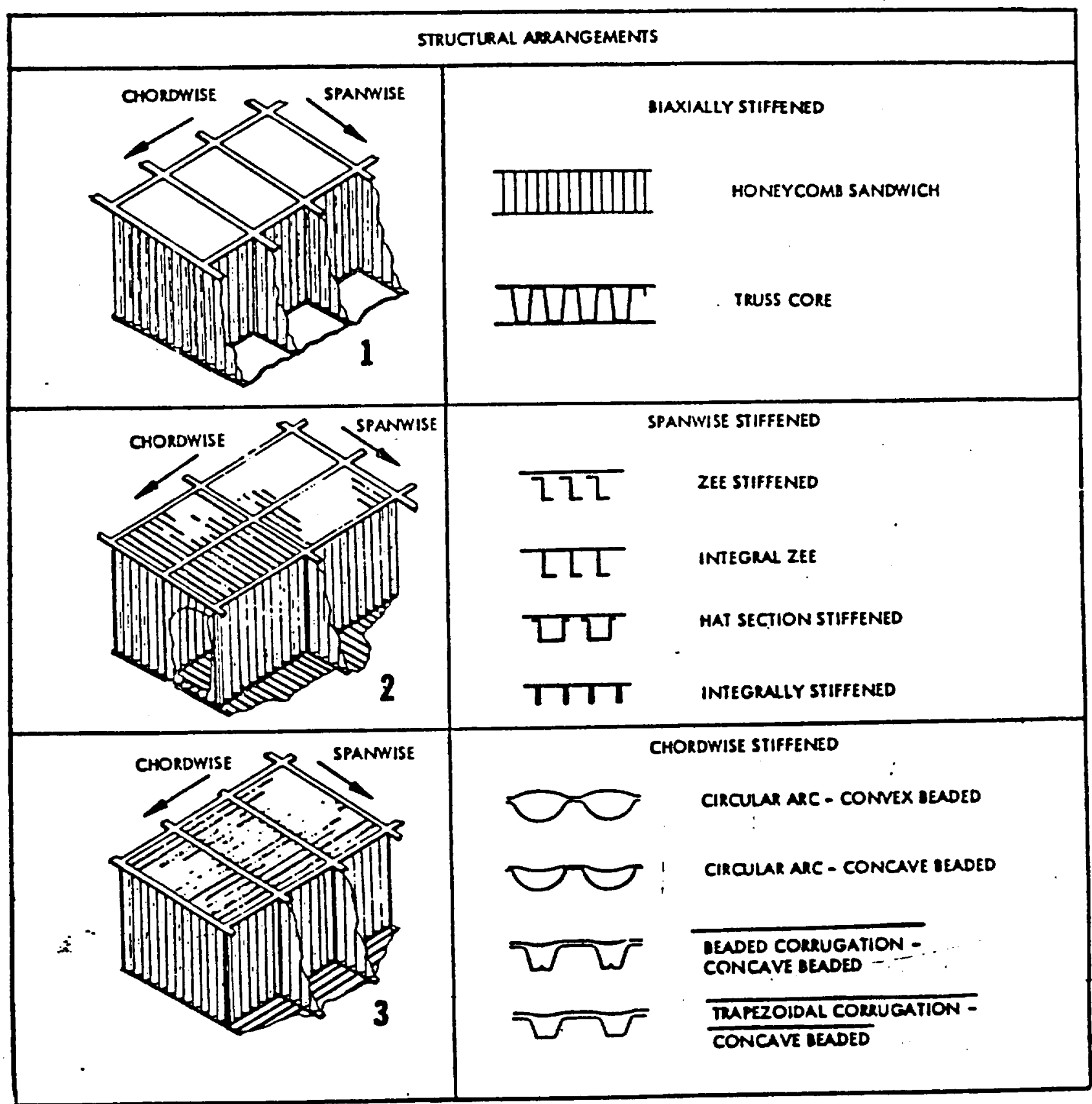


The mission and environmental requirements were based on the revised configuration generated in AE6351. In summary they are as follows:

$\begin{array}{ll}\text { Cruise Speed, } \mathrm{M} & =2.4 \\ \text { Maximum range } & =5000 \mathrm{nmi} \\ \text { Cruising Altitude } & =63000 \mathrm{ft} . \\ \text { Initial } W_{\text {Toow }} & =720000 \mathrm{lb} \\ \text { Structure life } & =20 \text { years } * 4000 \mathrm{hrs} / \text { year }=80,000 \text { flight hours }\end{array}$

Due to the high speed flight condition, the outer skin of the aircraft will undergo severe temperature changes. Several studies show that the maximum skin temperature will be between 350 degrees and 400 degrees Fahrenheit. At these elevated temperatures, some of the material properties will be degraded and thus the load carrying capability of the airplane structure will be reduced. Thermal fatigue cycle resulting from repeated heating and cooling will affect the long term performance capability of the primary structure. Therefore it is necessary to test and evaluate the material performance at these high temperature conditions and consider their effects on structural integrity.

Federal Airworthiness Requirement 25 defines the basic guidelines for designing aircraft structures. Some of the key definitions are listed.

\section{Limit Loads: maximum loads to be expected in service. \\ Ultimate Loads: limit load multiplied by factor of safety \\ Factor of Safety: 2.5 unless otherwise specified}

The analysis procedure is a process to analyze the given structural concepts of the wing structure under the load-temperature environment for the HSCT airplane, and other various design guidelines specified previously. The structural concept under consideration should be tested at critical conditions. The airplane structure should be able to withstand all the loading conditions safely within and on the flight boundaries specified by a V-n diagram. It is not practical to test the structural concepts at every condition of this flight envelope.

Various critical wing structural locations were identified by Lockheed. Each of these locations is called point design region. The number of these locations increased as the analysis required more detailed and accurate predictions of structural response. Each of these point design locations can be analyzed with the loading conditions obtained from the critical flight conditions. At each point design region a unit wing box is constructed for more detailed strength-weight 
analysis and the performance of each material candidate and structural concept is compared with other candidates.

From the 2-D finite element model and the unit wing box analysis, the performance of each candidate concept is evaluated. With these results an updated baseline configuration can be created to reflect the performance of these concepts. Final evaluation and overall performance of the best concept(s) are tested on a 3-D finite element model. The analysis and sizing from this 3-D model gives more accurate weight distributions and the size information for each structural member. The information needed for the cost evaluation and manufacturability, producibility and other evaluations is obtained from this 3-D analysis.

Lockheed's analysis procedure was conducted in two phases. During the first phase, the candidate concepts were screened. The most promising concept(s) were selected in the second phase. 


\section{Task I ( initial screening of concepts)}

Initial Screening

Define load-temperature environment:

Define 2-D structural model for the wing

Aerodynamic heating analysis to find average temperature and thermal gradient

Define point design regions

Weight-Strength analysis for wing panel:

Optimize panel for most critical tension or compression design condition Strength-Analysis

Compression - Local/General instability using plastic deformation theory with Ramberg-Osgood stress-strain relation

Tension - Equivalent Stress $<=$ Gross Area Fatigue

Damage tolerance

\section{Detail Concept Analysis}

Define more point design regions and design environment from the previous analysis

used in the initial screening

Weight-Strength analysis + Damage tolerance + Sonic Fatigue

Results are the weight ranking of basic wing arrangement to be evaluated for cost and performance analysis ( point design weight, total weight )

\section{Task II (selection of best concept)}

Modification of Basic Configuration

Modify the basic configuration used in task I based on the best structural concept(s)

Develop 3-D analysis model

Point Design Analysis for structural concepts

ultimate load, load-fatigue, sonic-fatigue, damage tolerance, vibration-flutter analysis

Compare 3-d model with task I model

Further Study on aeroelastic load, internal loads, vibration-flutter

The final selection process of the best structural concept include such considerations as cost, aerodynamics, and manufacturability. In the Lockheed study the material candidates were evaluated for each structural concept under specific flight conditions and were ranked based upon the specific weight of the unit wing box. In ranking the materials based on their merits with respect to weight considerations, it was found out that the compressive buckling weight index given by 


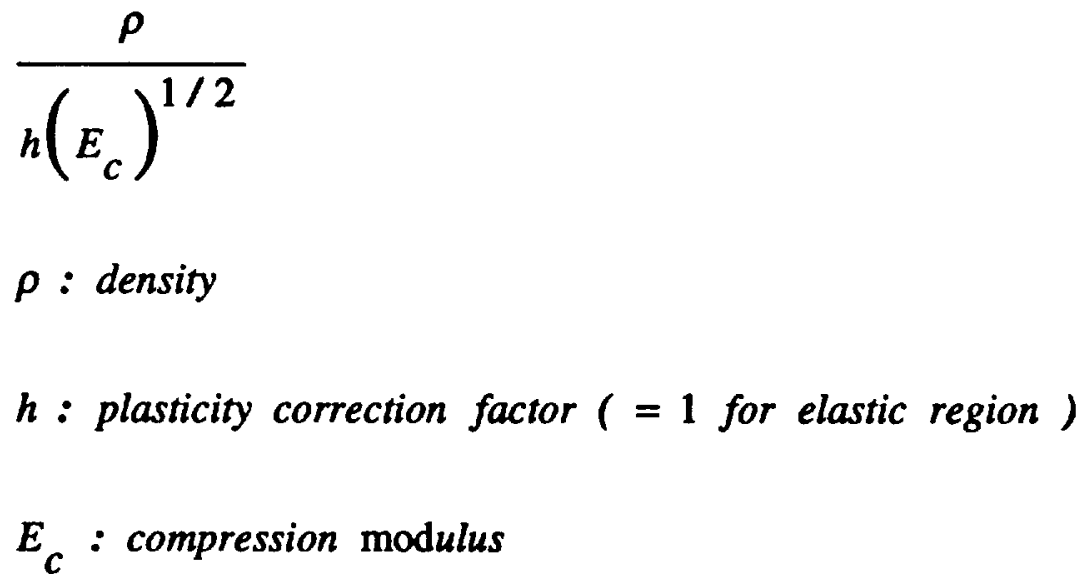

was very close to the material performance predicted by the task I analysis of the Lockheed method.

The aerodynamic loading on the wing results in compression on the upper wing panel and tension on the lower skin. The material's capability to withstand a buckling load is very critical in determining the total weight of the wing structure. In most wing structures, the upper and lower skin panels account for more than $60 \%$ of the total wing structural weight. Therefore, for simplicity, the above equation is used for the evaluation of the candidate materials in the task I procedure.

For a detailed analysis of the structural concepts, a 3-D finite element model was developed based on the baseline configuration. This 3-D finite element model was used by ASTROS (Automated STRuctural Optimization System ).

\section{ASTROS:}

\section{capabilities:}

static and dynamic analysis / flutter analysis / structural sizing capability

Limited aerodynamic analysis capability for wing load calculation

limitations:

no local or global stability analysis capability

no thermal stress analysis capability

\subsubsection{Results}


Structural Analysis Results

\section{MATERIAL TYPE}

\begin{tabular}{|c|c|c|}
\hline Part & $\begin{array}{l}\text { TI-6Al-4V } \\
\text { Weight (lbs) }\end{array}$ & \\
\hline Spar-Web & : 286.89 & $(1.1 \%)$ \\
\hline Spar Cap & : 1069.3 & $(4.1 \%)$ \\
\hline Rib-Web & $: 202.8$ & $(0.8 \%)$ \\
\hline Rib-Cap & $: 0.0$ & $(0.0 \%)$ \\
\hline Top-Skin & $: 12349.2$ & $(47.0 \%)$ \\
\hline Bottom-Skin & $: 12349.2$ & $(47.0 \%)$ \\
\hline Total Weight: & 26257.4 & $(100 \%)$ \\
\hline
\end{tabular}


Material Candidate Ranking based on the relative compressive buckling weight index:

\begin{tabular}{llll} 
Ti-6Al-4V & Ti-10-2-3-(1) & Ti-10-2-3-(2) & Ti-10-2-3-(3) \\
\hdashline 1.0 & 0.874 & 0.93 & $1.03 *$
\end{tabular}

* The lower the index is, the more efficient the structure is.

As Lockheed's study suggested, hybrid structural arrangement shows promise on the weight saving of the wing structure. This concept should be further studied in more detail.

\section{References}

[1] Douglas Aircraft Company, "Study of High-Speed Civil Transport", NASA-CR- 4235, 1989.

[2] Arrow Wing Supersonic Structural Design Concepts Evaluation, NASA CR-132575, 1977.

[3] Niu, Michael C.Y., "Airframe Structural Design ", Conmilit Press Ltd., 1988.

[4] Roskam, J., "Airplane Design - Part I:Preliminary Sizing of Airplane", Roskam Aviation and Engineering Corporation, 1989.

[5] Roskam, J., "Airplane Design - Part V:Component Weight Estimation", Roskam Aviation and Engineering Corporation, 1989.

[6] "Code of Federal Regulations 14" FAR 25 


\subsection{Materials / Producibility}

\subsubsection{Introduction}

The airframe and engine material requirements for an economically viable high speed civil transport are very demanding. Airframe engineered materials must have increased strength, stiffness, a high elastic modulus, high temperature regime capability $\left(350^{\circ} \mathrm{F}\right.$ Long Term $-400^{\circ} \mathrm{F}$ Peak) Figure 7.7.1, a service life design of 25 years, and a high level of safety. ${ }^{2}$ In addition, they must help lower the cost of airframe structure and reduce weight. A savings in structural weight not only leads to an ability for increased payload but also means reduced power requirements.

\section{Skin Temperatures for Mach 2.4 Transport}

\section{Painted Surface}

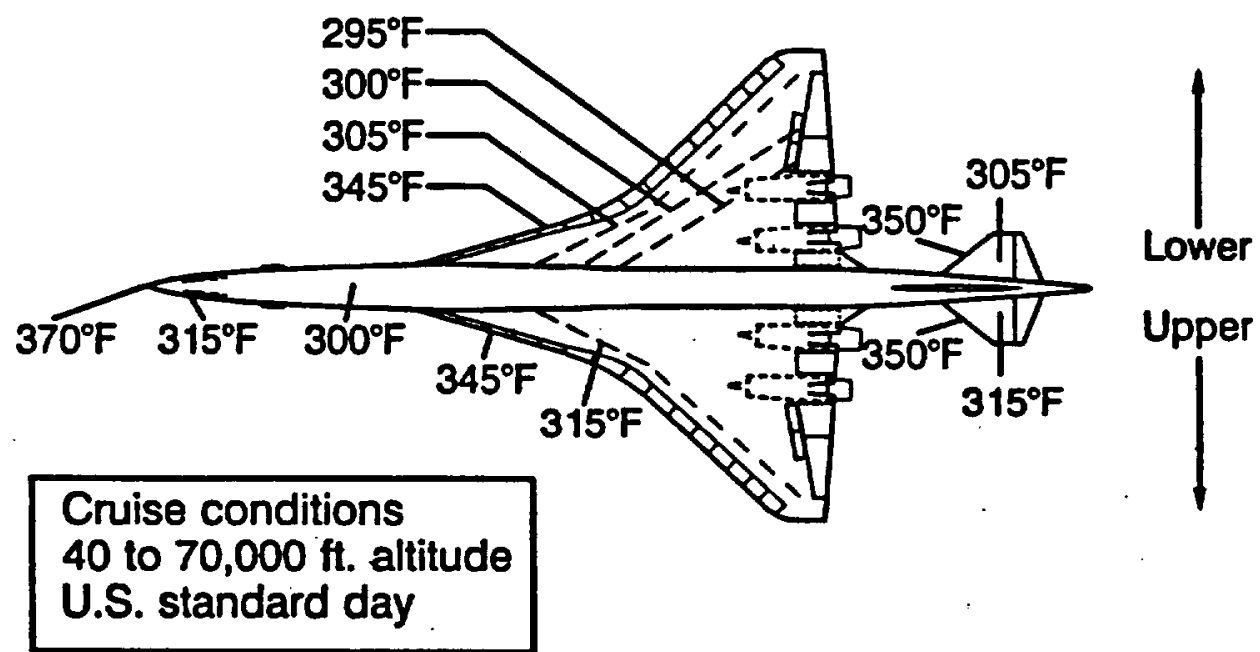

\section{Figure 7.7.1 Material Temperature Capability2}

The primary materials being investigated for use in the wing design are titanium alloys and composite materials. Current focus is on optimizing them for performance, low cost, manufacturability, and service life durability, low cost processing and fabrication technology, and a fundamental understanding of damage mechanisms and development of comprehensive life prediction methodology3. Aluminum alloys such as Aluminum-lithium and wrought PM Aluminum with high temperature capability and greater strength are being investigated but titanium alloys are a suitable alternative to light aluminum alloys when prolonged operating temperatures are 
greater than $150^{\circ} \mathrm{C}$ or so that can be withstood by aluminum without excessive deformation due to creep, or when somewhat greater strength is required without significant weight increases 6 . There is still significant research needed or new aluminum materials. Also metal matrix composites will be investigated for the wing tip structure but, titanium alloys are the main consideration for the primary wing structure.

Composite materials will be used primarily as reinforcement of the titanium structure for the wing. This is due to the low risk stance assumed by most airline manufacturers. Although, Boeing is using an all composite empennage on their new 777's, it is not a HSCT and manufacturers have had more experience in manufacturing large subsonic aircraft in large quantities. Even so, they have yet to implement an all composite wing on large transport aircraft. So, it is very unlikely that the HSCT will have an all composite wing until there is further development, testing, and confidence with large subsonic designs of all composite wings before implementing their usage on a supersonic design.

The advantages of selecting materials and the processes used to produce them are in realizing the facilities/manufacturing processes needed up front, ability to look at reliability/inspectability, costs (PRICE H, Designer's Cost Tool), and being able to choose proven and reliable suppliers ${ }^{2}$. This also helps to look at the challenges in the development of metallic materials for the HSCT which are to:

- characterize current alloys

- design and produce improved alloys tailored for HSCT needs

- substantiate supplier capabilities

- define property requirements

- define cost constraints

- obtain government support for focused R\&D efforts to support HSCT technology ${ }^{2}$

\subsubsection{Titanium Alloys}

The commercial use of titanium has only been around since the 1950 's. A Lockheed ${ }^{1}$ study considered using titanium alloys during the 1970's time period for HSCT applications. They performed a thorough evaluation of materials, processing, properties, and cost of different titanium alloys that were currently under study in the 1970's. Their conclusion was to use the Ti-6Al-4V (annealed) alloy as the primary structural material for their near-term supersonic transport design.

In evaluating the various titanium alloys in the 1970's time-period, Lockheed examined material efficiency parameters which included:

- specific tensile strength $\left(F_{\mathrm{tu}} / \mathrm{r}\right)$

- Specific elastic modulus $(\mathrm{E} / \mathrm{r})$

- damage tolerance capability $\left(\mathrm{K}_{\mathrm{I}} / \mathrm{F}_{\mathrm{ty}}\right)^{2}$ 
- room temperature stress corrosion susceptibility $\left(\mathrm{K}_{\mathrm{Iscd}} \mathrm{r}\right)$

- room temperature formability ( $\mathrm{r} / \mathrm{t})$

- maximum tension-tension fatigue strength at $10^{6}$ cycles

They also viewed materials for modulus-density critical elements, such as wing skins which are critical in buckling of stiffness load conditions in the forms of Ti-8Al-1V-1Sn, Ti-6Al-6V-2Sn, Ti6Al-2Sn-2Mo-2Cr-2Zv-0.25Si(Ti-6-22-22), Ti-6Al-4V, and Ti-5Al-2.5Sn. Of all these, Ti-5Al$2 \mathrm{Sn}$ and Ti-6-22-22 warranted consideration for replacements for Ti-6Al-4V.

Tensile-strength critical elements such as the solution treated and aged beta titanium alloys, such as, Ti-8-8-2-3 were also studied. They provided the ability to be available in cold rolled sheet-strip-extrusion, room temperature forming to relatively complex contours, and simple aging processes not requiring rapid quenching from special protective atmospheres, which could be combined with cold work to obtain even higher strength levels. The main problems here were that the 1960's aging cycles resulted in lower fracture toughness properties. Also, fatigue data was very limited and therefore, the use of these alloys required further development and testing which was not available in that time frame. Studies also included aging response, cleaning methods, fusion welding, and weld bonding.

The attractive feature about using Ti-6Al-4V is that it was used in the late 1960's as the primary structure for the Lockheed SR71 and North American XB-70's. Because of this, many of the manufacturing problems for titanium were solved due to the military's requirements for their aircraft, and the Ti-6 Al- $4 \mathrm{~V}$ has become the workhorse of the aerospace industry. 4

The advantage of using titanium is that it has an edge over both aluminum and steel on a strength/density basis. Titanium can also be used in temperature ranges up to $1150^{\circ} \mathrm{F}$. It is currently being used in airframes as high-strength and high-toughness forgings, firewalls to insulate engines from structures, and in wing skins and support structure for military and commercial aircraft as stated in earlier examples. Also, titanium alloys have better ratios of fatigue properties to strength than do either aluminum or steels. 6

In the more recent time frame of the 1980's up to the present, further studies have been performed and new alloys have been created and evaluated. A current Boeing study 2 for advanced materials for a high-speed civil transport suggests newer titanium alloys and their development thrusts for the HSCT primary aircraft structure as well as some of the same ones investigated in the Lockheed study due to further study and development. They include:

- High Strength/Toughness Sheet/Plate Alloy (170 - $200 \mathrm{ksi})$

- Alloy Ti-15V-3Cr-3Al-3Sn (Ti-15-3)

- Alloy Ti-6Al-2Sn-2Zr-2Mo-2Cr (Ti-6-22-22)

- High Strength Casting Alloy (170 - 200 ksi) 
- Alloy Ti-15V-3Cr-3Al-3Sn (Ti-15-3)

- Very High Strength Fastener Alloy (220 ksi)

- Alloy Ti-3Al-8V-6Cr-4Mo-4Zr

- New Ti met Alloy

- Very High Strength Forging Alloy (200 - 220 ksi)

- Alloy now being defined

Another study presented by Titanium Metal \&Alloys Ltd. ${ }^{7}$ shows that they have developed a newer alloy, $\mathrm{Ti}-10 \mathrm{~V}-2 \mathrm{Fe}-3 \mathrm{Al}$, which possesses the optimum combination of mechanical properties, fabricability, and cost, to satisfy newer and more demanding applications for high strength titanium alloys. Table 7.7.1 shows a property comparison with competitive materials.

\begin{tabular}{|c|c|c|c|c|c|c|}
\hline Propenty & $\begin{array}{l}\text { Ti-10.2.3 } \\
\text { STA(1) }\end{array}$ & $\begin{array}{l}\text { Ti } 10-2-3 \\
\operatorname{STA}(2)\end{array}$ & $\begin{array}{l}\operatorname{Ti} 10-2-3 \\
\operatorname{STA}(3)\end{array}$ & $\begin{array}{l}\text { Ti-6Al-4V } \\
\text { Annealed }\end{array}$ & $\begin{array}{l}\text { 15.SPH } \\
\text { H900 }\end{array}$ & $\begin{array}{c}\text { PH } 13-9 \mathrm{MO}_{0} \\
\mathrm{H} 1000\end{array}$ \\
\hline $\begin{array}{l}\text { Densily } \\
8^{/ A \mathrm{~cm}^{3}} \\
\text { (/b/in') } \\
\text { Tensile } \\
\text { Sirengih }\end{array}$ & $\begin{array}{c}4.65 \\
(0.168)\end{array}$ & $\begin{array}{c}4.65 \\
(0.168)\end{array}$ & $\begin{array}{c}4.65 \\
(0.168)\end{array}$ & $\begin{array}{c}451 \\
(0.163)\end{array}$ & $\begin{array}{c}7.80 \\
(0.282)\end{array}$ & $\begin{array}{c}7.76 \\
(0.279)\end{array}$ \\
\hline $\begin{array}{l}\text { MPa } \\
\left(10_{\text {psi }}\right) \\
\text { KIc }\end{array}$ & $\begin{array}{l}1241 \\
(180)\end{array}$ & $\begin{array}{l}1100 \\
(160)\end{array}$ & $\begin{array}{c}896 \\
(130)\end{array}$ & $\begin{array}{l}896 \\
(130)\end{array}$ & $\begin{array}{l}1310 \\
(190)\end{array}$ & $\begin{array}{l}1414 \\
(205)\end{array}$ \\
\hline $\begin{array}{l}\text { Mpa } \sqrt{m} \\
\text { (Ksi Vin) } \\
\text { Specific }\end{array}$ & $\begin{array}{c}44 \\
(40)\end{array}$ & $\begin{array}{l}82.5 \\
(75)\end{array}$ & $\begin{array}{l}110 \\
(100)\end{array}$ & $\begin{array}{l}49.5 \\
(45)\end{array}$ & $\begin{array}{c}33^{\circ} \\
(30)\end{array}$ & $\begin{array}{c}88 \\
(80)\end{array}$ \\
\hline $\begin{array}{l}\text { Tersile } \\
\text { Sirength' } \\
\text { Specific } \\
\text { KI' }\end{array}$ & $\begin{array}{c}267 \\
(1071) \\
9.5 \\
(238)\end{array}$ & $\begin{array}{c}236 \\
(950) \\
17.7 \\
(446)\end{array}$ & $\begin{array}{c}199 \\
(797) \\
23.7 \\
(595)\end{array}$ & $\begin{array}{c}199 \\
\cdot(797) \\
10.9 \\
(276)\end{array}$ & $\begin{array}{c}168 \\
(674) \\
4.2 \\
(106)\end{array}$ & $\begin{array}{l}182 \\
(735) \\
11.3 \\
(287)\end{array}$ \\
\hline \multicolumn{7}{|c|}{$\begin{array}{l}\text { I. The property divided by the density in SI (English) units } \\
\text { Ti la-2-3 }\end{array}$} \\
\hline \multicolumn{2}{|c|}{$\begin{array}{c}\text { STA I = ST.BETA MINUS } 36^{\circ} \mathrm{C} \\
\text { AGE S00' } \mathrm{C} \text { Bhr }\end{array}$} & \multicolumn{3}{|c|}{$\begin{array}{c}\text { STA } 2=\text { ST.BETA MINUS } 36^{\circ} \mathrm{C} \\
\text { AGE } 540^{\circ} \mathrm{C} 8 \mathrm{hr}\end{array}$} & \multicolumn{2}{|c|}{$\begin{array}{c}\text { STA } 3=\text { ST.BETA MINUS } 36^{\circ} \mathrm{C} \\
\text { AGE } 590^{\circ} \mathrm{C} 8 \mathrm{ht}\end{array}$} \\
\hline
\end{tabular}

\section{Table 7.7.1. Property Comparisons with Competitive Materials 6}

This material exhibits greater formability characteristics allowing more subtle combinations of mechanical properties. In addition, it can be produced with comparable current titanium forging equipment and dies at much closer to form parts. Lower cost dies and operating temperatures can produce equally well produce parts of a similar configuration produced with Ti-6 Al-4V with an added benefit of superior post forge properties being obtained in Ti-10-2-3 by heat treatment.

The most exciting feature of this new alloy is its suitability for isothermal forging. This alloy is capable of producing components up to $650 \mathrm{~mm}$ (25") dia, or somewhat larger where parts are non-axis symmetric. This system for work piece heating and manipulation is fully automated and can handle pieces up to $200 \mathrm{kgs}$ in weight. Most importantly, the automatic control of the 
forging reproduces shape, structure, and quality from piece to piece in a way that has not previously been possible. This level of control will allow a further section and weight reduction of finished parts.

Current airframe materials research at NASA Langley ${ }^{3}$ is concentrating on new Aluminum alloy variants that will have improved fracture toughness and stress corrosion resistance, new processing techniques such as near net shape forming, and the environmental effects on these materials.

\subsubsection{Composite Materials}

Lockheed's ${ }^{1}$ main concept for use of composite materials was in the application of composites to the primary structure for selective reinforcement of the basic titanium structure. The composites considered were:

- Graphite and Boron polymide matrix composites which can sustain service temperatures of $500^{\circ} \mathrm{F}$ to $6000^{\circ} \mathrm{F}$. Graphite being used for thermal stress/deformation reduction. Boron for high compressive efficiency.

- Boron/aluminum composites which have a high compressive structural efficiency which makes it suitable for use as a stiffening element in concert with titanium structural elements.

To maximize the return for minimum cost and risk, the application was primarily unidirectional reinforcing of members carrying axial loads (spar caps and stringers). Other guidelines were that all exposed surfaces were titanium, all load transfer at joints were made through titanium structure, and at least minimum gage titanium was maintained on all design concepts.

Lockheed's evaluation and results of exploring benefits to be derived from selective composite reinforcement of titanium structure and various arrangements of materials and plies are shown in the following tables and figures. Although the information is 1970-1972 technology, they provide a basis for looking at the positive effects of using composites in the HSCT design. 
Table 7.7.2 Preliminary Design Composite Properties 1

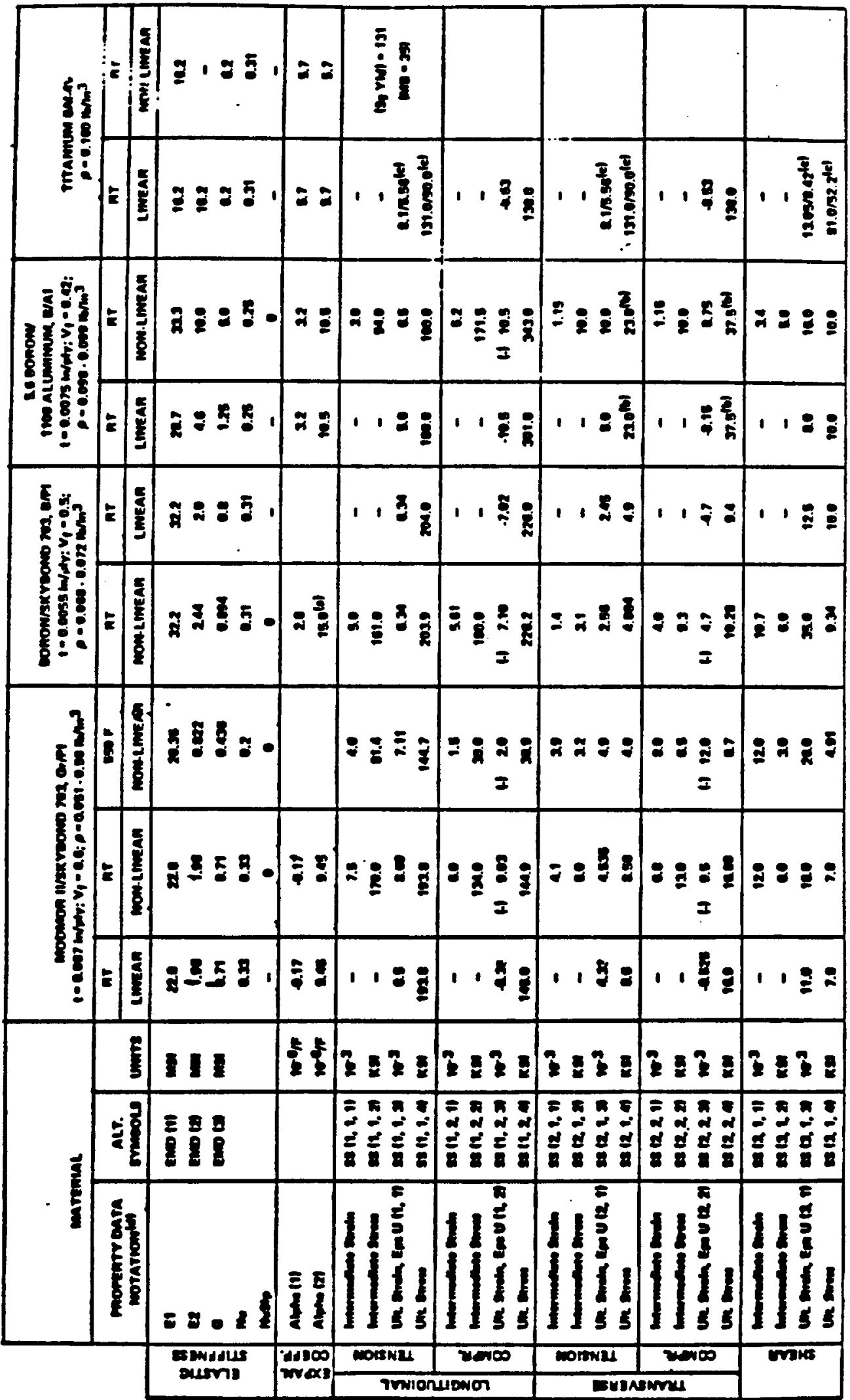

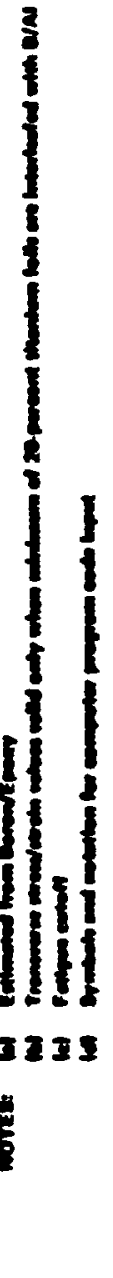




\subsubsection{Current Concepts and Considerations}

The maturation of composite technology is still in progress but significant progress and understanding has been made. The main considerations in using composites in the HSCT wing design are the costs of development, testing, production, and maintenance; safety, a critical concern with manufacturing and government certifying agencies; conservatism due to financial penalties from equipment downtime; and absorbing military service and flight experience. 4

The main advantages of using composite materials today for developing the HSCT wing are the quantum jump in weight saving potential, high strength-to-weight and stiffness-to-weight ratios, and ability of the designer to optimize a structure for shape and weight. In contrast, the disadvantages are that design costs are higher due to the fact that testing, production and prototype tooling costs are higher, quality control is higher, and higher raw material costs. In order for composite materials to truly be viable, designers must emphasize structural simplification, look at reducing part count, eliminate costly design features, and realize that in some areas of aircraft structures, metal material is still the most cost effective. ${ }^{4}$

Current goals and key objectives for materials as defined by researchers at NASA Langley 3 are presented in the following figures. These charts show that researchers are examining all aspects of materials in order to produce a viable HSCT design.

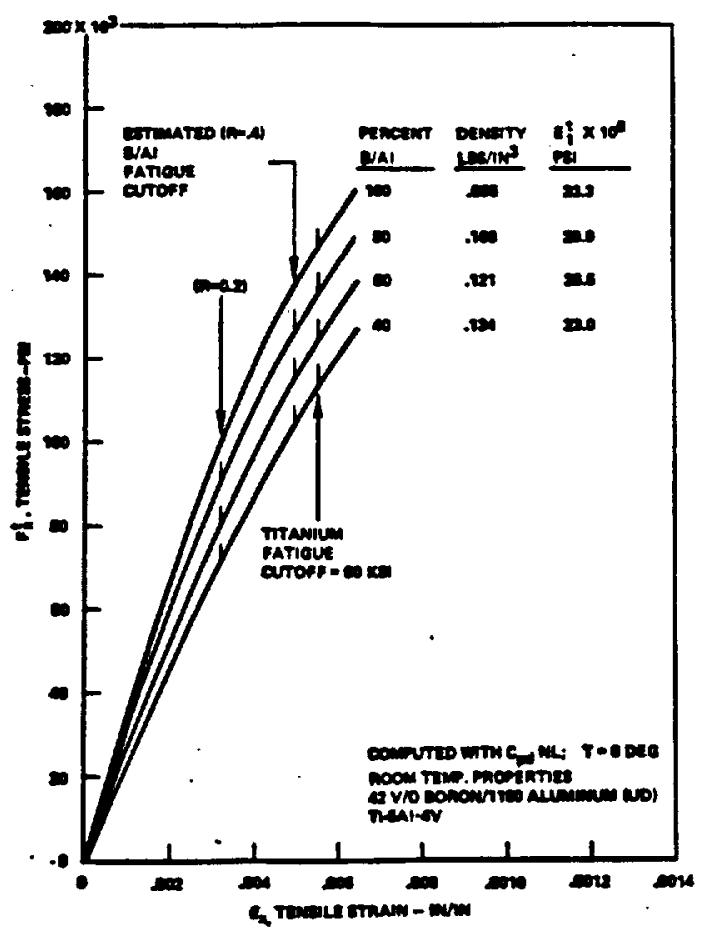

Eigure 7.2.2 Tensile Strength of Titanium Reinforced with Boron-Aluminum 1 


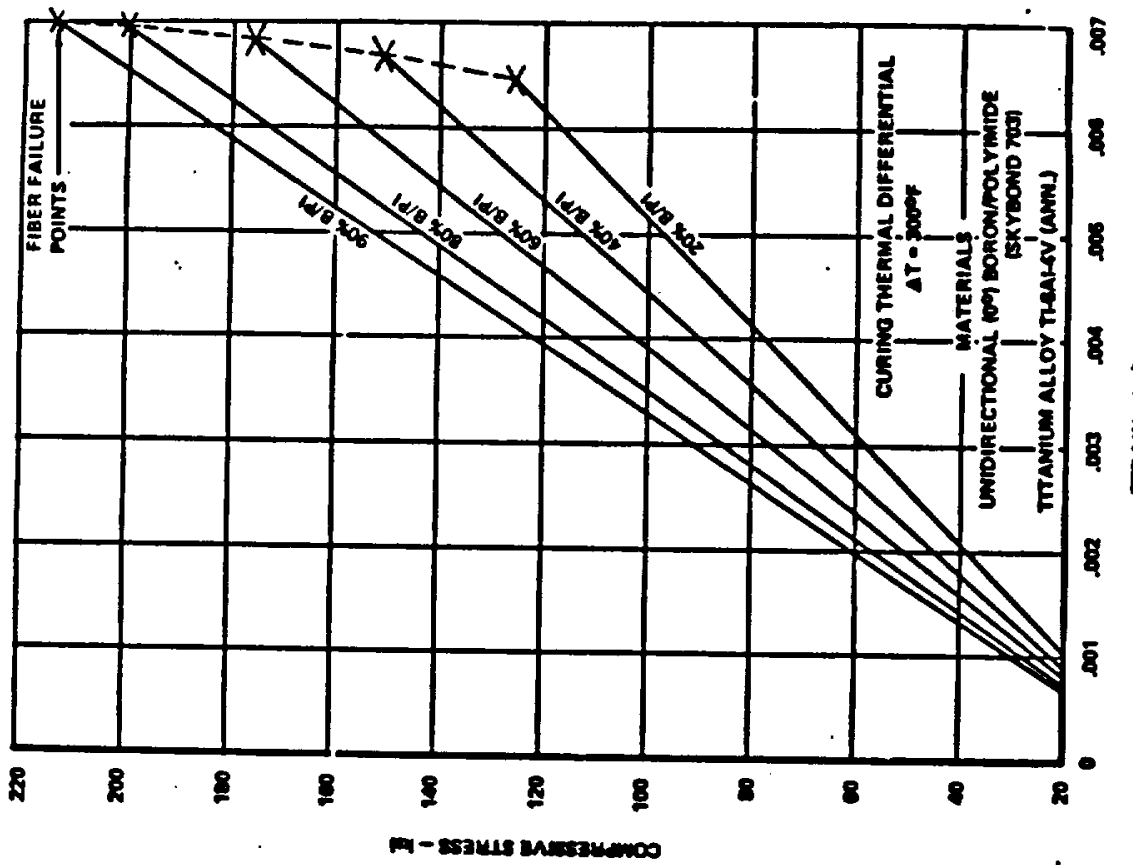

Eigure 7.7.3 Tensile Strength of B/PI Reinforced Titanium 1

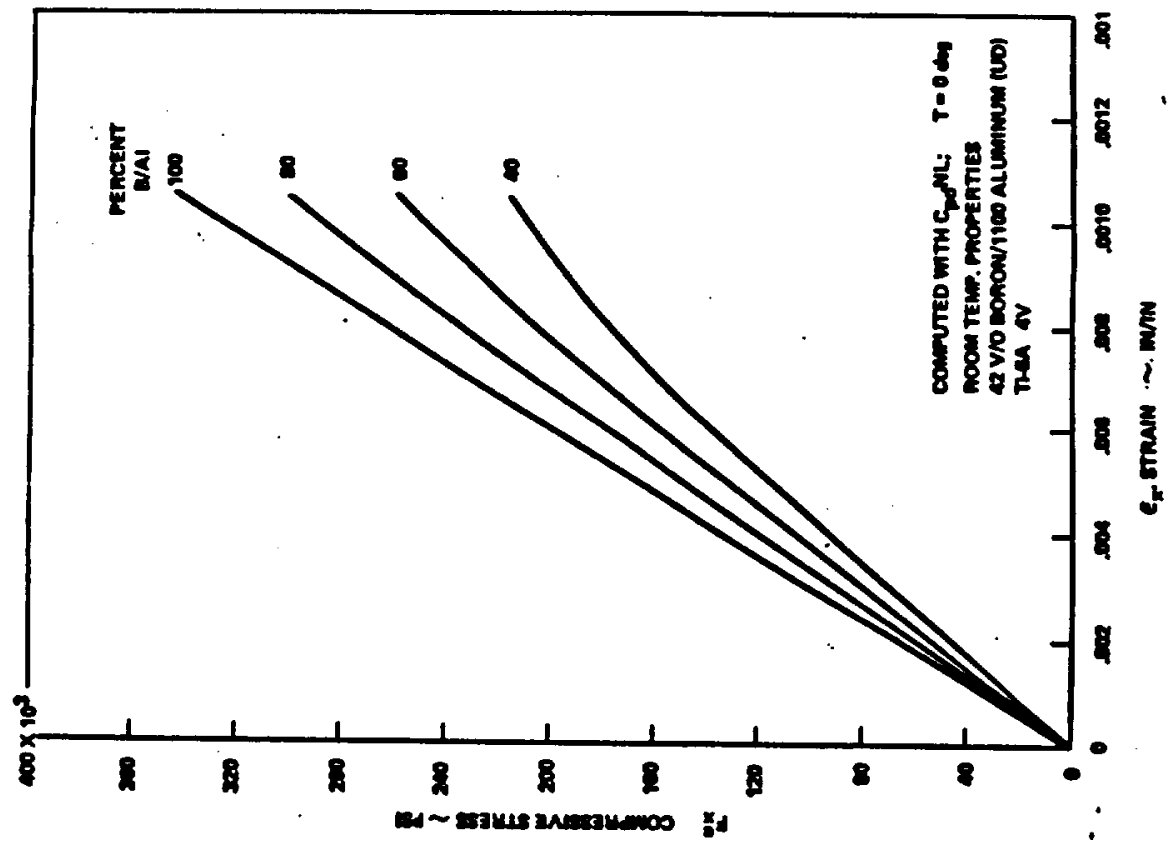

Figure 7.7.4 Compressive Strength of Titanium Reinforced With Boron Aluminum 1 


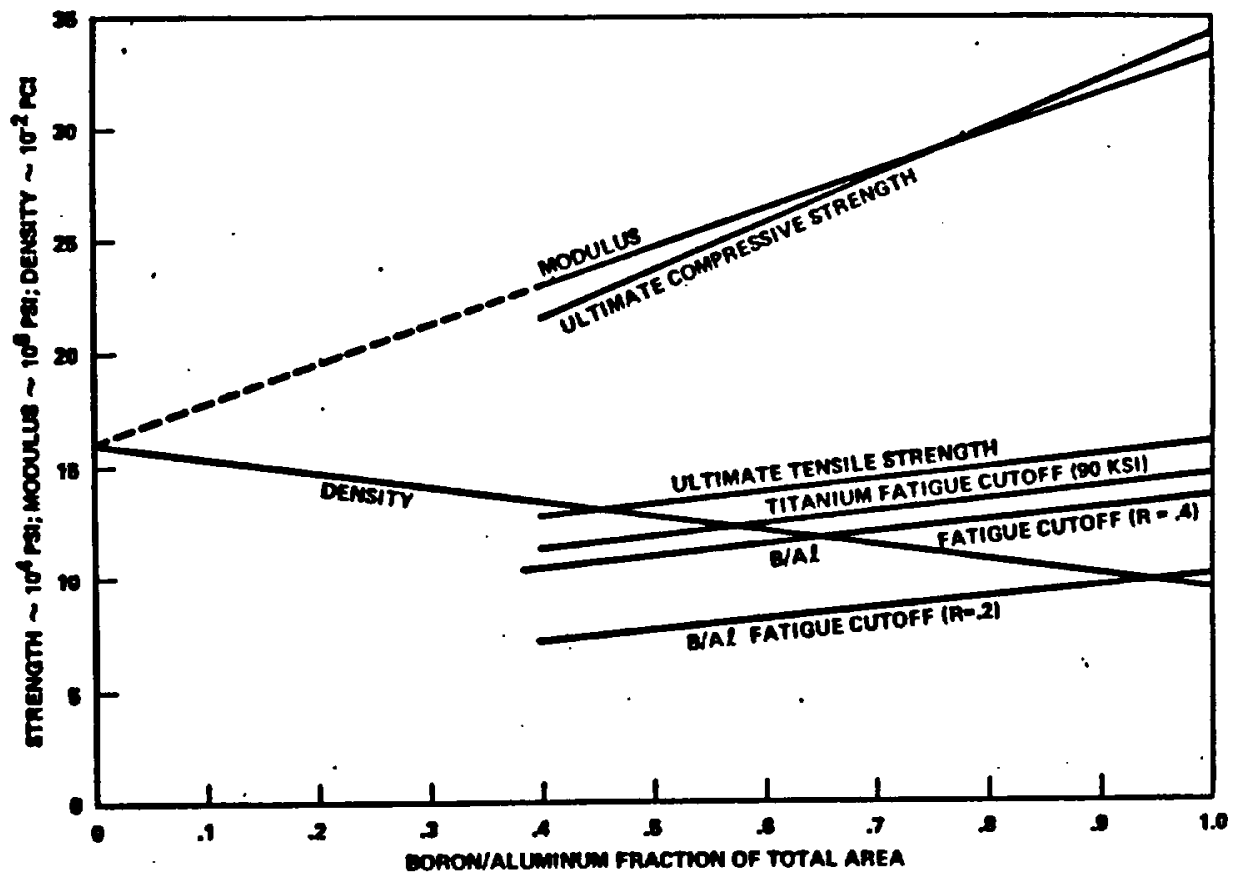

Eigure 7.7.5 Strength. Stiffness and Density of Titanium Reinforced with Boron-Aluminum1

GOAL

To develop a mechanics characterizalion of the deformation, strength and Hite of advanced stuctural materials

KEY ORUECTIVS

- Leminated Composites: residual strength and fie prediction methodology

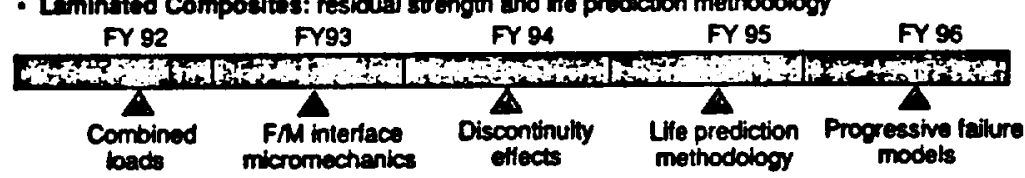

- Textlle Composites: stifiness, strength, and damage tolerance

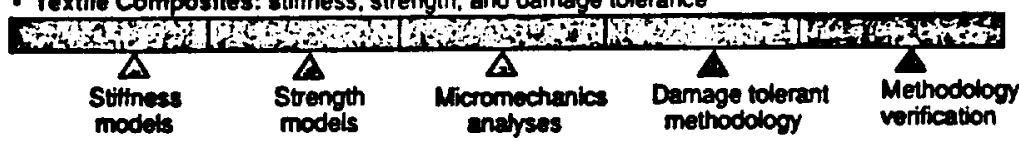

- Elevated Temperature Composhes: thermomechanical fatigue, thermoviscoplasticity, durability

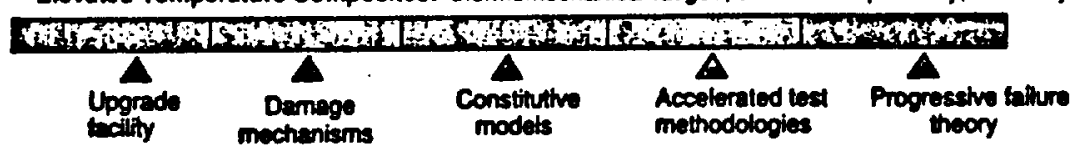

- Llght Metallic Alloys: fracture mechanics and fatigue crack growth models

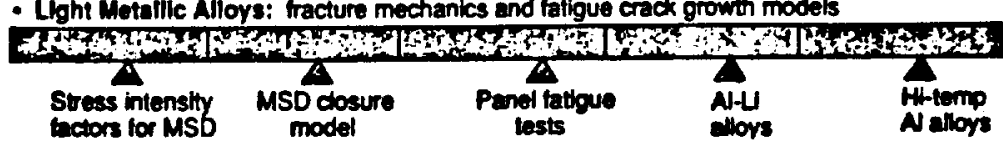

Eiqure 7.6. Mechanics of Materials 3 
GOAL

To synthesize, characterize and improve the performance potential of new metallic alloys and melal-matrix composites lor tuture aerospace structures

\section{KEY OB.JECTIYES}

- Advanced light alloy and MMC development

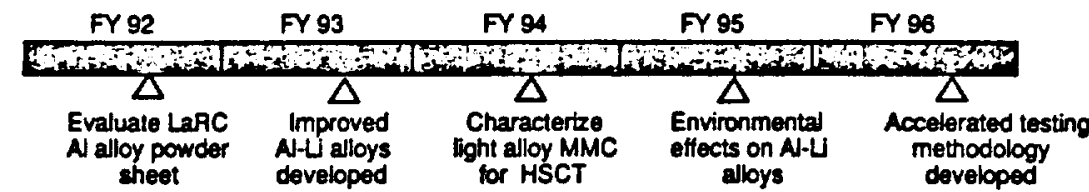

- Develop innovative metals processing

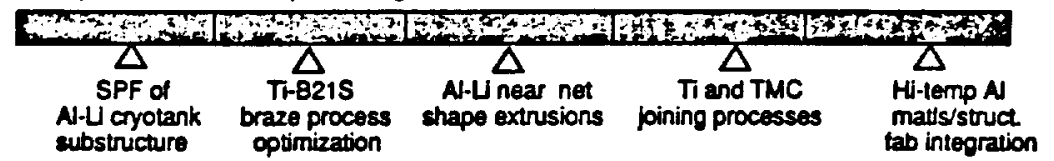

- Develop high temperature thin gage metals and MMC's

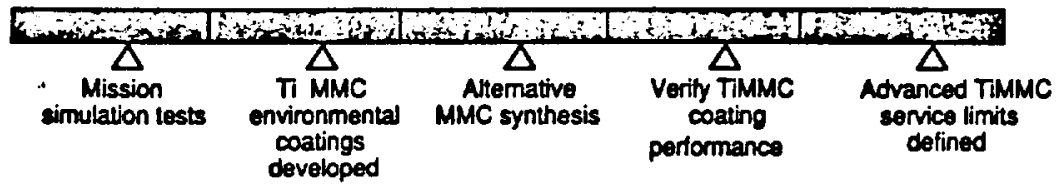

\section{Eigure 7.7.7 Metallic Materials 3}

GOAL

To gynthesize and characterize new high-pertornance polymers for adhesives, matrices and films and to develop the tectinology for processing new resins and fibers into advanced composite materlals and establish the scientific basis for predicting behavior

\section{KEY OBJECTIVES}

- Synthesis of novel new polymers for films, adhesives and matrices

FY 92

$$
\text { FY } 93
$$

FY 94

FY 95

Fr 96

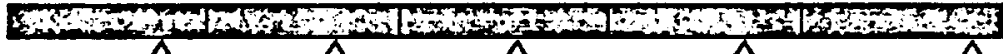

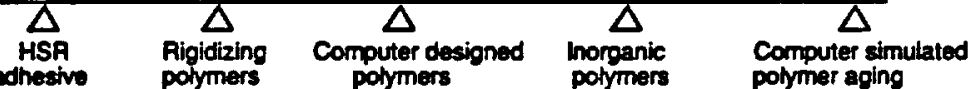

- Optimize resin chemistry for compostie matrices

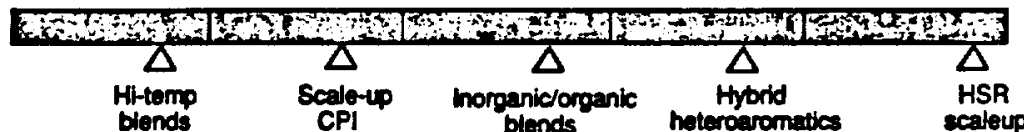

- Develop advanced prepregging and processing technologies tor polymer matrix composites

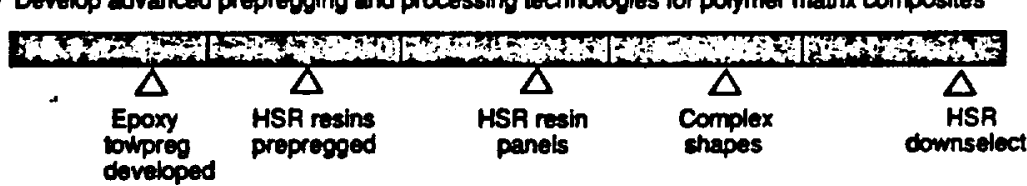

Eigure 7.7.8 Polymeric Materials 


\subsubsection{Composite Usage}

Proposed composite usage shall include thermoset and thermoplastic resins, and possibly some metal matrix composites. The following chart shows the relative advantages of thermosets and thermoplastics.

THERMOSET MATRICES

\section{THERMOPLASTIC MATRICES}

(Characteristics)

- Undergo chemical change when cured

- Processing is irreversible

- Low viscosity/high flow

- Long (2 hours) cure

- Tacky prepreg

- Relatively low processing temperature

- Good fiber wetting

- Formable into complex shapes

- Formable into complex shapes

- Low viscosity

- Long processing time

- Restricted storage

- Requires refrigeration
- Non-reacting, no cure required

- Post-formable, can be reprocessed

- High viscosity/low flow

- Short processing times possible

- Boardy prepreg

(Advantages)

- Superior toughness to thermosets

- Reusable scrap

- Rapid (low cost) processing

- Infinite shelf life without refrigeration

- High delamination resistance

(Disadvantages)

- Less chemical solvent resistance than thermosets

- Requires very high processing temperatures

- Outgassing contamination

- Limited processing experience available

- Less of a database compared to thermoset

To summarize this chart, thermoset matrices offer lower melt viscosity's, lower processing temperatures and pressures, are more easily prepregged and are lower cost. In contrast, thermoplastic matrices offer indefinite shelf life, faster processing cycles, simple fabrication, and generally do not require controlled-environment storage or post curing. So, even though a lot of fabrication problems have to be overcome, most structural designers still believe that thermoplastic matrix resins are the next generation of composites. 5

The main thermoset resins to study in our wing design are polymides which have higher service temperatures, thermo-oxidatively stable, and maintain mechanical properties at higher temperatures. These are difficult to process and expensive. The other thermoset resins are bismaleinides (BMI) which have a temperature around $350^{\circ} \mathrm{F}$ to $400^{\circ} \mathrm{F}$, good mechanical strength 
and stiffness, and are easy to process with toughened versions becoming available. Thermoset resins have been around and are the most prominent organic matrix materials in the airframe industry. 5

Thermoplastic matrices are not new to the airframe industry, but one of the most critical factors is lack of an extensive database of performance properties over service time. Military aircraft structural applications serve as the major drivers for developing thermoplastics for use a high-temperature composite matrices. The four major requirements are:

- High temperature capabilities (range $350^{\circ} \mathrm{F}$ ) under severe hot/wet environmental conditions.

- Better damage tolerance in primary structures

- Easily automated in order to drive down manufacturing process costs

- Lower total part-acquisition and lifetime costs (including material, processing, and supportability $)^{5}$

Metal matrix composites such as the Boron/aluminum composite mentioned in Lockheed's report is still a current consideration in airframe structure to carry the primary axial loads. This is done by selectively introducing into the beam or stiffener flanges in the form of aligned boron filaments threaded completely through lobes or other apertures embodied in the metal structure. Reinforcing the structure in this manner allows for a lighter structure while still permitting the retention of traditional metal joining and assembly techniques such as riveting and welding. It is claimed that boron-reinforced structural components are from $25 \%$ to $45 \%$ lighter than metal counterparts. 5

Although metal matrix composites can help reduce weight significantly, there are still some difficulties that remain to be solved for metal matrix composites 5 :

- High cost

- Cannot be extruded or forged

- Lack of machining and joining techniques

- Need to improve the adhesion of the fibers to the matrix

- Complex and expensive fabrication methods for metal matrix composites with continuous reinforcements.

There is a lack of data for these materials due to the fact that composite material design allowable data is usually part of a company's proprietary data because numerous varieties exist and many improved products become available from year to year. It is recommended to look at Lockheed's data because some of their analyses are still valid for current times. Using the data presented in this section can help determine what effects the addition of composite materials will have on the wing design. Figures 7.7.9 and 7.7.10 show how composite applications have beneficial effects on the design and development of materials. 


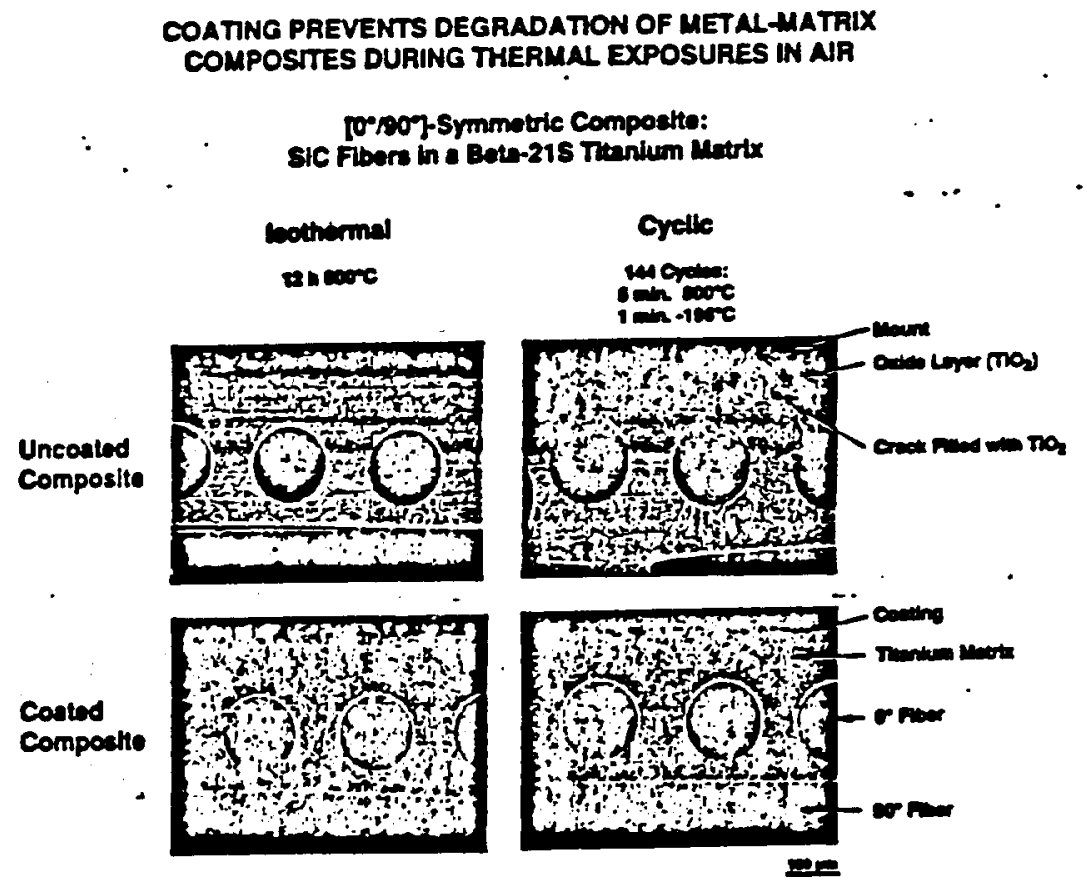

Figure 7.7.2 Degradation of Metal-Matrix Composites 3

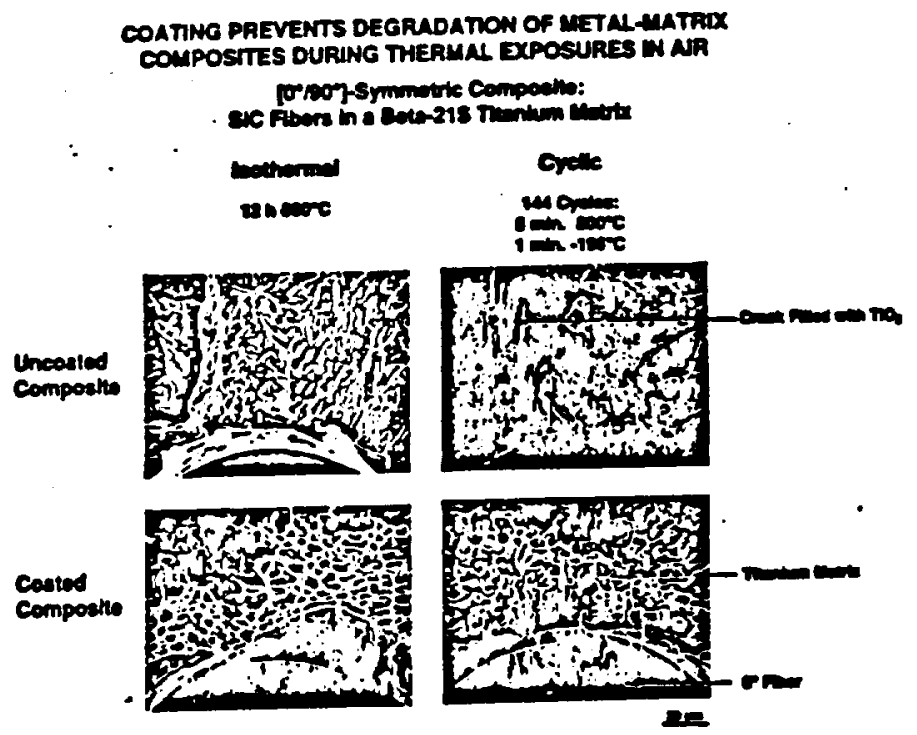

Eigure 7.7.10 Degradation of Metal-Matrix Composites 3

In conclusion, the materials group recommends that the structures and costs groups examine the different composite and metal material aircraft wing concepts based off Figures 7.7.11 and 7.7.12. Different concepts need to be evaluated to determine the most cost effective 
combinations. This can be done by using data from PRICE $H$ and the RAND report for the cost group as well as structural analysis from the structural concept evaluation group.

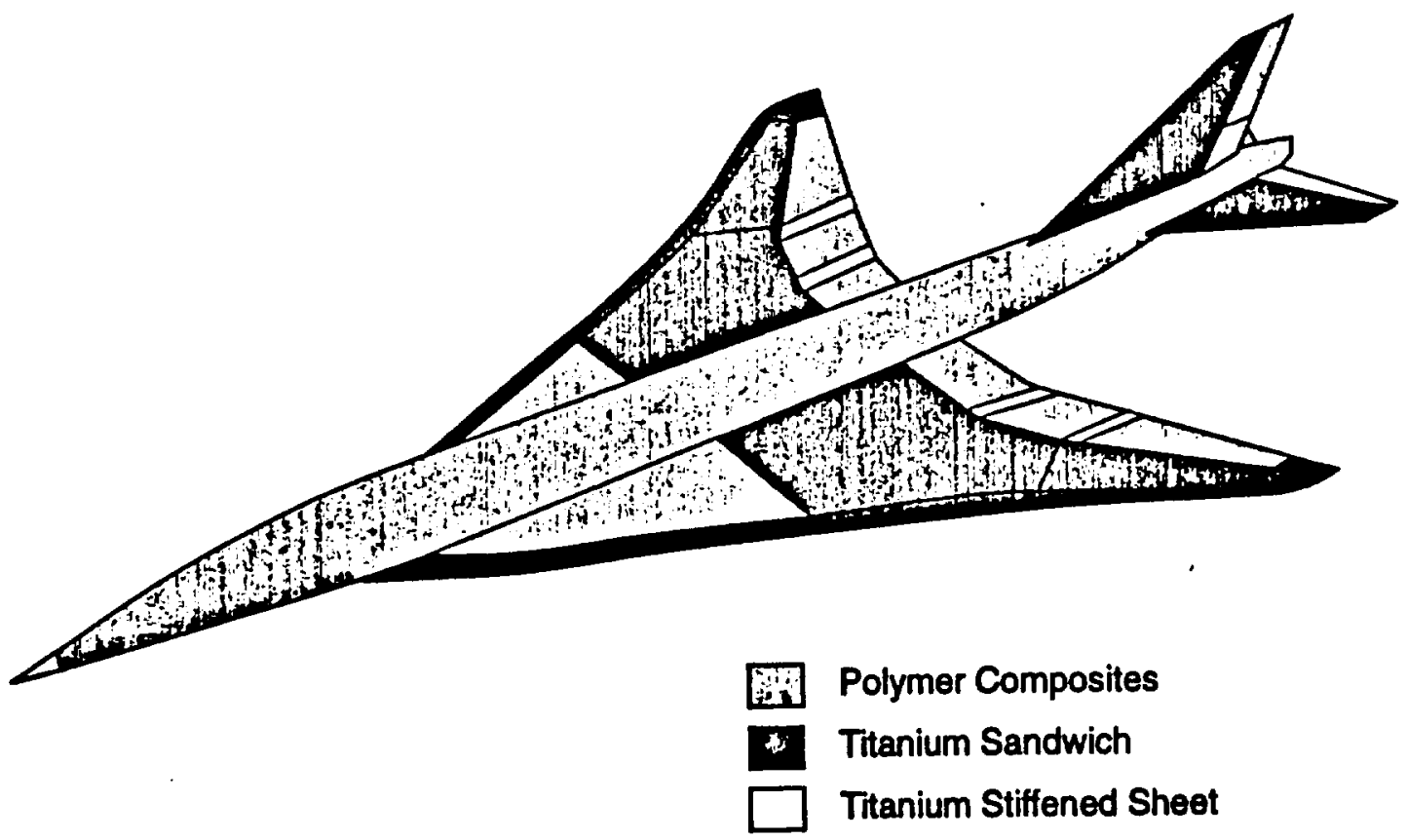

Figure 7.7.11 Material Usage 3

\section{Proposed Usage of Materials for the HSCT}

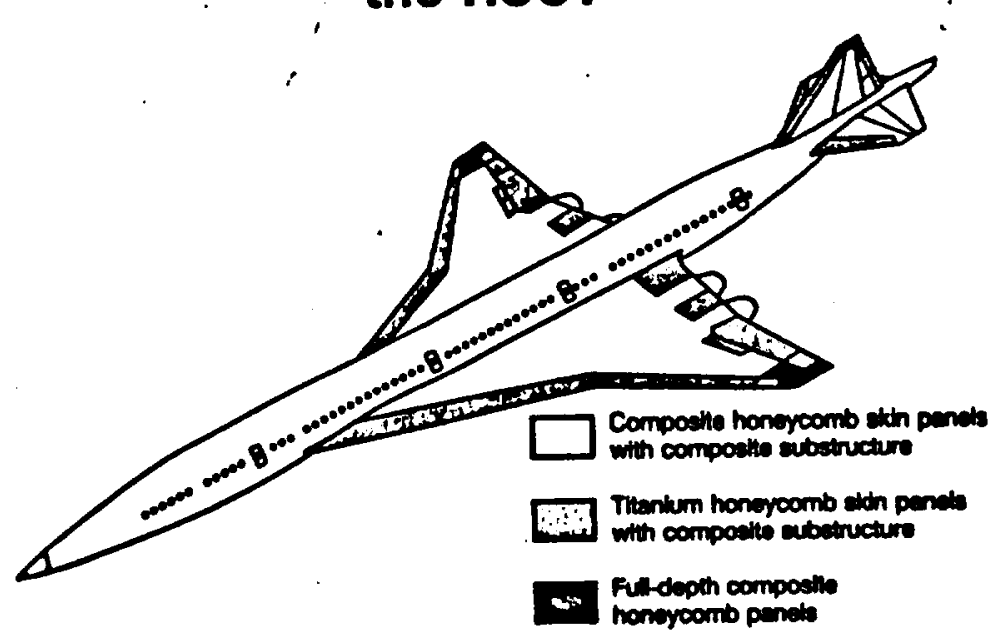

Eigure 7.7.12 Material Usage 2

Figure 7.7.13 presents a current overview of the High Speed Research materials research being performed at NASA. ${ }^{3}$ The 1993 thrusts for polymer/composites at NASA include new resin synthesis, processability, optimizing molecular structure, and process modeling - flow in 3-D 
textile preforms, and prepregging - tow preg development for advanced technology polymers (ATP).

HSR MATERIALS RESEARCH

Requirements/Needs

Composites

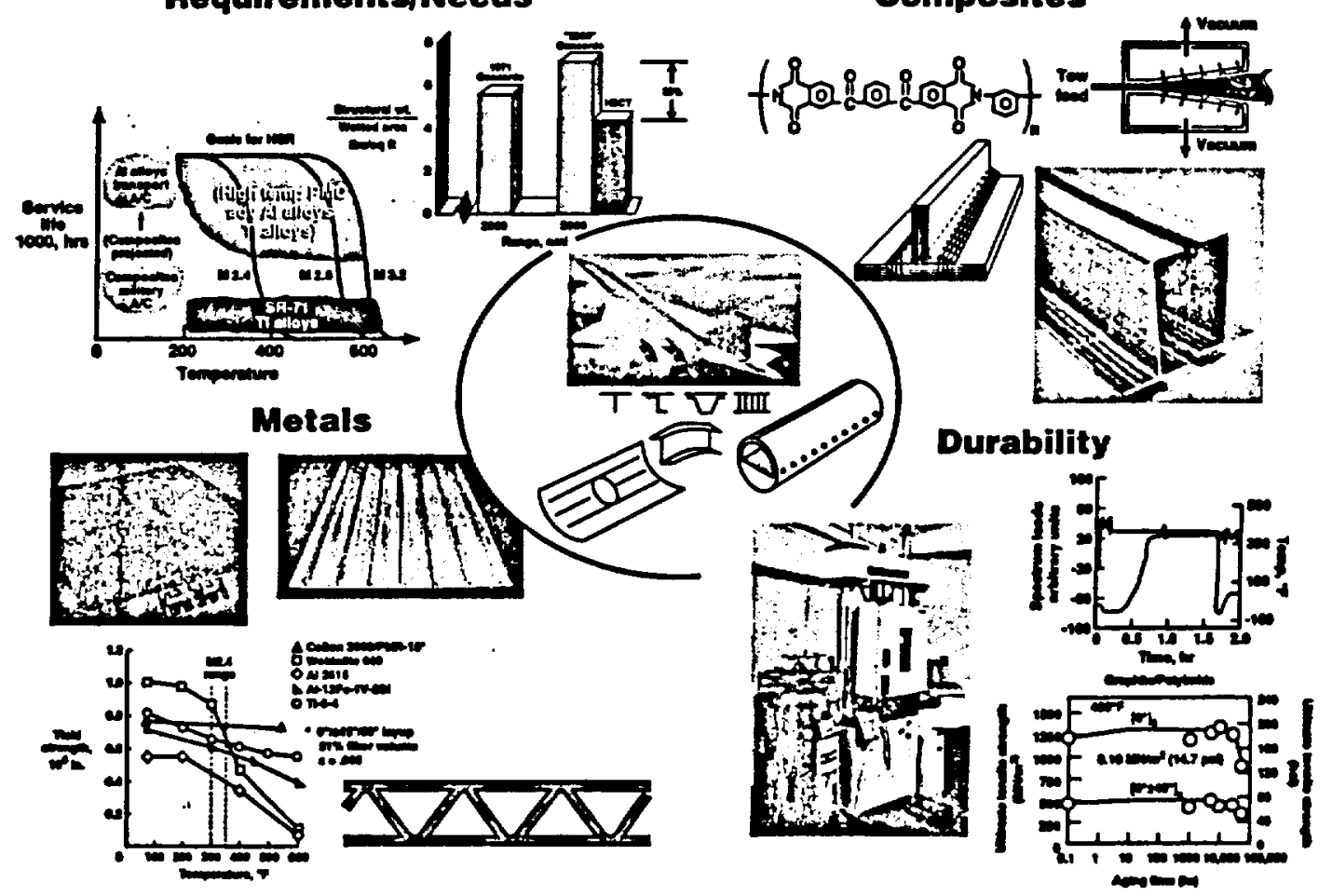

Figure 7.7.13 HSR Materials Research 3

\subsubsection{Manufacturing and Producibility Concepts}

The main purpose of looking at the producibility of the wing is to look at designing for low cost production and manufacturability. This will include using the principles of concurrent engineering, design for production, and examining automation procedures. Concurrent Engineering studies indicate that a large percentage of the final cost of a product is determined in the early phases of the product life cycle. So it is imperative that we examine these factors early on to choose the proper manufacturing techniques to help reduce cost and improve manufacturability.

Concurrent Engineering allowed all the disciplines of the Georgia Tech HSCT Design Group to communicate. This is extremely important since $70 \%$ of the product cost is determined in the first $5 \%$ of the design process. Through concurrent engineering the project development can be changed from a sequential process to a simultaneous involvement of the necessary disciplines. This means that the designers take materials and producibility, inspection, maintainability, structures, and cost into consideration to a greater degree than in the traditional manner. Since the 
designer cannot be expected to become thoroughly familiar with all of the other disciplines, all disciplines are involved in the beginning so they can evaluate the concepts as they develop. 5

The purpose of designing for production is to develop a design which exploits a manufacturing method and yields a product of high quality and low cost. This occurs through interdisciplinary involvement between the manufacturer and their various representatives with designers. Producibility technology studies were performed as an integral part of the analytical design effort to focus upon the practical requirements of manufacture for metal and composite structures by Lockheed. The important aspects of producibility are:

- Fabrication Technologies

- Manufacturing Guidelines

- Fabrication Limits and Constraints

- Materials and Processes Compatibility

In fact, any product development cycle in manufacturing is as follows:

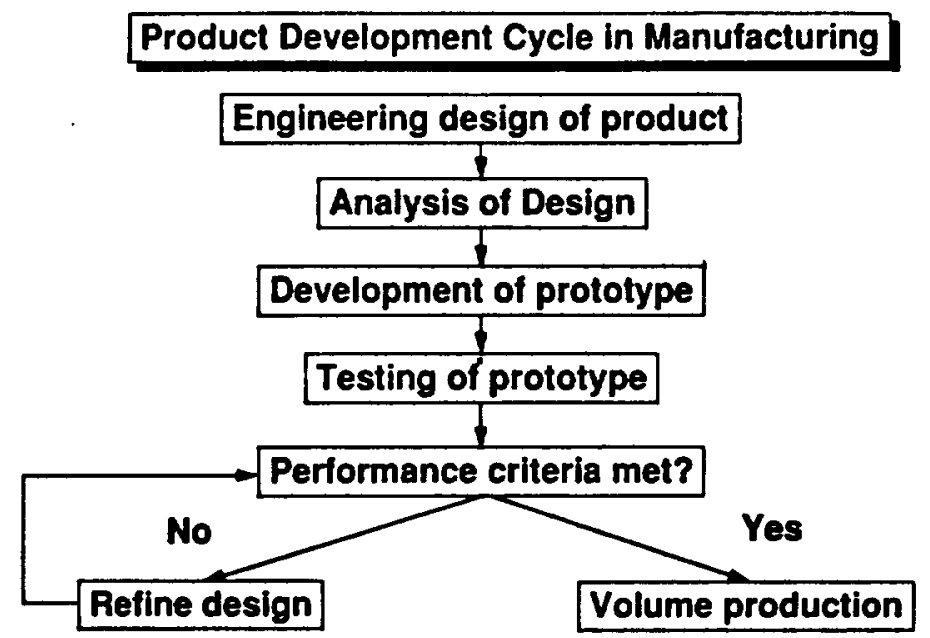

The goals of the product development cycle are:

(a) Design for customer (Quality)

- Design a functionally and visually appealing product

- Provide mechanical reliability for the long haul

(b) Design for manufacturability (Cost)

- Product can be made cost-effectively

(c) Reduce design cycle (Time)

- Do a better job in a shorter length of time

- Minimize liabilities

In order to reach these goals the designer should:

- Develop modular designs 
- Design parts for repeat use

- Use off-the-shelf components

- Standardize and rationalize

- Design for ease of component fabrication

- Design for ease of assembly

- Design for commonality

- interfacing with other disciplines

- include sufficient details in the preliminary concept to enable other disciplines to evaluate the design

- take tooling into consideration

- use simple processes and operations 5

\subsubsection{Fabrication}

Fabrication costs are driven by the design requirements of the structure. These requirements determine a set of candidate materials, such as the ones examined in the previous section. This will determine a set of fabrication processes. Normally, superior performance requires more expensive materials and fabrication techniques. So, primary structures, for example, wing skins are highly loaded structures. They demand high-performance materials and are expensive to make. On the other hand, secondary parts can be made by cheaper materials and cheaper and quicker manufacturing processes.

\subsubsection{Fabrication Techniques}

This section will detail different fabrication techniques as presented by the Lockheed report as well as modern sources on manufacturing for composites and titanium.

The traditional and most common method of composite fabrication in the aircraft industry is manual lay up plus autoclave cure, but different methods can be used for different parts. Some of these are:

Filament Winding:1 Large structures can either be autoclave cured or room temperature cured by this method.

Braiding: For long and continuos lengths of simple cross section.

Vacuum bag curing: The maximum external pressure is limited to $14.7 \mathrm{psi}$ (atmospheric). Heat is supplied by an oven. In this method the cost can be less than those products cured in autoclaves.

Thermal expansion curing: This process is relatively cheap but care must be taken in the design of the fixtures so that the proper pressures are created. 
Hot roll forming: For the production of long and continuous members of constant crosssectional shape.

Injection molding: Molds are expensive, so this method is best for small and high part numbers. Cycle times less than 5 minutes.

Compression molding: For large in size simple in shape parts. Cycle times are long(hours).

Hot stamping: Process temperature around $700^{\circ} \mathrm{F}$. Process pressure around 5,000 psi. This process is suitable for chopped fiber reinforcements.

Thermoforming: Is related to hot stamping, but is used when the fibers are required to maintain specific orientations.

Pultrusion: The process consists of pulling dry fibers through a resin bath and then through steel dies which define the shape of the part and control the amount of resin in the part.

Hydroforming: The procedure uses a hydraulic press which is fitted with a flexible pressurizing medium on the upper plate and a rigid form block on the lower plate. Press time can be about 30 minutes.

Elastic reservoir molding: For producing sandwich components consisting of a rigid foam core with reinforcing facesheets.

\subsubsection{Wing Fabrication}

Concerning the wing fabrication, our recommendations are based on Lockheed, the Rand report, and current titanium production techniques.

Since the wing size is large, there are needed improvements on the level of automation in manufacturing processes. It is the key to the practical application of composites and it has already been extensively applied to simple structures such as tubes and straight constant-cross-section configurations. It is up to companies to develop automated tape laying systems as well as a completely integrated system which will permit a hands-off fabrication of wing covers. Cure cycle control, braiding, weaving, simple press, and injection molding methods all are capable of being automated processes.

The degree of automation should be contemplated and determined by the designer but they are not expected to be up-to-date on the most current manufacturing systems available. Also some manufacturing systems are still being developed. Therefore, it is up to the designer to involve those people who are aware of the new systems in the development of the design. Figures 7.7.14 and 7.7.15 show an integrated manufacturing approach for wing skin fabrication and different structural product concepts that can be produced through modern fabrication techniques. 


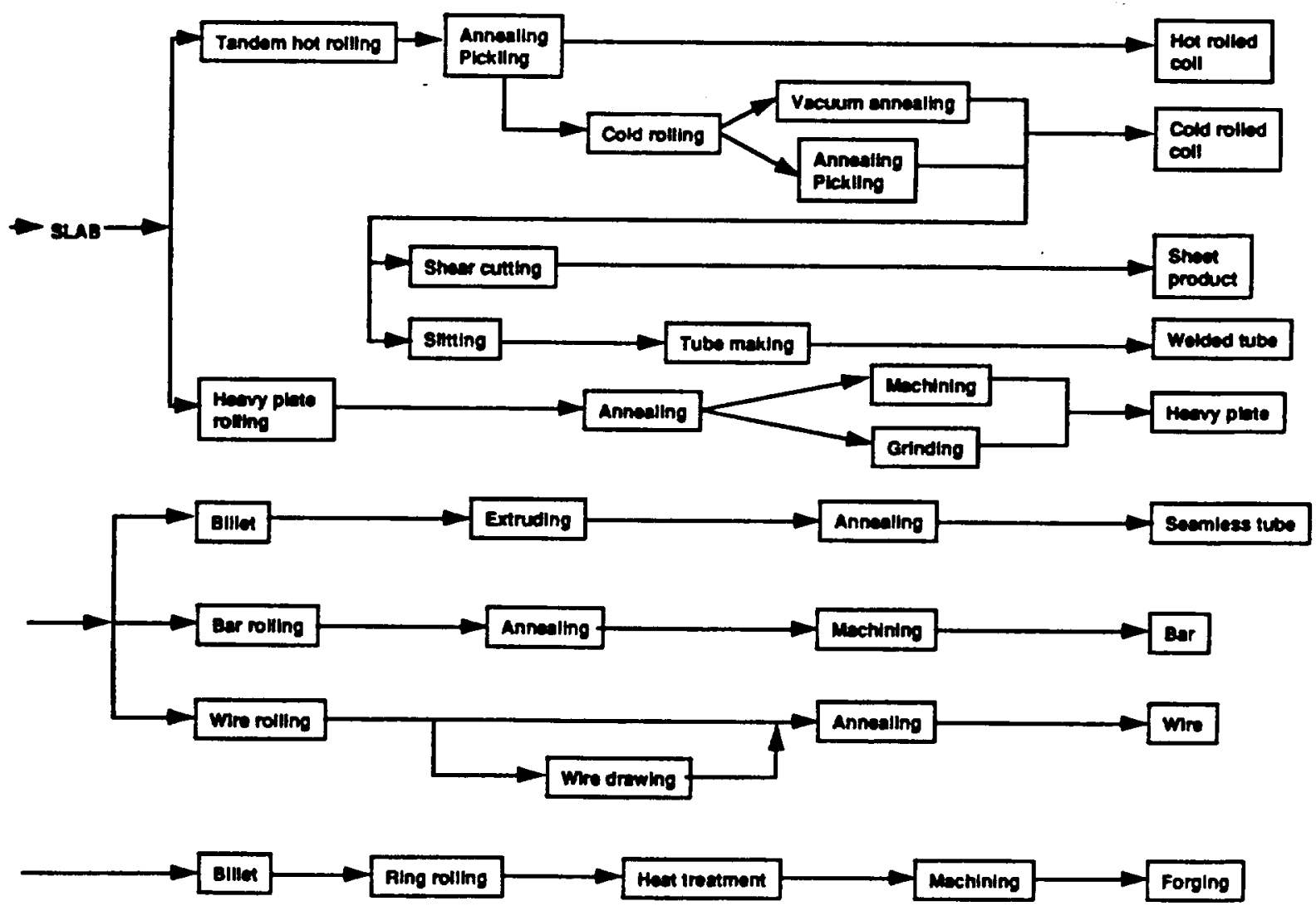

Eigure 7.7.14 Final Titanium Manufacturing Processes and Products 


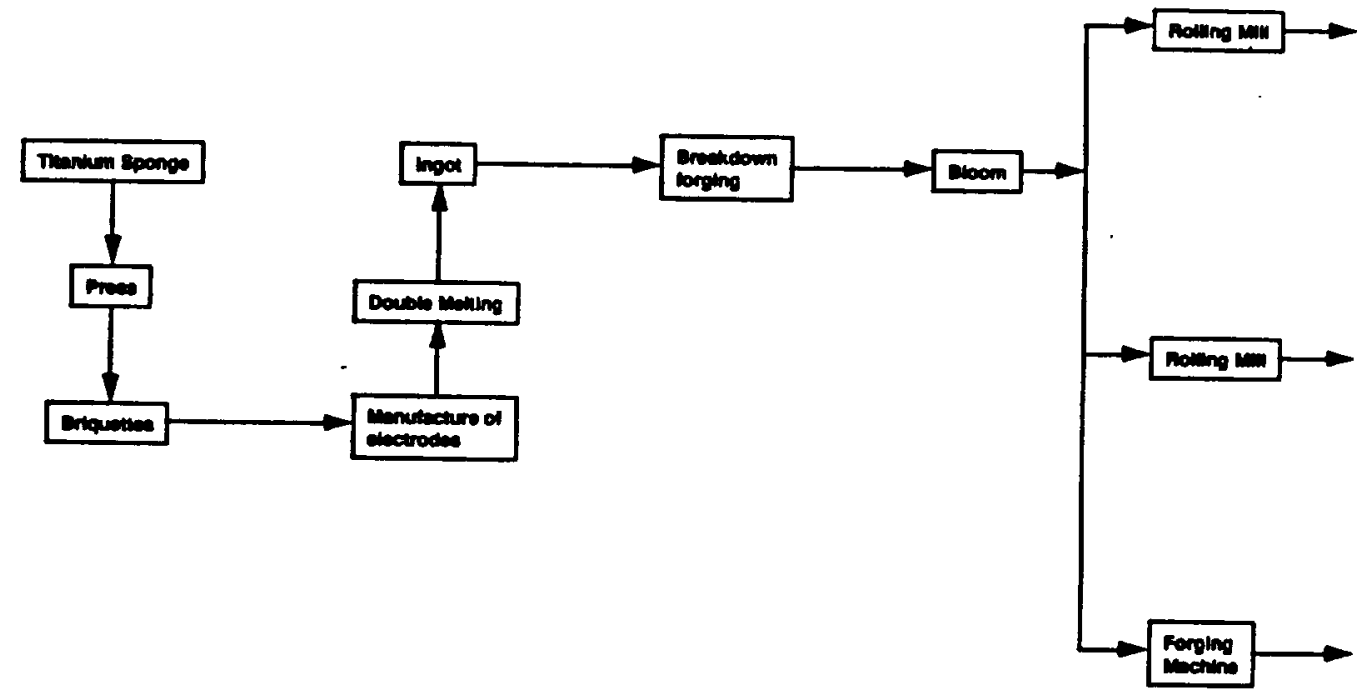

Eigure 7.7.15 Final Titanium Manufacturing Processes and Products

The best type of basic automation that immediately offers high cost savings in composite construction is the use of high-speed tape laying machines. The preparation of composite materials under automatic processing is increasing, and filament-wound structures are amenable to it, but accurate timing is crucial if curing requirements are to be met.

To improve costs composite materials such as polymer matrix composites and metal matrix composites as well as new metal alloys such as aluminum-lithium and powder metallurgy alloys should be incorporated into the design when possible. These materials can be incorporated into primary structure and complex shaped components such as wing skins, spars and ribs, etc., but only after sufficient research, testing, and evaluation is performed on the composite structure. This is why some materials are not yet being applied to this design.

Experience achieved by the military defense industry should use different/new methods to overcome existing problems. An example is when processing temperatures exceed $6500^{\circ} \mathrm{F}$. Many conventional manufacturing procedures and equipment must be revised or replaced. Both metal and rubber tools cannot be used in autoclaves due to the fact that they can be damaged. Therefore, manufacturing processes which minimize autoclave use for thermoplastics are being developed (such as pultrusion).

To meet the requirements of tight dimensional control of high temperature components, the development of crack free surface, compound contoured, resistance heated ceramic dies ( $15 \mathrm{ft} x$ $35 \mathrm{ft}$ ) with constant surface temperature controls are required. The disadvantages of ceramic tooling are:

- High Cost

- Lack of easy machinability

- Difficult repairs 
- Low fracture resistance

- Low tensile strength and brittleness

- Low thermal conductivity

- Relative coarse surface

- Long heat-up and cool down times 5

So, making these tools could be one of the major manufacturing problems to be solved. Since ceramic material is frangible, attempts are being made to reinforce it to allow its use for large tool surfaces. Reinforcements such as bars, wire, mesh, screen, and fibers can be imbedded in ceramic tools. But, steel reinforcements are prohibited because of the coefficient of thermal expansion incompatibility of the two materials. And also, glass and kevlar fibers are prohibited as they do not bond well to ceramic materials. Despite the difficulties, ceramics are castable and can be used as large tools for surface with compound contours.

Other manufacturing methods include:

Welding thin gage sheet $(.010-.030 \mathrm{in})$

- Gas tungsten arc welding (GTAW) ${ }^{6}$, often called tungsten inert gas (TIG) welding, is an arc welding technique in which the heat is produced between a nonconsumable electrode and the work metal. The electrode, weld pool, arc and adjacent heated areas of the work piece are protected from atmospheric contamination by a gaseous shield.

Table 7.7.3 presents the suggested welding procedure schedule for GTAW of titanium.

\begin{tabular}{|c|c|c|c|c|c|c|c|}
\hline 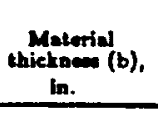 & $\begin{array}{l}\text { Tungaten } \\
\text { oloctrode } \\
\text { diemeter, } \\
\text { in. }\end{array}$ & $\begin{array}{c}\text { rillor } \\
\text { rod } \\
\text { dienpter, } \\
\text { in. }\end{array}$ & $\begin{array}{l}\text { Nonale } \\
\text { sien } \\
\text { ID, in. }\end{array}$ & $\begin{array}{l}\text { Ehielding } \\
\text { ren now, } \\
n^{3} / h\end{array}$ & $\begin{array}{c}\text { Wolding } \\
\text { current } \\
\mathbf{A}\end{array}$ & $\begin{array}{l}\text { Number } \\
\text { of : } \\
\text { pemee }\end{array}$ & $\begin{array}{l}\text { Treval } \\
\text { opeod } \\
\text { (d). } \\
\text { in./min }\end{array}$ \\
\hline \multicolumn{8}{|c|}{ Bquaro-groove and fillet welda: } \\
\hline $\begin{array}{l}0.024 \\
0.065 \\
0.093 \\
0.125 \\
0.18 \\
\end{array}$ & $\begin{array}{l}1 / 16 \\
1 / 16 \\
3 / 32 \\
3 / 92 \\
3 / 32 \\
\end{array}$ & $\begin{array}{l}= \\
1 / 16 \\
1 / 16 \\
1 / 1\end{array}$ & $\begin{array}{l}3 / 8 \\
8 / 8 \\
8 / 8 \\
3 / 8\end{array}$ & $\begin{array}{l}18 \\
18 \\
25 \\
25 \\
25 \\
\end{array}$ & $\begin{array}{l}20-35 \\
28-140 \\
170-215 \\
100-235 \\
220-280 \\
\end{array}$ & $\begin{array}{l}1 \\
1 \\
1 \\
1 \\
2 \\
\end{array}$ & $\begin{array}{l}6 \\
8 \\
8\end{array}$ \\
\hline \multicolumn{8}{|c|}{ V-groore and fillot weida: } \\
\hline $\begin{array}{l}0.28 \\
0.375 \\
0.50\end{array}$ & $\begin{array}{l}1 / 8 \\
1 / 8 \\
1 / 8 \\
\end{array}$ & $\begin{array}{l}1 / 8 \\
1 / 8 \\
3 / 32 \\
\end{array}$ & $\begin{array}{l}0 / 8 \\
3 / 4 \\
3 / 4\end{array}$ & $\begin{array}{r}20 \\
38 \\
10 \\
\end{array}$ & $\begin{array}{r}275-320 \\
300-360 \\
328-426 \\
\end{array}$ & 2 & 6 \\
\hline \multicolumn{8}{|c|}{ 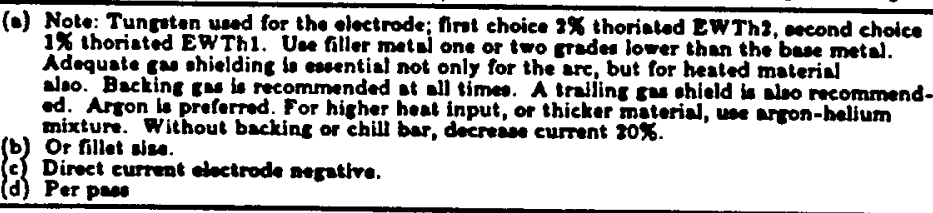 } \\
\hline
\end{tabular}

Table 7.7.3. Suggested welding procedure schedule for GTAW of titanium (a) 6

The minimum material thickness (b) in. (0.024in) in this table is bigger than $.010 \mathrm{in}$. So, for the thickness less than 0.024 in, a good method should be developed.

- Vacuum forming (1450\%) 
Since the crack free surface, compound contoured, resistance heated ceramic dies (15ft $\mathrm{x}$ $35 \mathrm{ft})$ can be made, the vacuum forming $\left(1450^{\circ} \mathrm{F}\right)$ seems to be feasible.

- Continuous roll forming (cold $<14500^{\circ}$ )

Titanium alloy sheet and plate are strain hardened by cold forming. They exhibit a high

degree of springback in cold forming. ${ }^{6}$ To overcome this characteristic, overformed method or hot size after cold forming can be used. Recent studies that hot form does not greatly affect final properties. Forming at temperatures from $1100^{\circ} \mathrm{F}-1500^{\circ} \mathrm{F}$ allows the material to deform more readily, and its stress relieves the deformed material. It also minimizes the degrees of springback.

- Weld Bonding

In order to reduce the number of mechanical fasteners and improve fatigue life, Lockheed's study pointed that weld bonding of the beaded outer skin to inner skin is proposed to assemble the wing surface panels. There was no further information on this method.

- $\quad$ Riveting - weld bond panel to substructure

Since the wing is a heavily-loaded structure, we titanium riveting was selected for connecting weld bond panel to substructure.

- Isothermal Brazing -- beaded panels -- spar cap clips

The possibility of galvanic corrosion must be considered when filler metals are selected for brazing titanium-base metals, because titanium is an active metal. Braze filler metals initially used for brazing titanium and its alloys were silver with additions of lithium, copper, aluminum, or tin. These are used in low temperature ranges of $1000^{\circ} \mathrm{F}$ to $1100^{\circ} \mathrm{F}$. Commercial braze filler metals, including silver-palladium, titanium-nickel, titanium-nickel-copper, and titanium-zirconiumberyllium are now available. These can be used in the $1600{ }^{\circ} \mathrm{F}$ to $1700^{\circ} \mathrm{F}$ range. ${ }^{6}$

- $\quad$ E.B. welding spar -- mating wing assembly

Electron beam welding (EBW) ${ }^{6}$ is a high-energy density fusion welding process. Originally, EBW generally was performed only under high-vacuum $\left(\leq 1 \times 10^{-4}\right.$ torr) conditions. It is obvious that the high-vacuuming working conditions limit modern aircraft manufacturing.

Currently, three distinct modes of EBW are used:

1. High-vacuum (EBW-HV), where the work piece is in the ambient pressure ranging from $10^{-6}$ to $10^{-3}$ torr.

2. Medium-vacuum (EBW-MV), where the work piece may be in a vacuum ranging from 10-3 to 25 torr.

3. Nonvacuum (EBW-NW), where the work piece is at atmospheric pressure in air or protective gas.

In general, equipment costs for EBW are higher than those for conventional welding processes, but higher joining quality can be achieved. 
Figure 7.7.16 demonstrates a typical fabrication scheme to produce Boron/Aluminum composites that will be placed on the wing tip. Figure 7.7.17 details the titanium wing skin production process.

\begin{tabular}{|c|c|c|c|}
\hline \begin{tabular}{|c|} 
Step 1 \\
$\begin{array}{c}\text { Apply Aluminum } \\
\text { foll }\end{array}$ \\
\end{tabular} & \begin{tabular}{|l|} 
Step 2 \\
Cut to \\
Shape \\
\end{tabular} & \begin{tabular}{|l|} 
Step 3 \\
$\begin{array}{l}\text { Lay up } \\
\text { desired } \\
\text { plies }\end{array}$
\end{tabular} & $\begin{array}{c}\text { Step } 4 \\
\text { Vacuum } \\
\text { encapsulate }\end{array}$ \\
\hline Step 5 & \multicolumn{2}{|c|}{ Step 6} & Step 7 \\
\hline $\begin{array}{l}\text { Heat to } \\
\text { fabrication } \\
\text { temperature }\end{array}$ & \multicolumn{2}{|c|}{$\begin{array}{l}\text { Apply pressure } \\
\text { and hold for } \\
\text { consolidation cycle }\end{array}$} & $\begin{array}{l}\text { Cool, remove, } \\
\text { and } \\
\text { clean part }\end{array}$ \\
\hline
\end{tabular}

Elgure 7.7.16 Flow Chart of Producing Boron/Aluminum Composites 5

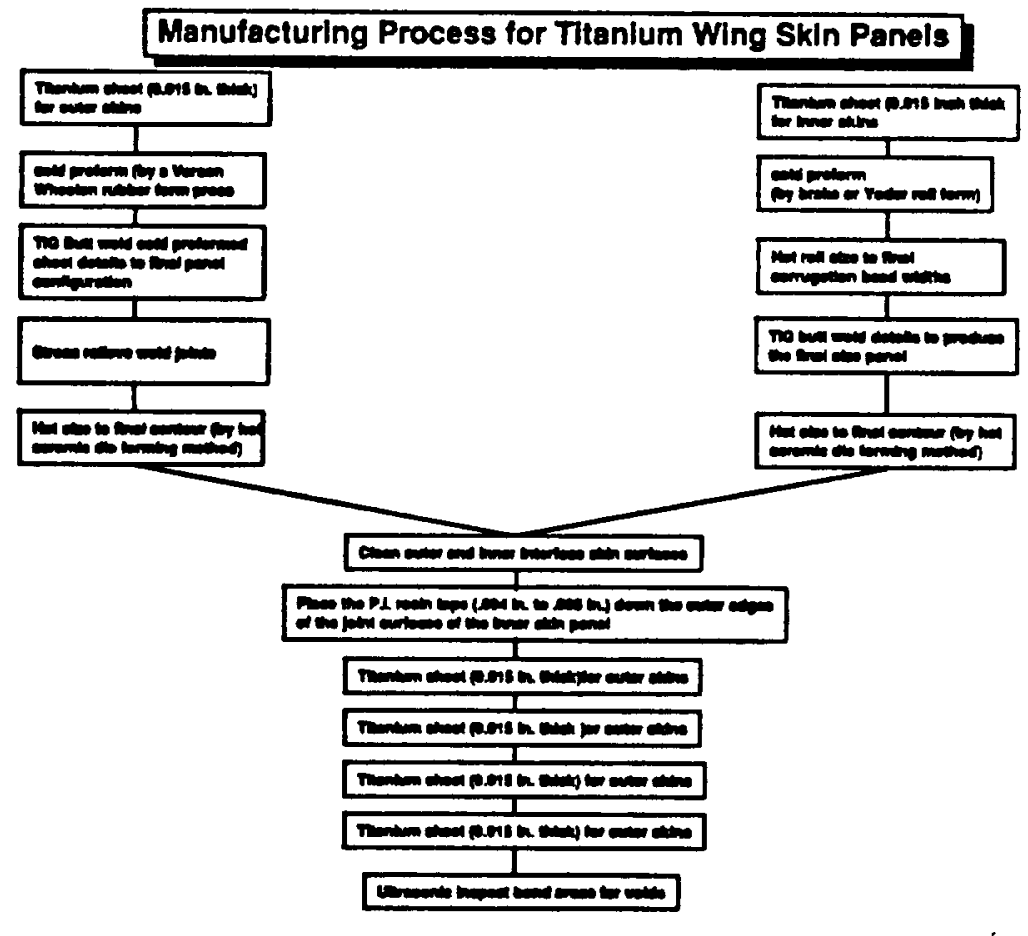

Eigure 7.7.17 Titanium Wing Skin Production Process

For a design incorporating the Monocoque Wing-Honeycomb Sandwich Surface Panel fabrication, and for detail parts fabrication, the key parameters in these selected problem areas are 
the size effect of the structural components on the fabrication technologies and facility requirements. Optimistically speaking, by the time production is started for the HSCT, with continued research, most of the manufacturing problems will be solved due to the maturity of titanium production technology and increasing maturation with composite manufacture. Figure 7.7.18 shows the wing manufacturing flow plan.

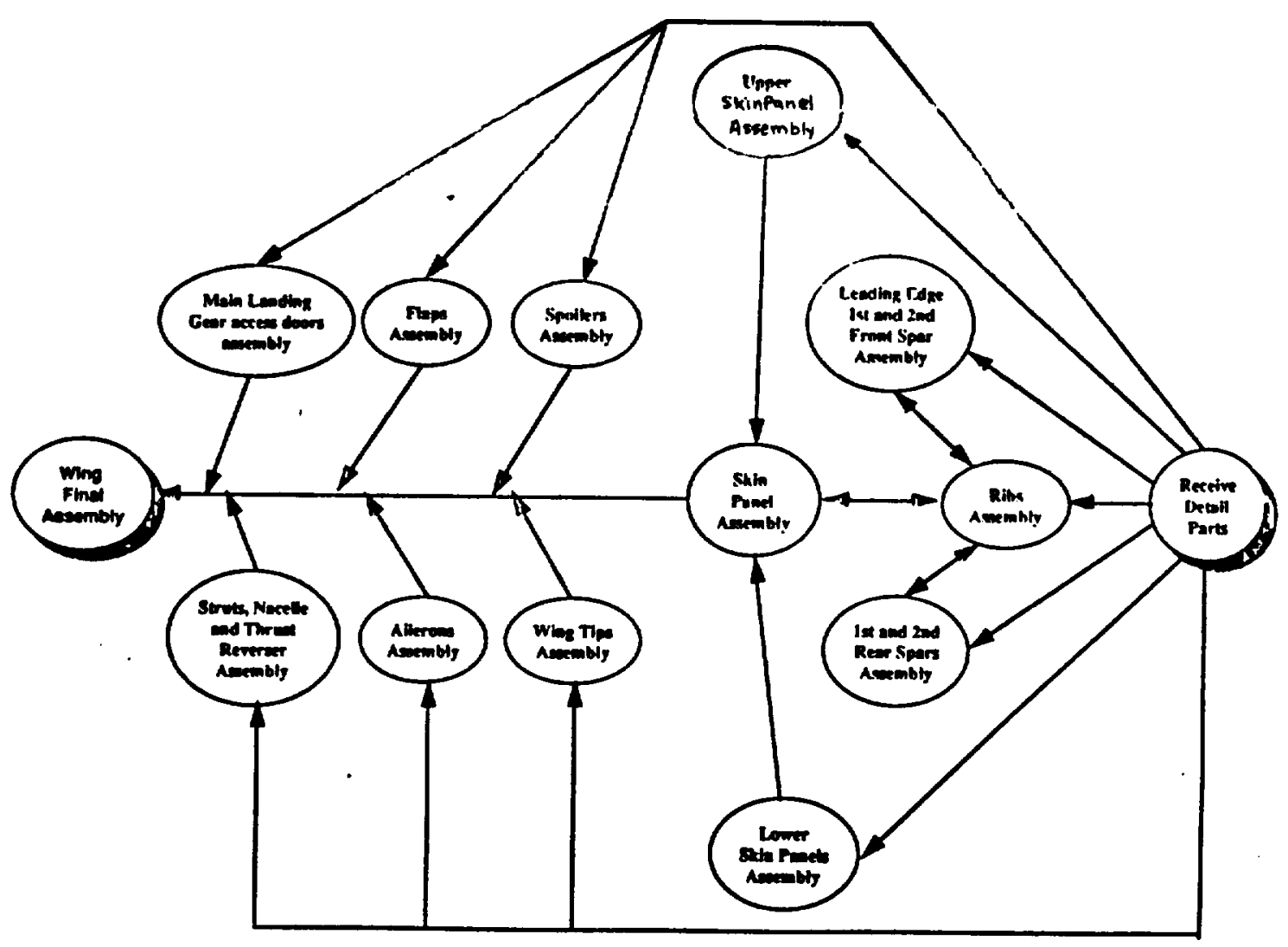

Figure 7.7.18 Wing Manufacturing Flow Plan 


\section{References}

1. NASA CR-132575: Substantiating Data Report: Arrow-Wing Supersonic Cruise Aircraft Structural Desien Concpets Evaluation. Vol 2, Section 7,1975.

2. Quist, William E.,Advanced Materials for a High Speed Civil Transport, Presented to the Capital Metals and Materials Forum, November 9, 1990, Boeing Commercial Airplane Group, Seattle, Washington.

3. Cazier, F.W., Jr., HSR Airframe Materials and Structures, Presented to Aerospace Research and Technology Subcommitte for Materials and Structures, NASA Langley Research Center, November 4-5, 1992.

4. Niu, Michael C.Y., Airframe Structures Design. Conmilit Press Ltd, Hong Kong, 1992

5. Niu, Michael C.Y., Composite Airframe Structures:Practical Design Information and Data. Conmilit Press Ltd., Hong Kong, 1992.

6. Donachie, Matthew J., Jr., ed. Titanium: A Technical Guide. ASM International, Metals Park, OH, 1988.

7. Peacock, D.K., C.Eng. "New Alloys. New Processes Advance Titanium Forging Application", Aircraft Engineering, 1988. 


\subsection{Economics and Cost}

\subsubsection{Introduction}

The commercial aircraft industry is heavily reliant upon the health of the airline industry, a reliance that could even be characterized as detrimental. The contemporary airline industry is wrought with labor problems, fuel cost concerns, and intensive competition that is a result of a non-differentiable service. These factors lead to low investment returns at best and gigantic losses at worst. In fact, the airline industry realized positive returns for only five years in the 1980 s, the largest return was only $3.2 \%$ in 1988 [20]. For the 11 years from 1979 to 1989, the industry had a profit of only $\$ 1.6$ billion [22]. Only two years later, the industry was victimized by a shortfall of $\$ 3.8$ billion [20]. In fact, since 1990, the airline industry has combined losses of $\$ 8$ billion [12], over $\$ 2$ billion more than the combined profits of the whole industry during its entire existence.

However, the airline industry does have potential for future success. To an extent, the industry's losses are skewed low due to several carriers that consistently posted losses and then filed for bankruptcy. For example, over the past 20 years, the average operating profit margin for the industry has been $2.3 \%$ or $3.2 \%$ if one excludes three problem carriers [5]. Additionally, certain aviation markets will expand rapidly during the 1990s and the early part of the next century. Boeing estimates that the industry will have an average operating profit margin of $4.0 \%$ from 1992-2000 [5]. From 1990 to 2000, Boeing estimates that worldwide airline revenue will double from $\$ 200$ billion per year to $\$ 400$ billion per year. This will push the airline portion of world GDP from $1.4 \%$ to $1.8 \%$ [5].

One market of interest to the HSCT is flight to Asia. Boeing predicts that $\$ 857$ billion (1992 U.S. dollars) of commercial airplanes will be sold worldwide through 2010 [5]. By the year 2015, one estimate places the dollar percentage of HSCT deliveries at 30\% [3].

The financial implications of the HSCT are extremely important to understand. Without funding or a market, there will be no development of a high speed commercial aircraft. Russel H. Hopps, former Vice President for engineering at Lockheed, stated, "to launch a commercial aircraft one must understand cost, timing, environmental considerations, and, most importantly, economic viability" [3]. Hopps then defines the meaning of economic viability as the condition when a product "will make money for the investors, make money for the builders, and make money for the users" [3]. Hopps underscores the importance of economic viability and aircraft design when he states the following:

Economic viability, as I said earlier, is what commercial aircraft design is all about. Once you make this favorable assumption, it follows that it doesn't matter if the aircraft is Mach $2,5,10$, or transatmospheric. If it's economically viable, the financial community will 
stand in line to fund this program because there is a profit to be made. So, the assumption itself causes a paradox; it eliminates any problem [3].

To have an HSCT airplane program, there must be the funding. George James, President of Airline Economics, Inc., describes the HSCT airplane program as being financed in the three phases outlined below:

[3]

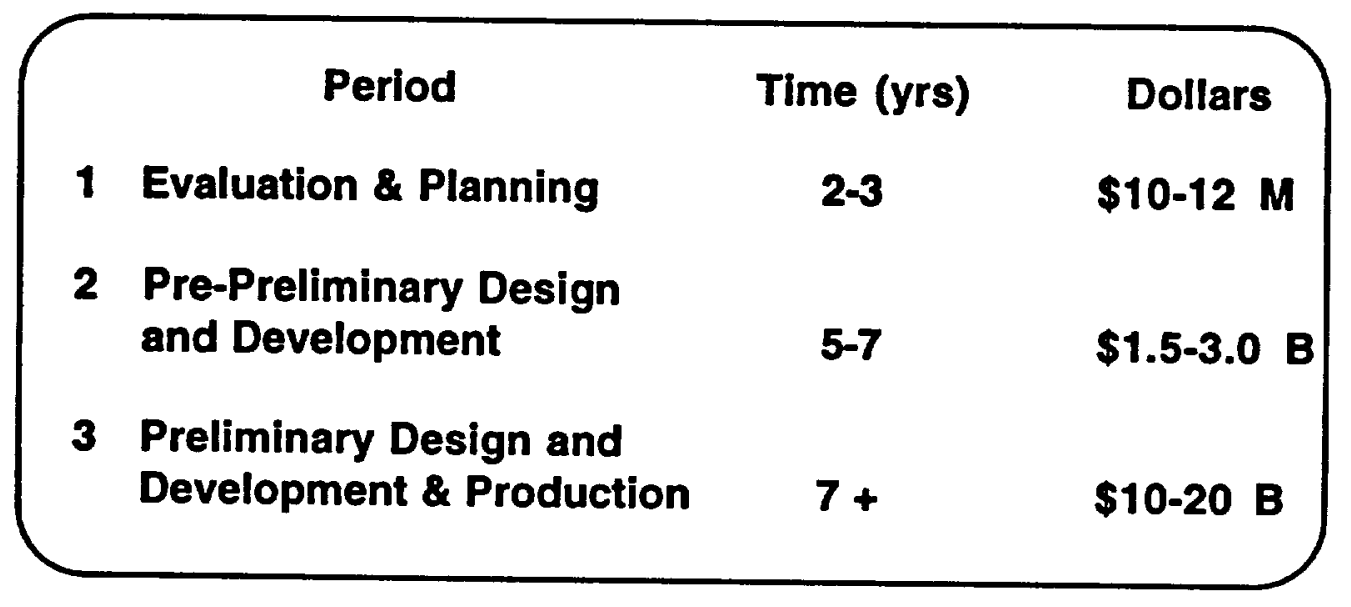

Table 7.8.1 HSCT Funding

The funding source for the first period is likely to be airframe manufacturers and airlines. This phase would be analogous to the Boeing and Lockheed studies. The second period should be financed by governments [3] because at this stage it is still premature for financial markets to become involved. Hopps emphasizes this idea when he states:

Where is the money going to come from to develop this base to move rapidly on a 2015 program? It was our opinion that people will not fund a program that takes 35 years to obtain a return on their investment. Why do I say 35 years? If you're talking about a 2015 airplane, you have 25 years until the airplane goes into service. Based on today's commercial programs, you're looking at an additional 10 years to a positive cash flow, thus 35 years. You cannot convince me that people are going to put out billions of dollars and wait 35 years to get a return on that investment. It just is not realistic! [3]

The "conventional sources" for financing such as banks and other institutions will not be active until the third stage of the program [3].

A McDonnell Douglas estimate projects that a 1000-unit HSCT airplane program would create 200,000 jobs and would increase U.S. GNP $\$ 500$ billion over the entire life cycle. Although the $\$ 500$ billion amount may include a factor for the multiplier effect, the conclusion is still the same: the HSCT is an enormous program financially. This reason alone could almost force the HSCT to done as an international consortium. When one considers research and development requirements, environmental concerns, airport and Five Freedom restrictions, and the international destination dimension of the HSCT, it becomes quickly apparent that an international 
consortium is probably the only feasible solution. For most American businesses, the concept of participating in a consortium is still quite foreign. One reason for this is almost one-hundred years of anti-trust regulation dating back to the railroad development era. As a result,

We needed information in order to determine what kind of consortia and financing were needed for this program--and remember, it's financing, not finance ... It is not as if we were trying to estimate the cost of doing all of this. We were trying to come up with how we would finance it once we estimated the cost [3].

But, of course, the cost is quite important as well. The estimated cost of the HSCT is the thrust of the next section.

\subsubsection{Manufacturing Cost}

The estimation of manufacturing cost is the most important part of this section. Specifically, this section is to deal with the manufacturing costs that relate specifically and uniquely to the wing component. Then, a system level cost estimating tool will take the component level information and use this to "close the loop" of the concurrent engineering design process. However, before the component analysis and tradeoffs are presented, some material for airplane cost at the system level will be discussed.

Jan Roskam, professor at the University of Kansas, has published a series of books on airplane design. The eighth book of the series deals with estimating airplane cost. The general equations that compute the profit, manufacturing, and acquisition cost are presented on the following page. A list briefly explaining each variable follows:

CACQ:

Caed $_{m}$ :

$\mathrm{Capc}_{\mathrm{m}}$ :

Cavionics $_{\mathrm{m}}$ :

$\mathrm{C}(\mathrm{e}+\mathrm{a})_{\mathrm{m}}$ :

CEF:

Cfin ${ }_{m}$ :

Cfto $\mathrm{m}$ :

Cint $m$ :

Cman:

$\mathrm{Cman}_{\mathrm{m}}$ :

Cmatm:

Cops/hr:

Cpm:

CrRo:

$\mathrm{Cqc}_{\mathrm{m}}$ :

$\mathrm{Ctool}_{\mathbf{m}}$ :

Ffin $_{\mathrm{m}}$

Fftoh:
Acquisition Cost

Airframe Engineering and Design Cost

Airplane Production Cost

Avionics Equipment Cost per Airplane

Engine and Avionics Cost

Cost Escalation Factor

Cost of Financing the Manufacturing Program

Production Flight Test Operations Cost

Cost of Interior

Manufacturing Cost

Manufacturing Labor Cost

Manufacturing Material Cost

Airplane Operating Cost Per Hour

Cost Per Propeller during Manufacturing

Manufacturer's Profit

Quality Control Cost

Tooling Cost

Financing Factor

Overhead Factor Associated with Production Flight Test 


\section{Fprom: $\quad$ Suggested Profit}

MHRaed program: Total Number of Engineering Hours Required for Program

MHRtool program: Total Number of Tooling Hours Required for Program

Ne:

Number of Engines per Airplane

Nm:

Np:

$\mathrm{Re}_{\mathbf{m}}:$

Number of Airplanes built to Production Standard

Number of Propellers per Airplane

tpft:

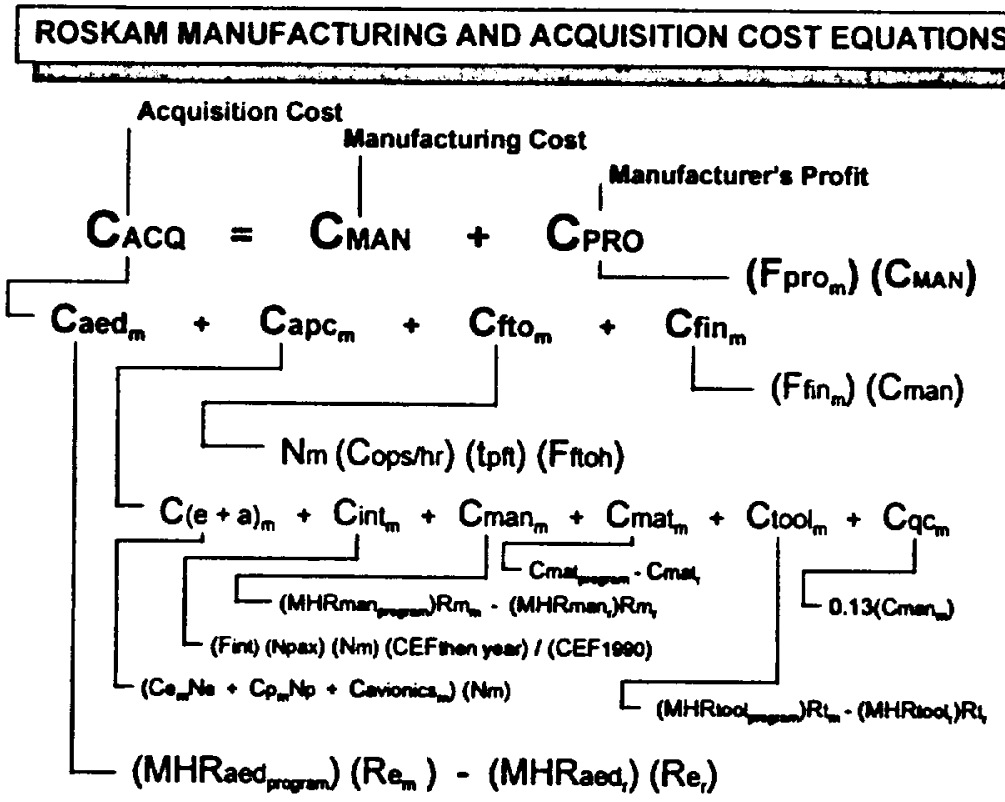

Eiqure 7.8.1 Roskam Mfg and Acquisition Cost Eqns

Dr. Roskam goes into greater detail and includes some empirical relationships so that actual costs may be determined. The equations present a useful way of conceptualizing the relationships between various costs; however, there are better methods of actually computing the costs for an airplane program. The purpose here is to merely show the relationships between all the costs succintly. A program called ACSYNT (Aircraft Synthesis) is much faster and easier to use than the empirical equations of the general aforementioned cost equations.

The primary focus of the economics and cost section of this document is to determine the optimal wing with respect to cost. A secondary goal is to determine the actual cost of producing the wing. Note that these two goals are slightly different: the primary goal emphasizes making economic and design tradeoffs to reduce the cost of the wing while the secondary goal is merely to forecast what that wing might actually cost. It would seem that determining the total cost of the wing would be necessary to make the tradeoffs to optimize the wing. In actuality, one of the costing models presented here does not emphasize cost prediction, but allows engineers to see the economic tradeoffs associated with their designs. This model is the Designer's Cost Trade-off 
Tool which is a derivative of another costing tool presented here, PRICE H (Programmed Review of Information for Costing and Evaluation--Hardware). Note that PRICE $\mathrm{H}$ is not a pricing model [19]. Additionally, a parametric costing model developed by the RAND Corporation in 1981 for structural modifications will be used. At the system level, the UNIX based program ACSYNT will be used to verify results and to compare the wing to other components of the HSCT. Finally, ACSYNT will be used to close the economic "loop" at the system level as stated previously.

The diagram that follows shows the wing that has been analyzed for costing relationships. Note that the structural analysis elsewhere in this document only considers the primary structure, the lightly shaded area of the figure. In addition to the primary structure, cost analysis considered the leading edge and trailing edge of the wing and the strake. These sections are depicted as white and dark gray, respectively. Thus, the wing that the structural analysis deals with is approximately 53,000 pounds when titanium is used while the wing defined for cost analysis here weighs almost 69,000 pounds.

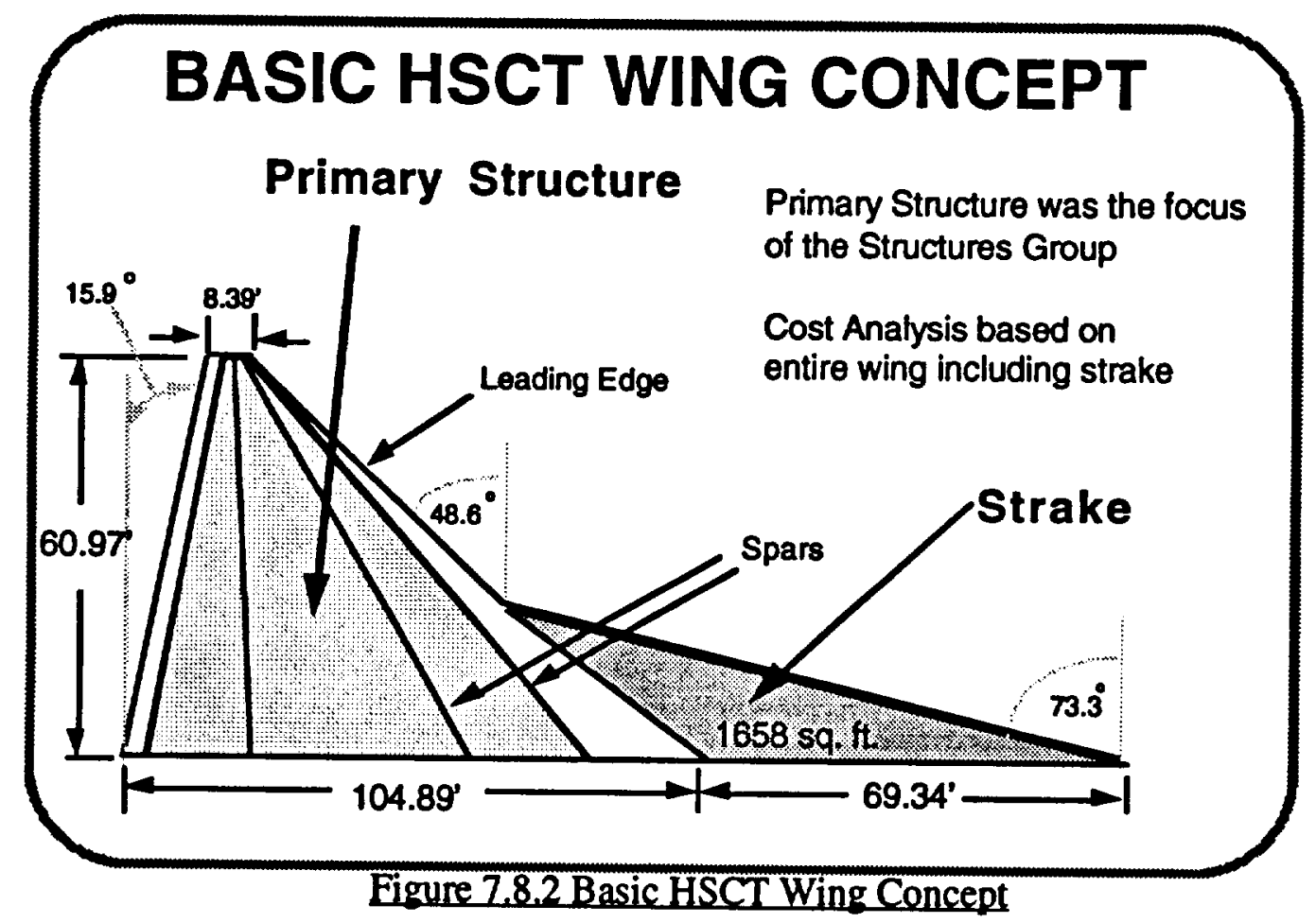

\subsubsection{Rand Model for Airframe Structural Modifications}

In 1981, the RAND Corporation published a parametric costing method for structural modification for aircraft. Unfortunately, the study "did not yield a well-ordered set of parametric and deterministic estimating equations" [4]. Thirteen aircraft were used for the database, although the methodology by which manufacturers allocated costs differed significantly. Thus, it was not possible to review accounting records to obtain an accurate view of the cost picture. Problems 
with allocating subcontract work to "materials costs" tended to cause inconsistency with total labor hours and materials costs. Additionally, some accounting systems identified some work hours to an aircraft by section while other work loads were considered as belonging to subsystems and then were allocated to each section in a logical manner [4]. Such problems will plague any attempt to determine a parametric relationship between aircraft, especially when the aircraft differ in type, size, mission, and producer.

For the HSCT, there will be some variability from the RAND study because many of the aircraft were fighters and only a few were supersonic. Because a parametric relationship could not be determined if a lot of separation was used, fighters and transports as well as supersonic and subsonic aircraft were grouped together. As expected, the RAND report found that "supersonic aircraft seem to require more expensive materials, as well as more hours to design and produce" [4].

The model uses weight as the primary input. The study produces an equation for the number of hours required to produce 100 aircraft. For the 100th unit cumulative average manhours required for engineering, the following equation is used:

$$
E_{100}=84.89 W^{50}
$$

[4]

This equation is only valid for weights ranging from $3,700 \mathrm{lbs}$. to $82,000 \mathrm{lbs}$. In addition, the learning curve percentage, coefficient of determination $\left(r^{2}\right)$, standard error of estimate (SEE), and the logarithmic form of the mean value for man-hours through the 100th unit. In the case of engineering hours for the wing, the following results were found:

Coefficient of Determination:

Mean 100th unit man-hours:

Standard Error of Estimate:

Learning Curve Percentage:
0.83

8267

0.30

$55 \%$

\section{[4]}

The coefficient of determination is a measure of the variability in the dependent variable (cost) that is explained by the independent variable (weight). Often, the correlation coefficient is given which is the positive or negative square root of the coefficient of determination, depending on the regression slope. In this case, the correlation coefficient is 0.911 which indicates a rather descent goodness of fit. The Standard Error of Estimate is used to determine the standard error percentages. For engineering hours, a standard error of 0.30 means error percentages of $-26 \%$ and $+35 \%$.

The learning curve is a very important aspect of the aerospace industry. For a learning curve value of $55 \%$, the corresponding $b$ factor or cost-quantity factor is found by the following: 


$$
b=\frac{\log L \%}{\log 2}
$$

Thus, a 55\% learning curve corresponds to $a b$ factor of -.8625 . This is used in determining the number of engineering hours for unit 1 and the hours required for any number of units. For unit 1 engineering hours, $E_{1}$, the following relationship is used:

$$
E_{1}=\frac{E_{100}}{100}
$$

For the cumulative average number of engineering hours for any number of units, in this case $x$ units, the following equation may be used:

$$
E_{x}=E_{1}\left(x^{b}\right)
$$

The above equation for $\mathrm{E}_{\mathrm{x}}$ includes both the nonrecurring and recurring engineering hours required.

Engineering work is defined as the number of hours the prime contractor required to manufacture and develop the basic airframe [4]. Specifically, engineering work included the following:

1) design, consisting of studies, stress analysis, aerodynamics, weight and balance analyses, and integration

2) wind-tunnel models and mockups

3) laboratory testing of components, subsystems, and static and fatigue articles

4) preparation, release, and maintenance of drawings, and process and material specifications [4]

For the HSCT wing engineering effort, the nonrecurring total is $1,183,102$ hours for the first unit. For the one-hundredth unit, the average engineering hours per aircraft is 22,286 which includes both recurring and nonrecurring hours. For five hundred units, this total drops to only 5,561 engineering hours per aircraft. Since the standard error percentages are $+35 \%$ and $-26 \%$, this means the range is between 4,115 and 7,507 hours. Considering the supersonic nature of the HSCT, it is likely that the true number of engineering hours would vary between the calculated 5,561 hours and 7,507 hours per aircraft assuming a 500 unit production run. Note that the 1981 RAND study entails structural modifications of existing aircraft, not the original development costs. A Douglas Aircraft study found that the design engineering on a modification program ranged from $30-60 \%$ of the original development in terms of hours per pound for a given cost weight. However, this $30-60 \%$ estimate did not include major purchased parts [4]. It is also interesting to note that $34-67 \%$ of nonrecurring engineering hours of structural modification programs was attributed to development and system testing, system engineering, and program management [4]. Considering the Douglas study again, these numbers indicate that nonrecurring engineering hours in a modification program can range between $50-100 \%$ of the new development engineering on an hours per pound basis. With respect to the learning curve, modification 
programs are considered to have steeper learning curve slopes than the initial development, although the RAND report indicates that a 55\% learning curve is "representative of new development programs" [4]. Extreme caution must be used in adjusting a learning curve factor because the total number of hours and cost of a program is extremely sensitive to the learning curve percentage. The following chart shows four different production levels comparing average unit cost as a percentage of first unit cost and the learning curve percentage. Note that both scales are lograthimic.

\section{LEARNING CURVE}

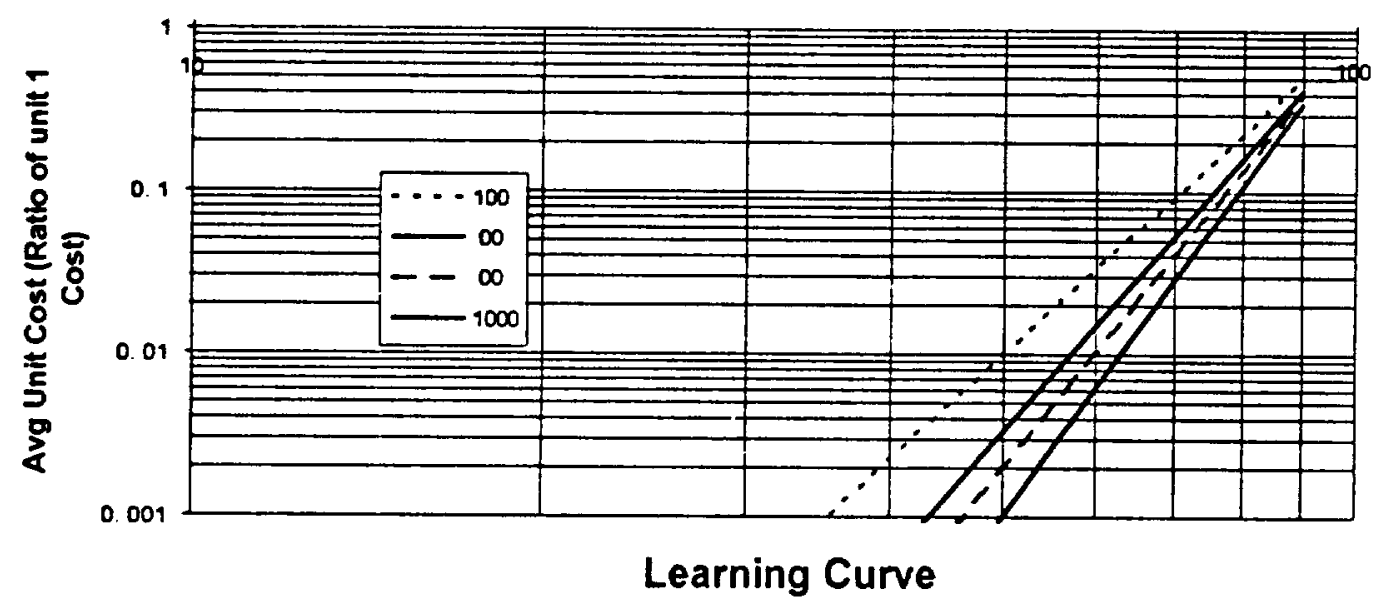

Eigure 7.8.3 Learning Curve

The graph emphasizes the sensitivity cost and labor effort are to the learning curve factor.

Tooling work includes "all effort expended in tool and production planning, designing, fabrication, assembly, installation, modification, maintenance, rework, and programming and preparation of tapes for numerically controlled machines" [4]. Tooling should not be confused with general equipment which is considered capital. General equipment includes milling machines, presses, routers, and lathes while tooling refers such things as assembly tools, dies, jigs, fixtures, and work platforms that are used only for a specific airframe program [4]. The tooling hours for the first unit for the HSCT was calculated as $5,580,321$ or 118,483 per unit for a 100 unit production run. For 500 units, the number of tooling hours required decreased to 30,830 . The standard error percentages are $+65 \%$ to $-40 \%$ which imply a range of tooling hours from 18,498 to 100,369 hours, a considerable range. This substantial error is in part attributable to the fact that estimating tooling hours requires more than a set of equations, but an intimate knowledge of the exact tooling requirement and an awareness of the tooling available [4]. 
Since production costs and hours are usually the largest component of cost when burden is added, accurate estimates of production effort are essential. In contrast to engineering and tooling learning curves of $55 \%$ and $56 \%$, respectively, the learning curve for structural modifications is 77\%, a figure that is considered to be almost $10 \%$ flatter than an initial production program [4]. The NASA Langley estimation of the airframe learning curve was $81.5 \%$ for the HSCT baseline. As a result, the 77\% learning curve from the RAND report was considered valid, despite the caveat of a flatter learning curve for modification programs.

Production hours include:

all recurring direct labor necessary to machine, process, fabricate, and assemble the major structure of an aircraft and to install purchased parts and equipment, engines, avionics, and ordinate items .... also included is the labor component of off-site manufacturing assemblies or certain parts that are design-controlled for the basic aircraft [4].

For the HSCT wing, the number of hours for the first unit was 968,657 or 170,620 per aircraft for the first 100 units. For 500 units, 92,997 production hours were required.

The RAND structural modification study presents a simplistic method for estimating recurring and nonrecurring production labor hours based solely on the weight of the wing. However, a better methodology would employ considerations such as the type of part or employee skill. These factors contributing to the manufacturing complexity are used in the PRICE H and Design to Cost methodologies.

Quality control is the effort expended to make certain that the prescribed specifications and standards are achieved. Usually, quality control is computed as a percentage of production effort. For the RAND study, it seemed that a $10 \%$ figure was reasonable. Thus, the quality control effort for a 500 unit run was 9,300 hours.

The following table summarizes the findings for the 1981 RAND structural modification study. The labor rates used to compute the costs were based on labor rates from a 1990 RAND report which indicated the following labor rates:

$\begin{array}{ll}\text { Engineering } & \$ 80.80 \text { /hour } \\ \text { Tooling } & \$ 70.60 \text { hour } \\ \text { Manufacturing } & \$ 66.10 / \text { hour } \\ \text { Quality Assurance } & \$ 65.60 \text { hour }\end{array}$

[16]

The actual 1993 labor rates were based on a 4\% increase per year from these 1990 labor rates.

LABOR First Unit Effort 500 Units Labor Cost




\begin{tabular}{|c|c|c|c|c|}
\hline $\begin{array}{l}\text { Engineering } \\
\text { Tooling } \\
\text { Production } \\
\text { Quality Assurance } \\
\text { TOTAL LABOR }\end{array}$ & $\begin{array}{r}1,183,102 \\
5,580,321 \\
968,657 \\
96,866\end{array}$ & $\begin{array}{l}\text { hrs } \\
\text { hrs } \\
\text { hrs } \\
\text { hrs }\end{array}$ & $\begin{aligned} 5,561 & \text { hrs } \\
30,830 & \text { hrs } \\
92,997 & \text { hrs } \\
9,300 & \text { hrs }\end{aligned}$ & $\begin{array}{r}\$ 505,434 \\
\$ 2,448,377 \\
\$ 6,914,653 \\
\$ 686,257 \\
\$ 10,554,721\end{array}$ \\
\hline
\end{tabular}

Table 7.8.2 Labor Rates

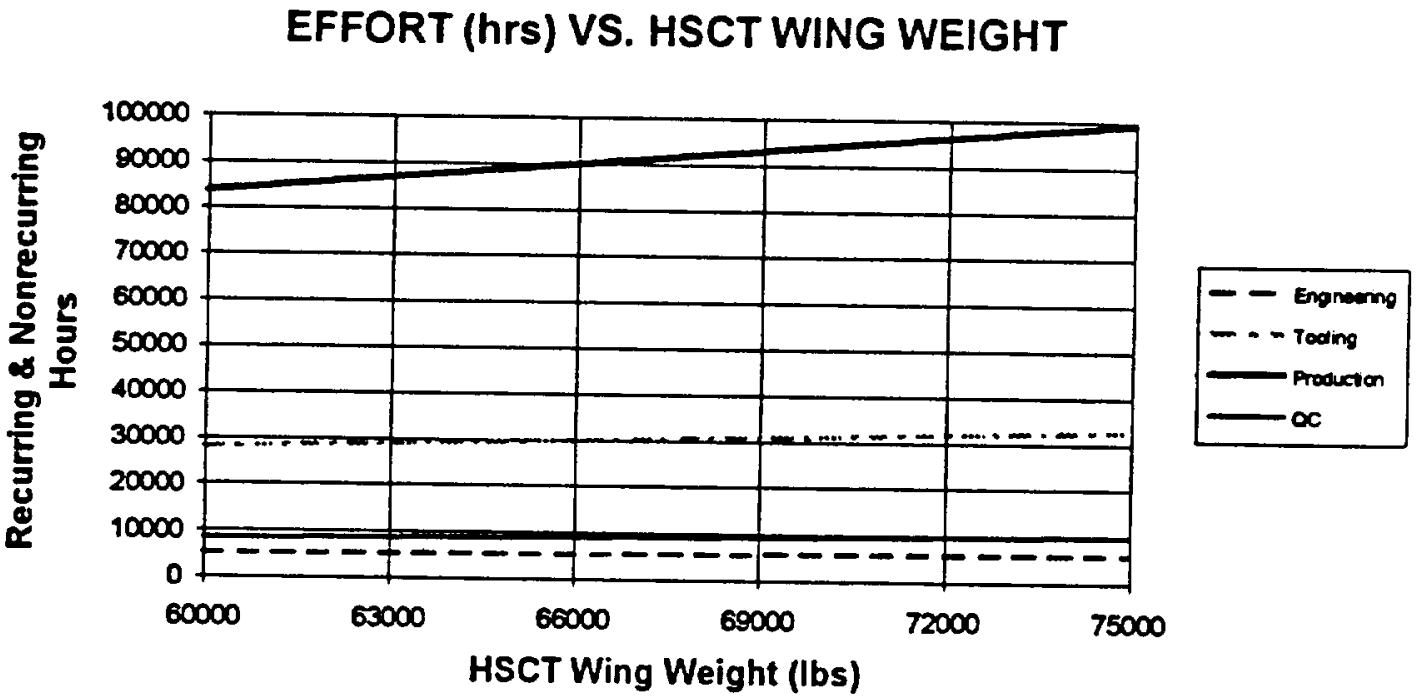

Eigure 7.8.4 Effort (Hrs) vs. Wing Weight

Manufacturing materials is the last category of the RAND study. Manufacturing materials includes "raw and semifabricated material plus purchased parts used in the manufacture of airframe assemblies" [4]. Examples of items in this category include such parts as motors, landing gear, instruments, and generators. For a 500 unit production run of the HSCT, the total cost in 1977 dollars is $\$ 1,779,566$. Assuming an inflation rate of $8 \%$ since 1977 , the materials cost is $\$ 6,096,691$.

\section{RAND STRUCTURAL MOD STUDY \\ Labor Costs: \\ Material Costs: \\ $\$ 10.5 M$ \\ TOTAL RDT\&E + MFG COST: $\$ 16.6 \mathrm{M}$}

Table 7.8.3 Rand Structural Model Study 
Remember that these figures use a burdened labor rate $(\$ 1993)$ that does not include profit. More importantly, these numbers represent the wing as determined for a strucutrual modification program. New development programs usually require more effort, particularly with respect to engineering work.

\subsubsection{Price H}

PRICE H is a parametric cost estimating model developed in the 1960s and is used extensively in the aerospace and defense industry. It is an excellent costing model for engineers and designers to use to reach cost objectives. The model has two different domains: electronics and non-electronics. The non-electronics domain is also referred to as structure and is the focus of the HSCT wing design. The dollars used in the model are normalized to $1972 \$$.

The two main inputs to the model are the weight and manufacturing complexity. The weight is the total weight for all of the parts of a given type for the structure and is not too difficult to obtain. The manufacturing complexity requires a considerable amount of information to accurately gage. However, the more information that is available, the more accurate the complexity factor can be and the more accurate the overall costing estimate. It should be noted that the total objective of this model may not actually be the determination of the cost, but the understanding of the economic tradeoffs in choosing a certain material, a certain machining precision, or a certain manufacturing process. The preliminary outputs of the model are First Piece Cost (in per unit weight), drawing count, and mean time between failures (MTBF) [19]. With additional information, one may also determine the complete unit recurring production cost.

The manufacturing complexity, MCPLXS, is defined in the following manner:

$$
M C P L X S=\frac{3.185185\left(P_{T T F M}^{.32}\right)\left(\text { Parts }^{04}\right)(1+.06(N-\text { MATUR }))}{\left(P R E C I^{.081}\right)\left(M I^{.024}\right)}\left[a_{1} a_{2} a_{3} \ldots a_{n}\right]
$$

PLTFM: Platform - An indication of the type of system being designed whether it be ground transportation, air transportation, space, or manned space. The HSCT application is called "Airbome" and is a factor of 1.8 .

Parts: $\quad$ The number of parts.

N: $\quad$ Factor based on the Platform, $N=3$ if the Platform is less than 2 or $\mathrm{N}=4$ if the Platform is greater than 2

MATUR: Assembly Difficulty, Maturity - This factor incorporates the problems due to tight part tolerances or labor intensive processes that cost a great deal of time and money. This factor generally ranges from 1 to 6 . 
PRECI: $\quad$ Precision - Indicates the tolerances for a fabricated assembly or part. The number used for the generation of MCPLXS is the precision in inches. For example, a precision tolerance of 0.005 inches means PRECI $=0.005$.

MI: Machinability Index - An index that indicates the difficulty in machining a given material. Titanium has a MI of 30 , all composites have a MI of 18, aluminum alloys range from 140 to 190 , and steel alloys generally range from 30 to 60 although some are as low as 15.

$a_{1}, a_{2}, a_{3}$, etc. Additional factors used to compute a realistic TFPC

Maturity values of interest for the HSCT application are listed in the following table:

\section{Description}

Highest precision assembly, requires special instrumentation, final tolerances under 0.001 (Machined \& Fabricated Items)

Assembly tolerances $2 X$ tougher than build tolerances of parts (Machined \& Fabricated Items)

Assembly tolerances same as parts tolerances $/ \mathrm{NP}=1$ (most common) (Machined \& Fabricated Items)

Composite struts (Laminated Composites)

Honeycomb composite structures, inserts machined (Laminated Composites)

Composite struts bonded (Laminated Composites)

Manual composite fabrication assembly (Laminated Composites)

Manual composite fabrication assembly \& mechanized pattern cutting (Laminated Composites)
Value

1.0

3.0

1.85

2.2

\section{[8]}

In addition to the parameters described above, one may use additional inputs when the data is available. For example, if the distance over which a machining tolerance is known, one may use this information to determine a Distance Factor that is multiplied by the MCPLXS value calculated above. Another factor is used when the yield loss for a material is excessive. For composite parts are under 20 pounds, an additional factor is used to increase the manufacturing complexity. Also, if the surface of a part requires a special finish, a Surface Finish factor is used that requires a specified tolerance (in microinches). Finally, there is a special factor for machining an excessive amount of slug weight. 
Once the MCPLXS factor is determined and the weight is known, the First Piece Cost may be calculated. Dr. Robert R. Solverson published a paper entitled Design to Cost with PRICE H that employs a first piece cost called Theoretical First Piece Cost or TFPC [19]. TFPC may be found using charts that compare the weight and manufacturing complexity or TFPC may be found using a graphical solution or formula with weight and manufacturing complexity. The chart below shows the relationship between TFPC and a given weight and complexity factor for a given component.

TFPC VS. WEIGHT

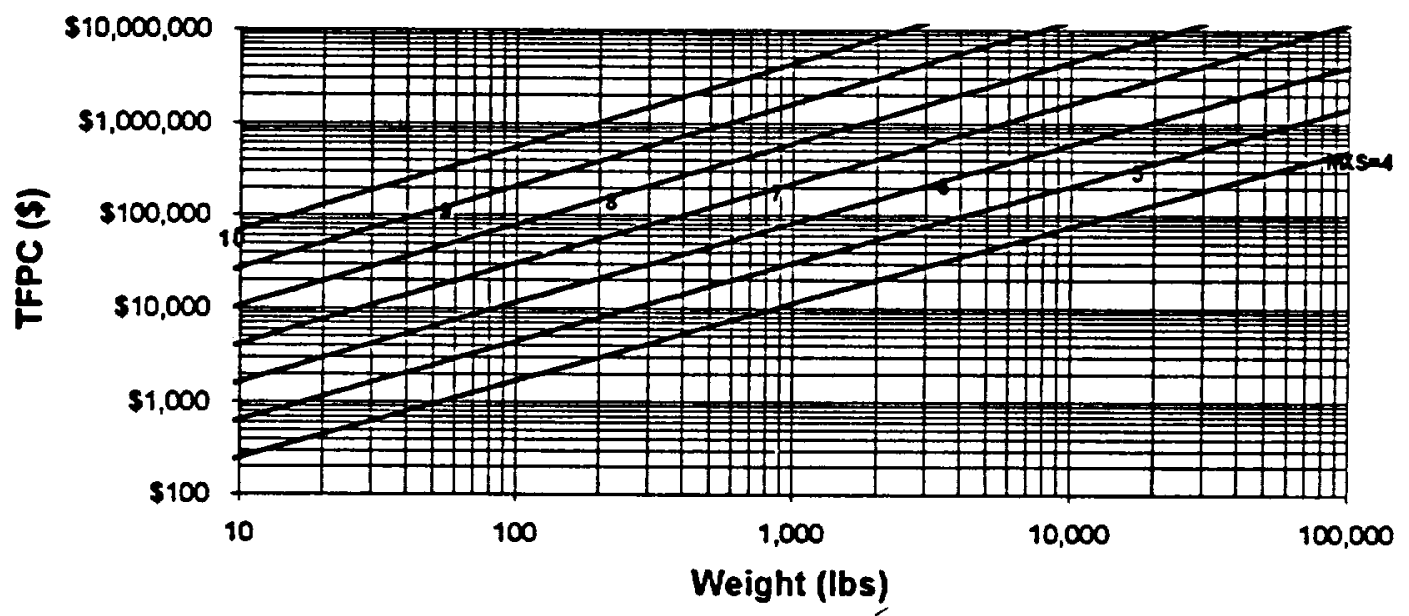

Eigure 7.8.5 TFPC vs. Weight

After TFPC is found, a Design to Unit Production Cost (DTUPC) or Unit Recurring Production Cost may be found. To determine the complete unit recurring production cost, one multiplies the TFPC by a calibration constant, $\mathrm{K}_{01}$ and eleven recurring production cost factors. Specifically, these eleven factors take into account:

- Specification severity

- Escalation factor (1972 dollars $=1.0)$

- Number of production shifts

- Previous prototype development effects

- Engineering changes

- Schedule sensitivity

- Production quantity

- Hughes production support factor

- Engineering support, program management, data

- General and administrative expenses

- Fee and cost of capital

[19]

Since the above eleven factors are not influenced by TFPC, one may simply combine these eleven factors into a single factor to determine the Complete Unit Recurring Cost. This combined factor, 
$M_{p}$, gives an output at the "Price Level" which means that this indicates the selling price to a consumer since it accounts for the manufacturer fee or profit. Related to the amount of Computer Aided Design and Computer Aided Manufacturing (CAD-CAM) used in the process and the number of similar components, $M_{p}$ for a 100\% CAD-CAM system is 2.3474 if no like items are present and 1.9747 if two items are rather similar [19].

For the HSCT analyzed for costing purposes, the following part list was used:

Part Description

Top Cover Panel

Bottom Cover Panel

Top Spar Caps

Bottom Spar Caps

Spar Webs

Rib Webs

Posts

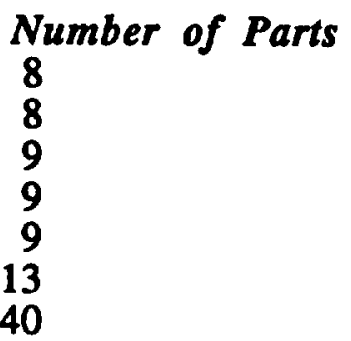

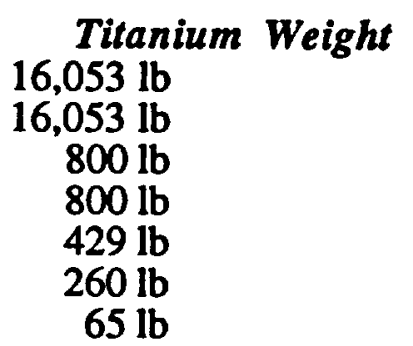

Three different material configurations were considered: all titanium, all aluminum, all composite, and a combination of titanium with a composite leading edge and trailing edge and a boron/aluminum wing tip. The composite structure was computed in two ways. One way computes the manufacturing complexity by using the number of parts, the precision factors, the machinability index, etc. for the composite material. A second estimate was computed using published complexity factors from PRICE. For example, a manufacturing complexity factor of 6.40 was used for the skins and a MCPLXS of 7.50 was used for the spar caps and spar webs. The resulting wing based on the published material is $\$ 13.8$ million. Recall that this includes $M_{p}$ and that PRICE H output is in 1972 U.S. dollars. Thus, this figure represents the complete unit recurring cost. By comparison, the wing based on computed composite complexity factors was $\$ 9.1$ million. The wing with a composite leading edge, composite trailing edge, composite wing tip, and titanium center structure was based on computed manufacturing complexity factors and was $\$ 9.8$ million. The all titanium wing was found to be $\$ 8.6$ million while the all aluminum wing was the least expensive at $\$ 7.7$ million complete unit recurring cost. These results are tabulated below: 


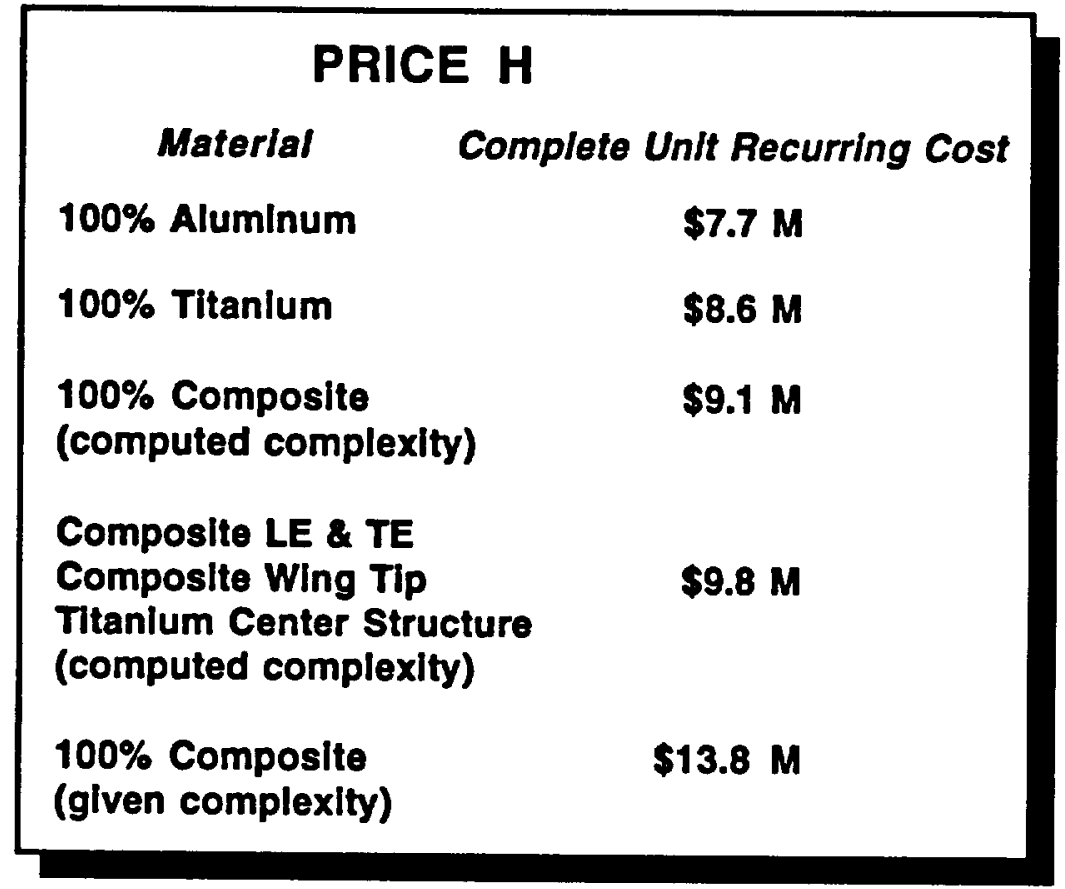

Table 7.8.4 Price H Costs

Note that these numbers are in $\$ 1972$. Also note the inconsistencies for the composite materials. The computed complexity factors found to generate the $\$ 9.1$ million estimate are questionable so this estimate is probably invalid. However, the $\$ 13.8$ million estimate is probably reasonable since the complexity factors generating this estimate are from a PRICE H document. Unfortunately, these complexity factors could not be used to generate a hybrid wing; that is, a wing with composite leading and trailing edges and a titanium center structure. The comparison between the $\$ 8.6$ million titanium wing and the $\$ 13.8$ million composite wing is quite reasonable, particularly in light of the fact that composite weight savings was a little too conservative at $7 \%$. According to a RAND study of advanced materials, the composite material premium compared to titanium is about $30 \%$ [16], a figure that is somewhat consistent with the results presented here.

\subsubsection{Designer's Production Cost Trade-Off Tool}

The Designer's Production Cost Trade-Off Tool is a derivative of the PRICE H costing model. Rather than requiring extensive manufacturing complexity calculations like the PRICE $H$ model, the Designer's Production Cost Trade-Off Tool employs a simplistic equation with only three empirical constants that are dependent upon the manufacturing complexity. The equation is:

$$
C O S T=W E I G H T^{a *} b+\frac{W E I G H T^{*} c}{Q}[2]
$$

where the constants are a measure of the following: 


\section{a: Cost of Materials \\ b: Manufacturing Complexity \\ c. Cost of Tooling based on Material Density \& Fabrication Technique}

The factor $Q$ is the quantity of a given part for the first 500 production units. Thus, if a wing has 11 spar caps per wing and 2 wings per aircraft, the $Q$ value is $500 * 11 * 2=11,000$.

The main manufacturing complexity problems with the Designer's Trade-Off Tool are determining the best materials, manufacturing process, and, if applicable, precision required for machining. Examples of different processes include forging, sand casting, investment casting, and machining. The materials play an important role in determining the difficulty of the process as well as the expense of the tooling requirement. However, materials that are difficult to process do not necessarily have the highest tooling factors. For example, titanium is extremely difficult to work with yet has a lower tooling factor than magnesium as well as aluminum. Nonetheless, as the following pages indicate, the aluminum is still the least expensive material, despite requiring additional weight to support the wing. The overall manufacturing results for the wing are as follows:

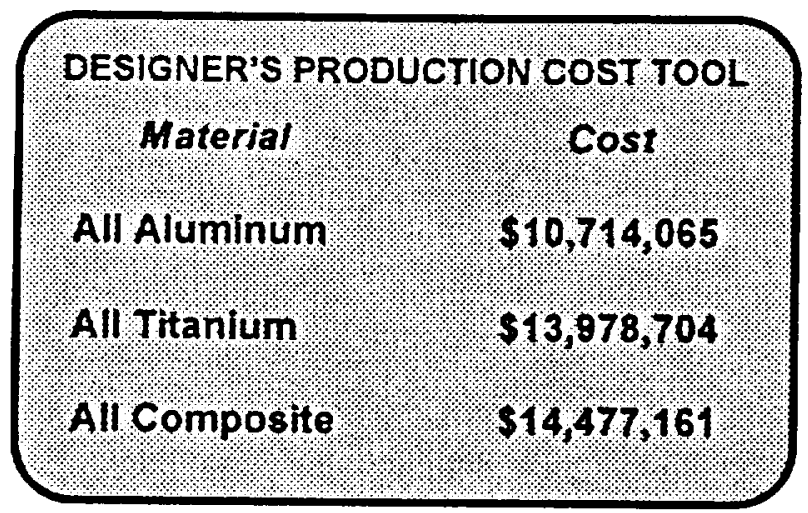

Table 7.8.5 Designer's Production Cost Estimates

Note that the titanium and composite difference is perhaps too small. Also note that these figures are in 1972 dollars and that the Designer's Production Cost Tool is not meant for use as a cost estimate generator. Rather, it is for use as a design tool to make quick judegments about economic implications of designs. 
Table 7.8.6 Wing Unit Recurring Production Cost

\begin{tabular}{|c|c|c|c|c|c|c|}
\hline $\begin{array}{l}\text { PRICE H } \\
\text { MATERIAL: }\end{array}$ & Titanium & & & Platform: & 1.8 & \\
\hline Part Description & $\begin{array}{c}\text { Volume } \\
\text { (in^3) }\end{array}$ & $\begin{array}{c}\text { Weight } \\
\text { (Ib) }\end{array}$ & $\begin{array}{l}\text { No. } \\
\text { Parts }\end{array}$ & Precision & $\begin{array}{l}\text { Mach. } \\
\text { Index }\end{array}$ & $\begin{array}{l}\text { Assembly } \\
\text { Difficulty }\end{array}$ \\
\hline Top Cover Panel & 100337.12 & 14930.16 & 8 & 0.003 & 30 & 3 \\
\hline Bottom Cover Panel & 100337.12 & 14930.16 & 8 & 0.003 & 30 & 3 \\
\hline Top Spar Caps & 4344.02 & 646.39 & 9 & 0.003 & 30 & 3 \\
\hline Bottom Spar Caps & 4344.02 & 646.39 & 9 & 0.003 & 30 & 3 \\
\hline Spar Webs & 2330.99 & 346.85 & 9 & 0.003 & 30 & 3 \\
\hline Rib Webs & 1657.69 & 246.66 & 13 & 0.003 & 30 & 3 \\
\hline Posts & 398.36 & 59.28 & 40 & 0.003 & 30 & 3 \\
\hline Part Description & Complexity & TFPC & Design & Repeat? & Mp & Part Total \\
\hline Top Cover Panel & 6.16 & 956286 & & yes & 1.9747 & $1,888,377$ \\
\hline Bottom Cover Panel & 6.16 & 956286 & & yes & 1.9747 & $1,888,377$ \\
\hline Top Spar Caps & 6.19 & 67863 & & no & 2.3474 & 159,301 \\
\hline Bottom Spar Caps & 6.19 & 67863 & & no & 2.3474 & 159,301 \\
\hline Spar Webs & 6.19 & 39926 & & no & 2.3474 & 93,723 \\
\hline Rib Webs & 6.28 & 32658 & & no & 2.3474 & 76,660 \\
\hline Posts & 6.57 & 12758 & & no & 2.3474 & 29,947 \\
\hline & & & & & & $4,295,687$ \\
\hline WING UNIT RECURR & G PRODUCTION & cost: & & $\$ 8,591,375$ & & \\
\hline MATERIAL: & Composite & Composite W & Veight S & $\begin{array}{l}\text { Platform: } \\
\text { avings: }\end{array}$ & $\begin{array}{l}1.8 \\
7 \%\end{array}$ & \\
\hline Part Description & $\begin{array}{l}\text { Volume } \\
\left(\text { in`3) }^{\wedge}\right.\end{array}$ & $\begin{array}{l}\text { Weight } \\
\text { (lb) }\end{array}$ & $\begin{array}{r}\text { No. } \\
\text { Parts }\end{array}$ & Precision & $\begin{array}{l}\text { Mach. } \\
\text { Index }\end{array}$ & $\begin{array}{l}\text { Assembly } \\
\text { Difficulty }\end{array}$ \\
\hline Top Cover Panel & 100337.12 & 14930.16 & $N / A$ & $N / A$ & N/A & $N / A$ \\
\hline Bottom Cover Panel & 100337.12 & 14930.16 & N/A & N/A & N/A & N/A \\
\hline Top Spar Caps & 4344.02 & 646.39 & N/A & N/A & N/A & $N / A$ \\
\hline Bottom Spar Caps & 4344.02 & 646.39 & N/A & N/A & N/A & N/A \\
\hline Spar Webs & 2330.99 & 346.85 & N/A & N/A & N/A & N/A \\
\hline Rib Webs & 1657.69 & 246.66 & N/A & N/A & N/A & N/A \\
\hline Posts & 398.36 & 59.28 & N/A & N/A & N/A & N/A \\
\hline Part Description & Complexity & TFPC & Design & Repeat? & $M p$ & Part Total \\
\hline Top Cover Panel & 6.40 & 1218858 & & yes & 1.9747 & $2,406,879$ \\
\hline Bottom Cover Panel & 6.40 & 1218858 & & yes & 1.9747 & $2,406,879$ \\
\hline Top Spar Caps & 7.50 & 246733 & & no & 2.3474 & 579.180 \\
\hline Bottom Spar Caps & 7.50 & 246733 & & no & 2.3474 & 579,180 \\
\hline Spar Webs & 7.50 & 143681 & & no & 2.3474 & 337,277 \\
\hline Rib Webs & 8.30 & 233187 & & no & 2.3474 & 547,382 \\
\hline Posts & 7.00 & 19189 & & no & 2.3474 & 45,044 \\
\hline & & & & & & $6,901,821$ \\
\hline WING UNIT RECURF & RODUCTIO & ST: & & $\$ 13,803,642$ & & \\
\hline
\end{tabular}


Table 7.8.6 Wing Unit Recurring Production Cost (Cont)

\begin{tabular}{|c|c|c|c|c|c|c|}
\hline \multirow{2}{*}{$\begin{array}{l}\text { PRICE H } \\
\text { MATERIAL: } \\
\text { Part Description }\end{array}$} & \multicolumn{3}{|c|}{ Aluminum (7075-T6) } & $\begin{array}{l}\text { Platform: } \\
\text { Weight Penalty: }\end{array}$ & \multicolumn{2}{|c|}{1.8} \\
\hline & $\begin{array}{l}\text { Volume } \\
\left(\text { in^}^{\wedge}\right)\end{array}$ & $\begin{array}{c}\text { Weight } \\
\text { (lb) }\end{array}$ & $\begin{array}{l}\text { No. } \\
\text { Parts }\end{array}$ & Precision & $\begin{array}{l}\text { Mach. } \\
\text { Index }\end{array}$ & $\begin{array}{c}\text { Assembly } \\
\text { Difficulty }\end{array}$ \\
\hline Top Cover Panel & 100337.12 & 17659.33 & 8 & 0.003 & 160 & 3 \\
\hline Bottom Cover Panel & 100337.12 & 17659.33 & 8 & 0.003 & 160 & 3 \\
\hline Top Spar Caps & 4344.02 & 764.55 & 9 & 0.003 & 160 & 3 \\
\hline Bottom Spar Caps & 4344.02 & 764.55 & 9 & 0.003 & 160 & 3 \\
\hline Spar Webs & 2330.99 & 410.25 & 9 & 0.003 & 160 & 3 \\
\hline Rib Webs & 1657.69 & 291.75 & 13 & 0.003 & 160 & 3 \\
\hline Posts & 398.36 & 70.11 & 40 & 0.003 & 160 & 3 \\
\hline Part Description & Complexity & TFPC & \multicolumn{2}{|c|}{ Design Repeat? } & Mp & Part Total \\
\hline Top Cover Panel & 5.92 & 859401 & \multicolumn{2}{|r|}{ yes } & 1.9747 & $1,697,059$ \\
\hline Bottom Cover Panel & 5.92 & 859401 & \multicolumn{2}{|r|}{ yes } & 1.9747 & $1,697,059$ \\
\hline Top Spar Caps & 5.95 & 61510 & \multicolumn{2}{|r|}{ no } & 2.3474 & 144,388 \\
\hline Bottom Spar Caps & 5.95 & 61510 & \multicolumn{2}{|r|}{ no } & 2.3474 & 144,388 \\
\hline Spar Webs & 5.95 & 36258 & \multirow{2}{*}{\multicolumn{2}{|c|}{$\begin{array}{l}\text { no } \\
\text { no }\end{array}$}} & 2.3474 & 85,111 \\
\hline Rib Webs & 6.04 & 29589 & & & 2.3474 & 69,457 \\
\hline Posts & 6.31 & 11491 & \multicolumn{2}{|r|}{ no } & 2.3474 & 26,975 \\
\hline & & & & & & $3,864,439$ \\
\hline \multicolumn{4}{|c|}{ WING UNIT RECURRING PRODUCTION COST: } & $\$ 7,728,877$ & & \\
\hline \multirow[t]{2}{*}{ MATERIAL: } & \multirow{2}{*}{\multicolumn{4}{|c|}{$\begin{array}{c}\text { Composite (Calculated Complexity) Platform: } \\
\text { Composite Weight Savings: } \\
\text { Volume } \quad \text { Weiaht }\end{array}$}} & \multirow{2}{*}{\multicolumn{2}{|c|}{$\begin{array}{l}1.8 \\
7 \%\end{array}$}} \\
\hline & & & & & & \\
\hline Part Description & $\begin{array}{c}\text { Volume } \\
\left(\text { in^3) }^{\wedge}\right.\end{array}$ & $\begin{array}{l}\text { Weight } \\
\text { (Ib) }\end{array}$ & $\begin{array}{l}\text { No. } \\
\text { Parts }\end{array}$ & Precision & $\begin{array}{l}\text { Mach. } \\
\text { Index }\end{array}$ & $\begin{array}{c}\text { Assembly } \\
\text { Difficulty }\end{array}$ \\
\hline Top Cover Panel & 100337.12 & 14930.16 & 1 & 0.003 & 18 & 1.8 \\
\hline Bottom Cover Panel & 100337.12 & 14930.16 & 1 & 0.003 & 18 & 1.8 \\
\hline Top Spar Caps & 4344.02 & 646.39 & 8 & 0.003 & 18 & 2 \\
\hline Bottom Spar Caps & 4344.02 & 646.39 & 8 & 0.003 & 18 & 2 \\
\hline Spar Webs & 2330.99 & 346.85 & 9 & 0.003 & 18 & 2 \\
\hline Rib Webs & 1657.69 & 246.66 & 13 & 0.003 & 18 & 2 \\
\hline Posts & 398.36 & 59.28 & 40 & 0.003 & 18 & 2 \\
\hline Part Description & Complexity & TFPC & Design & Repeat? & Mp & Part Total \\
\hline Top Cover Panel & 6.16 & 947902 & & yes & 1.9747 & $1,871,823$ \\
\hline Bottom Cover Panel & 6.16 & 947902 & & yes & 1.9747 & $1,871,823$ \\
\hline Top Spar Caps & 6.61 & 102879 & & no & 2.3474 & 241,498 \\
\hline Bottom Spar Caps & 6.61 & 102879 & & no & 2.3474 & 241,498 \\
\hline Spar Webs & 6.65 & 62202 & & no & 2.3474 & 146,014 \\
\hline Rib Webs & 6.74 & 51113 & & no & 2.3474 & 119,982 \\
\hline Posts & 7.05 & 20207 & & no & 2.3474 & 47,435 \\
\hline
\end{tabular}




\section{Table 7.8.6 Wing Unit Recurring Production Cost (Cont)}

PRICE H

MATERIAL:

pr: Ti, tip B/AI, LE/TE: comp.

$$
\begin{array}{ll}
\text { Platform: } & 1.8 \\
\text { Weight Savings: } & 7 \%
\end{array}
$$

\begin{tabular}{|c|c|c|c|c|c|c|}
\hline Part Description & $\begin{array}{l}\text { Volume } \\
\left(\text { in^ }^{\wedge}\right)\end{array}$ & $\begin{array}{l}\text { Weight } \\
\text { (lb) }\end{array}$ & $\begin{array}{l}\text { No. } \\
\text { Parts }\end{array}$ & Precision & $\begin{array}{l}\text { Mach. } \\
\text { Index }\end{array}$ & $\begin{array}{l}\text { Assembly } \\
\text { Difficulty }\end{array}$ \\
\hline Top Cover Panel-Ti & 70235.98 & 11237.76 & 5 & 0.003 & 30 & $\overline{3}$ \\
\hline Bottom Cover Panel-Ti & 70235.98 & 11237.76 & 5 & 0.003 & 30 & 3 \\
\hline Top Cover Panel-LETE & 20067.42 & 2986.03 & 1 & 0.003 & 18 & 1.8 \\
\hline Bottom Cover Panel-LETE & 20067.42 & 2986.03 & 1 & 0.003 & 18 & 1.8 \\
\hline Top Cover Panel-B/AI & 10033.71 & 1493.02 & 1 & 0.003 & 16 & 2 \\
\hline Bottom Cover Panel-B/Al & 10033.71 & 1493.02 & 1 & 0.003 & 16 & 2 \\
\hline Top Spar Caps & 4344.02 & 646.39 & 9 & 0.003 & 30 & 3 \\
\hline Bottom Spar Caps & 4344.02 & 646.39 & 9 & 0.003 & 30 & 3 \\
\hline Spar Webs & 2330.99 & 346.85 & 9 & 0.003 & 30 & 3 \\
\hline Rib Webs & 1647.69 & 245.18 & 13 & 0.003 & 30 & 3 \\
\hline Posts & 398.36 & 59.28 & 40 & 0.003 & 30 & 3 \\
\hline
\end{tabular}

Part Description Complexity

TFPC Design Repeat?

Top Cover Panel-Ti

Bottom Cover Panel-Ti

Top Cover Panel-comp.

Bottom Cover Panel-comp.

Top Cover Panel-B/Al

Bottom Cover Panel-B/AI

Top Spar Caps

Bottom Spar Caps

Spar Webs

Rib Webs

Posts

6.05

6.05

6.16

6.16

6.10

6.10

6.19

6.19

6.19

6.28

6.57

\begin{tabular}{lcc} 
exity & TFPC & Design Repeat \\
\hline 05 & 667520 & yes \\
05 & 667520 & yes \\
6 & 240703 & no \\
6 & 240703 & no \\
0 & 126680 & no \\
0 & 126680 & no \\
9 & 67863 & no \\
9 & 67863 & no \\
9 & 39926 & no \\
28 & 32489 & no \\
57 & 12758 & no
\end{tabular}

(2)

Mp

1.9747

1.9747

2.3474

2.3474

2.3474

2.3474

2.3474

2.3474

2.3474

2.3474

2.3474
Part Total

$1,318,152$

$1,318,152$

565,027

565,027

297,370

297,370

159,301

159,301

83,723

76,265

29.947 
Table 7.8.7 Wing Production Cost

\begin{tabular}{|c|c|c|c|c|c|c|}
\hline $\begin{array}{l}\text { INPUTS: } \\
\text { Part Description }\end{array}$ & \multicolumn{2}{|c|}{ Method } & Material & $\begin{array}{l}\text { Volume } \\
\left(\text { in }^{\wedge} 3\right)\end{array}$ & $\begin{array}{l}\text { Weight } \\
\text { (Ib) }\end{array}$ & $\begin{array}{r}\text { Quantity } \\
\text { (per wing) }\end{array}$ \\
\hline Top Cover Panel & \multicolumn{2}{|c|}{ Machining (.003) } & $\mathrm{Ti}$ & 100337.12 & 16053.94 & 8 \\
\hline Bottom Cover Panel & \multicolumn{2}{|c|}{ Machining (.003) } & $\mathrm{Ti}$ & 100337.12 & 16053.94 & 8 \\
\hline Top Spar Caps & \multicolumn{2}{|c|}{ Forging } & $\mathrm{Ti}$ & 4344.02 & 695.04 & 9 \\
\hline Bottom Spar Caps & \multicolumn{2}{|l|}{ Forging } & $\mathrm{Ti}$ & 4344.02 & 695.04 & 9 \\
\hline Spar Webs & \multicolumn{2}{|l|}{ Forging } & $\mathrm{Ti}$ & 2330.99 & 372.86 & 9 \\
\hline Rib Webs & \multicolumn{2}{|l|}{ Forging } & $\mathrm{Ti}$ & 1647.69 & 263.63 & 13 \\
\hline Posts & \multicolumn{2}{|l|}{ Forging } & $\mathrm{Ti}$ & 398.36 & 63.74 & 40 \\
\hline \multirow{2}{*}{$\begin{array}{l}\text { OUTPUTS: } \\
\text { Part Description }\end{array}$} & \multicolumn{3}{|c|}{ Coefficients } & \multirow{2}{*}{\multicolumn{2}{|c|}{ Mfg Cost Tooling Cost" }} & TOTAL \\
\hline & $\mathbf{a}$ & b & c & & & cost \\
\hline Top Cover Panel & 0.855 & 779 & 57800 & $3,071,212$ & 231,979 & $3,303,181$ \\
\hline Bottom Cover Panel & 0.855 & 778 & 57800 & $3,071,212$ & 231,979 & $3,303,191$ \\
\hline Top Spar Caps & 0.845 & 386 & 57800 & 87,294 & 8.927 & 106,222 \\
\hline Bottom Spar Caps & 0.845 & 386 & 57800 & 97,294 & 8,827 & 106,222 \\
\hline Spar Webs & 0.845 & 386 & 57800 & 57,496 & 4,790 & 62.287 \\
\hline Rib Webs & 0.845 & 416 & 57800 & 46,220 & 2.344 & 48,565 \\
\hline Posts & 0.845 & 516 & 57800 & 57,331 & 2.344 & 59,675 \\
\hline
\end{tabular}

TOTAL PRODUCTION COST:

\begin{tabular}{|l|}
\hline WING PRODUCTION COST: \\
\end{tabular}

$\begin{array}{lll}\text { MATERIAL: } & \text { Composites } & \text { Composite Weight Savings: }\end{array}$

\begin{tabular}{llcrrr}
$\begin{array}{l}\text { INPUTS: } \\
\text { Part Description }\end{array}$ & \multicolumn{1}{c}{ Method } & Material & $\begin{array}{c}\text { Volume } \\
\text { (in^3) }\end{array}$ & $\begin{array}{c}\text { Weight } \\
\text { (lb) }\end{array}$ & $\begin{array}{r}\text { Quantity } \\
\text { (per wing) }\end{array}$ \\
\hline Top Cover Panel & Skin Member & C & 100337.12 & 14930.16 & 1 \\
Bottom Cover Panel & Skin Member & C & 100337.12 & 14930.16 & 1 \\
Top Spar Caps & Machined Section & C & 4344.02 & 646.39 & 9 \\
Bottom Spar Caps & Machined Section & C & 4344.02 & 646.39 & 9 \\
Spar Webs & Machined Section & C & 2330.99 & 346.85 & 9 \\
Rib Webs & Machined Section & C & 1647.69 & 245.18 & 13 \\
Posts & Machined Section & C & 398.36 & 59.28 & 40 \\
\hline
\end{tabular}

\begin{tabular}{|c|c|c|c|c|c|c|}
\hline OUTPUTS: & & efficie & & & & TOTAL \\
\hline Part Description & $\mathbf{a}$ & b & c & Mfg Cost & $\lg \cos t^{n}$ & $\operatorname{cost}$ \\
\hline Top Cover Panel & 0.854 & 550 & 40000 & $2,018,431$ & $1,194,413$ & $3,212,844$ \\
\hline Bottom Cover Panel & 0.854 & 550 & 40000 & $2,018,431$ & $1,184,413$ & $3,212,844$ \\
\hline Top Spar Caps & 0.854 & 857 & 40000 & 215,349 & 5,746 & 221,095 \\
\hline Bottom Spar Caps & 0.854 & 857 & 40000 & 215,349 & 5.746 & 221,095 \\
\hline Spar Webs & 0.854 & 857 & 40000 & 126,550 & 3,083 & 129,633 \\
\hline Rib Webs & 0.854 & 811 & 40000 & 100,030 & 1,509 & 101,539 \\
\hline Posts & 0.854 & 1257 & 40000 & 138,022 & 1,509 & 139,531 \\
\hline 801 & & & & & & $7,238,580$ \\
\hline
\end{tabular}

WING PRODUCTION COST: 


\section{Table 7.8.7 Wing Production Cost (Cont)}

\begin{tabular}{|c|c|c|c|c|c|c|}
\hline \multicolumn{7}{|c|}{ DESIGNER'S PRODUCTION COST TRADE-OFF TOOL } \\
\hline $\begin{array}{l}\text { INPUTS: } \\
\text { Part Description }\end{array}$ & \multicolumn{2}{|c|}{ Method } & Material & $\begin{array}{l}\text { Volume } \\
\left(\text { in^3) }^{\circ}\right.\end{array}$ & $\begin{array}{l}\text { Weight } \\
\text { (Ib) }\end{array}$ & $\begin{array}{r}\text { Quantity } \\
\text { (per wing) }\end{array}$ \\
\hline Top Cover Panel & \multirow{4}{*}{\multicolumn{2}{|c|}{$\begin{array}{l}\text { Machining (.003) } \\
\text { Machining (.003) } \\
\text { Forging } \\
\text { Forging }\end{array}$}} & Al & 100337.12 & 17659.33 & 8 \\
\hline Bottom Cover Panel & & & Al & 100337.12 & 17659.33 & 8 \\
\hline Top Spar Caps & & & Al & 4344.02 & 764.55 & $\theta$ \\
\hline Bottom Spar Caps & & & Al & 4344.02 & 764.55 & 9 \\
\hline Spar Webs & \multicolumn{2}{|c|}{ Forging } & Al & 2330.99 & 410.25 & $\boldsymbol{\theta}$ \\
\hline Rib Webs & \multicolumn{2}{|l|}{ Forging } & Al & 1647.69 & 289.99 & 13 \\
\hline Posts & \multicolumn{2}{|l|}{ Forging } & Al & 398.36 & 70.11 & 40 \\
\hline \multirow{2}{*}{$\begin{array}{l}\text { OUTPUTS: } \\
\text { Pant Description }\end{array}$} & \multicolumn{3}{|c|}{ Coefficients } & \multirow{2}{*}{\multicolumn{2}{|c|}{ Mfg Cost Tooling Cost" }} & TOTAL \\
\hline & $\mathbf{a}$ & $\mathbf{b}$ & c & & & $\operatorname{cost}$ \\
\hline Top Cover Panel & 0.850 & 533 & 99400 & $2,170,978$ & 438,834 & $2,609,812$ \\
\hline Bottom Cover Panel & 0.850 & 533 & 99400 & $2,170,978$ & 438,834 & $2,609,812$ \\
\hline Top Spar Caps & 0.831 & 148 & 5000 & 36,844 & 849 & 37,694 \\
\hline Bottom Spar Caps & 0.831 & 148 & 5000 & 36,844 & 849 & 37,694 \\
\hline Spar Webs & 0.831 & 148 & 5000 & 21,964 & 456 & 22,420 \\
\hline Rib Webs & 0.831 & 157 & 5000 & 17,464 & 223 & 17,687 \\
\hline Posts & 0.831 & 195 & 5000 & 21,691 & 223 & 21,914 \\
\hline \multicolumn{4}{|c|}{ TOTAL PRODUCTION COST: } & & & $55,357,033$ \\
\hline
\end{tabular}

WING PRODUCTION COST:

$\$ 10,714,065$ 


\subsubsection{ACSYNT}

ACSYNT is a computer code that is useful as a top level tool for analyzing costs at the system level. Essentially, ACSYNT determines all of its costs based on weight and parametric relationships of airplane programs from history. This is in fact very similar to the methodology of the 1981 RAND study for structural modifications. ACSYNT has the capability of allowing the user to specify cost escalation factors for special manufacturing and design complexity. For the HSCT wing, three different materials were analyzed: $100 \%$ titanium, $60 \%$ titanium with $30 \%$ graphite/bismaleimide and $10 \%$ boron/aluminum, and $100 \%$ composite. The resulting complexity factors were 2.00 for the all titanium, 2.16 for the three material wing, and 2.80 for the all composite (unspecified composite) wing. The results were manufacturing costs only for a 500 unit production run in 1992 dollars are listed below:

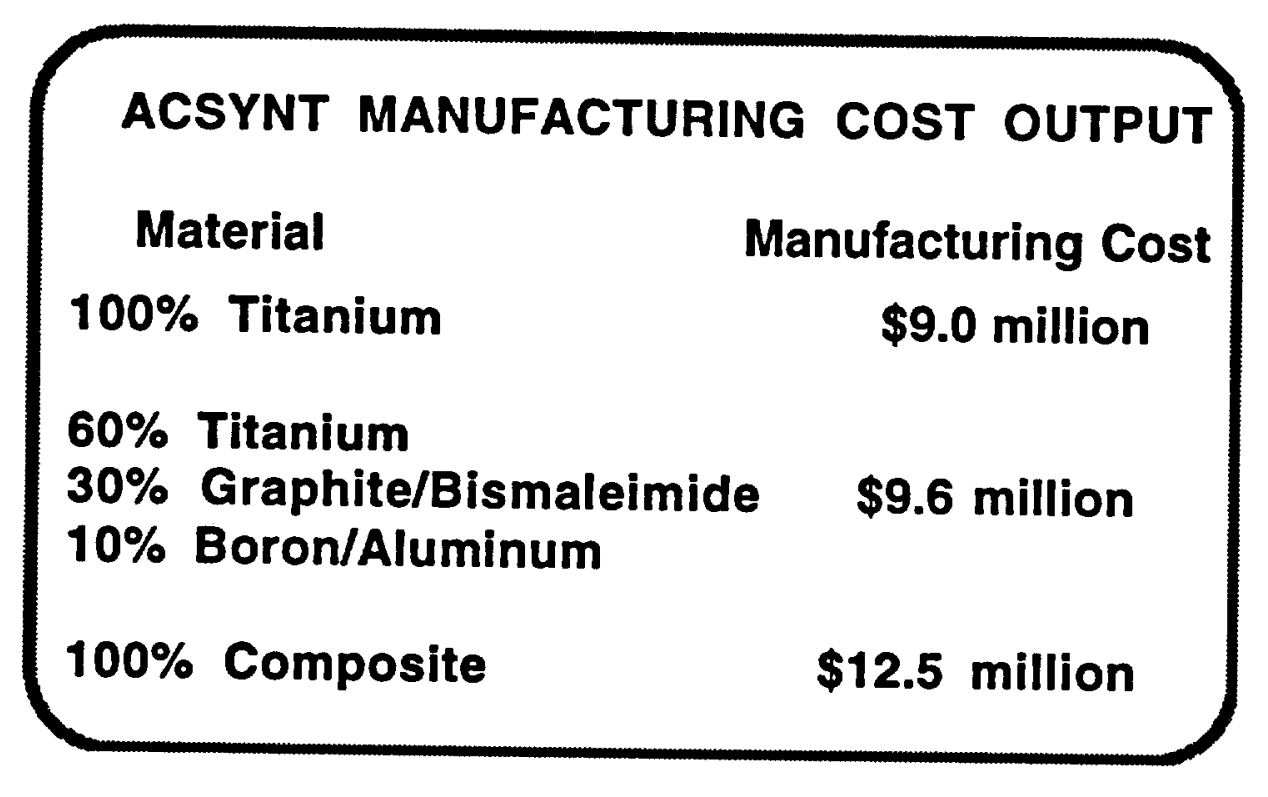

Table 7.8.8 ACSYNT Manufacturing Costs

Note that the $30 \%$ premium for composite material compared to titanium [16] is consistent with the $39 \%$ difference determined here. To give some idea of the order of magnitude of the production costs compared to other program costs, the following pie chart compares the Research, Development, Testing, and Evaluation (RDT\&E) to the aircraft production costs. Note that the summation of the fee, operational vehicles, and other category comprise the aircraft production costs. The other category includes such items as spares, facilities, sustaining costs, ground support equipment, initial transportation, and miscellaneous expenses. The following relationship depicts an all composite wing: 


\section{HSCT AIRPLANE PROGRAM COSTS}

(System Costs)

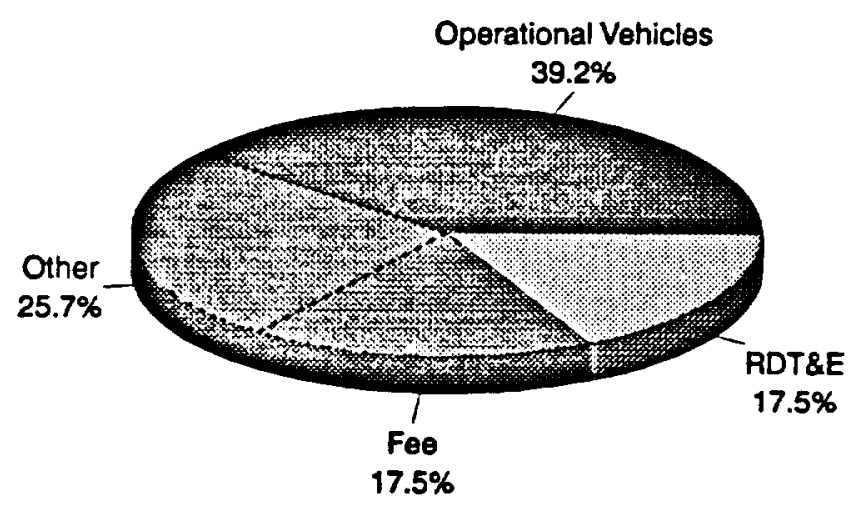

Senares: ACSWNT eurput

\section{Eiqure 7.8.6 HSCT Airplane Program Costs}

For a breakdown of the manufacturing costs of an all composite wing, one determines that the wing is $13.8 \%$ of all manufacturing costs or about $28 \%$ of airframe structure costs. 


\section{MANUFACTURING COSTS}

(By Major Sub-System)

ALL COMPOSITE WING

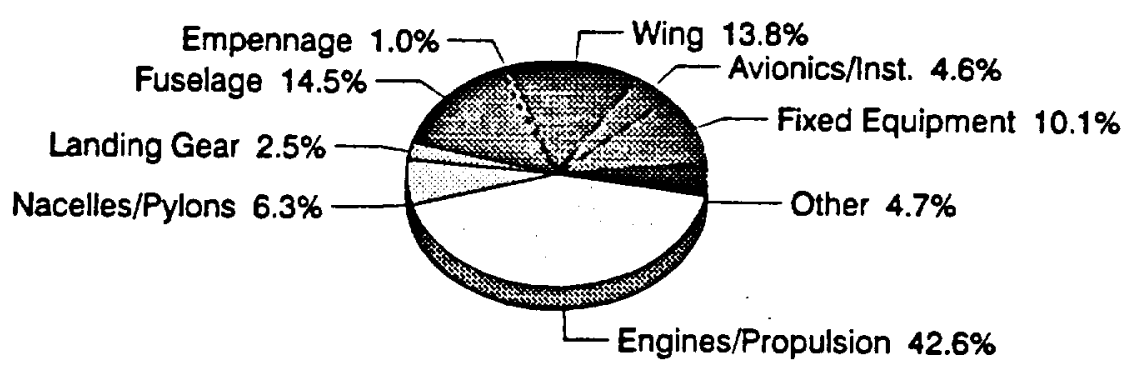

Saurce: ACSYNT Outpu

Eigure 78.7 Manufacturing Costs

Using the $13.8 \%$ figure from above and the total average unit costs in the bar chart that follows, an idea of the total cost of the wing can be determined. Note that this includes all fees, development, spares, overhead, etc. that are part of the initial aircraft price for airlines. For the all composite wing, the average unit cost for a 500 unit production run is $\$ 226.0$ million.

\section{HSCT UNIT COST COMPARISONS}

(By Wing Material Type)

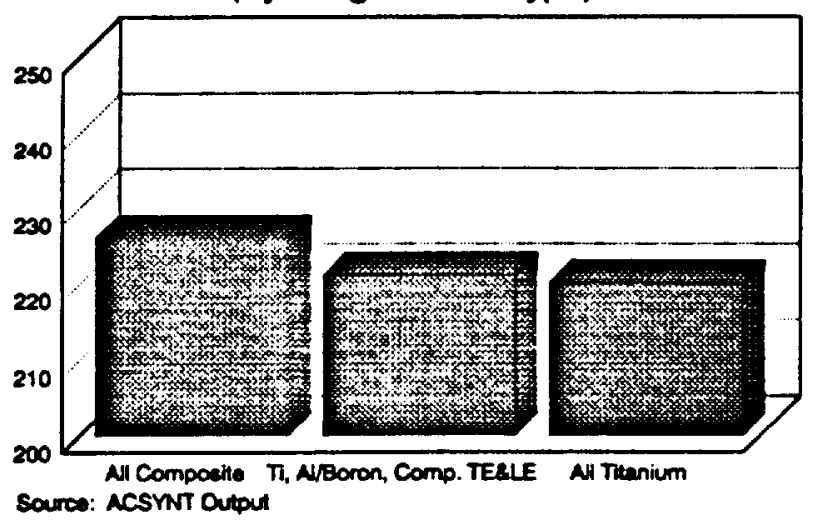

Eigure 7.8.8 HSCT Unit Cost Comparisons 


\subsubsection{Lockheed Cost Estimations}

The Lockheed study of the HSCT computed the costs for five design concepts:

1) Chordwise stiffened (mechanically fastened)

2) Spanwise stiffened (mechanically fastened)

3) Monocoque (mechanically fastened)

4) Monocoque (joined by welding)

5) Composite reinforced (mechanically fastened)

[9]

Using the Lockheed in-house computer code ASSET (Advanced Synthesis and Evaluation Technique), Lockheed determined costs on a per pound basis.

Lockheed had a very detailed design so it was able to take three regions as representative for the wing's forward area, aft box area, and wing tip. Thus, the three regions could estimate the cost for the entire wing based on sizing data such as skin thickness, cap size, etc. Production cost analysis was estimated for three different types of panel designs: weld bonded beaded panel, weld bonded hat stiffened panel, and aluminum brazed honeycomb core sandwich [9]. The Lockheed results are tabulated as follows:

\section{CHORDWISE STIFFENED}

Forward Wing Area

Aft Wing Area

Outer Wing Area

Additives

Assembly \& Tank Seal

TOTAL

SPANWISE STIFFENED

Forward Wing Area

Aft Wing Area

Outer Wing Area

Additives

Assembly \& Tank Seal

TOTAL

\section{MONOCOQUE}

Forward Wing Area

Aft Wing Area

Outer Wing Area

Additives

Assembly \& Tank Seal

TOTAL

Tooling (hrs) Fabrication (hrs) Materials (\$)

$$
\begin{array}{r}
273,088 \\
136,768 \\
45,825 \\
0 \\
308,403 \\
764,084
\end{array}
$$

244,528

73,971

27,845

47,977

716,000

$1,110,321$

375,753

222,845

51,610

50,412

$1,622,959$

$2,323,579$
586,327

651,933

247,470

80,230

$1,565,960$

701,500

631,398

315,018

154,119

78,566

$1,880,601$

$1,193,511$

$1,544,077$

$1,042,782$

137,170

64,661

$3,982,201$
$2,934,480$

$1,494,318$

968,517

$2,627,000$

$8,024,315$

$1,431,916$

443,033

335,402

361,102

$2,556,000$

$5,127,453$

$1,645,564$

$1,394,018$

123,880

530,048

$2,600,000$

$6,293,510$ 


WELDED MONOCOQUE
Forward Wing Area
Aft Wing Area
Outer Wing Area
Additives
Assembly \& Tank Seal
TOTAL
COMPOSITE
REINFORCED
Forward Wing Area
Aft Wing Area
Outer Wing Area
Additives
Assembly \& Tank Seal
TOTAL

[9]

\begin{tabular}{rrr}
410,091 & $1,259,993$ & 711,592 \\
171,652 & $1,586,825$ & 391,810 \\
84,715 & $1,048,537$ & 583,724 \\
50,412 & 137,170 & 530,048 \\
90,336 & 0 & $3,900,000$ \\
807,206 & $4,032,525$ & $6,117,174$ \\
& & \\
& & \\
143,630 & $1,393,795$ & $1,670,706$ \\
248,931 & 546,183 & $2,776,071$ \\
46,454 & 430,149 & $1,011,601$ \\
0 & 0 & 0 \\
354,001 & 61,366 & $2,627,000$ \\
793,016 & $2,431,493$ & $8,085,378$ \\
\hline
\end{tabular}

Table 7.8.9 Structural Concept Costs 
On a per pound basis, the results are:

\begin{tabular}{|lccccc|}
\hline & $\begin{array}{c}\text { Chordwise } \\
\text { Stiffened }\end{array}$ & $\begin{array}{c}\text { Spanwise } \\
\text { Stiffened }\end{array}$ & Monocoque & $\begin{array}{c}\text { Welded } \\
\text { Monocoque }\end{array}$ & $\begin{array}{c}\text { Composite } \\
\text { Reinforced }\end{array}$ \\
$\begin{array}{l}\text { Production } \\
\text { (hours/lb) }\end{array}$ & 10.8 & 16.0 & 40.8 & 13.4 & 14.7 \\
$\begin{array}{l}\text { Material } \\
\text { (dollar/lb) } \\
\text { Toolmake }\end{array}$ & 22.2 & 27.1 & 70.0 & 67.1 & 45.0 \\
(hours/lb) & 114.0 & 73.9 & 109.6 & 101.8 & 149.7 \\
\hline
\end{tabular}

[9]

Table 7.8.10 Structural Concept Costs per pound

Lockheed chose the chordwise stiffened concept, the same design studied in this document.

\subsubsection{Comparison of Models}

It is important to be absolutely certain one understands what the assumptions and outputs of each cost model are prior to a comparison of the results between them. The 1981 RAND study computes the estimated recurring labor, nonrecurring labor, and materials costs required to produce a wing. Since the engineering effort includes design, development, testing, and other related activities, the engineering hours projected includes the RDT\&E effort. Using fully burdened labor rates, the profit, financing, general $\&$ administrative expenses, and other factors are included in the labor rate so one can consider the summation of labor rates multiplied by man-hours as the total cost of the wing exclusive of materials costs. Adding in the materials costs, one obtains the total RDT\&E and manufacturing cost for the wing. This amount comes to $\$ 16.6$ million. The ACSYNT model gives a recurring manufacturing wing cost of $\$ 9.0$ million for an all titanium wing or $\$ 12.5$ million for an all composite wing. Operational vehicles (production) account for $39.2 \%$ of the entire aircraft unit cost and the combination of manufacturer fee plus RDT\&E is about 35\% of the acquisition price. Considering this information, the total cost for the all titanium wing would be 1.89 times the aforementioned recurring manufacturing costs for a total of $\$ 17.0$ million. An all composite wing would amount to $\$ 23.7$ million.

The Designer's Production Cost Trade-off Tool accounts for the cost of materials, manufacturing method, manufacturing complexity, number of parts, and tooling cost. A simplified costing methodology, the Designer's Production Cost Trade-off Tool computes relative production costs (manufacturing and tooling) of different product designs, costs that are "not meant for the 
Recurring Manufacturing Production Cost Estimate" [2]. For example, the tool does not differentiate between composite materials, but only uses that same parameters for a general heading of "Composites." Actually, the exact composite material is graphite/epoxy. Additionally, the model does not account for financial and economic factors, factors essential for a true cost estimate. Such economic and business factors are included in the 1981 RAND estimates because they are a part of the fully burdened labor rate. According to the calculations presented here, an all aluminum wing would cost $\$ 10.7$ million while an all titanium wing would cost $\$ 14.0$ million. This results in a $30.8 \%$ premium for an all titanium wing, consistent with the RAND estimate for a premium on titanium compared to composites. Although the cost of the titanium material is over three times more expensive per pound than aluminum, the actual material costs are only 10 to $15 \%$ of the overall cost. The overall cost is dominated by tooling and production, although the tooling affect decreases significantly with larger production runs. Note that the above premiums on titanium for production and tooling are on a per pound basis. Since the composite material will reduce the weight of the aircraft, the $30.8 \%$ premium computed from the Designer's Cost Tradeoff Tool seems consistent with what one would expect. However, the Designer's Cost Trade-off Tool produces a cost estimate of only $\$ 14.5$ million for composites (assuming a conservative $7 \%$ weight savings) which is only a $4 \%$ increase over titanium. Since the RAND estimate is based on cost per unit weight, one may add back the $7 \%$ weight savings to normalize the estimate. The result only amounts to $5.7 \%$ which is still low compared to the $30 \%$ predicted by the RAND paper..

PRICE $\mathrm{H}$ is a complicated costing model that gives the Theoretical First Piece Cost (TFPC) and Design to Unit Production Cost (DTUPC), a term sometimes referred to as Unit Recurring Production Cost [19]. To determine DTUPC, a number of factors are multiplied together and then are multiplied by TFPC. Compared to the $\$ 9.0$ million from ACSYNT, the $\$ 8.6$ million from PRICE H would seem fairly close. However, the ACSYNT output does not include complete recurring costs, just complete recurring manufacturing costs. Additionally, ACSYNT output is in 1991 dollars while PRICE $H$ is in 1972 dollars. For the all composite wing, the comparison is $\$ 12.5$ million for ACSYNT and \$13.8 million using published complexity factors for PRICE H. Also note that the ACSYNT estimate does not include RDT\&E costs, testing, profit, etc. but is only for manufacturing. In contrast, the PRICE $\mathrm{H}$ estimate includes everything, including profit.

\subsubsection{Utilization of Composite Materials}

The economic and costing tradeoffs made were done with respect to materials choice. Although the precision, number of parts, assembly difficulty, process, and other factors could be varied, a full understanding of the benefits and sacrifices could not be determined for many of the parts. Additionally, the effects of any of these factors alone would not be extremely great, with the 
exception of the precision. In contrast, a great deal of information was available for differing materials choices as well as the costs associated with these choices.

In general, composites are considered to cost more than metals because engineers require more time to deal with the differing plies to obtain a given strength and stiffness [16]. Also, there is a lack of familiarity and accepted standards for using composites [16]. Tools for composite use require more design effort and cost more [16]. Composite finished parts are difficult to work with because they cannot be reworked or refinished like metal parts [16]. Also, composite tools are not as durable as metal tools because imperfections may or may not be machined away to fix such imperfections [16]. After going through the autoclave, tools must be cleaned which takes a considerable amount of time [16]. Composite tool storage is more cumbersome than storing metal tools [16]. Additionally, there may be a need for a greater quantity of tools for composites because of the long required processing times of composites in the autoclave [16]. To achieve a production rate similar to metals, more tools will be necessary to make up for this additional time requirement. Finally, composites material costs themselves are considerably more expensive, although costs are expected to decrease significantly in the future. Furthermore, the rate of decrease of composite material costs is expected to be faster than for metals.

However, there are several reasons composites are considered to be more cost effective than metals. Composites offer a weight savings which makes their costs somewhat less since most cost relationships are based on a weight relationship. Additionally, composites reduce the number of parts. This reduces the assembly and manufacturing difficulty. For engineers, the reduced number of parts will make the complete design process easier [16].

Overall, recurring costs for composites are expected to average about 2 times that of either aluminum or steel and about $20-30 \%$ more than titanium. The actual relationship between the materials for recurring costs is summarized in the table below. The numbers represent the range of values costing experts at aerospace and defense companies projected for the mid-1990's time frame, in 1990 dollars. Also note that these relationships are for a cumulative average of 100 units of 1000 pounds of structure.

$\begin{array}{lcc}\text { Material } & \begin{array}{c}\text { Minimum } \\ (\$ / l b)\end{array} & \begin{array}{c}\text { Maximum } \\ (\$ / l b)\end{array} \\ \text { Aluminum } & 521 & 1,045 \\ \text { Steel } & 691 & 1,511 \\ \text { Titanium } & 703 & 1,649 \\ \text { Graphite/Epoxy } & 822 & 2,133 \\ \text { Graphite/Bismaleimide } & 812 & 2,499 \\ \text { Graphite/Thermoplastic } & 869 & 2,597\end{array}$


[16]

The weight savings is an extremely important implication for composites. For the 721,291 lb. baseline aircraft, $371,033 \mathrm{lb}$. or $51.44 \%$ of this gross weight is attributable to fuel. Thus, if one assumes a savings of roughly $1 \mathrm{lb}$. fuel to every $1 \mathrm{lb}$. of structural weight savings, one saves about 10 cents per flight on fuel alone. Considering an annual utilization rate of 1239 trips per year (from the baseline aircraft), this amounts to $\$ 124$ of operating cost savings for every pound of structural weight savings. Actually, the cost and weight savings are rather conservative because as one decreases the fuel weight, the fuel required to carry the fuel weight will decrease as well. However, the objective here is to give some idea of the operating cost savings related to aircraft design weight. On the negative side of the equation, composite materials require additional maintenance and inspection because their crack growth and fatigue performance is not fully understood. Inspection of composite parts is an extremely time consuming process and may cause the utilization rate to decrease in addition to causing the periodic maintenance costs to rise.

Note that the $\$ 124 / \mathrm{lb}$ fuel savings per year will be realized over the entire life of the aircraft, fifteen to twenty years. Furthermore, the above estimate uses a 1991 cost of fuel at 67 cents per gallon [5]. In 1990, fuel averaged 19\% higher at 80 cents per gallon. In 1991 dollars, Boeing predicts fuel prices to escalate to 74 cents per gallon by the year 2000 with oil averaging $\$ 20 / \mathrm{barrel}$ (\$1991) during 1992-2000 time-frame [5]. However, these estimates may be overly optimistic. OPEC is predicted to produce nearly $50 \%$ of the world oil by 2000 compared to $52 \%$ in 1977 . Recall that the late 1970's were a time of escalating fuel prices. Today OPEC produces about $40 \%$ of the world's oil, up form only $29 \%$ in 1985 [5]. Note also that fuel prices today are much less on a real basis than prices in 1980. Adding to the problem is the fact that five OPEC countries control almost $70 \%$ of the world's proven oil reserves. These volatile countries include Iran, Iraq, and Kuwait, countries that are expected to be operating at full potential. Finally, oil production from the former Soviet Union is expected to decrease. The impact of all this on the HSCT is the following:

\section{DOQFuel = FuelWeight FuelCos}

where the fuel weight is determined by the structural weight. Since fuel costs could be much higher than anticipated, airlines will be extremely interested in a plane that reduces their financial exposure in this are as much as possible. This concept goes back to the "Roskam Iceberg Effect" for aircraft design. Essentially, the iceberg states that the cost of designing the aircraft (RDT\&E) and, to an extent, even the acquisition cost of the aircraft is rather small compared to the operations cost of the aircraft over its entire life cycle. In the figure below, the RDT\&E costs are the "tip-ofthe-iceberg" with respect to the entire life cycle cost. 


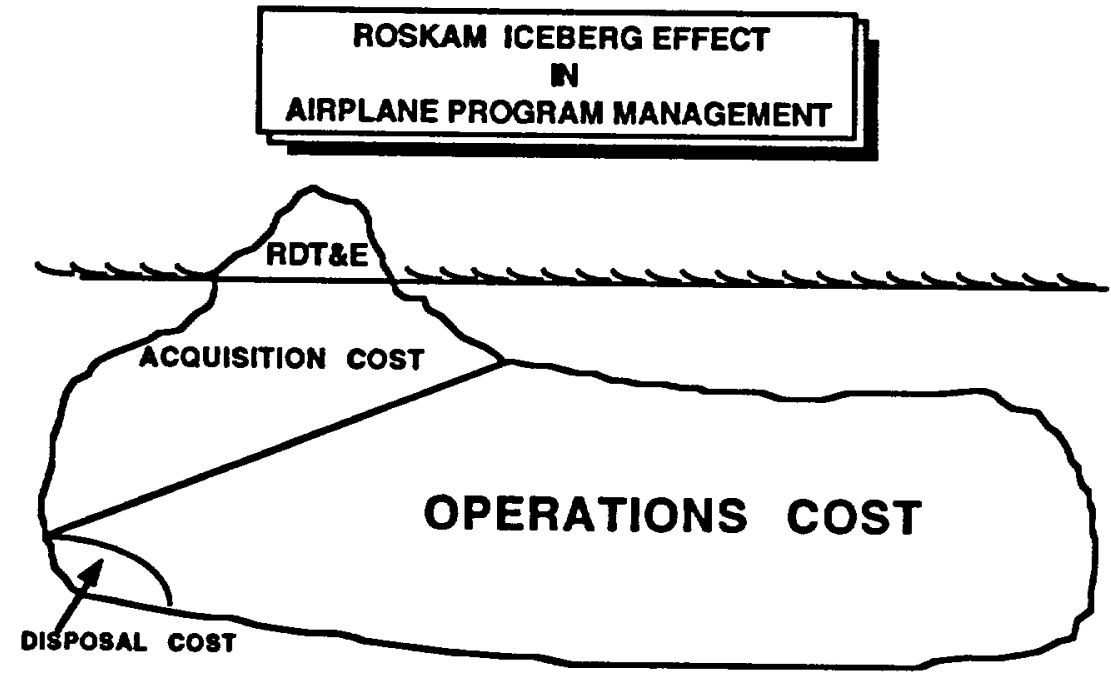

[17]

\section{Eigure 7.8.9 Roskam Iceberg Effect in Airline Program Mgmt.}

Essentially, the figure emphasizes the fact that in an airplane program, the RDT\&E account for the commitment of $95 \%$ of the life cycle cost of the aircraft, despite the relatively small cost of RDT\&E over the entire life cycle [17].

\subsubsection{Recommendations for further study}

Several avenues exist for exploration to make this study or a future study more beneficial. For example, more knowledge about the minimum precision for a given part could be extremely useful. Do differing panels of the skin have differing precisions or assembly difficulty levels? Do metals and composites require the same precision number or are they different? Additionally, it would be quite beneficial to calibrate the PRICE $\mathrm{H}$ model using data from a given manufacturer comparing a couple of planes of similar scope.

It would also be beneficial to have side-by-side comparisons of the Boeing 747 for each calculation. Not only would the 747 be somewhat representative of the HSCT, it is also a likely source of competition for sales. In contrast, the Concorde comparison may not be that meaningful since costs were astronomical as a result of the shortened production run. Additionally, the Concorde is not limited by noise and environmental constraints, nor does it have a reasonable payload compared to the HSCT presented here.

Finally, a couple parameters of the HSCT itself should be reconsidered. Two are the design cruise speed and the 5000 mile stage length. It has been noted that a Mach 2.7 HSCT would be capable of an additional Hong Kong to Tokyo flight per day, a flight worth \$35 million each year per plane. Other flights would have significant monetary benefits as well. However, there would be a tradeoff with respect to operating temperature, weight, fuel burn, etc. Another HSCT variable that should be considered is the market for short distance travel. Currently, the 
5000 mile stage length is the design range for the HSCT. This includes lengthy transoceanic flights and flights that exceed 5000 miles such as the Los Angeles to Sidney flight, a distance that would require stop in Honolulu. However, it has been suggested that a market defined in this way is overly conservative. A great potential exists for shorter flights that are completely over water such as the Seattle to Los Angeles flight or a Miami to New England distance. Numerous distances such as these exist throughout the world that could greatly enhance the market for the HSCT. As more units are demanded, more units may be produced which can have a significant effect on the unit cost and price of the aircraft, although the effects become limited as the production reaches and surpasses 1000 aircraft.

\subsubsection{Conclusions}

Comparisons across models is extremely difficult and often results in inconsistent results. Many reasons exist why this is true including differing input variables and differing cost outputs. For example, some models give costs while others give hours; some models separate recurring and nonrecurring costs while others only compute one or combine both together.

The Designer's Trade-off Tool is simple to apply and is good at instantaneously understanding the cost consequences or benefits of differing designs. It is not appropriate for cost estimating and does not take into account many specifics as the PRICE H costing model.

PRICE $\mathrm{H}$ is a powerful tool that requires a great deal of information. As more information becomes available, PRICE $H$ gives better results. PRICE $H$ is useful for making tradeoffs when a number of parameters have already been determined or when a full understanding of the cost of a system or component is necessary.

The 1981 RAND study on aircraft structural modifications is useful to get a ballpark estimate of the labor efforts required to design and produce the wing. Combined with accurate labor rates, the costs may be determined. However, the use of the study can at best only serve as a rough guess because the study reports structural modifications of existing aircraft while the HSCT is an airplane program that is not even into development yet.

ACSYNT is not very useful for the component level, but is very useful in understanding the effects of a component level change on the entire system. Thus, ACSYNT is a good tool to "close the loop" for the HSCT design. When a reasonable design is determined, the revised weight and complexity information can be input to ACSYNT and the corresponding changes on gross weight, fuel weight, direct operating cost, return on investment, net present value, and acquisition cost may be ascertained.

Any costing model can only give approximations of the cost of an aircraft or sub-system. Since costing estimates are based on parametric relationships of aircraft that may or may not be very similar in performance or type, some error is expected in any case. Experience in knowing 
how to adjust a cost estimate for a type of aircraft, for a given manufacturer, or for any other specification is important to give reliable cost estimates. Costing models are usually proprietary within corporations because competitors could use such information to their advantage if a detailed cost prediction methodology was known. As a result, there is a limit to which one may accurately predict cost. Furthermore, even veteran cost estimators can disagree widely on the numbers. For example, the responses for the recurring manufacturing labor required for graphite/epoxy (based on 1990 dollars, cumulative average hours for 100 units for 1000 pounds of structure) varied between 2.8 hours $/ \mathrm{b}$ and 33.4 hours $/ \mathrm{lb}$.

Composite materials have the opportunity to save a great deal of money for airlines in terms of direct operating costs. Although the RDT\&E and acquisition costs may be much higher for aircraft with significant percentages of composite materials, the resulting benefit on the life cycle cost of the HSCT can far outweigh these costs. Additionally, composites will become economically more feasible with time, and will decrease in price at a faster rate than metal alloys such as titanium.

\section{References}

1Alchian, Armen. "Reliability of Progress Curves in Airframe Production," Vol. 31, No. 4, October 1963, pp. 679-693.

Econometrica.

\section{2"Appendix II: Designer's Production Cost Trade-off Tool"}

${ }^{3}$ Bettelle Memorial Institute. High Speed Commercial Flight - from Inquiry to Action. Edited by James P. Loomis. The Proceedings of the Second High Speed Commercial Flight Symposium, October 19-20, 1988.

${ }^{4}$ Birkler, J. L, and Large, J. P. A Method for Estimating the Cost of Aircraft Structural Modification. The RAND Corporation, Document R-2565-AF, March 1981.

SBoeing Commercial Airplane Group. 1992 Current Market Outlook - World Market Demand and Airplane Supply Requirements. February 1992.

"Collard, D. "Concorde Airframe Design and Development," Proceedings of the Society of Automotive Engineers. Paper 912162, pp. 2620-2641, 1991.

TEames, John D. "Concorde Operations," Proceedings of the Society of Automotive Engineers. Paper 912161, pp. 2603-2615, 1991.

8General Electric Company. "Section 8: MCPLXS Generator", 1990

9Lockheed Corporation. LR 28185-4. Section 16.

10Majd, Saman, and Pindyck, Robert S. "The Learning Curve and Optimal Production Under Uncertainty," RAND Journal of Economics. Vol. 20, No. 3, Autumn 1989, pp. 331-343. 
11"Market Studies Indicate Demand For High-Speed Civil Transport," Aviation Week \& Space Technology. November 21, 1988, pp. 54-61.

120'Brian, Bridget. "Tired of Airline Losses, AMR Pushes Its Bid To Diversify Business," The Wall Street Journal, 18 February 1993, p. A1 col. 1.

130tt, James. "Competition To Forge New Airline Structures," Aviation Week \& Space Technology. March 15, 1993, pp. 63-70.

14PRICE Parametric Cost Models. "Composite Material Study," Technical Bulletin No. 15, December 1990.

15Parametric Study of Transport Aircraft Systems Cost and Weight. Prepared for NASA under Contract No. NAS2-8703. Science Applications, Inc., April 1977.

16RAND Corporation. Advanced Airframe Structural Materials: A primer and Cost Estimating Methodology. 1990.

${ }^{17}$ Roskam, Jan. Airplane Design, Part VIII: Airplane Cost Estimation: Design, Development, Manufacturing and Operating. 1990.

18Schrage, D. P. "Relating Economics to Rotorcraft Design Parameters through a Criterion Function," AIAA Paper 93-1180. AIAA/AHS/ASEE Aerospace Design Conference, February
$16-19,1993$.

${ }^{19}$ Solverson, Robert R. "Design to Cost with PRICE H" Aerospace Design Conference, February 16-19, 1993 (Irvine, CA). AIAA 93-1030

${ }^{20}$ Standard \& Poors' Corporation. "Hope Springs Eternal," Industry Surveys. June 25, 1992, pp. A43-A44.

21Van der Velden, J. M. "An Economic Model for Evaluating High-Speed Aircraft

Designs," NASA Contractor Report 177530, May 1989.

22Verchere, Ian. "Aircraft Finance Loses Its Nerve," Interavia Aerospace Review, April 1991, pp. 49-50.

23Velocci, Anthony L, Jr. "Fewer Players to See Late-Decade Upturn," Aviation Week \& Space Technology. March 15, 1993, pp. 38-39. 


\subsection{Layout / Mass}

Mass analysis and layout is where and how the components of the aircraft system are distributed. Mass analysis is closely linked with the disciplines of Stability and control, Structures, Aerodynamics and Propulsion.

The Layout drawings show the locations for the center of gravities for most major components and the overall configuration and dimensions for the aircraft.

\subsubsection{Summary of Lockheed's Study}

Specifics of the Lockheed baseline can be found in the Lockheed report.[1] The dimensions are detailed in section 2 while the mass distribution and center of gravity analysis are in section 15.

The Lockheed TASK I configuration is an arrow wing with vertical fins on the wings as well as a vertical stabilizer. The takeoff weight was 750,000 pounds with a 4200 nautical mile range and 49000 pounds of payload. The length is 90.5 meters with a planform of 1005 square meters.

For the mass analysis Lockheed studied each of its wing construction concepts and the impact each would have on total weight and critical concerns such as flutter. The center of gravity travel was determined as were moments of inertia.

\subsubsection{Georgia Tech's Methodology}

This quarter Georgia Tech has attempted to use the Lockheed study as a background upon which to apply the methods taught in the graduate design courses. The interaction of mass analysis with structures and materials is obvious, each structure adds mass to the aircraft and the structures group attempts to minimize mass while maintaining project objectives. The propulsion group adds engines and fuel to the equations. Center of gravity information is necessary for proper trimming and control of the aircraft involving the aerodynamics, stability and control groups. Input from these groups was cycled through analysis and back for additional group input to reach a converged configuration. Tools used included FLOPS, ACSYNT, and spreadsheet methods.

\subsubsection{Results}

The accompanying drawings show the overall configuration which resulted; dimensions are given on figure 7.9.3.1 while some CG component locations are detailed on figure 7.9.3.2. Preliminary component weight estimation came from FLOPS and ACSYNT baselines developed in 
the previous quarters these values showed good agreement varying by large percentages only when the component weight was small, less than $5 \%$ or so of the baseline weights for significant size components. (See table 7.9.1)

Components and payload were distributed in the aircraft so that the static margin for the aircraft was in the 5 to 10 percent range recommended by Nicolai[2]. When empty the aircraft has a 5\% static margin. After addition of passengers the margin is slightly larger. 100000 pounds of fuel is tanked in the forward fuselage and tank scheduling is preformed to allow for shifting of the aerodynamic center during transonic and supersonic flight regimes.

FLOPS was used after locations of equipment and components were fixed to generate moments of inertia for use by stability and control. The resulting values are shown in table 7.4.9. 
Table 7.9.1 Comparison of Weight Generated by FLOPS and ACSYNT MASS ANALYSIS COMPARISON OF ACSYNT TO FLOPS

\begin{tabular}{|c|c|c|c|}
\hline WEIGHT ANALYSIS & ACSYNT & FLOPS & PERCENT \\
\hline COMPONENT & POUNDS & POUNDS & VARIATION \\
\hline AIRFRAME STRUCTURE & 180754 & 176086 & 2.7 \\
\hline WING & 70648 & 70377 & 0.03 \\
\hline FUSELACE & 62200 & 61139 & 1.7 \\
\hline HORZONTAL TALL & 4681 & 4138 & 13.1 \\
\hline VERTICAL TAIL & 2797 & 2442 & 14.5 \\
\hline NACEUES & 9997 & 9423 & 6.1 \\
\hline LANDING GEAR & 30431 & 28567 & 6.5 \\
\hline PROPULSION & 52877 & 54251 & 2.5 \\
\hline ENGNES & 47981 & 48000 & 0.04 \\
\hline FUEL SYSTEM & 4896 & 4938 & 0.9 \\
\hline FDXED EQUIPMENT & 60893 & 65407 & 6.9 \\
\hline HYD \& PNEUMATIC & 4356 & 4575 & 4.7 \\
\hline ELECTRICAL & 4890 & 5407 & 9.6 \\
\hline AVIONICS & 2984 & 2929 & 1.8 \\
\hline INSTRUMENTATION & 1931 & 1893 & 2.0 \\
\hline DE-ICE \& AIR COND & 4277 & 8679 & 50.7 \\
\hline AUX POWER SYSTEM & 1599 & 1566 & 2.0 \\
\hline FURNISH \& EQPT & 29678 & 29042 & 2.2 \\
\hline FLIGHT CONTROLS & 11178 & 11278 & 0.9 \\
\hline MISC & 0 & 7913 & 100.0 \\
\hline FUEL & 371033 & 361244 & 2.7 \\
\hline PAYLOAD & 61735 & 63916 & 3.4 \\
\hline FLGHT CREW (3) & 675 & 675 & 0.0 \\
\hline PASSENGERS (305) & 51850 & 50305 & 3.1 \\
\hline BACGACE & 9210 & 12936 & 28.8 \\
\hline CALCULATED TOTAL & 727291 & 727504 & 0.03 \\
\hline EMPTY WEIGHT & 294523 & 295744 & 0.4 \\
\hline
\end{tabular}


Table 7.9.2 Horizontal CG Locations (Referenced from A/C Nose)

\begin{tabular}{|c|c|c|}
\hline COMPONENT & POUNDS & INCHES \\
\hline AIRFRAME STRUCTURE & 176086 & 2126.5 \\
\hline WING & 70377 & 2113.8 \\
\hline FUSELAGE & 61139 & 1860 \\
\hline HOREONTAL TAIL & 4138 & 3450 \\
\hline VERTICAL TAIL & 2442 & 3421 \\
\hline NACEUES & 9423 & 2569.75 \\
\hline LANDING GEAR & 28567 & 2279.639 \\
\hline PROPULSION & 54251 & 2544.8 \\
\hline ENGINES & 48000 & 2569.75 \\
\hline MISC. SYST & 1313 & 2257.6 \\
\hline FUEL SYSTEM & 4938 & 2379.0 \\
\hline FLXED EQUIPMENT & 65409 & 1899.6 \\
\hline HYD \& PNEUMATKC & 4575 & 2018.2 \\
\hline ELECTRICAL & 5407 & 1211.9 \\
\hline AVIONICS & 2929 & 800.0 \\
\hline INSTRUMENTATION & 1893 & 1111.3 \\
\hline ARCONDITON & 8332 & 2139.2 \\
\hline DE-KCE & 387 & 2127.1 \\
\hline AUX POWER SYSTEM & 1566 & 3360.0 \\
\hline FURNISH \& EQPT & 29042 & 1840.0 \\
\hline FLGHT CONTROLS & 11278 & 2364.9 \\
\hline WEGHT EMPTY & 295746 & 2153.0 \\
\hline CREW AND BAGGAGE-FLIGHT 3 & 675 & 480 \\
\hline - CABIN 11 & 1795 & 1840.0 \\
\hline UNUSABLE FUEL & 1982 & 2100 \\
\hline ENGINE OIL & 386 & 2569.8 \\
\hline PASSENGER SERVICE & 4150 & 1840.0 \\
\hline CARGOCONTAINERS & 2450 & 1840.0 \\
\hline OPERATING WEGHT EMPTY & 307184 & 2141.0 \\
\hline PASSENGERS (294) & 48512 & 1840 \\
\hline PASSENGER BACGAGE & 12936 & 1840 \\
\hline ZEROFUEL WEGHT & 368632 & 2090.8 \\
\hline MISSION FUEL & 358876 & 2100 \\
\hline RAMP (GROSS) WEIGHT & 727508 & 2095.4 \\
\hline
\end{tabular}


Table 7.9.3 Summary of Polnts Used for CG Chart

\begin{tabular}{|c|c|c|}
\hline MINUS PASSENGERS & 716070 & 2099.6 \\
\hline WEGHT EMPTY & 295746 & 2153.0 \\
\hline OPERATING WEIGHT EMPTY & 307184 & 2141.0 \\
\hline FUEL ADDMION & 666060 & 2118.9 \\
\hline RAMP (GROSS) WEIGHT & 727508 & 2095.4 \\
\hline FUEL BURNOFF & 368632 & 2090.8 \\
\hline OPERATING WEIGHT EMPTY & 307184 & 2141.0 \\
\hline OGMVMT & 57.7 & \\
\hline \multicolumn{3}{|l|}{ LE MAC 1984.198} \\
\hline $\begin{array}{l}C / 4 \text { MAC } @ 2195.23 \\
T E M A C @ 2828.314\end{array}$ & 6.8 & \\
\hline MAC 844.116 & & \\
\hline
\end{tabular}

Table 7.9.4 Overall Aircraft Moments of Inertia

FULYYLOADED

$\mathrm{LX}=.23027 \mathrm{E}+5$

$\mathrm{IY}=.18129 \mathrm{E}+6$

LB IN^2/1,000,000

$\mathrm{IZ}=.20061 \mathrm{E}+6$

$\mathrm{IXZ}=-.40440 \mathrm{E}+4$ 


\section{Eigure 7.9.3.1 Aircraft Dimensions}
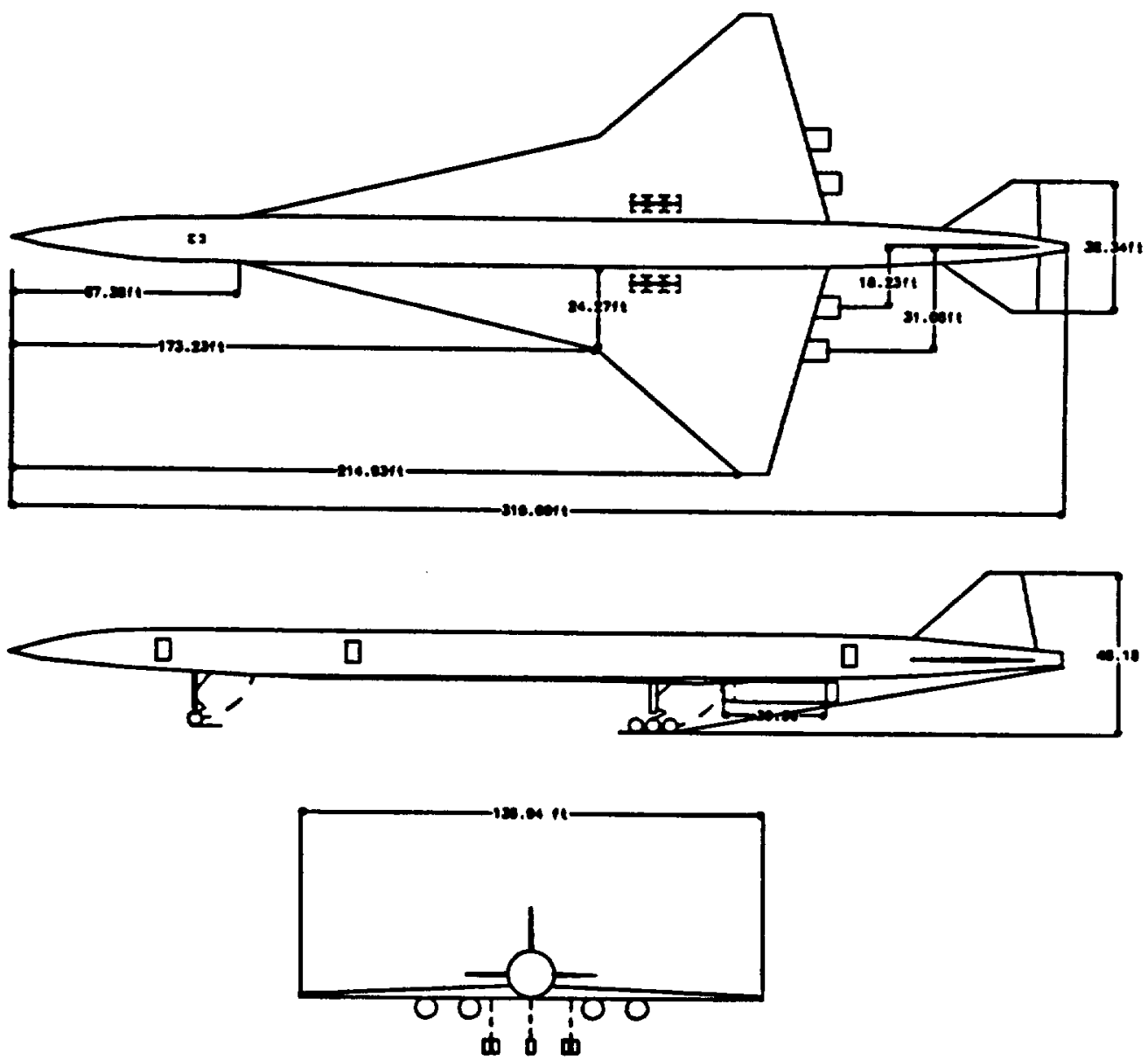
Eigure 7.9.3.2 Component CG locations

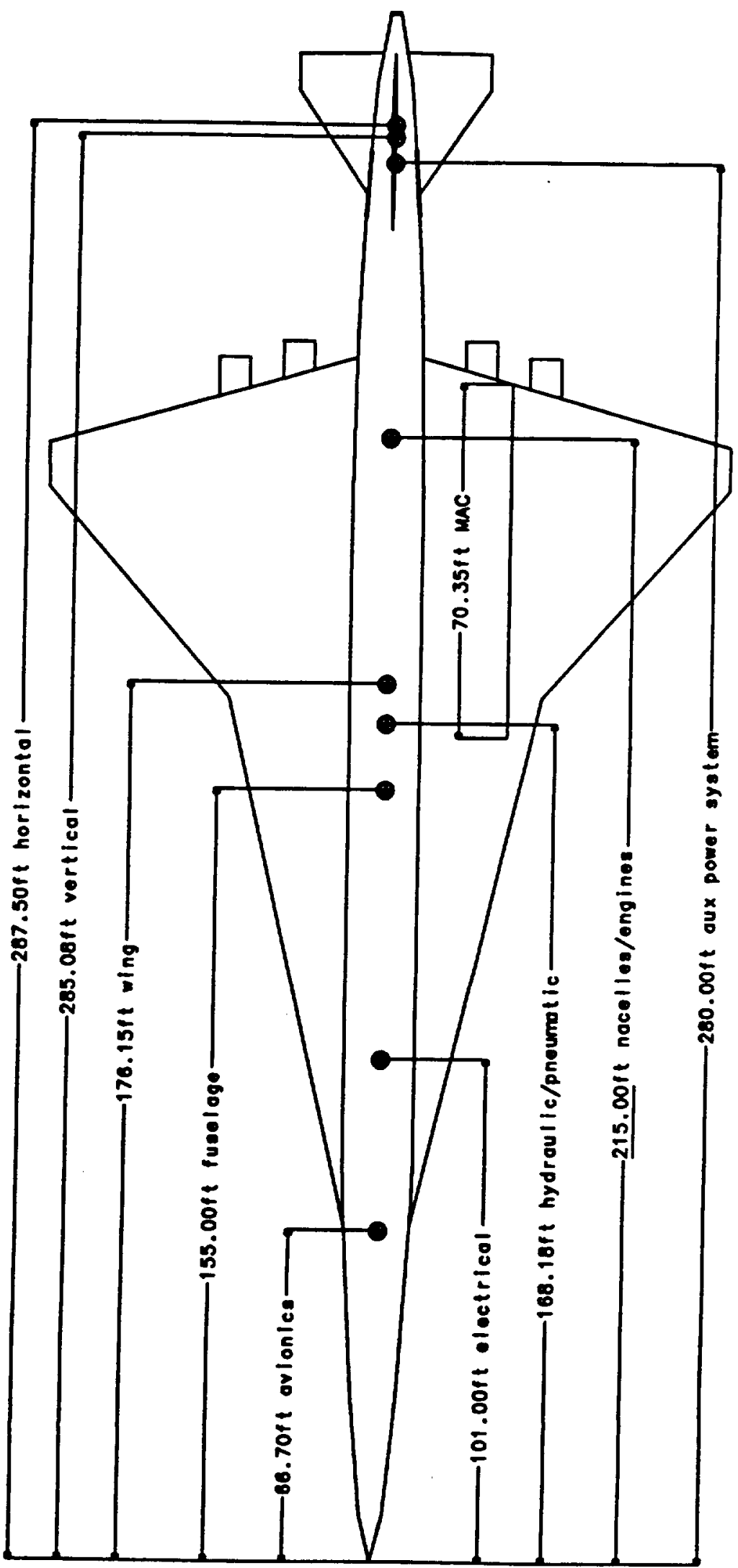




\section{Eigure 79.3.3 HSCT CG travel}

HSCT CG TRAVEL

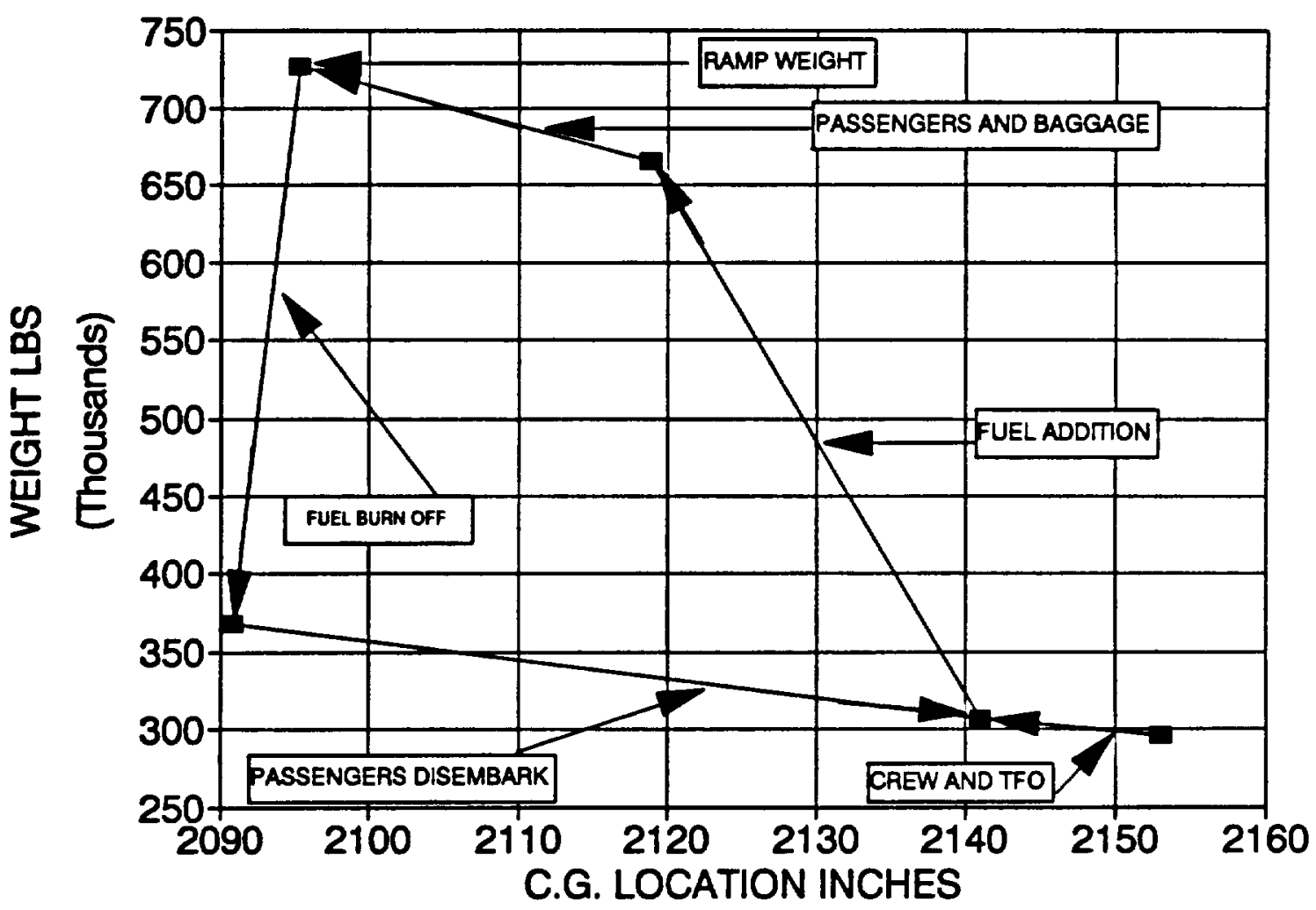




\section{References}

1. Messina, A.F., et al., NASA CR-132575: Substantiating Data Report: Arrow Wing Supersonic Cruise Aircraft Structural Design Concepts Evaluation. Vol 1 Section 3, 1977

2. NICOLAI, Fundamentals of Aircraft Design, 1984, METS, Inc. 


\subsection{Acoustics}

\subsubsection{Introduction}

Acoustics is extremely important for the HSCT because it may ultimately cause numerous problems at the certification stage and the operation stage of the airplane program. If the noise of the supersonic transport is not reduced sufficiently to meet the Stage III requirements outlined in Federal Aviation Regulations (FAR) Part 36, it has been stated that the HSCT will not be certified for operation. Additionally, communities may enforce more stringent requirements of aircraft noise than that of the Federal Aviation Administration (FAA). Although this design has assumed no supersonic flight over land, there still exists the opportunity to design a low sonic boom aircraft that would have a sonic signature acceptable to the public. Although the Concorde is a supersonic transport and is in no way close to Stage III certification, the Concorde is outlawed in many cities throughout the world. Additionally, there will be at least 20 times more HSCTs built than Concordes if the HSCT program commences. Furthermore, the HSCT is guaranteed no special permission like the Concorde to operate in violation of noise certification requirements [7].

Acoustics is a rather broad area that can imply a number of things for the HSCT. The word acoustics itself is defined as "the scientific study of sound, esp. of its generation, transmission, and reception." For the HSCT, acoustics can have many meanings including, but not limited to the following:

- Interior Noise

- Landing and Takeoff Certification Requirements

- Sonic Boom Signature

- Sonic Fatigue

- Jet Source Noise Research

- Community Response to Aircraft Noise

Interior noise is the noise experienced by the passengers of the HSCT. Although not studied here, there are presently a number of studies with active noise control that emphasize reproducing sounds to cancel out disturbing sounds. In an HSCT, it may be possible to design special speakers built into the backs of seats to emit sounds completely out of phase with the bothersome jet noise so that the passenger experiences a great reduction in noise. Such procedures are more effective with high frequency noise than low frequency noise. Interior noise can also be reduced by utilizing interior sidewalls made of composite materials [5]. Community response to aircraft noise is also a very important topic and will be briefly discussed in the landing and takeoff certification requirements section.

This acoustics study will discuss some of the Federal Aviation Regulations, sonic boom considerations, takeoff and landing procedures, and sonic fatigue issues that relate to the HSCT 
and the wing. Finally, this section is concluded with some recommendations for the HSCT presented here.

\subsubsection{FAA Regulations}

The HSCT is constrained by FAR Part 25 and FAR Part 36. The Stage III requirements of FAR Part 36 are considered here because they are more stringent by offering less flexibility than the FAR Part 25. Specifically, Part 25 allows manual throttling and flap reduction under an altitude of $\mathbf{4 0 0}$ feet while Part 36 requires fixed flaps and no throttle changes until an altitude of 689 feet is achieved [6].

The HSCT will be required to meet Stage III requirements and possibly Stage IV parameters. Stage IV specifications have not become law as of 1993 and thus cannot be considered. Stage III gives three noise limits to be adhered to:

- Takeoff (flyover)

- Sideline

- Approach

Sideline noise is defined as any point parallel and 450 meters from the extended centerline of the runway. The actual figure used for the sideline noise observation is the highest of any of these points parallel to the runway centerline. Another frequently used statistic is aircraft noise measurement is flyover noise, the point 6500 meters from the brake release located on the extended centerline. The approach noise is measured 2000 meters from the threshold on the extended centerline of the runway.

Since the HSCT by necessity must weigh less than 850,000 pounds, it is required to have a takeoff acoustic signature of no more than $104 \mathrm{EPNdB}$ at 850,000 pounds, reduced at the rate of 4 EPNdB per halving of this 850,000 weight [7]. The unit EPNdB is a measure of the Effective Perceived Noise Level (EPNL) which is a basic sound pressure level, weighted for tone frequency and integrated to account for noise duration. The Effective Perceived Noise Level gives a considerable penalty for tonal sounds [6]; however, the HSCT is expected not to have any. Specifically, the EPNL is found by the following formula where PNLT is the Tone-corrected Perceived Noise Level [6]:

$$
E P N L=10 \log _{\pi}^{\pi} 10^{\frac{P N L T}{10}} d t
$$

Considering the HSCT is about 720,000 pounds, the maximum takeoff noise permitted is 103 EPNdB.

For sideline noise considerations, aircraft weighing 882,000 pounds or more are allowed 103 EPNdB, reduced at the rate of 2.56 EPNdB per halving of the 882,000 pounds [7]. Thus, the HSCT must have no more than 102 EPNdB for sideline noise considerations. 
The maximum allowed approach noise is 105 EPNdB for aircraft of weights of 617,300 pounds or more, reduced at the rate of $2.33 \mathrm{EPNdB}$ per halving of 617,300 pounds [7]. Thus, the HSCT must adhere to a constraint of approximately 104 EPNdB upon approach.

The FAA has allowed some tradeoffs between the three requirements. Thus, the HSCT may exceed the maximum allowed noise for a given requirement provided that all of the following be met:

- The greatest exceedance is within 2 EPNdB of the maximum allowed

- The sum of all exceedances is no more than 3 EPNdB

- All exceedances are canceled out by noise observations under the maximum allowed for other stations

These requirements and specifications can be combined into a single number, known as the Noise Figure of Merit (NFOM) [1]. The NFOM is the maximum of any of the following equations:

$$
\begin{aligned}
& E P N L_{1}-E P N L_{1}-2 \\
& E P N L_{3}-E P N L_{\alpha}-2 \\
& .5\left[E P N L_{+}+E P N L_{3}-E P N L_{,},-E P N L_{\alpha}\right]
\end{aligned}
$$

EPNL: $\quad$ HSCT flyover noise

EPNL: $\quad$ HSCT sideline noise

EPNL $1, \quad$ FAR 36 noise limit as it applies to the HSCT

EPNL, $\quad$ FAR sideline noise limit as it applies to the HSCT

Thus, a positive NFOM indicates that the noise of the aircraft must be reduced to meet certification requirements while a negative or zero NFOM means the HSCT can be Stage III certified. The FAA Stage III HSCT requirements are summarized in the table below:

\begin{tabular}{|lc|}
\hline Station & Maximum EPNdB \\
Takeoff & 103 \\
Approach & 104 \\
Sideline & 102 \\
\hline
\end{tabular}

Table 7.10.1 Station Noise Limits 


\subsubsection{Takeoff / Landing Procedures and Noise}

Generally, takeoff, approach, and sideline noise may be reduced by using advanced ejector nozzles, advanced takeoff procedures, and utilization of high lift devices.

Operational procedures are an effective way of reducing the noise generated by the HSCT. The general lessons learned from operational procedure noise studies can likely be applied to any HSCT design configuration to assist with Stage III certification. There are two kinds of reduced noise operational procedures: basic and advanced. Currently, the FAA limits the use of advanced procedures for safety considerations. However, there is a Notice of Proposed Rule Making (NPRM) under review for flexibility for differing flight conditions. One potential outcome may be the permission for aircraft to operate with computer controlled flaps and throttles during the certification procedure [6].

Olson has utilized the Flight Optimization System (FLOPS) to test five takeoff procedures for an HSCT in many ways resembling the one presented for this report. These five procedures include [6]:

1. Reduced throttle at takeoff

2. Delayed rotation

3. Early cutback

4. Auto throttle

\section{Accelerated climb}

The first three procedures are considered basic procedures while the last two are advanced procedures. Delayed rotation is the increase in the rotation velocity until the maximum filed length is achieved. The result is an increase in the obstacle velocity for engine-out takeoff procedure which in turn increases the HSCT's rate of climb and reduces flyover noise. The early cutback procedure entails reducing the throttle as soon as an altitude of 689 feet is achieved. However, the lowest flyover noise happens when the aircraft is 19,000 feet from brake release, usually at an altitude of 1200 feet. Thus, cutback at the minimum 689 feet could serve to trade an increased flyover noise for decreased sideline noise [6].

The two advanced takeoff procedures include auto throttle and accelerated climb. Computers can be used for the auto throttle procedure to maximize engine thrust on or near the ground and reduce throttle settings as soon as the aircraft becomes airbome [6]. To accomplish accelerated climb, the HSCT is accelerated while executing a fixed, but decreased, flight trajectory [6]. Although this results in a decrease in HSCT altitude at the flyover measurement point, the higher climb speed permits a decreased cutback throttle.

The results of Olson's study were an optimized basic takeoff procedure of a $97 \%$ takeoff throttle setting combined with early cutback and a 199 knot rotation velocity resulting in a field length of the maximum permissible 11,000 feet. This resulted in a reduction of $3.44 \mathrm{EPNdB}$ at 
flyover and 2.39 EPNdB at sideline compared to the baseline and a $72 \%$ reduction of the 100 EPNdB noise footprint area. The Noise Figure of Merit was 4.37 EPNdB. The noise footprint areas for the $100 \mathrm{EPNdB}$ and 110 sound levels were 8.6 square miles and 1.6 square miles, respectively. The best advanced procedure had an even higher rotation velocity of 203 knots and called for a $250 \mathrm{knot}$ accelerated climb velocity before cutback. The combination of these two advanced procedures resulted in a reduction of the NFOM to only $2.12 \mathrm{EPNdB}$, although the flyover noise was 1.31 EPNdB higher than the basic procedure. The improved NFOM was largely driven by a decrease of sideline noise of 7.3 EPNdB. The advanced procedures resulted in a 110 EPNdB noise footprint area of only 1.45 square miles while the 100 EPNdB footprint area was reduced from the baseline area to 7.0 square miles [6]. The HSCT developed for this study had the following sideline noise characteristics:

\begin{tabular}{|ll|}
\hline Station $(f t)$ & EPNdB \\
10,000 & 115.28 \\
12,000 & 116.34 \\
14,000 & 114.05 \\
16,000 & 113.96 \\
18,000 & 113.87 \\
20,000 & 113.81 \\
22,000 & 113.75 \\
\hline
\end{tabular}

Table 7.10.2 GT HSCT Station Noise Calculations

Thus, the sideline noise for this design is $116.34 \mathrm{EPNdB}$ since the highest value is taken, a value far in excess of the FAA required value of 102 EPNdB. However, these values have the capability of being reduced by the methods described in this section.

Utilization of high lift and other aerodynamic devices can assist in reducing HSCT noise generation. High lift research applicable to the HSCT includes leading edge vortex flaps, use of canards, and leading edge boundary layer control. Employing the high lift technology resulted in a NFOM of -2.74 EPNdB for the basic procedure of 205.4 knot rotation at flyover and a NFOM of -1.10 EPNdB for $87 \%$ throttle combined with 188.5 knot rotation and early cutback. This yielded a 42\% decrease in 100 EPNdB noise footprint area, a reduction to 4.0 square miles for the basic 205.4 knot rotation procedure. For the auto-throttle and accelerated climb procedure, the NFOM was reduced to $-3.45 \mathrm{EPNdB}$ and $-2.92 \mathrm{EPNdB}$ for flyover and sideline, respectively. The 
combined advanced procedures resulted in a 47\% reduction in $100 \mathrm{EPNdB}$ footprint area compared to using no high-life technology. The resulting area was 3.72 square miles [6].

A study conduced by Golub, Powell, Preisser, and Seiner also utilized the NASA Aircraft Noise Prediction Program (ANOPP) used by Olson after completing FLOPS trajectory analysis. The Golub et. al. study analyzed the effects of reducing thrust and increasing lift. Their study indicates that increasing lift alone will generate no significant noise savings. Decreasing thrust alone cannot be done since the aircraft cannot takeoff in a reasonable distance. However, the combination of high lift and reduced thrust can result in favorable noise reduction. By decreasing the thrust setting to $80 \%$ and increasing lift $60 \%$ sideline noise was reduced $4.29 \mathrm{EPNdB}$ while centerline noise was reduced a similar amount, 4.26 EPNdB. The takeoff field length penalty over the baseline for a $20 \%$ reduction in thrust and $60 \%$ increase in lift is only 1050 feet, a reasonable distance. The noise footprint areas were decreased from 23.33 square miles for 100 EPNdB to 14.01 square miles. The $110 \mathrm{EPNdB}$ area was reduced from 6.67 square miles to 3.61 square miles [2].

Golub et. al. note that the centerline parameter is an easier number to reduce compared to flyover noise, partly because the centerline noise is measured at a fixed point. One technique to reduce centerline noise is to capitalize on the following relationship:

$$
\text { SPLoc 20logr }
$$

where $r$ is the distance from the measurement point to the HSCT. Specifically, one desires to maximize the distance from the HSCT to the noise point by increasing the airplane's climb angle. Another way centerline noise may be reduced is by minimizing this proportionality:

\section{$S P L \propto 650$ og}

where $v$ is the jet exhaust velocity. Here, noise is reduced by decreasing power prior to reaching the centerline measurement point.

Takeoff and landing noise can also be reduced at the source--the jet itself. There are essentially two sources of supersonic jet noise: mixing noise and shock noise. Mixing noise includes fine grain turbulence and large scale turbulence, an intense noise or Mach wave emission that can be from 0.1 to $1.0 \%$ of the jet's mechanical energy [2]. Shock noise is divided into two parts as well: screech and broadband. Screech is the "interaction of the most unstable spatial mode of the jet with shock waves" [2]. When screech is present, it dominates the noise in the forward arc of the acoustic signature of the aircraft. Broadband is the interaction of turbulence with shock waves. The biggest contributor to broadband noise is large scale turbulence. This is because there is an interaction with the shock waves that causes acoustic waves to be formed that are added in phase. Broadband shock noise is not very directional and has its largest contributions toward the forward arc. Broadband shock noise is best reduced by decreasing the shock strength [2]. 
Golub et. al. examined the effects of using noise suppression at the jet to reduce engine noise. Success depended much upon the assumptions of what noise was present. For example, if both mixing and broadband noise was assumed present, an attempt to suppress mixing noise 20 $\mathrm{dB}$ resulted in a decrease of sideline and centerline noise of $2.50 \mathrm{EPNdB}$ and $2.39 \mathrm{EPNdB}$, respectively. Similarly, attempts to reduce shock noise $20 \mathrm{~dB}$ only resulted in a decrease of sideline noise of 3.67 EPNdB and centerline noise of 3.84 EPNdB. However, if both mixing and shock noise were suppressed $20 \mathrm{~dB}$ together, the results were a decrease of $20.25 \mathrm{EPNdB}$ for both the centerline and sideline locations [2].

FAA Stage III requirements ignore the noise footprint areas generated by the HSCT. Although reduced climb performance has a slightly negative impact on the Noise Figure of Merit, it has a potentially great effect on the community acceptance of the HSCT, an acceptance that will be a function of the 100 EPNdB noise footprint area. Studies have shown that noise levels over 100 EPNdB for turbojet aircraft can have deeper consequences than sound alone. Vibration in walls, window rattling, and motion of hanging things may actually have a greater impact on a community's perception of bothersome aircraft than the sound itself [6]. Past studies have suggested that people can detect vibration in the floor of a typical house if the outdoor overall sound pressure level (OASPL) exceeds about $95 \mathrm{~dB}$ [2]. For the turbojet Concorde, this translates into about 98 to $100 \mathrm{EPNdB}$ [2]. As a result, many airport noise limits already surpass those of Part 36, airports crucial to the HSCT economic success.

\subsubsection{Sonic Boom}

The market for the HSCT would be expanded considerably if the aircraft were capable of flying supersonically over land. However, reducing the sonic boom signature represents a formidable task.

For low boom design, the wing planform is the critical component to be designed first [5]. Control surfaces, engines, and the fuselage are integrated into the design and sized after a planform that has potential is determined. Several critical design parameters exist that help determine the HSCT's size, weight, and shape. Some of these include the Mach number, the ratio of noise to tail shock, the altitude, and the bluntness of the nose. Often, low boom configurations employ the so called "platypus nose" for a rounded wing apex [5]. Also, low boom configurations have high leading edge sweeps and extremely long lifting lengths, on the order of 300 feet or more. The aircraft also employ a slender airfoil shape and a thickness ratio of about $2.5 \%$ [5]. Strake sweeps of $\mathbf{8 3}$ degrees are common as well. The strake sweep for the configuration presented here is only 73 degrees. The following figure gives the reader some idea of the low boom configuration design. 


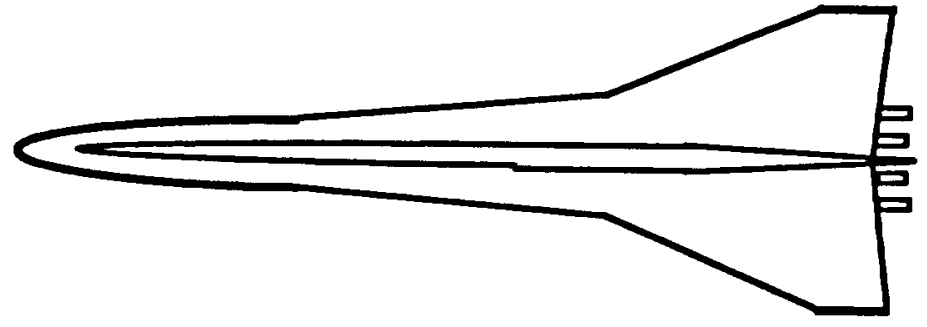

Eigure 7.10.1 Low Boom Configuration

Two sonic boom constraints are a sound level of $72 \mathrm{dBA}$ on the ground and a shock strength on the ground of $0.75 \mathrm{lb} / \mathrm{ft}^{2}$ [3]. The $72 \mathrm{dBA}$ was determined from human response testing during the 1970s and will thus need to be revisited. To reduce ground sound level to 72 $\mathrm{dBA}$, the pressure difference across the shock must be decreased to $.75 \mathrm{lb} / \mathrm{ft}^{2}$ in all likelihood [3]. This means that lifting surfaces must be swept to a great degree and that the wing loading must be low.

Lift is extremely important for sonic boom. The wing loading of a an acceptable design was $63 \mathrm{lb} / \mathrm{ft}^{2}$ [3] which compares to the wing loading of the aircraft presented here of about 89 $\mathrm{lb} / \mathrm{ft}^{2}$. To achieve this lower wing loading, the wing and strake run essentially the length of the plane. In the case of one potential design, the wing and strake length totaled 300 feet on a 310 foot-long HSCT. The economic tradeoff here is that better cruise performance is achieved with a higher wing loading, although increasing the wing loading negates the low boom efforts. The location of the nacelles can increase lift up to $10 \%$ of the total so their placement is critical. For designing to low sonic boom, it is important to get a smooth lift distribution. To achieve this, a $15 \%$ loss in payload to 237 passengers was sacrificed as well as an increase in gross takeoff weight of $2 \%$ and an increase in empty weight of $8 \%$. The engine size had to be increased $6 \%$ although block fuel was essentially unchanged [3]

Unfortunately, the difficulty in arriving at an acceptable design increases rapidly as the Mach number is increased above 1.7. Over Mach 1.7, the wave form begins to look like the classical N-wave shape. The peak pressure moves toward the front of the HSCT, and at some time, the two will merge [3]. Higher altitudes also make low boom design difficult.

For the $5000 \mathrm{~nm}$ mission examined in this report, one must expect a low sonic boom aircraft to be penalized by additional gross takeoff weight and a higher lift-to-drag ratio, although the block fuel will remain about constant. However, if the $.75 \mathrm{lb} / \mathrm{ft}^{2}$ constraint is assumed, the liftto-drag ratio is decreased, opposite of what a low sonic boom aircraft desires. Also, the number of passengers must be reduced which results in an increase of the block fuel per passenger ratio of $17 \%$, a result that will significantly increase the critical fare premium over subsonic competition aircraft. 


\subsubsection{Sonic Fatigue}

The Lockheed study dealt exclusively with the sonic fatigue aspects of the HSCT wing. The study was done in three steps:

1) Estimate the acoustic environment for the baseline HSCT

2) Define analysis and design charts for use in detail analysis

3) Conduct detail analysis on representative wing panels

[4]

Prior to a sonic fatigue assessment, the structure and acoustic environment must be known.

The sonic environment was based on a Mach 2.7 duct burning turbofan engine. Using the performance specifications of the engine and empirical relationships describing acoustic levels, noise contours were generated for the airplane. Contours were then modified to account for operating procedures, engine geometric characteristics, and the presence of structure in an acoustic field [4]. Due to nozzle area and velocity differences, the contours were scaled. Also, the use of a noise suppressor was considered as well.

With respect to sonic fatigue resistance, the two most important properties of a structure are its:

- Resonant Frequencies

- "Quality of detail design"

Resonant frequencies are important because stresses can be induced as a result of excitation of the structure at the structure's resonant frequency. These loads may be fifty times as great as the corresponding static loads. The importance of the resonant condition is increased for structural components subjected to broadband noise. "Quality of detail design" is important for the "amplitude of vibratory response which the structure can withstand for a satisfactory period of time without fatigue cracking" [4]. Because the fatigue life of a component is more sensitive to the number of higher loads, it is the highest value of the vibratory stresses that determines the fatigue life of a component. Thus, designs should provide even load distributions rather than areas where loads are concentrated. This concentration consideration limits the effectiveness of conducting a panel analysis for the fatigue life because differing panels have differing loads and resulting fatigue lives. The Lockheed study analyzed three types of panels:

- Orthotropic panels with unequal stiffness along the two principal axes

- Monocoque panels that can be modeled by plate theory and show descent stiffness in both of the two principal axes

- Unstiffened skin panels that may be modeled as a plate between stiffeners for analyzing vibrating skin 
In fatigue life prediction, a spectrum must be defined for the environment of the aircraft. Here the spectrum is in terms of sound levels and frequency. Lockheed used five spectrum frequencies for its sonic fatigue analysis. The final result is a minimum sonic fatigue margin expressed in $\mathrm{dB}$ per $\mathrm{Hz}$ for each of the three general type of wing structure studied by Lockheed.

The tools, knowledge, and data available for the HSCT presented in this paper did not permit a detailed study of the sonic fatigue performance.

\subsubsection{Acoustics Conclusions and Recommendations}

Acoustics is an important aspect of the HSCT because FAA Stage III noise regulations can potentially block the certification of the aircraft. Even if the HSCT passes the FAA requirements, some international airports may impose additional noise constraints on the airplane. Furthermore, Stage IV requirements are expected to be announced in the late 1990s with possibilities of enforcement of Stage IV maybe as early as the first decade of the twenty-first century, about the same time the first HSCT production units will become available.

Research in takeoff and landing procedures offers all HSCT designs an acoustic improvement without too much concern with the design effort. In contrast, engine placement and sonic boom planform are extremely design intensive. Noise suppression at the jet also requires a great deal of design effort to minimize penalties, although the acoustic benefits of noise suppression are significant. However, noise suppression must attempt to reduce all types of noise at the same time to be most effective [2].

Other opportunities for noise reduction exist as well. For example, the new 157,000 pound MD-90 equipped with two IAE V2500 turbofan engines placed the two engines on either side of the fuselage in the rear of the aircraft. The result was a reduction in flyover noise during takeoff and landing due to the deflection of part of the engine noise by the wings located in front of the engines. Additionally, straddling the engines on either side of the fuselage was effective in reducing the sideline noise contribution from the opposite side engine. Using some of the takeoff procedures described earlier, the MD-90 has an optional thrust cutback system that reduces power at preprogrammed altitudes determined before takeoff [5].

Although it would be ideal to produce an aircraft that is capable of supersonic flight over land, it seems that at this time, such a design would have too many design tradeoffs with too few benefits. It has been suggested that there is an inherent penalty for low sonic boom [3]. Additionally, the earth is a planet that is $2 / 3$ water; as a result, a number of city pairs under 5000 nautical miles should be considered as areas for a potential HSCT market. For example, flights from Seattle to Los Angeles could be exclusively over water, and a substantial time savings would be enjoyed by the passengers. Likewise, flights from Miami to the northeast corridor could benefit 
from this redefinition of the HSCT market. In fact, a majority of the world's cities are located on water.

\section{References}

'Barger, Raymond L. and Melson, N. Duane. "Comparison of Jet Plume Shape Predictions and Plume Influence on Sonic Boom Signature," NASA Technical Paper 3172, 1992.

2Golub, R. A., Powell, C. A., Preisser, J.S., and Seiner, J. M. "Supersonic Jet Noise: Its Generation, Prediction and Effects on People and Structures," Society for Automotive Engineers, \#901927.

3Haglund, George T. "HSCT Designs for Reduced Sonic Boom," AIAA Paper for AIAA Aircraft Design Systems and Operations Meeting, September, 1991.

${ }^{4}$ Lockheed Corporation. LR 28185-3. Section 14.

5Mack, Robert J. and Needlemann, Kathy E. "A Methodology for Designing Aircraft to Low Sonic Boom Constraints," NASA Technical memorandum 4246, 1991.

Olson, E. D. "Advanced Takeoff Procedures for High-Speed Civil Transport Community Noise Reduction," SAE Technical Paper Series (\#921939). October, 1992.

7"Part 36-Noise Standards: Aircraft Type and Airworthiness Certification." Federal Aviation Regulations (CFR 14), Part 36.

${ }^{8}$ Smith, Bruce A. "Quiet Operations Key to MD-90 Success," Aviation Week \& Space Technology, March 22, 1993. 


\subsection{Results}

The work completed for AE6352 entailed research and analysis focusing on the High Speed Civil Transport wing. Some of the Seven Management and Planning Tools were used early in the quarter to help the team determine the complex interrelationships among the various disciplines. Tree Diagrams, Interrelationship Diagraphs, and QFD Matrices were used to determine the relationships between several key design areas and the cost parameters used to make a wing concept selection.

Analysis tools were identified and used for many of the design areas. FLOPS and ACSYNT were used at the system level. Other off-the-shelf codes were used for more detailed wing analysis. ASTROS was used for wing structural analysis and optimization. VORLAX and WINGDES were used for aerodynamics analysis. Several cost estimation tools were used for wing concept manufacturing cost estimates.

A methodology and database were established that can be used and expanded by next year's design teams. 


\subsection{Conclusions}

The sequence of Aerospace Systems Design Courses shown in Figure 8.1 addressing Integrated Design and Manufacturing for the High Speed Civil Transport has been completed for the first year. This report is submitted to summarize and document the results of the research and analyses conducted in these courses.

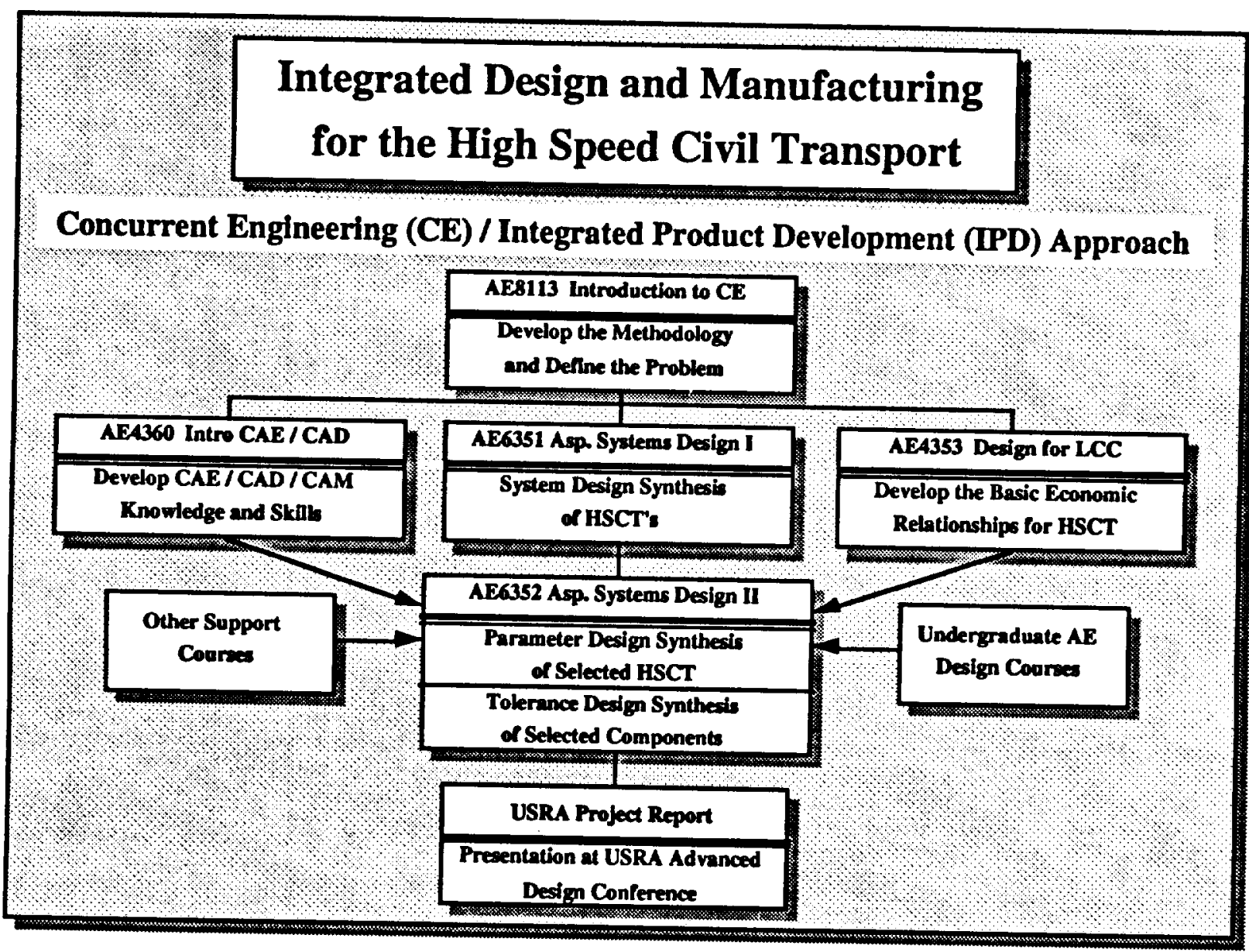

Eiqure 8.1: Georgia Tech NASA USRA ADP Aerospace Systems Design Courses

Overall, the results of the year's efforts can be summarized as follows:

- A methodology and framework for Integrated Design and Manufacturing has been established.

- Analysis tools for the fundamental disciplines have been identified and are functional in most areas. 
- A Computer Integrated Environment is being established to facilitate Multi-Disciplinary Design Optimization (MDO) and Integrated Product Development (IPD). 